\title{
Sarcopenia in COPD : functional and metabolic implications
}

Citation for published version (APA):

Franssen, F. M. E. (2009). Sarcopenia in COPD : functional and metabolic implications. [Doctoral Thesis, Maastricht University]. Universitaire Pers Maastricht. https://doi.org/10.26481/dis.20090130ff

Document status and date:

Published: 01/01/2009

DOI:

10.26481/dis.20090130ff

Document Version:

Publisher's PDF, also known as Version of record

\section{Please check the document version of this publication:}

- A submitted manuscript is the version of the article upon submission and before peer-review. There can be important differences between the submitted version and the official published version of record.

People interested in the research are advised to contact the author for the final version of the publication, or visit the DOI to the publisher's website.

- The final author version and the galley proof are versions of the publication after peer review.

- The final published version features the final layout of the paper including the volume, issue and page numbers.

Link to publication

\footnotetext{
General rights rights.

- You may freely distribute the URL identifying the publication in the public portal. please follow below link for the End User Agreement:

www.umlib.nl/taverne-license

Take down policy

If you believe that this document breaches copyright please contact us at:

repository@maastrichtuniversity.nl

providing details and we will investigate your claim.
}

Copyright and moral rights for the publications made accessible in the public portal are retained by the authors and/or other copyright owners and it is a condition of accessing publications that users recognise and abide by the legal requirements associated with these

- Users may download and print one copy of any publication from the public portal for the purpose of private study or research.

- You may not further distribute the material or use it for any profit-making activity or commercial gain

If the publication is distributed under the terms of Article $25 \mathrm{fa}$ of the Dutch Copyright Act, indicated by the "Taverne" license above, 


\section{Sarcopenia in COPD}

functional and metabolic implications 
(C) F. Franssen, Maastricht 2009

ISBN: $978-90-9023821-0$

Layout: Tiny Wouters

Cover: Mascha Hellenbrand

Production: Datawyse | Universitaire Pers Maastricht

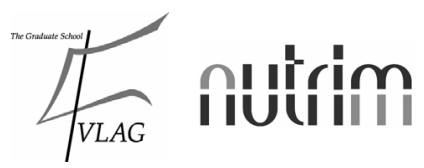

The studies presented in this thesis were performed at the Nutrition and Toxicology Research Institute Maastricht (NUTRIM), which participates in the Graduate School VLAG (Nutrition, Food Sciences, Agro-Biotechnology and Health Sciences), accredited by the Royal Netherlands Academy of Arts and Sciences (KNAW) and at CIRO Horn.

Printing of this thesis was financially supported by AstraZeneca, Boehringer Ingelheim, Chiesi, Danone Research - Centre for Specialised Nutrition, GlaxoSmithKline, Grünenthal, Novartis, Nycomed and Pfizer. 


\section{Sarcopenia in COPD}

\section{functional and metabolic implications}

\section{PROEFSCHRIFT}

ter verkrijging van de graad van doctor aan de Universiteit Maastricht,

op gezag van de Rector Magnificus, Prof. mr. G.P.M.F. Mols

volgens het besluit van het College van Decanen,

in het openbaar te verdedigen

op vrijdag 30 januari 2009 om 14.00 uur

door

Frits Maria Elisabeth Franssen 


\section{Promotores:}

Prof. dr. ir. A.M.W.J. Schols

Prof. dr. E.F.M. Wouters

\section{Beoordelingscommissie:}

Prof. dr. ir. R.P. Mensink (voorzitter)

Prof. dr. S.D. Anker (Campus Virchow-Klinikum, Berlijn, Duitsland)

Prof. dr. M.P. Van Dieijen-Visser

Prof. dr. M.I. Polkey (Royal Brompton Hospital, London, Verenigd Koninkrijk)

Prof. dr. C.D.A. Stehouwer 
Voor Mara en Marijn 


\section{Table of contents}

$\begin{array}{lll}\text { Chapter } 1 & \text { General introduction } & 9\end{array}$

$\begin{array}{lll}\text { PART } 1 & \text { Physiological implications of sarcopenia } & 27\end{array}$ in COPD

Chapter 2 The contribution of starvation, deconditioning and 29 aging to the observed alterations in peripheral skeletal muscle in chronic organ diseases.

A systematic review

Chapter 3 Arm mechanical efficiency and arm exercise

capacity are relatively preserved in chronic obstructive pulmonary disease

Chapter 4 Limb muscle dysfunction in chronic obstructive pulmonary disease: effects of muscle wasting and exercise training

Chapter 5 Effects of whole-body exercise training on body composition and functional capacity in normalweight patients with chronic obstructive pulmonary disease

Chapter 6 Summary and discussion on part 1

PART 2 Substrate metabolism in relation to sarcopenia in COPD

Chapter 7 Increased postabsorptive and exercise-induced whole-body glucose production in patients with chronic obstructive pulmonary disease

Chapter 8 Whole-body resting and exercise-induced lipolysis in sarcopenic patients with chronic obstructive pulmonary disease

Chapter 9 Greater whole-body myofibrillar protein breakdown in cachectic patients with chronic obstructive pulmonary disease 
Chapter 10 Perspective: chronic obstructive pulmonary disease and obesity: more than adipose tissue mass matters

Samenvatting

List of publications 235

Dankwoord 239

Curriculum vitae 



\section{Chapter 1}

\section{General introduction}





\section{General introduction}

\section{Chronic obstructive pulmonary disease}

Chronic obstructive pulmonary disease (COPD) is defined as a disease characterized by progressive airflow limitation that is not fully reversible ${ }^{1}$. The airflow limitation is caused by a combination of small airway obstruction (obstructive bronchiolitis) and destruction of lung parenchyma (emphysema). Typical presenting symptoms of patients with COPD are exertional dyspnoea and exercise intolerance. As defined by the Global initiative for chronic Obstructive Lung Disease (GOLD) criteria $^{1}$, conventional staging of severity of COPD is based on the degree of chronic airflow limitation measured by the forced expiratory volume in one second $\left(\mathrm{FEV}_{1}\right)$. Cigarette smoking is the most important risk factor for the development and progression of COPD. It has been estimated that $80-90 \%$ of all patients with COPD have a history of tobacco smoking ${ }^{2}$, although less than $25 \%$ of all smokers develop the disease ${ }^{3}$. Other identified risk factors for COPD are indoor and outdoor air pollutants ${ }^{4}$, occupational exposures, genetic predisposition, female gender ${ }^{5}$ and cured meat consumption ${ }^{6}$. The current estimated worldwide prevalence of COPD GOLD stage II and higher is around $10 \%{ }^{7}$. In 2001 , COPD was the fifth leading cause of death around the world and it is projected that it will be the third leading cause by $2020^{8}$.

In the classical view of the disease, COPD was considered a respiratory disease only, based on the presence of chronic airflow limitation ${ }^{9}$. In the last decades however, important manifestations beyond the lungs were described. These extra-pulmonary manifestations are also referred to as the systemic effects of COPD ${ }^{10}$ and are included in the most recent GOLD definition of the disease ${ }^{1}$. These effects include weight loss and nutritional abnormalities ${ }^{11}$, skeletal muscle dysfunction ${ }^{12}$, increased risk of cardiovascular disease ${ }^{13}$, hormonal and metabolic disturbances ${ }^{14}$, osteoporosis ${ }^{15}$ and anxiety and depression ${ }^{16}$. The new understanding of COPD has important clinical implications. In addition to traditional pharmacological therapy focused on treating chronic airflow limitation, management of COPD now requires a more holistic approach. Pulmonary rehabilitation programs aimed at reversing some of the extra-pulmonary manifestations of advanced COPD have been developed. Significant improvements in exercise tolerance ${ }^{17}$, 
nutritional status ${ }^{18}$ and health-related quality of life ${ }^{19}$ were achieved by pulmonary rehabilitation and this type of non-pharmacological therapy is now considered one of the essential components of disease management.

While the list of systemic effects of COPD is still growing, the drivers of these manifestations are only partially understood. Systemic inflammation is recognized as one of the key mechanisms behind many of the extra-pulmonary manifestations. In addition to an amplified inflammatory response of the respiratory tract to cigarette smoke and other irritants, a low-grade persistent abnormal inflammatory response is present in the systemic circulation of patients with COPD. This reaction is characterized by enhanced numbers of leukocytes in the circulation and increased circulating concentrations of acute-phase proteins, such as C-reactive protein (CRP) and fibrinogen along with acute-phase cytokines like tumour necrosis factor-a (TNF-a) and interleukin- $6(\text { IL- } 6)^{20}$. The origin of this low-grade systemic inflammation is unclear, although there are several possible mechanisms. The lack of correlation between inflammatory markers in respiratory samples and values in blood in COPD patients, suggests that the systemic inflammatory response is not a result of "spilling over" of pulmonary inflammation into the systemic compartment ${ }^{21}$. There is evidence showing that cigarette smoking itself can cause systemic inflammation, which persists long after quitting 22 . Also, other organs may contribute to continuous systemic inflammation in COPD. Increased plasma TNF-a levels were observed after submaximal exercise in patients with severe COPD, suggesting that exercising muscle is a possible site of origin ${ }^{23}$. In addition, there's a growing scientific interest in bone marrow and fat mass as potential sources of pro-inflammatory mediators in COPD. Although it has recently been suggested that COPD should be considered a "chronic systemic inflammatory syndrome ${ }^{24}$, there are several other potential mechanisms contributing to the systemic manifestations of the disease. These include semi-starvation, deconditioning, aging and chronic gas exchange abnormalities.

\section{Body composition in COPD}

Low body weight and involuntary weight loss are well-recognized findings in patients with COPD, affecting $10-20 \%$ of patients with mild to moderate disease ${ }^{25}$ and around $37 \%$ of patients with severe COPD $^{26}$. Traditionally, weight loss was considered an inevitable 
epiphenomenon of the progression of the disease. In the last decades however, it became clear that low body mass index in COPD is related to increased mortality risk $^{27}$, independent of disease severity $^{28}$. In addition, it was shown that low body weight can be reversed by nutritional supplementation integrated in pulmonary rehabilitation ${ }^{29}$. Most importantly, weight gain was associated with decreased mortality risk in patients with severe COPD ${ }^{29}$.

In addition to loss of body weight, which reflects an imbalance between dietary intake and energy expenditure, alterations in body composition are commonly observed in COPD. In the two compartment model, body mass is divided in fat mass (FM) and fatfree mass (FFM). FFM is further divided in an intracellular compartment, reflecting muscle mass and other metabolizing tissues, and an extracellular compartment. FFM is commonly used as an indirect measure for muscle mass in patients with COPD and there are several techniques available to assess FFM in clinical practice ${ }^{30}$. Loss of FFM was observed in a substantial proportion of patients with COPD and was not always accompanied by weight loss. The prevalence of pulmonary cachexia, defined as weight loss with a disproportional loss of FFM, varied between $11 \%$ in moderate to severe COPD out-patients ${ }^{25}$ and $26 \%$ in severe patients eligible for pulmonary rehabilitation. In addition, hidden depletion of FFM was observed in $10-15 \%$ of normal-weight COPD patients ${ }^{31,32}$. The latter subgroup of patients is also referred to as the sarcopenic phenotype of COPD, referring to the age-related decline in muscle mass in the elderly ${ }^{33}$. The loss of FFM is a significant clinical and societal problem in patients with COPD, independent of body weight. It contributes to skeletal muscle weakness ${ }^{34}$, exercise intolerance ${ }^{35}$ and reduced health-related quality life $(\mathrm{HRQOL})^{36}$. The clinical relevance of the sarcopenic phenotype was further emphasized by studies showing a greater degree of physical impairment and a worse HRQOL in normal-weight COPD patients with low FFM compared to underweight patients with a relatively preserved $\mathrm{FFM}^{32,36}$. In addition, it was shown that FFM-index is an even more important determinant of prognosis in moderate-to-severe COPD than $\mathrm{BMI}^{31,37}$.

\section{Skeletal muscle dysfunction in COPD}

Exercise intolerance is one of the most frequent symptoms in patients with COPD. Traditionally, abnormal lung mechanics, impaired gas exchange and destruction of pulmonary vasculature were considered the pathophysiologic mechanisms behind the 
reduced ability to sustain exercise in COPD. As part of the current concept of COPD as a multi-organ-system disease, there now is clear evidence that dysfunction of skeletal muscles contributes to exercise intolerance. Reduced quadriceps muscle strength was observed in a majority of COPD patients ${ }^{38}$ and was associated with impaired walking distance and maximal oxygen consumption during cycle ergometry $^{39}$. In addition, reduced limb muscle endurance may contribute to muscle weakness and exercise intolerance in COPD $^{40}$. Finally, it was suggested that disturbances in muscle energy metabolism and decreased work economy in COPD ${ }^{41}$ contribute to increased total daily expenditure ${ }^{42}$. This might contribute to energy imbalance and in the longer-term result in weight loss in these patients.

The pathophysiology of skeletal muscle dysfunction in COPD is complex and not yet completely understood. Several structural alterations were described in skeletal muscle of COPD patients, including reduced muscle mass ${ }^{43}$ and a shift from fibre type I to II in vastus lateralis muscle ${ }^{44}$. Furthermore, reduced activities of oxidative enzymes (citrate synthase, succinate dehydrogenase and 3hydroxyacyl-CoA dehydrogenase) were consistently detected in quadriceps muscle biopsies of moderate-to-severe COPD patients in comparison to controls ${ }^{45,46}$.

\section{Metabolic alterations in COPD}

The observed structural and functional changes in skeletal muscle of patients with COPD indicate a reduced oxidative capacity and suggest alterations in cellular energy metabolism in these patients. In muscle biopsies obtained in COPD patients at rest, increased levels of inosine monophosphate (IMP) and decreased ratios of adenosine triphosphate (ATP) to adenosine monophosphate (AMP) and phosphocreatine to creatine were observed in comparison to controls ${ }^{47}$, suggesting a compromised muscular energy status in these patients. Insufficient energy supply was also demonstrated during exercise in COPD in studies using ${ }^{31} \mathrm{P}$ nuclear magnetic resonance spectroscopy, which is a technique that allows noninvasive quantification of energy metabolism in vivo. Increased and progressive phosphocreatine depletion and enhanced acidification were observed during forearm muscle exercise in COPD patients compared to controls ${ }^{48}$. While skeletal muscle glycolytic enzymatic activities are unaffected in COPD, the observed early increase in 
blood lactic acid during exercise in COPD is related to reduced skeletal muscle oxidative capacity ${ }^{49}$.

Despite marked disturbances in energy metabolism in COPD, limited studies investigated intermediary glucose metabolism in this disease and available data are inconclusive. Jakobsson et al. ${ }^{50}$ reported normal fasting plasma glucose and insulin levels in a small group of advanced normal-weight COPD patients with chronic hypoxia. Hjalmarsen et al. ${ }^{51}$ observed normal fasting glucose, insulin, glucagon, cortisol and adrenaline levels in normal-weight normoxemic patients, hypoxemic patients and hypoxemic patients on long-term oxygen therapy (LTOT), in comparison to controls. However, hypoxemic patients on LTOT were characterized by impaired glucose tolerance following an oral glucose tolerance test, which led to the conclusion that glucose metabolism is altered in severely hypoxemic COPD patients. An important point of criticism towards this study is the fact that $50 \%$ of the LTOT patients and none of the other subjects were using oral corticosteroids at the time of the test, which are known for their ability to induce hyperglycemia. In another study by Jakobsson et al. ${ }^{52}$ resting postprandial hyperglycemia was described in COPD patients with chronic respiratory failure receiving LTOT at home in comparison to normoxemic patients, suggesting altered glucose metabolism. Finally, Goldstein et al. ${ }^{53}$ described an increased carbohydrate oxidation in hypermetabolic malnourished patients with emphysema and normoglycemia in comparison to underweight controls. The combined results of the available studies suggest some disturbances in intermediary glucose metabolism in subgroups of COPD patients with hypoxemia or underweight. However, all previous studies investigated glucose metabolism by measuring glucose concentrations, representing only the result of the balance between whole-body glucose production, i.e. gluconeogenesis and glycogenolysis and glucose tissue uptake. Glucose kinetics have not been studied in COPD.

Although it is well-recognized that fat oxidative capacity is reduced in COPD, potential disturbances in intermediary lipid metabolism are yet unknown. Triglycerides stored in the adipocytes form the main energy reserve of the body. Following hormonal stimulation, trigycerides are hydrolyzed to their components free fatty acids (FFA) and glycerol and these are released into the systemic circulation. This process is called lipolysis and is mainly stimulated by 
catecholamines. During $\beta$-adrenergic stimulation with isoprenaline, the increase in plasma FFA was significantly reduced in COPD patients with a sarcopenic phenotype, compared to controls with comparable BMI but significantly lower fat mass ${ }^{54}$. Furthermore, the increase in energy expenditure during $\beta$-adrenergic stimulation was blunted in the sarcopenic patients ${ }^{54}$. These results suggest that an impaired whole-body lipolytic rate may play a role in the pathophysiology of the sarcopenic phenotype in COPD, characterized by relatively or absolutely increased fat stores. In other chronic conditions, disturbances in adipocyte lipolysis have been associated with alterations in body fat mass. In human obesity, impaired adipose tissue lipolytic response is recognized as an important factor in the development and maintenance of increased fat mass ${ }^{55,56}$, while increased lipolysis is one of the possible mechanisms behind cachexia in cancer patients ${ }^{57}$.

Insulin plays a central role in the regulation of intermediary metabolism. It controls the level of blood glucose by its inhibitory effect on glucose production, affecting both glycogenolysis and gluconeogenesis ${ }^{58}$. In addition, insulin increases the rate of glucose uptake from the blood into skeletal muscle cells and adipocytes by increasing the number of glucose transporter proteins 4 (GLUT4) at the plasma membrane. Insulin resistance is defined as a state in which a given concentration of insulin is associated with a subnormal glucose response ${ }^{59}$. It is a central component of the metabolic syndrome, which is a common basis of cardiovascular disease and reduced insulin sensitivity commonly occurs in chronic disease, such as chronic heart failure ${ }^{60}$ and chronic liver disease ${ }^{61}$. Some recent studies suggested that resistance of glucose metabolism to insulin action is present in a number of patients with COPD as well ${ }^{62,63}$. Possible underlying mechanisms and clinical consequences of insulin resistance in COPD are currently unknown. In addition to effects on intermediairy glucose metabolism, insulin is considered the most important inhibitor of lipolysis ${ }^{64}$ and it is a growth factor for many cells.

Based on the divergent physiological effects of insulin in humans, it is hypothesized that disturbances in insulin function are related to several of the systemic manifestations of COPD, including nutritional depletion, alterations in muscle energy metabolism and increased cardiovascular mortality. Indeed, available evidence suggests altered insulin concentrations in patients with $\operatorname{COPD}^{63,65}$, but the clinical importance is yet unknown. 
Despite recent advances in the identification and understanding of the extra-pulmonary manifestations of COPD, numerous questions remain unanswered. The distribution of skeletal muscle dysfunction and exercise intolerance between lower and upper limbs is yet unknown, since most studies focused on the lower extremities. Information on upper limb performance may contribute to the understanding of the etiology of skeletal muscle dysfunction, disturbed energy metabolism and functional limitation in COPD. Furthermore, better characterization of lower and upper extremity functioning will enable development or optimization of nonpharmacological and pharmacological therapeutic strategies in these patients.

Also, the relationship between body composition and various aspects of muscle function, such as strength, endurance and mechanical efficiency is only partially understood. It is essential to gain insight into the mechanisms behind muscular dysfunction in order to develop specific exercise training and other anabolic interventions. Potential adaptations in glucose metabolism, lipolytic rate and insulin homeostasis are currently unexplored in COPD. These might contribute to or result from disturbances in body composition, skeletal muscle function and energy metabolism or various other systemic manifestations of the disease. The clinical consequences of alterations in intermediary metabolism remain to be unravelled as well. 


\section{Aims of the thesis}

In order to increase our understanding of the etiology of skeletal muscle dysfunction and develop specific interventions aimed at restoring muscle function, the first aim of this thesis was to study the distribution of skeletal muscle dysfunction between lower and upper extremities in patients with COPD. Historically, most studies focused on skeletal muscle dysfunction of the lower limbs, while limited information is available about muscle performance of the upper limbs in these patients. A low FFM and disturbances in muscle energy metabolism contribute to skeletal muscle dysfunction in COPD patients and heterogeneity in the distribution of these factors between different muscle groups may result in clinically important locoregional differences in muscle function. Therefore, various features of skeletal muscle function, including strength, endurance and mechanical efficiency, were assessed and the relationship with alterations in FFM was studied in detail in these patients.

The impact of disturbances in muscle energy metabolism and skeletal muscle function on intermediary metabolism in COPD is yet unknown. Furthermore, alterations in glucose metabolism, lipolytic rate and myofibrillar protein turnover may contribute to a shift in body composition towards low FFM in patients with COPD. Therefore, investigation of substrate metabolism using stable isotope tracer methodology in relation to alterations in body composition in patients with COPD was the second aim of this thesis. 


\section{Outline of the thesis}

The thesis is divided in two parts. First, the results of the studies focused on skeletal muscle function and exercise capacity are presented (chapter 2-5), followed by a summary and discussion on this subject (chapter 6). Secondly, the studies on metabolic alterations in COPD are presented (chapter 7-10).

\section{Physiological implications of sarcopenia in COPD}

Similarities in skeletal muscle function, morphology and energy metabolism in patients with COPD, chronic heart failure and chronic renal failure were systematically reviewed in chapter 2. Impaired skeletal muscle function, reduced oxidative capacity and a shift towards more glycolytic muscle fibre types are well-recognized features of these chronic conditions. Also, the contribution of semistarvation, deconditioning and the aging process to the observed alterations in chronic disease conditions was investigated in this chapter.

Chapter $\mathbf{3}$ and $\mathbf{4}$ of the thesis focused on potential differences in leg and arm muscle function and exercise capacity in COPD patients and controls.

Increased energy expenditure related to physical activity had been reported in patients with COPD. In accordance with this observation, reduced mechanical efficiency of lower extremity exercise had been observed. In chapter 3, mechanical efficiency and peak exercise capacity of upper limb exercise were compared to those of lower limb exercise. The results indicate that in contrast to the lower extremities, mechanical efficiency and exercise capacity of the upper extremities are relatively preserved in COPD.

Impaired quadriceps muscle strength and endurance had been consistently reported in COPD, while conflicting information was available on the function of other peripheral muscle groups. Therefore, chapter $\mathbf{4}$ focused on the comparison of quadriceps and biceps muscle function in COPD patients and controls. Furthermore, the influence of FFM and the effects of whole-body exercise training on quadriceps and biceps muscle strength and endurance were studied in this chapter. The results of chapter $\mathbf{4}$ suggest that loss of muscle strength is equally distributed between quadriceps and biceps muscle in COPD and is mainly determined by the amount of FFM.

FFM is related to functional capacity in COPD. Moreover, reduced FFM is associated with increased mortality risk. Most studies investigated 
alterations in body composition and potential effects of anabolic interventions on exercise tolerance and survival in malnourished COPD patients. In chapter 5, the anabolic effects of whole-body exercise training were studied in normal-weight COPD GOLD III-IV patients. Also, the relationship between changes in body composition and improvements in muscle function and exercise capacity were analysed. The results indicate that exercise training per se is able to induce an anabolic response in these patients, that is only partly related to functional improvements.

\section{Substrate metabolism in relation to sarcopenia in COPD}

Reduced skeletal muscle oxidative capacity and chronic hypoxemia may affect intermediary glucose metabolism in COPD. In chapter $\mathbf{7}$, whole-body resting and exercise-induced glucose kinetics were measured in COPD patients and controls using stable isotope tracer methodology. Since body composition and glucose metabolism are interrelated, potential differences in whole-body glucose production between normal-weight and underweight patients were explored. In addition, insulin sensitivity was estimated using the homeostatic modelling technique. The results indicate that glucose production is increased in COPD, especially in underweight patients. In normalweight patients with preserved FFM, alterations in insulin sensitivity are found.

A blunted lipolytic and thermogenic response to $\beta$-adrenergic stimulation had been observed in sarcopenic COPD patients and might contribute to a relative preservation of fat mass in the sarcopenic phenotype. Chapter $\mathbf{8}$ focused on possible differences in whole-body resting and exercise-induced lipolytic rate between patients with normal body weight and preserved fat mass, underweight patients and matched healthy controls. The results of this chapter show that the contribution of an altered lipolytic rate to the sarcopenic phenotype is unlikely, although the regulation of lipolysis seems altered in COPD subgroups.

Disturbances in skeletal muscle protein metabolism may also contribute to loss of FFM in cachectic or sarcopenic patients with COPD. Chapter 9 investigated potential differences in myofibrillar and whole-body protein breakdown between COPD patients and controls with a normal body weight and FFM and COPD patients with a low body weight and FFM. The study shows that cachexia in COPD is associated with increased myofibrillar protein breakdown, while whole-body protein turnover is not different between groups. 
In this thesis, physiological and metabolic implications of a sarcopenic COPD phenotype are described. These patients are characterised by loss of FFM in the presence of a normal body weight, resulting in a relative or absolute increase in fat mass. There is growing evidence suggesting that abundance of fat mass is related to a systemic inflammatory state and metabolic disturbances. In chapter $\mathbf{1 0}$ the relationship between COPD and obesity was reviewed. In addition, it is hypothesized that alterations in adipose tissue function in early stage COPD patients with abundant fat mass may contribute to systemic inflammation, loss of FFM and insulin resistance in COPD. 


\section{References}

1. Rabe KF, Hurd S, Anzueto A, Barnes PJ, Buist SA, Calverley P, Fukuchi Y, Jenkins $C$, Rodriguez-Roisin R, van Weel C, Zielinski J. Global Initiative for Chronic Obstructive Lung Disease. Global strategy for the diagnosis, management, and prevention of chronic obstructive pulmonary disease: GOLD executive summary. Am J Respir Crit Care Med 2007;176:532-555.

2. Feenstra $T L$, van Genugten $M L$, Hoogenveen $R T$, Wouters $E F$, Rutten-van Molken MP. The impact of aging and smoking on the future burden of chronic obstructive pulmonary disease: A model analysis in the Netherlands. Am J Respir Crit Care Med 2001;164:590-596.

3. Mannino DM. COPD: Epidemiology, prevalence, morbidity and mortality, and disease heterogeneity. Chest 2002;121:121S-126S.

4. Mannino DM, Buist AS. Global burden of COPD: Risk factors, prevalence, and future trends. Lancet 2007;370:765-773.

5. Gan WQ, Man SF, Postma DS, Camp P, Sin DD. Female smokers beyond the perimenopausal period are at increased risk of chronic obstructive pulmonary disease: A systematic review and meta-analysis. Respir Res 2006;7:52.

6. Varraso R, Jiang R, Barr RG, Willett WC, Camargo CA, Jr. Prospective study of cured meats consumption and risk of chronic obstructive pulmonary disease in men. Am J Epidemiol 2007;166:1438-1445.

7. Buist AS, McBurnie MA, Vollmer WM, Gillespie S, Burney P, Mannino DM, Menezes $A M$, Sullivan SD, Lee TA, Weiss KB, Jensen RL, Marks GB, Gulsvik A, Nizankowska-Mogilnicka E; BOLD Collaborative Research Group. International variation in the prevalence of COPD (the BOLD study): A population-based prevalence study. Lancet 2007;370:741-750.

8. Guilherme A, Virbasius JV, Puri V, Czech MP. Adipocyte dysfunctions linking obesity to insulin resistance and type 2 diabetes. Nature reviews 2008;9: 367-377.

9. Pauwels RA, Buist AS, Calverley PM, Jenkins CR, Hurd SS. Global strategy for the diagnosis, management, and prevention of chronic obstructive pulmonary disease. NHLBI/WHO global initiative for chronic obstructive lung disease (GOLD) workshop summary. Am J Respir Crit Care Med 2001;163:1256-1276.

10. Wouters EF, Creutzberg EC, Schols AM. Systemic effects in COPD. Chest 2002;121:127S-130S.

11. Schols AM. Pulmonary cachexia. Int J Cardiol 2002;85:101-110.

12. Gosker HR, Wouters EF, van der Vusse GJ, Schols AM. Skeletal muscle dysfunction in chronic obstructive pulmonary disease and chronic heart failure: Underlying mechanisms and therapy perspectives. Am J Clin Nutr 2000;71: 1033-1047.

13. Sin DD, Wu L, Man SF. The relationship between reduced lung function and cardiovascular mortality: A population-based study and a systematic review of the literature. Chest 2005;127:1952-1959.

14. Creutzberg EC, Casaburi R. Endocrinological disturbances in chronic obstructive pulmonary disease. Eur Respir J Suppl 2003;46:76s-80s.

15. Biskobing DM. COPD and osteoporosis. Chest 2002;121:609-620.

16. Brenes GA. Anxiety and chronic obstructive pulmonary disease: Prevalence, impact, and treatment. Psychosom Med 2003;65:963-970.

17. Goldstein RS, Gort EH, Stubbing D, Avendano MA, Guyatt GH. Randomised controlled trial of respiratory rehabilitation. Lancet 1994;344:1394-1397.

18. Schols AM, Soeters PB, Mostert R, Pluymers RJ, Wouters EF. Physiologic effects of nutritional support and anabolic steroids in patients with chronic obstructive pulmonary disease. A placebo- controlled randomized trial. Am J Respir Crit Care Med 1995;152:1268-1274. 
19. Lacasse Y, Brosseau L, Milne S, Martin S, Wong E, Guyatt GH, Goldstein RS. Pulmonary rehabilitation for chronic obstructive pulmonary disease. Cochrane Database Syst Rev 2002:CD003793.

20. Gan WQ, Man SF, Senthilselvan A, Sin DD. Association between chronic obstructive pulmonary disease and systemic inflammation: A systematic review and a meta-analysis. Thorax 2004;59:574-580.

21. Vernooy $\mathbf{J H}$, Kucukaycan $\mathrm{M}$, Jacobs JA, Chavannes $\mathrm{NH}$, Buurman WA, Dentener MA, Wouters EF. Local and systemic inflammation in patients with chronic obstructive pulmonary disease: Soluble tumor necrosis factor receptors are increased in sputum. Am J Respir Crit Care Med 2002;166:1218-1224.

22. Yanbaeva DG, Dentener MA, Creutzberg EC, Wesseling G, Wouters EF. Systemic effects of smoking. Chest 2007;131:1557-1566.

23. Rabinovich RA, Figueras M, Ardite E, Carbo N, Troosters T, Filella X, Barbera JA, Fernandez-Checa JC, Argiles JM, Roca J. Increased tumour necrosis factor-alpha plasma levels during moderate-intensity exercise in COPD patients. Eur Respir J 2003;21:789-794.

24. Fabbri LM, Rabe KF. From COPD to chronic systemic inflammatory syndrome? Lancet 2007;370:797-799.

25. Vermeeren MA, Creutzberg EC, Schols AM, Postma DS, Pieters WR, Roldaan AC, Wouters EF. Prevalence of nutritional depletion in a large out-patient population of patients with COPD. Respir Med 2006;100:1349-1355.

26. Palange $P$, Forte $S$, Felli $A$, Galassetti $P$, Serra $P$, Carlone $S$. Nutritional state and exercise tolerance in patients with COPD. Chest 1995;107:1206-1212.

27. Wilson DO, Rogers RM, Wright EC, Anthonisen NR. Body weight in chronic obstructive pulmonary disease. The national institutes of health intermittent positive-pressure breathing trial. Am Rev Respir Dis 1989;139:1435-1438.

28. Landbo C, Prescott E, Lange P, Vestbo J, Almdal TP. Prognostic value of nutritional status in chronic obstructive pulmonary disease. Am J Respir Crit Care Med 1999; 160:1856-1861.

29. Schols AM, Slangen J, Volovics L, Wouters EF. Weight loss is a reversible factor in the prognosis of chronic obstructive pulmonary disease. Am J Respir Crit Care Med 1998;157:1791-1797.

30. Schols AM, Wouters EF, Soeters PB, Westerterp KR. Body composition by bioelectrical-impedance analysis compared with deuterium dilution and skinfold anthropometry in patients with chronic obstructive pulmonary disease. Am J Clin Nutr 1991;53:421-424.

31. Vestbo J, Prescott E, Almdal T, Dahl M, Nordestgaard BG, Andersen T, Sorensen TI, Lange P. Body mass, fat-free body mass, and prognosis in patients with chronic obstructive pulmonary disease from a random population sample: Findings from the Copenhagen City Heart Study. Am J Respir Crit Care Med 2006; 173:79-83.

32. Schols AM, Soeters PB, Dingemans AM, Mostert R, Frantzen PJ, Wouters EF. Prevalence and characteristics of nutritional depletion in patients with stable COPD eligible for pulmonary rehabilitation. Am Rev Respir Dis 1993;147: 1151-1156.

33. Morley JE, Baumgartner RN, Roubenoff R, Mayer J, Nair KS. Sarcopenia. J Lab Clin Med 2001;137:231-243.

34. Engelen MP, Schols AM, Does JD, Wouters EF. Skeletal muscle weakness is associated with wasting of extremity fat- free mass but not with airflow obstruction in patients with chronic obstructive pulmonary disease. Am J Clin Nutr 2000;71:733-738.

35. Baarends EM, Schols AM, Mostert R, Wouters EF. Peak exercise response in relation to tissue depletion in patients with chronic obstructive pulmonary disease. Eur Respir J 1997;10:2807-2813. 
36. Mostert R, Goris A, Weling-Scheepers C, Wouters EF, Schols AM. Tissue depletion and health related quality of life in patients with chronic obstructive pulmonary disease. Respir Med 2000;94:859-867.

37. Schols AM, Broekhuizen R, Weling-Scheepers CA, Wouters EF. Body composition and mortality in chronic obstructive pulmonary disease. Am J Clin Nutr 2005; 82:53-59.

38. Hamilton AL, Killian KJ, Summers $E$, Jones NL. Muscle strength, symptom intensity, and exercise capacity in patients with cardiorespiratory disorders. Am J Respir Crit Care Med 1995;152:2021-2031.

39. Gosselink R, Troosters T, Decramer M. Peripheral muscle weakness contributes to exercise limitation in COPD. Am J Respir Crit Care Med 1996;153:976-980.

40. Allaire J, Maltais F, Doyon JF, Noel M, LeBlanc P, Carrier G, Simard C, Jobin J. Peripheral muscle endurance and the oxidative profile of the quadriceps in patients with COPD. Thorax 2004;59:673-678.

41. Baarends EM, Schols AM, Akkermans MA, Wouters EF. Decreased mechanical efficiency in clinically stable patients with COPD. Thorax 1997;52:981-986.

42. Baarends EM, Schols AM, Pannemans DL, Westerterp KR, Wouters EF. Total free living energy expenditure in patients with severe chronic obstructive pulmonary disease. Am J Respir Crit Care Med 1997;155:549-554.

43. Wuyam B, Payen JF, Levy P, Bensaidane H, Reutenauer H, Le Bas JF, Benabid AL. Metabolism and aerobic capacity of skeletal muscle in chronic respiratory failure related to chronic obstructive pulmonary disease. Eur Respir J 1992;5:157-162.

44. Gosker H, Zeegers M, Wouters E, Schols AM. Muscle fibre type shifting in the vastus lateralis of patients with COPD is associated with disease severity: A systematic review and meta-analysis. Thorax 2007.

45. Jakobsson $\mathrm{P}$, Jorfeldt $\mathrm{L}$, Henriksson J. Metabolic enzyme activity in the quadriceps femoris muscle in patients with severe chronic obstructive pulmonary disease. Am J Respir Crit Care Med 1995;151:374-377.

46. Maltais F, LeBlanc P, Whittom F, Simard C, Marquis K, Belanger M, Breton MJ, Jobin J. Oxidative enzyme activities of the vastus lateralis muscle and the functional status in patients with COPD. Thorax 2000;55:848-853.

47. Pouw EM, Schols AM, van der Vusse GJ, Wouters EF. Elevated inosine monophosphate levels in resting muscle of patients with stable chronic obstructive pulmonary disease. Am J Respir Crit Care Med 1998;157:453-457.

48. Kutsuzawa T, Shioya S, Kurita D, Haida M, Ohta Y, Yamabayashi H. ${ }^{31} \mathrm{P}-\mathrm{NMR}$ study of skeletal muscle metabolism in patients with chronic respiratory impairment. Am Rev Respir Dis 1992;146:1019-1024.

49. Maltais F, Simard AA, Simard C, Jobin J, Desgagnes P, LeBlanc P. Oxidative capacity of the skeletal muscle and lactic acid kinetics during exercise in normal subjects and in patients with COPD. Am J Respir Crit Care Med 1996;153: 288-293.

50. Jakobsson $P$, Jorfeldt $L$, von Schenck $H$. Insulin resistance is not exhibited by advanced chronic obstructive pulmonary disease patients. Clin Physiol 1995; 15:547-555.

51. Hjalmarsen A, Aasebo U, Birkeland K, Sager G, Jorde R. Impaired glucose tolerance in patients with chronic hypoxic pulmonary disease. Diabetes Metab $1996 ; 22: 37-42$.

52. Jakobsson EJ, Jorfeldt L. Blood fuel metabolites at rest and during exercise in patients with advanced chronic obstructive pulmonary disease with and without chronic respiratory failure. Respiration 1990;57:304-309.

53. Goldstein SA, Thomashow BM, Kvetan V, Askanazi J, Kinney JM, Elwyn DH. Nitrogen and energy relationships in malnourished patients with emphysema. Am Rev Respir Dis 1988;138:636-644. 
54. Schiffelers SL, Blaak EE, Baarends EM, Van Baak MA, Saris WH, Wouters EF, Schols AM. Beta-adrenoceptor-mediated thermogenesis and lipolysis in patients with chronic obstructive pulmonary disease. Am J Physiol Endocrinol Metab 2001;280:E357-E364.

55. Blaak EE, Van Baak MA, Kemerink GJ, Pakbiers MT, Heidendal GA, Saris WH. Beta-adrenergic stimulation of energy expenditure and forearm skeletal muscle metabolism in lean and obese men. Am J Physiol 1994;267:E306-315.

56. Blaak EE, Van Baak MA, Kemerink GJ, Pakbiers MT, Heidendal GA, Saris WH. Beta-adrenergic stimulation of skeletal muscle metabolism in relation to weight reduction in obese men. Am J Physiol 1994;267:E316-322.

57. Zuijdgeest-van Leeuwen SD, van den Berg JW, Wattimena JL, van der Gaast A, Swart GR, Wilson JH, Dagnelie PC. Lipolysis and lipid oxidation in weight-losing cancer patients and healthy subjects. Metabolism 2000;49:931-936.

58. Cahill GF, Jr. Starvation in man. N Engl J Med 1970;282:668-675.

59. Moller DE, Flier JS. Insulin resistance - mechanisms, syndromes, and implications. N Engl J Med 1991;325:938-948.

60. Swan JW, Anker SD, Walton C, Godsland IF, Clark AL, Leyva F, Stevenson JC, Coats AJ. Insulin resistance in chronic heart failure: Relation to severity and etiology of heart failure. J Am Coll Cardiol 1997;30:527-532.

61. Picardi A, D'Avola D, Gentilucci UV, Galati G, Fiori E, Spataro S, Afeltra A. Diabetes in chronic liver disease: From old concepts to new evidence. Diabetes Metab Res Rev 2006;22:274-283.

62. Bolton CE, Evans M, Ionescu AA, Edwards SM, Morris RH, Dunseath G, Luzio SD, Owens DR, Shale DJ. Insulin resistance and inflammation - a further systemic complication of COPD. COPD 2007;4:121-126.

63. Koehler F, Doehner W, Hoernig S, Witt C, Anker SD, John M. Anorexia in chronic obstructive pulmonary disease - association to cachexia and hormonal derangement. Int J Cardiol 2007;119:83-89.

64. Miyoshi H, Shulman GI, Peters EJ, Wolfe MH, Elahi D, Wolfe RR. Hormonal control of substrate cycling in humans. J Clin Invest 1988;81:1545-1555.

65. Engelen MP, Wouters EF, Deutz NE, Menheere PP, Schols AM. Factors contributing to alterations in skeletal muscle and plasma amino acid profile in patients with chronic obstructive pulmonary disease. Am J Clin Nutr 2000;72:1480-1487. 



\section{Part 1}

Physiological implications of sarcopenia in COPD 



\section{Chapter 2}

The contribution of starvation, deconditioning and aging to the observed alterations in peripheral skeletal muscle in chronic organ diseases
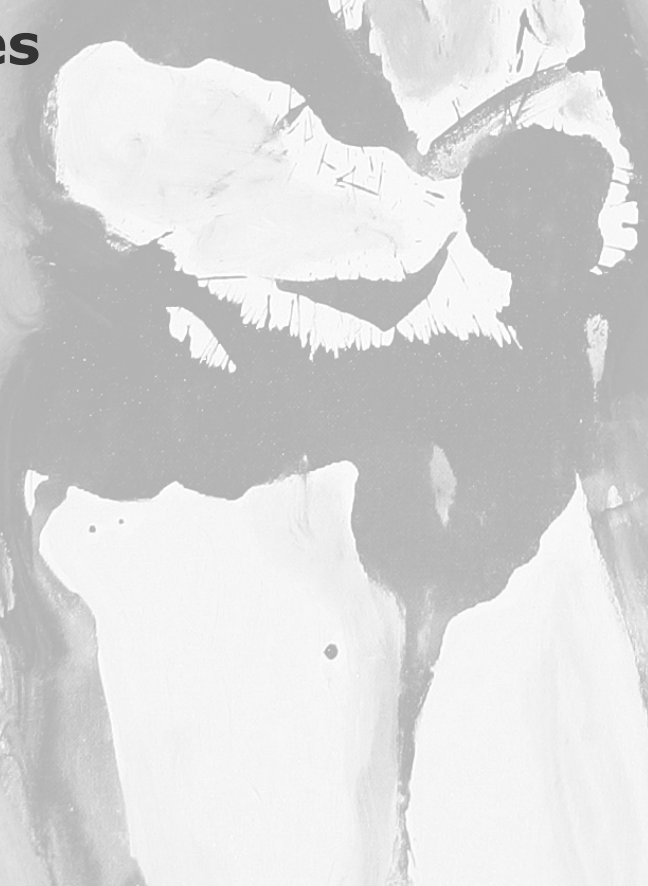

Frits M.E. Franssen, Emiel F.M. Wouters, Annemie M.W.J. Schols Clinical Nutrition 2002; 21: 1-14 


\section{Abstract}

Muscle weakness and early fatigue are common symptoms of chronic organ diseases, like chronic obstructive pulmonary disease (COPD), chronic heart failure (CHF) and chronic renal failure (CRF). It is becoming more and more clear that symptom intensities and exercise intolerance are related to muscle wasting and intrinsic alterations in peripheral skeletal muscle in these patient populations, while correlations with parameters of organ functioning are poor. Also, changes in muscle structure and function in COPD, CHF and CRF show much resemblance. Semistarvation, reduced physical activity and aging are external factors possibly confounding a direct relationship between the primary organ impairments and alterations in peripheral skeletal muscle and exercise capacity. Reducing the catabolic effects of the various contributing factors might improve muscle function and health status in chronic disease. In this review, we present a systematic overview of human studies on alterations in skeletal muscle function, morphology and energy metabolism in COPD, CHF, CRF and we compare the results with comparable studies in anorexia nervosa, disuse or inactivity and aging. Unravelling the relative contributions of these external factors to the observed alterations in the various diseases may contribute to targeted intervention strategies to improve muscle function in selected groups of patients. 


\section{Introduction}

Chronic obstructive pulmonary disease (COPD) is characterized by exertional dyspnoea and impaired exercise capacity. Research has shown that these symptoms are not only caused by airflow obstruction and loss of alveolar tissue. Skeletal muscle weakness contributes substantially to the complaints of patients with COPD. This skeletal muscle dysfunction can be related to loss of muscle mass and to observed intrinsic alterations in skeletal muscles of patients with COPD. Although the primary organ impairment in patients with chronic heart failure (CHF) is clearly different from that in COPD, the effects of this disease on muscle function and exercise capacity show much resemblance, as was reviewed by Gosker et al. ${ }^{1}$. Muscle weakness and fatigue have also long been recognized as presenting symptoms in patients with chronic renal failure (CRF). The number of studies investigating alterations in muscular function and structure in patients with CRF however is limited.

Besides disease related mediators such as inflammation, hypoxemia and acidosis, skeletal muscle function in these diseases may also be affected by external factors, closely related to the process of the disease and potentially confounding the relationship between the organ impairment and skeletal muscle and exercise performance. Reduction of physical activity, (semi)starvation and age-related changes in body composition and function are examples of these comorbid factors. The effects of these factors on human skeletal muscle and exercise capacity have been subject of many studies in the past.

Since muscle wasting is related to symptom intensity, functional capacity and quality of life, treating the wasting process has been associated with beneficial effects for the patients. At present, various strategies are available to promote anabolism, including exercise training, nutritional suppletion and pharmacological anabolic stimulation. To determine the best individual treatment, more insight is needed into the relative contributions of identified factors that may decrease anabolism or increase catabolism.

In this review, we present an overview of clinical studies that have investigated alterations in peripheral skeletal muscle function, muscle morphology and energy metabolism in chronic obstructive pulmonary disease, chronic heart failure and chronic renal failure. In order to get more insight in the pathophysiology of muscle dysfunction in these diseases, the results of these studies are compared with findings from human studies on alterations in skeletal 
muscle which occur during anorexia nervosa, disuse and deconditioning and sarcopenia. The contribution of these secondary conditions will be discussed, as well as controversies in the results of various studies. The results of studies on the defined comorbid factors will be presented first. Also, future fields of research and clinical implications will be highlighted.

\section{Methods}

\section{General}

Only peer reviewed publications from the medical literature were included. MEDLINE database was searched for relevant original articles and reviews. Also, references from included articles were studied. Only results from studies in humans were analysed.

\section{Muscle function}

Skeletal muscle strength and fatigue were used as measures for skeletal muscle function. Both studies in which muscle function was determined by voluntary contractions as well as studies that used electrical stimulation to evoke muscle contractions were included. Both isometric as well as isokinetic test protocols have been used in order to study muscular endurance.

\section{Muscle morphology and energy metabolism}

Results of biopsy studies were analysed in order to assess morphologic alterations in skeletal muscle. Changes in the number, size and distribution of the different muscle fibre types are presented (Table 2.1). Also, skeletal muscle capillarization is an important factor for normal muscle function. Since there are many morphometrical methods to assess the capillary bed, it is difficult to interpret the results of the different studies. The capillary density (the number of capillaries per $\mathrm{mm}^{2}$ ) (CD) and capillaries per fibre ratio $(C / F$ ratio) are global indices of capillarization. Other indices of capillarity are the number of capillary contacts per muscle fibre (CC) and the number of capillary contacts per muscle fibre in relation to the type and area of muscle fibre (CCFTA). 


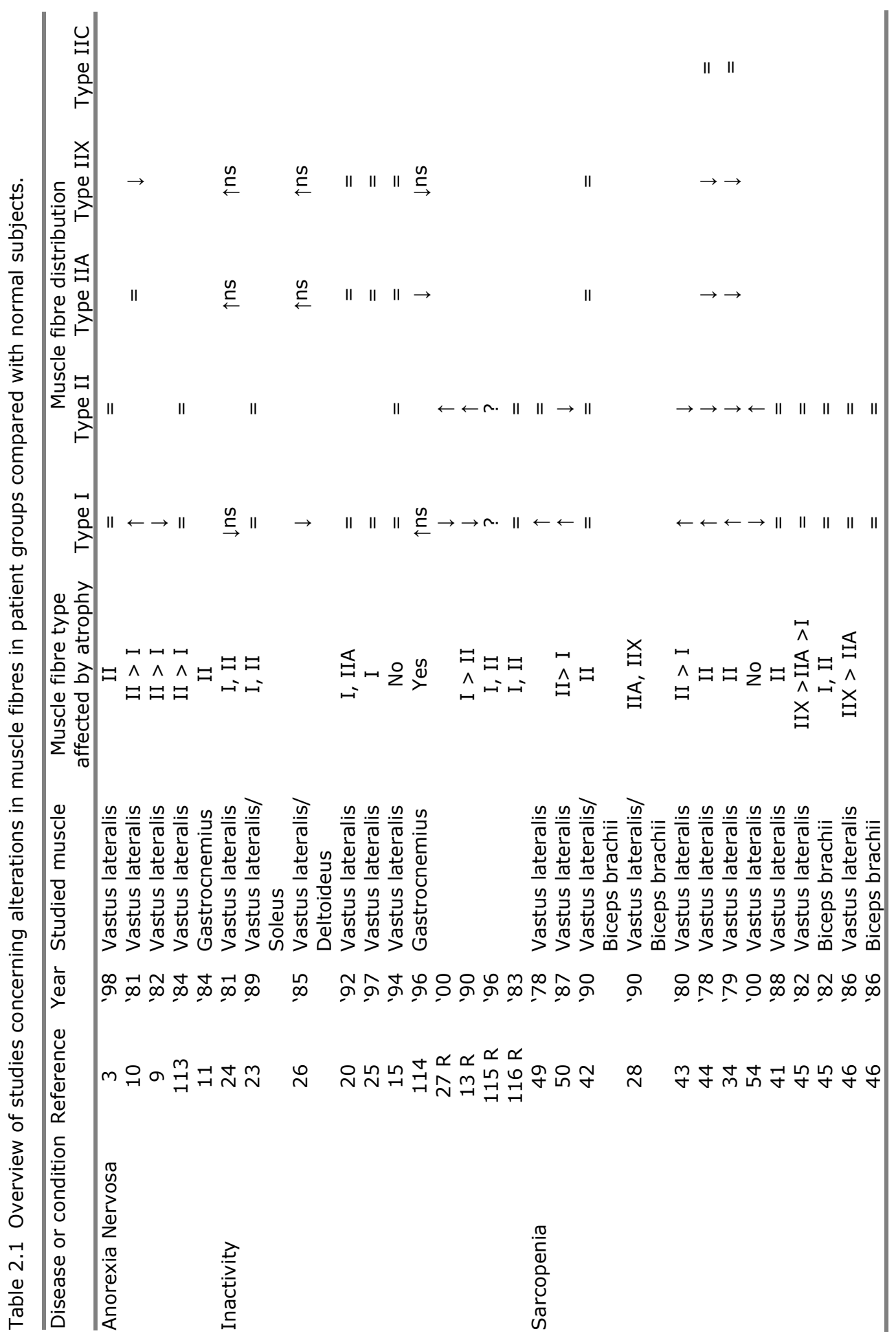




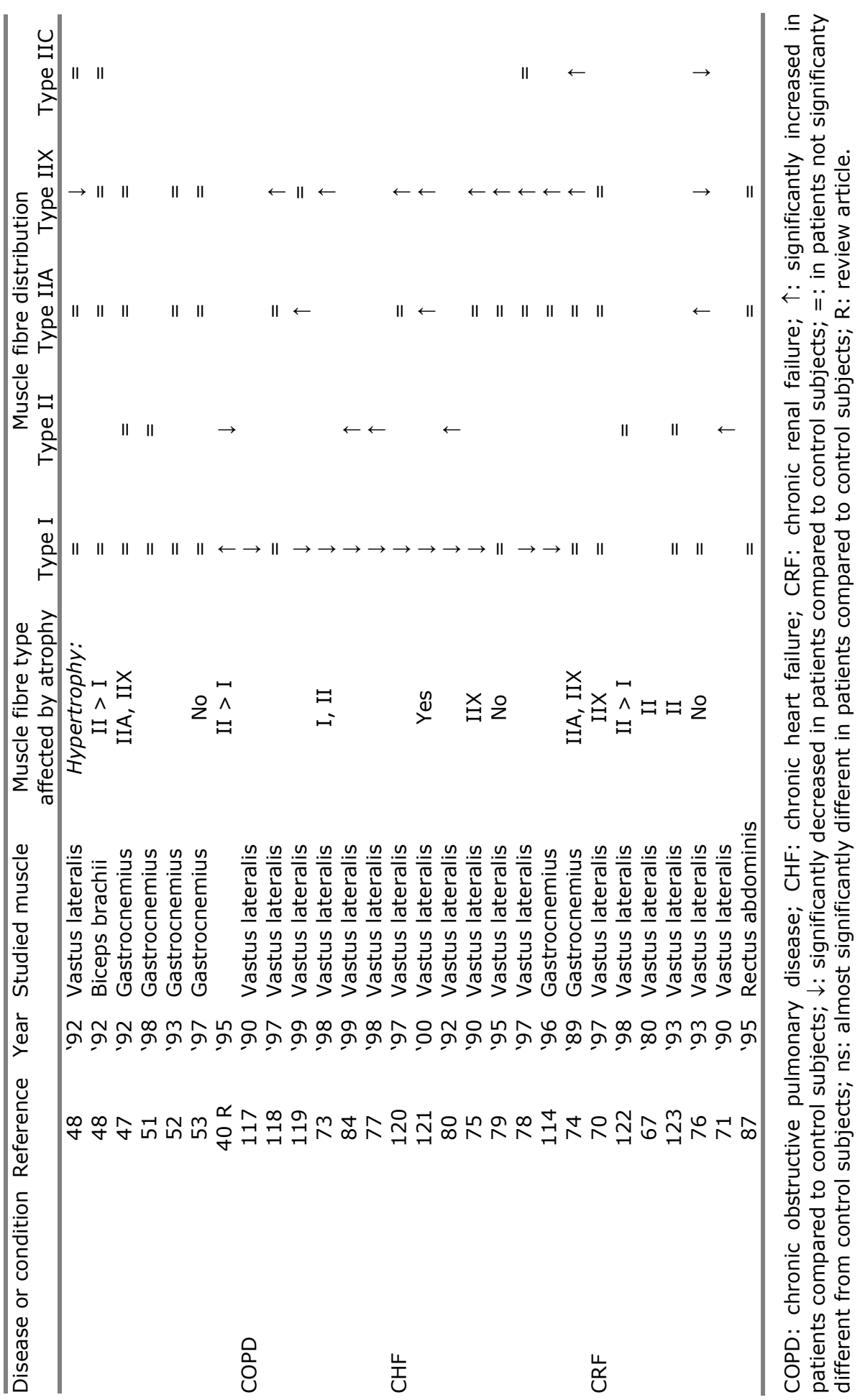




\section{Muscle energy metabolism}

Studies in which the activities of enzymes involved in muscle energy metabolism were investigated in muscle biopsies are summarized (Table 2.2). Citrate synthase (CS), succinate dehydrogenase (SDH), cytochrome-c oxidase (COX) and $\beta$-hydroxyacyl CoA-dehydrogenase (HAD) were used as measures for oxidative metabolism. The activities of phosphofructokinase (PFK), lactate dehydrogenase $(\mathrm{LDH})$, hexokinase (HK) and myokinase (MK) were used as indicators for glycolytic muscle metabolism.

\section{${ }^{31} \mathrm{P}$ Magnetic resonance spectroscopy}

Results from studies using ${ }^{31} \mathrm{P}$ magnetic resonance spectroscopy $\left({ }^{31} \mathrm{P}\right.$ MRS) are discussed and presented in Tables 2.3-2.5. With ${ }^{31} \mathrm{P}$ MRS direct and noninvasive measurement of bioenergetics in skeletal muscle is possible at rest, during exercise and during recovery from exercise. Particularly in dynamic experiments metabolic abnormalities can be characterized ${ }^{2}$. The principal signals detected by the apparatus in the tissues are the high energy phosphates, including phosphocreatine (PCr), inorganic phosphate $(\mathrm{Pi})$ and the ATP spectrum, and intracellular $\mathrm{pH}$. Many different indices of muscle energy status are used. The ratio $\mathrm{PCr} /(\mathrm{PCr}+\mathrm{Pi})$ and ATP concentration however are most frequently used. When this ratio is high, so is the energy status. Depletion of phosphocreatine results in lowering of the ratio. Changes in the $\mathrm{PCr} / \mathrm{Pi}$ or $\mathrm{PCr} /(\mathrm{PCr}+\mathrm{Pi})$ are dependent on aerobic metabolic rate and decreases indicate a lower use of aerobic metabolism. The recovery rate of phosphocreatine following submaximal exercise is a measure for mitochondrial capacity ${ }^{2}$. 


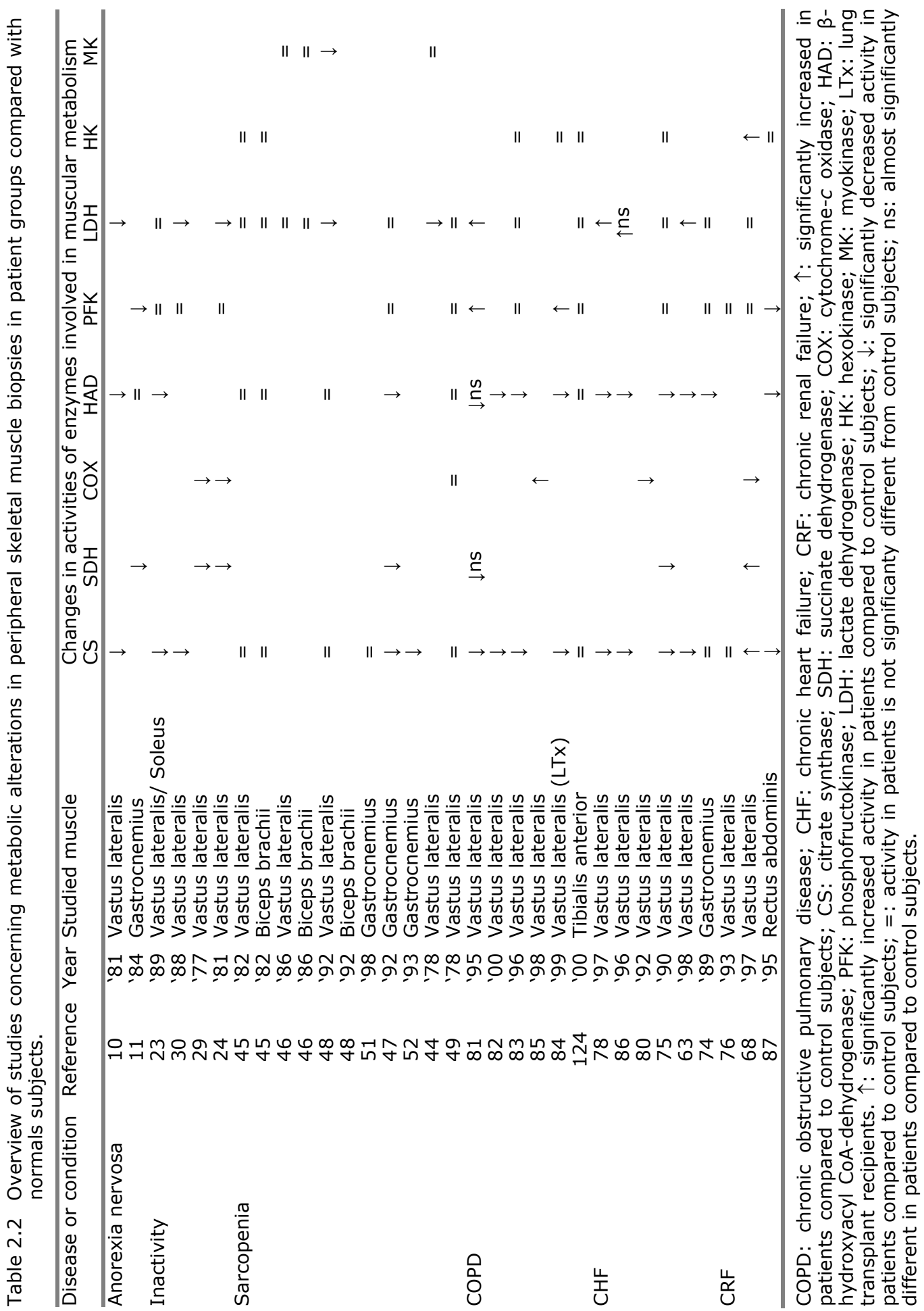




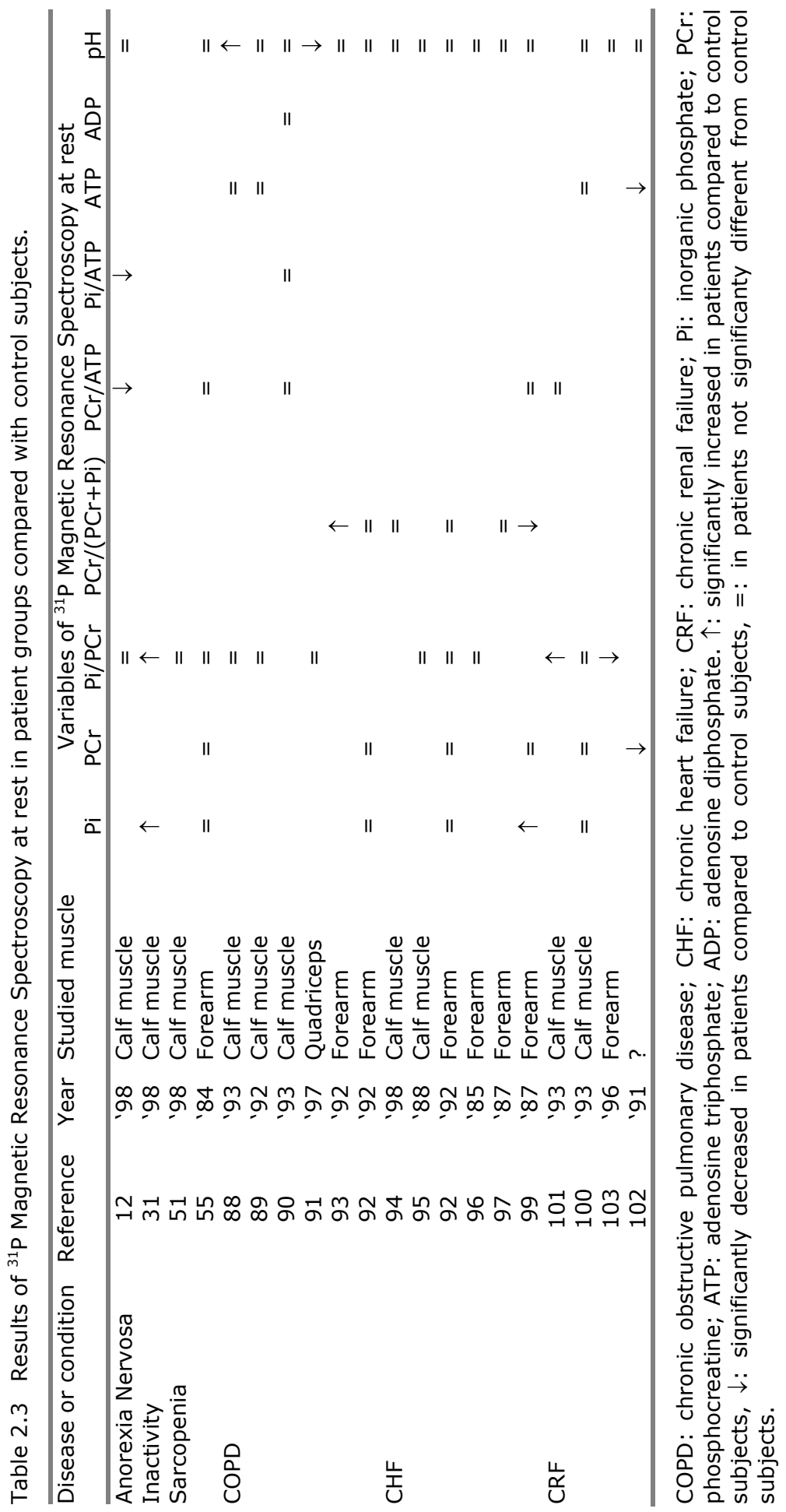




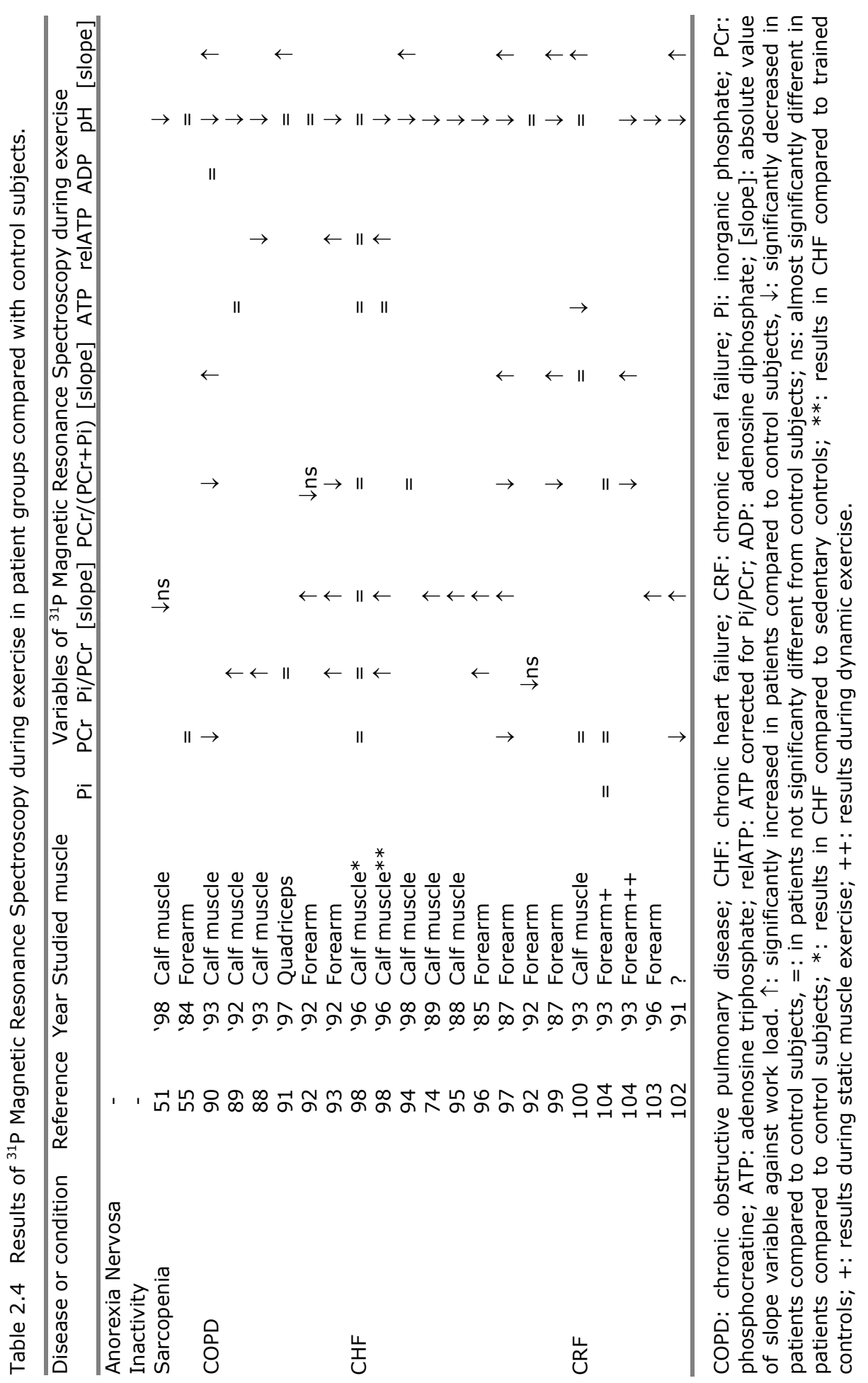




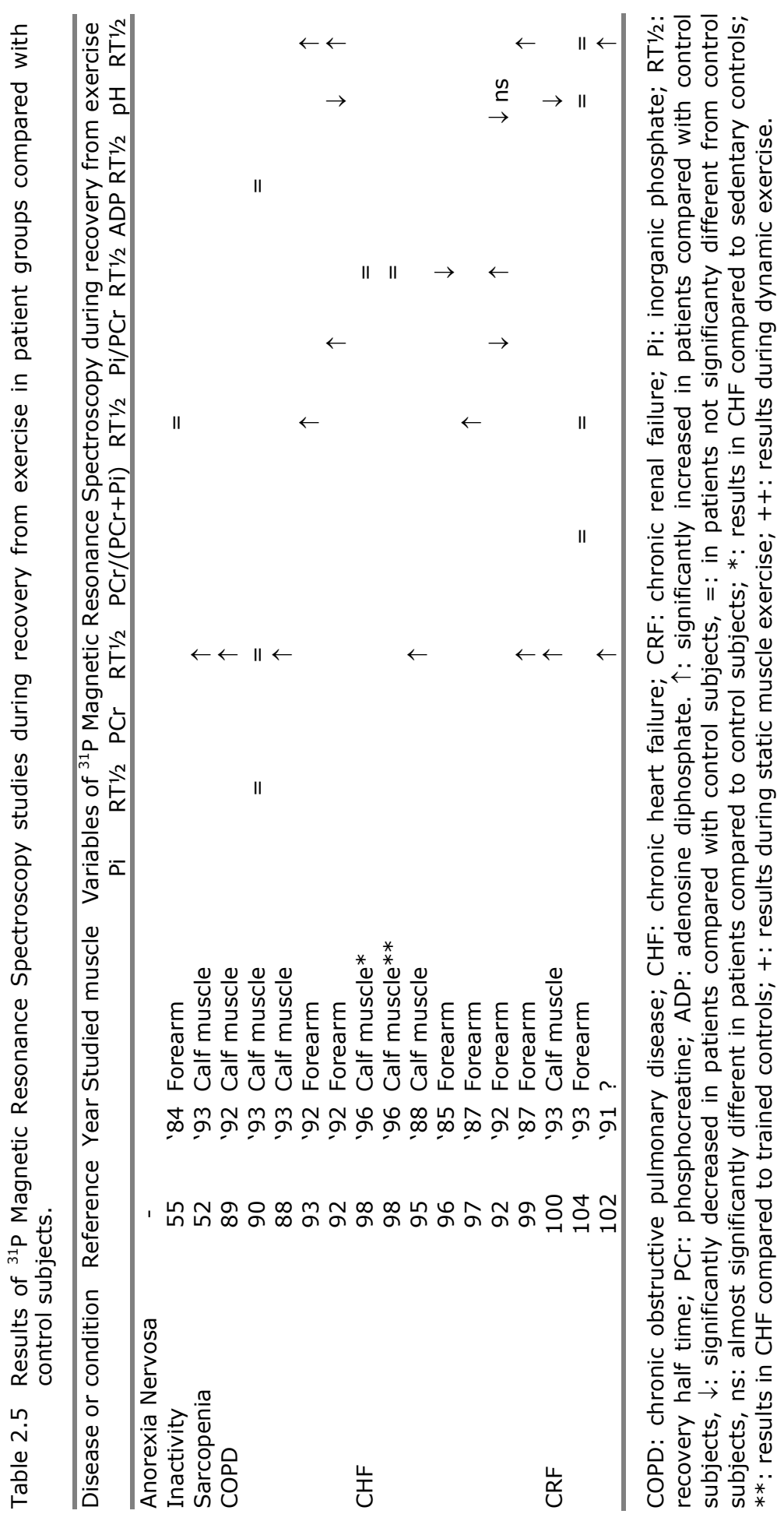




\section{Results}

\section{Anorexia nervosa}

\section{Muscle function}

Anorexia nervosa (AN) is a pertinent model in which to study the effects of chronic semistarvation on skeletal muscle, without any confounding inflammatory process. During early stages of the disease the reduced intake of carbohydrates and fats leads to a negative energy balance and a depletion of mainly fat mass. As undernutrition continues, protein-energy malnutrition and loss of skeletal muscle mass occur ${ }^{3}$.

Muscle dysfunction occurs in patients with anorexia nervosa 3,4 , with proximal muscle weakness being an important complaint ${ }^{3,5,6}$. The loss of upper limb muscle mass and function tends to be equal to or greater than that of the lower $\operatorname{limb}^{7,8}$. McLoughlin et al. ${ }^{3}$ reported that in female patients with severe self-induced weight loss, the mean voluntary contraction of the quadriceps muscle was significantly lower compared to healthy controls. Also, in the patient group, the force was significantly less than the predicted values for body weight. This might indicate that besides loss of muscle mass, other changes occur in the muscles of patients with AN. Russell et al. ${ }^{4}$ tested the isometric endurance of the adductor pollicis muscle with continuous electrical stimulation of the ulnar nerve and found a markedly increased fatigue in patients with anorexia nervosa compared to controls, which returned to normal after four weeks of oral refeeding.

\section{Muscle morphology}

Table 2.1 summarizes several studies on the effects of anorexia nervosa on skeletal muscle fibre. The primary muscle pathology in anorexia nervosa is characterized by muscle fibre atrophy ${ }^{3,9-11}$ with especially type II fibres being affected. The relative proportions of type I, type IIA and type IIB muscle fibres in anorexia nervosa seem to be within the normal limits ${ }^{3,9,10}$, although both increased ${ }^{10}$ as well as decreased ${ }^{9}$ proportions of type I muscle fibres have also been reported.

Only one study investigated muscle capillarization in patients with $\mathrm{AN}^{10}$ but found no change. 


\section{Muscle energy metabolism}

Alterations in activities of enzymes involved in muscular metabolism are summarized in Table 2.2. Decreased activities of enzymes involved in glycolytic and mitochondrial pathways have been reported in muscle biopsies from patients with anorexia nervosa ${ }^{10,11}$, with glycolytic capacity being affected the most ${ }^{10}$.

We only found one study using ${ }^{31} \mathrm{P}$ magnetic resonance spectroscopy to investigate the changes in muscle metabolism in malnourished patients. Thompson et al. ${ }^{12}$ found significantly lower PCr/ATP and $\mathrm{Pi} / \mathrm{ATP}$ ratios, but no change in $\mathrm{Pi} / \mathrm{PCr}$ in patients compared to controls. Among the studied subjects however were elderly patients and persons with AIDS.

\section{Inactivity}

\section{Muscle function}

The effects of reduced physical activity and disuse on skeletal muscle have extensively been investigated in several experimental approaches in both animals as well as humans. These models include immobilization by casting, prolonged bed rest, non-weight bearing and limb suspension, and (simulated) microgravity. All these situations result in numerous adaptive changes in skeletal muscle and in muscular dysfunction. It is however difficult to compare the results of the various models on skeletal muscle, since the degree of atrophy is influenced by, among other factors, duration of immobilisation, length at which a muscle is immobilized, degree of disuse compared to normal usage and muscle pre-existing fibre type distribution ${ }^{13}$.

The loss of muscle strength after a period without weight-bearing ${ }^{14,15}$ or after immobilization ${ }^{16}$ is marked, and is a result of reduced motor neuron activity and muscle wasting. The amount of muscular atrophy is most pronounced during the early part of immobilization ${ }^{17}$. Muscles with the greatest decrease in utilisation are preferentially affected ${ }^{7,18}$. Upper limb muscles seem to experience fewer loss of muscle strength compared with lower limb muscles ${ }^{19}$. Moreover, extensor muscle groups experience greater decrease in strength than do the corresponding flexor muscles ${ }^{15,19-21}$. From this, it can be concluded that antigravity muscles that cross a single joint and contain a large proportion of slow fibres (soleus, vastus medialis) are most vulnerable to immobilisation-induced atrophy, followed by muscles 
that cross multiple joints (erector spinae, rectus femoris, gastrocnemius $)^{13}$.

Four weeks of simulated microgravity resulted in a significant increase in fatigability of ankle plantar and dorsal flexors, with the first being more affected by this period of bed rest ${ }^{21}$, again indicating that antigravity muscles are preferentially affected in this condition. The decrease in muscle endurance is less pronounced during voluntary sustained contraction than during electrically-sustained contraction, indicating a role for neural adaptions in the process of immobilization ${ }^{16}$. However, in a case study, Duchateau et al. ${ }^{22}$ reported that fatigability of triceps surae muscle was not affected after five weeks of bed rest.

\section{Muscle morphology}

Table 2.1 summarises several studies on the effects of reduced activity on skeletal muscle fibres. Loss of muscle mass and muscular atrophy are the most evident consequences of muscle disuse, with type I and type II fibres both being subject to atrophy ${ }^{20,23-25}$. Slowtwitch fibres however seem to be more susceptible to disuse than fast-twitch fibres ${ }^{13,18}$. According to several studies, the percentage of muscle fibres expressing myosin heavy chain (MHC) type I is found to be decreased during inactivity and detraining $13,24,26,27$, whereas the percentage of fibres expressing MHC type II was increased. Others however did not confirm this change in muscle fibre distribution $20,23,25$.

The results of studies on the influence of reduced physical activity on muscle capillarization are conflicting. Saltin et al. $^{28}$ reported a significant fall in capillary density during an 8-12 days period of bed rest. In the same study fibre size fell even more, resulting in an increase in the number of capillaries per muscle fibre and a reduction in diffusion distance. Hikida et al. $^{23}$ investigated alterations in capillarization in biopsies from vastus lateralis muscle and soleus muscle before and after 30 days of six degrees head-down bed rest and reported a significant decrease in capillary to fibre ratio in soleus muscle, but not in vastus lateralis muscle. Klausen et al. ${ }^{24}$ reported a decrease in capillary to fibre ratio and in the number of capillaries contacts per fibre (CC) during eight weeks of detraining after eight weeks of training. Fibre area per CC was unchanged in this study. Finally, Hather et al. ${ }^{20}$ did not find a significant change in capillary to fibre ratio and the number of capillaries surrounding the different fibre types after 6 weeks of left unilateral lower limb suspension. Capillary density increased by $15 \%$ and the number of capillaries per 
unit of type I and IIA fibre also increased significantly, as a result of fibre atrophy.

\section{Muscle energy metabolism}

Changes in activities of enzymes involved in energy metabolism as a result of decreased activity are shown in Table 2.2. There is convincing evidence of a reduction in muscle oxidative capacity, while glycolytic enzymes activities are maintained $23,24,29,30$.

Besides one case study ${ }^{31}$, the influence of immobilization on muscle metabolism using magnetic resonance spectroscopy has not been systematically investigated.

\section{Aging}

\section{Muscle function}

A decrease in lean body mass, mainly muscle mass, and an accumulation of intra-abdominal fat mass are both characteristics of the aging process and are referred to as sarcopenia ${ }^{32}$. The agerelated loss in muscle strength has been recognized for a long time. Until the mid-40s, muscle function is generally thought to be preserved, after which there is a deterioration of lean tissue and strength by about $5 \%$ per decade ${ }^{33,34}$. The loss of function is more pronounced in the lower than in the upper extremity, but it remains unclear if this is a result of an inherent biological difference, or a confounding effect of a greater change in habitual physical activity of the leg compared with the arm muscle groups.

Most studies on age-related effects on skeletal muscle function have focused on muscle strength rather than endurance. Available human studies however seem to indicate that muscle endurance is maintained during the normal aging proces ${ }^{34-36}$.

\section{Muscle morphology}

Besides the loss of muscle mass with aging other intrinsic differences, including reduced activity of motor neurons ${ }^{37}$, are present in muscles of older compared to younger persons, which might affect muscle function. The results of several studies on the effects of aging on skeletal muscle fibre are summarized in Table 2.1. With advancing age, both the number and the size of muscle fibres seem to be affected ${ }^{37-40}$. The decrease in total number of muscle fibres involves both fibre types ${ }^{41}$ and might be greater in type II muscle fibres. The muscular atrophy affects both types of muscle 


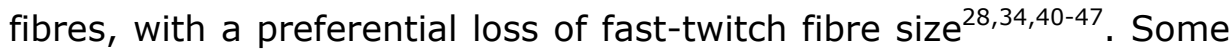
studies suggest that within the group of type II fibres, especially type IIX fibres are subject to atrophy with aging ${ }^{45,46}$. In contrast to these results, Aniansson et al. ${ }^{48}$ reported a significant increase in type I and mainly type II fibre areas in vastus lateralis muscle, with biceps brachii muscle showing the same tendencies. This was interpreted as a compensatory adaption for the loss of motor units with aging. With respect to changes in muscle fibre distribution with aging both increase in the percentage of type I fibres ${ }^{34,43,44,49,50}$ as well as no age-related redistribution ${ }^{41,42,45-48,51-53}$ or even a decreased proportion of type I fibres ${ }^{54}$ have been reported. In accordance with the greater age-related loss of muscle function in the lower extremity extremity compared with the upper extremity, several studies found the morphologic and histopathological alterations in biopsies from the biceps brachii muscle to be less than in those from vastus lateralis muscle $28,45,46$.

In 1979 Larsson et al. ${ }^{34}$ stated that besides the decline in type II fibre area, also age and fat free mass were independent variables correlating with the decrease in isometric and dynamic muscle strength during aging. They suggested that besides the alterations in muscle fibres other factors, such as reduced blood flow and metabolic abnormalities, would be responsible for this decrease.

The effect of increasing age on muscle capillarization is still disputed. Although some authors stated that muscle capillarization is not altered $^{45,46,53}$, other studies don't support this point of view ${ }^{47,54}$. Frontera et al. ${ }^{54}$ found a significant reduction in capillary-to-fibre ratio in a 12 year follow up of 12 healthy men with an initial age of 65 years. They stated that this might be due to the decline in proportion of type I fibres of these men, which are known to have a higher capillary-to-fibre ratio compared with type II fibres. The reduction in capillary-to-fibre ratio was confirmed by Coggan et al. ${ }^{47}$, who examined muscle biopsies from 20 older and 20 younger subjects. In this study capillary density and the number of capillaries in contact with each muscle fibre were also all significantly lower in older than in younger subjects.

\section{Muscle energy metabolism}

Changes in muscle energy metabolism with aging are reported in Table 2.2. Some studies reported a trend towards a reduction in the activity of oxidative and glycolytic systems $44,47,48,52$, although others could not confirm this ${ }^{45,46,51}$. Aniansson et al. ${ }^{46}$ reported higher activities of oxidative enzymes in the vastus lateralis muscle 
compared to the biceps brachii muscle, whereas glycolytic enzymatic activities were higher in the latter muscle. This could partly be explained by the relative preservation of muscle fibre size in the upper extremity.

Taylor et al. ${ }^{55}$ found no differences in high energy phosphates and $\mathrm{pH}$ at rest, during handgrip exercise and during recovery from exercise in a ${ }^{31} \mathrm{P}$ MRS study comparing muscle energetics of healthy volunteers of different age groups. This suggests that the aging process does not affect the muscle's metabolic capacity.

\section{Chronic organ disease}

\section{Muscle function}

Many patients with COPD experience weakness of peripheral skeletal muscles ${ }^{56-58}$ and loss of muscle mass. Bernard et al. ${ }^{7}$ reported that in COPD the relative reduction in isokinetic quadriceps strength was greater than that of the muscles of the shoulder girdle. Also, Gosselink et al. ${ }^{56}$ found that the isometric quadriceps force, expressed as a percentage of predicted, was lower compared with handgrip strength. Although the methods for determining strength of upper and lower limbs differed in these studies, the results indicate that in COPD muscle function of the upper limb might be relatively preserved.

The results of studies on muscular endurance capacity in patients with COPD are conflicting. Zarrata-Hartmann et al. ${ }^{59}$ reported that the isometric endurance of vastus lateralis muscle was normal in a group of chronic hypoxemic patients. In the same study however, static endurance of adductor pollicis muscle (mainly oxidative metabolism) and diaphragm were reduced in patients compared to normals. Short term oxygen breathing had a beneficial effect on endurance in adductor pollicis muscle. Newell et al. ${ }^{60}$ found no difference in static endurance of elbow flexors between patients with COPD and controls. Serres et al. ${ }^{61}$ found an impaired endurance of vastus lateralis muscle during repeated dynamic contractions in patients with COPD, compared with normal subjects. Only one study $^{58}$ evaluated dynamic endurance of the upper and lower extremities in COPD and found that endurance of the muscles of the upper arm was preserved in comparison to the quadriceps muscle. Results of studies on muscle weakness in patients with CHF show a generalized loss of peripheral muscle strength compared to normal subjects ${ }^{57,62,63}$. Muscle endurance is also negatively affected in heart 
failure ${ }^{63,64}$. Minotti et al. ${ }^{64}$ and Sunnerhagen et al. ${ }^{63}$ reported a reduction in both isometric as well as isokinetic quadriceps endurance in $\mathrm{CHF}$, compared to controls. Buller et al. ${ }^{65}$ found that isometric muscle endurance and strength of the adductor pollicis muscle, in contrast to the quadriceps muscle, were preserved in CHF. Within a population of patients with chronic heart failure, cachectic patients showed a greater loss of muscle strength and endurance than noncachectic patients ${ }^{66}$. In the same study strength per unit of muscle cross sectional area was also reduced in cachectic patients compared with noncachectic patients ${ }^{66}$, indicating that besides loss of muscle mass, other factors might contribute to muscle weakness in the patients. Other studies however reported normal strength/muscle size ratios in $\mathrm{CHF}^{64,65}$.

Commonly, patients with chronic renal failure present with muscle weakness, complaining of difficulty with rising from a chair or easy fatigability. The muscle weakness in these patients is more pronounced in the lower than in the upper limbs and is particularly present in the proximal muscles ${ }^{67,68}$. In these patients the quadriceps muscle and other muscle groups were found to be weaker, compared to healthy controls ${ }^{69-72}$. Fahal et al. ${ }^{70}$ reported that within a group of patients with CRF, malnourished persons showed a significant reduction in quadriceps strength and maximal relaxation rate compared to well-nourished patients ${ }^{70}$. Also, isometric quadriceps strength per kilogram body weight tended to be lower in patients compared to controls. To our knowledge there are no studies in patients with CRF relating muscle strength and endurance to skeletal muscle mass. Data on muscle endurance in chronic renal failure are rare. One study reported an increase in fatigability of biceps brachii muscle in patients with $\mathrm{CRF}^{72}$.

\section{Muscle morphology}

It is now generally clear that in peripheral skeletal muscles of patients with COPD a fibre type redistribution occurs, resulting in an increased percentage of fast-twitch fibres and a reduction of the proportion in type I or slow-twitch fibres (Table 2.1). Especially the relative number of type IIX fibres seems to be increased in these patients. Moreover, muscle fibre sizes are reduced in patients with $\mathrm{COPD}^{73}$. The degree in which both fibres types are affected by atrophy has to be further investigated.

Studies of peripheral muscle biopsies in patients with chronic heart failure show similar results as found in patients with COPD. Here also a shift from type I to type II, predominantly IIX, muscle fibres 
occurs. This alteration in fibre types is accompanied by a reduction in fibre size, which might affect all fibre types ${ }^{62}$ or preferentially type II $^{74}$ or only type IIX ${ }^{75}$ fibre cross sectional areas.

Results of biopsy studies in patients with chronic renal failure fail to show convincing alterations in fibre type distribution as described in patients with COPD and CHF. According to Clyne et al. $^{76}$ the proportion of type IIA fibres is increased and the percentage of type IIX fibres is reduced in chronic renal failure, with no change in the relative number of type $I$ fibres. Kempeneers et al. ${ }^{71}$ reported a preponderance of type II muscle fibres in vastus lateralis biopsies of renal transplant recipients after an endurance training programme of 24 weeks. This might indicate myopathic changes in these patients with a replacement of type I with type II fibres. According to several studies, fast twitch muscle fibre area seems to be reduced in patients with chronic renal failure.

Whittom et al. ${ }^{73}$ demonstrated that capillary to fibre ratio in the vastus lateralis muscle of patients with COPD was similar to that in normal subjects. In the same study, the number of capillary contacts per muscle fibre was lower for type I and type IIA fibres. There was no difference in the number of capillary contacts per unit of muscle fibre area between patients and controls. In contrast to these results, Jobin et al. ${ }^{77}$ reported a reduction in capillary density and capillaryto-fibres ratio in patients with COPD.

In patients with chronic heart failure, an increased ${ }^{74}$, normal ${ }^{62,78,79}$ and decreased ${ }^{80}$ capillary density have all been reported. Sullivan et al. ${ }^{75}$ reported a reduction in the number of capillaries adjacent to type I and type IIA muscle fibres in patients with $\mathrm{CHF}$, compared to controls. Capillary to fibre ratio however was unchanged, because the muscle fibres in patients tended to be smaller than in controls. The latter was confirmed by Mancini et al. ${ }^{74}$. Schaufelberger et al. ${ }^{78,79}$ found a reduction in capillary-to-fibre ratio in patients with CHF. The number of capillary contacts per muscle fibre and per muscle fibre area were not different in patients from controls.

To our knowledge, no studies on potential alterations in skeletal muscle capillarization in patients with chronic renal failure are available.

\section{Muscle energy metabolism}

The results of various studies on muscle energy metabolism in COPD are summarized in Table 2.2. There is accumulating evidence of increased activities of glycolytic enzymes and a reduction in aerobic metabolism in peripheral skeletal muscles of patients with COPD in 
comparison to normal subjects ${ }^{81-84}$. Sauleda et al. ${ }^{85}$ reported an increased activity of COX in skeletal muscle of patients with COPD.

Patients with chronic heart failure demonstrate similar skeletal muscle metabolic abnormalities, including reduced activities of enzymes involved in oxidative carbohydrate and fatty acid energy metabolism and a relative increase in anaerobic capacity ${ }^{74,75,78,80,86}$.

In only a few studies, muscle biopsies were taken from patients with chronic renal failure in order to investigate muscular metabolism. Clyne et al. ${ }^{76}$ found no alterations in oxidative enzymes activities in patients with CRF. Pastoris et al. ${ }^{68}$ reported a hypermetabolic tricarboxylic acid cycle, measured by the activities of citrate synthase and succinate dehydrogenase, but impaired oxidative phosphorylation. Activity of anaerobic enzyme hexokinase was increased in this study, while the activities of phosphofructokinase and lactate dehydrogenase, both enzymes involved in glycolytic metabolism, were unchanged in patients with CRF compared with normal subjects. Finally, Conjard et al. ${ }^{87}$ observed reduced activities of both oxidative and anaerobic metabolism in rectus abdominis muscle.

At rest, no major alterations are present in muscle energy status and $\mathrm{pH}$ measured with ${ }^{31} \mathrm{P}$ MRS in patients with COPD (Table 2.3) ${ }^{88-92}$. During muscle exercise the level of intramuscular phosphocreatine is decreased in patients with COPD and the rate of depletion of phosphocreatine is increased compared to normal subjects ${ }^{88-93}$. Also $\mathrm{pH}$ is lower and this acidification of skeletal muscle occurs faster in patients than in controls. In the recovery phase, patients with COPD show a prolonged half-time for phosphocreatine and $\mathrm{pH}$ recovery ${ }^{88-90,92,93}$, indicating that oxidative metabolism is impaired.

${ }^{31} \mathrm{P}$ NMR spectra of skeletal muscle at rest in patients with CHF seem to be in the normal range ${ }^{92,94-97}$. During local muscle exercise however, the results of the different studies convincingly show a greater degree and rate of energy status depletion and acidification in patients with $\mathrm{CHF}_{\text {, compared to normal subjects }}{ }^{74,94-99}$. Of special interest are the results of a study performed by Chati et al. ${ }^{98}$, who compared the ${ }^{31} \mathrm{P}$ NMR spectra of patients with CHF during calf muscle exercise with both sedentary and trained controls. Spectra from patients were clearly different from those obtained in trained controls. No differences however were found in variables of energy status between patients and sedentary controls. They concluded that metabolic abnormalities in patients with CHF are most likely a consequence of deconditioning. Energy spectra during the recovery 
phase are in line with results during exercise and show a delayed recovery ${ }^{92,95,97,99}$.

There are only a few studies available investigating muscular metabolism with ${ }^{31} \mathrm{P}$ MRS in patients with CRF and the results are contradicting. Although one study ${ }^{100}$ found normal ${ }^{31} \mathrm{P}$ NMR spectra at rest in six patients with CRF in comparison to sex and age matched healthy controls, other studies ${ }^{101,102}$ showed impaired muscular metabolism at rest. Also an increased energy status at rest has been reported in patients with $\mathrm{CRF}^{103}$. During muscular exercise, abnormalities in phosphorus spectra and $\mathrm{pH}$ are more clear. Depletion of phosphocreatine seems to be more enhanced in patients with CRF and $\mathrm{pH}$ is decreased compared to normal subjects ${ }^{102-104}$. Finally, in the recovery phase the prolonged recovery half times for phosphocreatine and $\mathrm{pH}$ seem to indicate an impaired oxidative metabolism in this disease ${ }^{100,102}$, although others could not confirm this ${ }^{104}$.

\section{Discussion}

The results of this review show that peripheral skeletal muscles are commonly involved in the process of chronic disabling diseases like COPD, CHF and CRF. Although the primary impairments clearly differ between these conditions, the alterations in skeletal muscles show much resemblance.

Firstly, changes in body composition, characterized by a loss of muscle mass, and a decrease in muscle strength occur in these three diseases. Several studies in patients with COPD, CHF and CRF have shown that a depletion of lean body mass is associated with a reduction in muscle force ${ }^{7,66,70,105}$. In COPD and CHF muscle mass seems to be the main determinant of muscle strength, as indicated by the normal ratio of strength to local muscle mass $7,64,65,105$. Future studies need to provide more information about the relationship between the quantity of muscle and muscle function in patients with CRF.

Various studies have evaluated muscular endurance in COPD and $\mathrm{CHF}$ and numerous protocols have been used to measure both isometric as well as isokinetic fatigability of muscle groups of the upper and lower extremities. The results seem to indicate that fatigability of the lower limbs is decreased in patients compared to controls. More standardized studies however are necessary to 
elucidate changes in upper limb endurance in these diseases and to evaluate muscle fatigue in CRF.

In the peripheral skeletal muscles of patients with COPD and CHF a relative shift in fibre type distribution occurs. The percentage of type I oxidative muscle fibres is decreased and the proportion of type II (mainly type IIX) glycolytic muscle fibres is increased. Also, muscle fibres seem to be smaller in patients compared to healthy persons. Preferential type II muscle fibre atrophy was also found in patients with CRF. Until now, no convincing evidence for alterations in muscle fibre composition in CRF has been found.

Studies on muscle energy metabolism in COPD, CHF and CRF show that abnormalities in metabolic functioning are common. In patients with COPD and CHF both the alterations in activities of metabolic enzymes, as well as the variables of ${ }^{31} \mathrm{P}$ magnetic resonance spectroscopy indicate that oxidative metabolism is impaired, and glycolytic metabolism is enhanced in these diseases. Although the results of studies on enzyme activities in CRF are not convincing, studies with ${ }^{31} \mathrm{P}$ MRS during and after exercise show the same results.

\section{Contribution of semistarvation}

Many patients with COPD, CHF and CRF suffer from weight loss and a depletion of lean body mass ${ }^{106-109}$. This condition has been related to increased morbidity and mortality ${ }^{110}$. Nutritional depletion in these diseases results from a disturbed energy balance, which mainly affects body fat mass, and an impaired protein balance, resulting in predominant loss of lean tissue. In anorexia nervosa (AN), energy intake is dramatically reduced and changes occur in body composition and skeletal muscle function and structure. Unlike in COPD and $\mathrm{CHF}$, but similar to $\mathrm{CRF}$, a muscle fibre type redistribution does not seem to occur in AN. Muscle fibre atrophy of mainly type II fibres in AN is in accordance with results from CRF and probably from COPD and CHF. Similar to COPD, CHF and CRF, oxidative metabolism seems to be impaired in AN, although in AN also glycolytic pathways are disturbed. It can be concluded that the state of a negative energy balance in chronic diseases might contribute to the observed changes in peripheral skeletal muscle.

\section{Contribution of deconditioning}

As a result of reduced activity or prolonged bed rest patients with chronic diseases like COPD, CHF and CRF are subject to varying 
degrees of deconditioning. Skeletal muscle alterations in patients show resemblance to those occurring during disuse. Both in chronic disease as well as in disuse, strength and endurance are affected. Atrophy occurs, although in disuse mainly type I fibres are affected, whereas in patients with chronic disease type II fibres seem to be preferentially affected. The potential alterations in fibre type distribution as a result of reduced activity are similar to those observed in COPD and CHF. Also, results from biopsy studies show that a decline in oxidative enzyme activities as described in chronic disease may very well be a result of deconditioning. Thus, deconditioning of peripheral muscles is very likely to be an important contributor to the alterations in peripheral skeletal muscles that occur in patients with COPD, CHF and CRF.

\section{Contribution of aging}

During aging, changes occur in human skeletal muscles, including a loss of muscle mass and function, loss and atrophy of mainly type II muscle fibres and a decline of metabolic capacity. The proportional increase in type I muscle fibres in elderly indicates that aging does not contribute to the observed fibre type redistribution in COPD, CHF or CRF. Moreover, most studies investigating alterations in skeletal muscle in chronic diseases made use of healthy age-matched control groups, so age-related changes would have been present in both groups, unless patients would respond different to aging. To our knowledge no studies have yet investigated age-related changes in patients with chronic disease.

Although more research is recommended, available studies indicate that both in aging as well as in the studied chronic diseases muscle energy metabolism is altered. Since studies in patients used healthy age-matched control groups, this suggests that besides aging, other factors negatively influence muscle metabolism in these diseases.

Changes in muscle capillarity may contribute to reduced oxygen delivery in skeletal muscle of patients with chronic organ disease and can be related to reduced oxidative metabolism. In this review, the results of studies on muscle capillarization have been described. The controversy in the results is remarkable, making it difficult to draw a simple conclusion about the changes that occur in peripheral skeletal muscle. The inability to compare the results is probably inherent to the fact that various methods were used to describe the capillary bed, as pointed out earlier in this review. 
Most studies on peripheral skeletal muscle in patients with chronic organ disease have focused on the lower limbs. It is known however that in COPD, patients experience dyspnoea particularly during activities which involve movements of the arms and shoulder girdle. In COPD, this has been attributed to the occurence of dyssynchronous thoracoabdominal breathing during unsupported arm exercise ${ }^{111}$. Also, Baarends et al. ${ }^{112}$ demonstrated that arm elevation in COPD tended to result in an increased metabolic and ventilatory response than in healthy subjects. Little is known however about the possible contribution of reduced strength and endurance of the upper limbs to impairment of arm activities and the occurrence of alterations in muscle fibres and energy metabolism in the arms, relative to the lower limbs. The available studies seem to indicate that muscle function of the upper limbs and shoulder girdle in patients with COPD is better preserved than that of the lower limbs ${ }^{7,56}$. This might also be true for patients with $\mathrm{CHF}^{65}$. No studies are available comparing upper and lower limb muscle function in patients with chronic renal failure. Although more studies in patients are certainly indicated, a possible cause for the relatively preserved function of the upper limbs could be the greater reduction of physical activity of the lower limbs, compared to the upper limbs as a result of the disease process. A relative maintenance of arm muscle function is also observed in sarcopenia. Again, differences in the decline of use between arms and legs with aging might explain these results.

\section{Conclusion}

In this review we have shown that alterations in peripheral skeletal muscle performance are remarkably similar in COPD, CHF and CRF. Also, changes in muscle morphology and energy metabolism occur in these chronic organ diseases. Results of studies on semistarvation and disuse indicate that these two factors may substantially contribute to the observed alterations. Potential differences in agerelated changes between patients with chronic organ disease and healthy subjects need to be further explored. Future investigations also need to unravel the role of changes in muscle capillarization in the described muscle abnormalities. Finally, from a therapeutic perspective muscle endurance and the exact relationship between alterations in skeletal muscle of the upper and lower limbs have to be systematically studied. 


\section{References}

1. Gosker HR, Wouters EF, van der Vusse GJ, Schols AM. Skeletal muscle dysfunction in chronic obstructive pulmonary disease and chronic heart failure: underlying mechanisms and therapy perspectives. Am J Clin Nutr 2000;71: 1033-1047.

2. Heerschap $A$, Houtman $C$, in 't Zandt $H J$, van den Bergh $A J$, Wieringa $B$. Introduction to in vivo ${ }^{31} \mathrm{P}$ magnetic resonance spectroscopy of (human) skeletal muscle. Proc Nutr Soc 1999;58:861-870.

3. McLoughlin DM, Spargo E, Wassif WS, Newham DJ, Peters TJ, Lantos PL, Russell GF. Structural and functional changes in skeletal muscle in anorexia nervosa. Acta Neuropathol (Berl) 1998;95:632-640.

4. Russell DM, Prendergast PJ, Darby PL, Garfinkel PE, Whitwell J, Jeejeebhoy KN. A comparison between muscle function and body composition in anorexia nervosa: the effect of refeeding. Am J Clin Nutr 1983;38:229-237.

5. McLoughlin DM, Wassif WS, Morton J, Spargo E, Peters TJ, Russell GF. Metabolic abnormalities associated with skeletal myopathy in severe anorexia nervosa. Nutrition 2000;16:192-196.

6. Alloway R, Shur E, Obrecht R, Russell GF. Physical complications in anorexia nervosa. Haematological and neuromuscular changes in 12 patients. $\mathrm{Br} \mathrm{J}$ Psychiatry 1988;153:72-75.

7. Bernard S, LeBlanc P, Whittom F, Carrier G, Jobin J, Belleau R, Maltais F. Peripheral muscle weakness in patients with chronic obstructive pulmonary disease. Am J Respir Crit Care Med 1998;158:629-634.

8. Polito A, Cuzzolaro M, Raguzzini A, Censi L, Ferro-Luzzi A. Body composition changes in anorexia nervosa. Eur J Clin Nutr 1998;52:655-662.

9. Lindboe CF, Askevold F, Slettebo M. Changes in skeletal muscles of young women with anorexia nervosa. An enzyme histochemical study. Acta Neuropathol 1982; 56:299-302.

10. Essen B, Fohlin L, Thoren C, Saltin B. Skeletal muscle fiber types and sizes in anorexia nervosa patients. Clin Physiol 1981;1:395-403.

11. Russell DM, Walker PM, Leiter LA, Sima AA, Tanner WK, Mickle DA, Whitwell J, Marliss EB, Jeejeebhoy KN. Metabolic and structural changes in skeletal muscle during hypocaloric dieting. Am J Clin Nutr 1984;39:503-513.

12. Thompson A, Damyanovich A, Madapallimattam A, Mikalus D, Allard J, Jeejeebhoy $\mathrm{KN} .{ }^{31} \mathrm{P}$-nuclear magnetic resonance studies of bioenergetic changes in skeletal muscle in malnourished human adults. Am J Clin Nutr 1998;67:39-43.

13. Appell $\mathrm{HJ}$. Muscular atrophy following immobilisation. A review. Sports Med $1990 ; 10: 42-58$.

14. Berg HE, Tesch PA. Changes in muscle function in response to 10 days of lower limb unloading in humans. Acta Physiol Scand 1996;157:63-70.

15. Adams GR, Hather BM, Dudley GA. Effect of short-term unweighting on human skeletal muscle strength and size. Aviat Space Environ Med 1994;65:1116-1121.

16. Duchateau J, Hainaut K. Effects of immobilization on electromyogram power spectrum changes during fatigue. Eur J Appl Physiol Occup Physiol 1991;63: 458-462.

17. Madsen OR, Egsmose C, Hansen B, Sorensen OH. Soft tissue composition, quadriceps strength, bone quality and bone mass in rheumatoid arthritis. Clin Exp Rheumatol 1998;16:27-32.

18. McComas AJ. Skeletal muscle: form and function. 1st edition, Champaign, IL, 1996.

19. Bloomfield SA. Changes in musculoskeletal structure and function with prolonged bed rest. Med Sci Sports Exerc 1997;29:197-206. 
20. Hather BM, Adams GR, Tesch PA, Dudley GA. Skeletal muscle responses to lower limb suspension in humans. J Appl Physiol 1992;72:1493-1498.

21. Portero P, Vanhoutte C, Goubel F. Surface electromyogram power spectrum changes in human leg muscles following 4 weeks of simulated microgravity. Eur J Appl Physiol Occup Physiol 1996;73:340-345.

22. Duchateau J. Bed rest induces neural and contractile adaptations in triceps surae. Med Sci Sports Exerc 1995;27:1581-1589.

23. Hikida RS, Gollnick PD, Dudley GA, Convertino VA, Buchanan P. Structural and metabolic characteristics of human skeletal muscle following 30 days of simulated microgravity. Aviat Space Environ Med 1989;60:664-670.

24. Klausen K, Andersen LB, Pelle I. Adaptive changes in work capacity, skeletal muscle capillarization and enzyme levels during training and detraining. Acta Physiol Scand 1981;113:9-16.

25. Berg $H E$, Larsson $L$, Tesch PA. Lower limb skeletal muscle function after 6 wk of bed rest. J Appl Physiol 1997;82:182-188.

26. Larsson $\mathrm{L}$, Ansved T. Effects of long-term physical training and detraining on enzyme histochemical and functional skeletal muscle characteristic in man. Muscle Nerve 1985;8:714-722.

27. Talmadge RJ. Myosin heavy chain isoform expression following reduced neuromuscular activity: potential regulatory mechanisms. Muscle Nerve 2000; 23:661-679.

28. Klitgaard H, Zhou M, Schiaffino S, Betto R, Salviati G, Saltin B. Aging alters the myosin heavy chain composition of single fibers from human skeletal muscle. Acta Physiol Scand 1990;140:55-62.

29. Henriksson J, Reitman JS. Time course of changes in human skeletal muscle succinate dehydrogenase and cytochrome oxidase activities and maximal oxygen uptake with physical activity and inactivity. Acta Physiol Scand 1977;99:91-97.

30. Jansson E, Sylven C, Arvidsson I, Eriksson E. Increase in myoglobin content and decrease in oxidative enzyme activities by leg muscle immobilization in man. Acta Physiol Scand 1988;132:515-517.

31. Vandenborne K, Elliott MA, Walter GA, Abdus S, Okereke E, Shaffer M, Tahernia $D$, Esterhai JL. Longitudinal study of skeletal muscle adaptations during immobilization and rehabilitation. Muscle Nerve 1998;21:1006-1012.

32. Roubenoff R, Rall LC. Humoral mediation of changing body composition during aging and chronic inflammation. Nutr Rev 1993;51:1-11.

33. Aoyagi Y, Shephard RJ. Aging and muscle function. Sports Med 1992;14: 376-396.

34. Larsson L, Grimby G, Karlsson J. Muscle strength and speed of movement in relation to age and muscle morphology. J Appl Physiol 1979;46:451-456.

35. Bemben MG, Massey $\mathrm{BH}$, Bemben DA, Misner J E, Boileau R A. Isometric intermittent endurance of four muscle groups in men aged 20-74 yr. Med Sci Sports Exerc 1996;28:145-154.

36. Backman E, Johansson V, Hager B, Sjoblom P, Henriksson KG. Isometric muscle strength and muscular endurance in normal persons aged between 17 and 70 years. Scand J Rehabil Med 1995;27:109-117.

37. Rogers MA, Evans WJ. Changes in skeletal muscle with aging: effects of exercise training. Exerc Sport Sci Rev 1993;21:65-102.

38. Moulias R, Meaume S, Raynaud-Simon A. Sarcopenia, hypermetabolism, and aging. Z Gerontol Geriatr 1999;32:425-432.

39. Evans WJ. What is sarcopenia? J Gerontol A Biol Sci Med Sci 1995;50:5-8.

40. Lexell J. Human aging, muscle mass, and fiber type composition. J Gerontol $A$ Biol Sci Med Sci 1995;50:11-16.

41. Lexell J, Taylor CC, Sjostrom M. What is the cause of the aging atrophy? Total number, size and proportion of different fiber types studied in whole vastus lateralis muscle from 15- to 83-year-old men. J Neurol Sci 1988;84:275-294. 
42. Klitgaard H, Mantoni M, Schiaffino S, Ausoni S, Gorza L, Laurent-Winter C, Schnohr P, Saltin B. Function, morphology and protein expression of aging skeletal muscle: a cross-sectional study of elderly men with different training backgrounds. Acta Physiol Scand 1990;140:41-54.

43. Scelsi R, Marchetti C, Poggi P. Histochemical and ultrastructural aspects of $\mathrm{m}$. vastus lateralis in sedentary old people (age 65-89 years). Acta Neuropathol 1980;51:99-105.

44. Larsson L, Sjodin B, Karlsson J. Histochemical and biochemical changes in human skeletal muscle with age in sedentary males, age 22-65 years. Acta Physiol Scand 1978;103:31-39.

45. Grimby G, Danneskiold-Samsoe B, Hvid K, Saltin B. Morphology and enzymatic capacity in arm and leg muscles in 78-81 year old men and women. Acta Physiol Scand 1982;115:125-134.

46. Aniansson A, Hedberg M, Henning GB, Grimby G. Muscle morphology, enzymatic activity, and muscle strength in elderly men: a follow-up study. Muscle Nerve 1986;9:585-591.

47. Coggan AR, Spina RJ, King DS, Rogers MA, Brown M, Nemeth PM, Holloszy JO. Histochemical and enzymatic comparison of the gastrocnemius muscle of young and elderly men and women. J Gerontol 1992;47:B71-76.

48. Aniansson A, Grimby G, Hedberg M. Compensatory muscle fiber hypertrophy in elderly men. J Appl Physiol 1992;73:812-816.

49. Orlander J, Kiessling KH, Larsson L, Karlsson J, Aniansson A. Skeletal muscle metabolism and ultrastructure in relation to age in sedentary men. Acta Physiol Scand 1978;104:249-261.

50. Poggi P, Marchetti C, Scelsi R. Automatic morphometric analysis of skeletal muscle fibers in the aging man. Anat Rec 1987;217:30-34.

51. Chilibeck PD, McCreary CR, Marsh GD, Paterson DH, Noble EG, Taylor AW, Thompson RT. Evaluation of muscle oxidative potential by ${ }^{31} \mathrm{P}-\mathrm{MRS}$ during incremental exercise in old and young humans. Eur J Appl Physiol 1998;78: 460-465.

52. McCully KK, Fielding RA, Evans WJ, Leigh JS Jr., Posner JD. Relationships between in vivo and in vitro measurements of metabolism in young and old human calf muscles. J Appl Physiol 1993;75:813-819.

53. Chilibeck PD, Paterson DH, Cunningham DA, Taylor AW, Noble EG. Muscle capillarization $\mathrm{O}_{2}$ diffusion distance, and $\mathrm{VO}_{2}$ kinetics in old and young individuals. J Appl Physiol 1997;82:63-69.

54. Frontera WR, Hughes VA, Fielding RA, Fiatarone MA, Evans WJ, Roubenoff R. Aging of skeletal muscle: a 12-yr longitudinal study. J Appl Physiol 2000;88: 1321-1326.

55. Taylor DJ, Crowe M, Bore PJ, Styles P, Arnold DL, Radda GK. Examination of the energetics of aging skeletal muscle using nuclear magnetic resonance. Gerontology 1984;30:2-7.

56. Gosselink R, Troosters T, Decramer M. Peripheral muscle weakness contributes to exercise limitation in COPD. Am J Respir Crit Care Med 1996;153:976-980.

57. Hamilton AL, Killian KJ, Summers E, Jones NL. Muscle strength, symptom intensity, and exercise capacity in patients with cardiorespiratory disorders. Am J Respir Crit Care Med 1995;152:2021-2031.

58. Clark CJ, Cochrane LM, Mackay E, Paton B. Skeletal muscle strength and endurance in patients with mild COPD and the effects of weight. Eur Respir J 2000;15:92-97.

59. Zattara-Hartmann MC, Badier M, Guillot C, Tomei C, Jammes Y. Maximal force and endurance to fatigue of respiratory and skeletal muscles in chronic hypoxemic patients: the effects of oxygen breathing. Muscle Nerve 1995;18: 495-502. 
60. Newell SZ, McKenzie DK, Gandevia SC. Inspiratory and skeletal muscle strength and endurance and diaphragmatic activation in patients with chronic airflow limitation. Thorax 1989;44:903-912.

61. Serres I, Gautier V, Varray A, Prefaut C. Impaired skeletal muscle endurance related to physical inactivity and altered lung function in COPD patients. Chest 1998; 113:900-905.

62. Lipkin DP, Jones DA, Round JM, Poole-Wilson PA. Abnormalities of skeletal muscle in patients with chronic heart failure. Int J Cardiol 1988;18:187-195.

63. Sunnerhagen KS, Cider A, Schaufelberger M, Hedberg M, Grimby G. Muscular performance in heart failure. J Card Fail 1998;4:97-104.

64. Minotti JR, Christoph I, Oka R, Weiner MW, Wells L, Massie BM. Impaired skeletal muscle function in patients with congestive heart failure. Relationship to systemic exercise performance. J Clin Invest 1991;88:2077-2082.

65. Buller NP, Jones $D$, Poole-Wilson PA. Direct measurement of skeletal muscle fatigue in patients with chronic heart failure. Br Heart J 1991;65:20-24.

66. Anker SD, Swan JW, Volterrani M, Chua TP, Clark AL, Poole-Wilson PA, Coats AJ. The influence of muscle mass, strength, fatigability and blood flow on exercise capacity in cachectic and non-cachectic patients with chronic heart failure. Eur Heart J 1997; 18:259-269.

67. Lazaro RP, Kirshner HS. Proximal muscle weakness in uremia. Case reports and review of the literature. Arch Neurol 1980;37:555-558.

68. Pastoris O, Aquilani R, Foppa P, Bovio G, Segagni S, Baiardi P, Catapano M, Maccario M, Salvadeo A, Dossena M. Altered muscle energy metabolism in postabsorptive patients with chronic renal failure. Scand J Urol Nephrol 1997;31: 281-287.

69. Diesel W, Noakes TD, Swanepoel C, Lambert M. Isokinetic muscle strength predicts maximum exercise tolerance in renal patients on chronic hemodialysis. Am J Kidney Dis 1990;16:109-114.

70. Fahal IH, Bell GM, Bone JM, Edwards RH. Physiological abnormalities of skeletal muscle in dialysis patients. Nephrol Dial Transplant 1997;12:119-127.

71. Kempeneers G, Noakes TD, van Zyl-Smit R, Myburgh KH, Lambert M, Adams B, Wiggins T. Skeletal muscle limits the exercise tolerance of renal transplant recipients: effects of a graded exercise training programme. Am J Kidney Dis 1990;16:57-65.

72. Wanic-Kossowska M, Koczocik-Przedpelska J. Myoneuropathy in patients with chronic renal failure treated with hemodialysis (HD) and intermittent peritoneal dialysis (IPD). I. Evaluation of myoelectric activity of selected skeletal muscles in patients with chronic renal failure treated with hemodialysis and intermittent peritoneal dialysis. Pol Arch Med Wewn 1996;95:229-236.

73. Whittom F, Jobin J, Simard PM, Leblanc P, Simard C, Bernard S, Belleau R, Maltais $\mathrm{F}$. Histochemical and morphological characteristics of the vastus lateralis muscle in patients with chronic obstructive pulmonary disease. Med Sci Sports Exerc 1998;30:1467-1474.

74. Mancini DM, Coyle E, Coggan A, Beltz J, Ferraro N, Montain S, Wilson JR. Contribution of intrinsic skeletal muscle changes to ${ }^{31} \mathrm{P}$ NMR skeletal muscle metabolic abnormalities in patients with chronic heart failure. Circulation 1989; 80:1338-1346.

75. Sullivan MJ, Green HJ, Cobb FR. Skeletal muscle biochemistry and histology in ambulatory patients with long-term heart failure. Circulation 1990;81:518-527.

76. Clyne N, Esbjornsson M, Jansson E, Jogestrand T, Lins LE, Pehrsson SK. Effects of renal failure on skeletal muscle. Nephron 1993;63:395-399.

77. Jobin J, Maltais F, Doyon JF, LeBlanc P, Simard PM, Simard AA, Simard C. Chronic obstructive pulmonary disease: capillarity and fiber-type characteristics of skeletal muscle. J Cardiopulm Rehabil 1998;18:432-437. 
78. Schaufelberger M, Eriksson BO, Grimby G, Held P, Swedberg K. Skeletal muscle alterations in patients with chronic heart failure. Eur Heart J 1997;18:971-980.

79. Schaufelberger M, Eriksson BO, Grimby G, Held P, Swedberg K. Skeletal muscle fiber composition and capillarization in patients with chronic heart failure: relation to exercise capacity and central hemodynamics. J Card Fail 1995;1:267-272.

80. Drexler $H$, Riede $U$, Munzel $T$, Konig $H$, Funke $E$, Just $H$. Alterations of skeletal muscle in chronic heart failure. Circulation 1992;85:1751-1759.

81. Jakobsson $\mathrm{P}$, Jorfeldt $\mathrm{L}$, Henriksson J. Metabolic enzyme activity in the quadriceps femoris muscle in patients with severe chronic obstructive pulmonary disease. Am J Respir Crit Care Med 1995;151:374-377.

82. Maltais F, LeBlanc P, Whittom F, Simard C, Marquis K, Belanger M, Breton MJ, Jobin J. Oxidative enzyme activities of the vastus lateralis muscle and the functional status in patients with COPD. Thorax 2000;55:848-853.

83. Maltais F, Simard AA, Simard C, Jobin J, Desgagnes P, LeBlanc P. Oxidative capacity of the skeletal muscle and lactic acid kinetics during exercise in normal subjects and in patients with COPD. Am J Respir Crit Care Med 1996;153: 288-293.

84. Wang XN, Williams TJ, McKenna MJ, Li JL, Fraser SF, Side EA, Snell GI, Walters EH, Carey MF. Skeletal muscle oxidative capacity, fiber type, and metabolites after lung transplantation. Am J Respir Crit Care Med 1999;160:57-63.

85. Sauleda J, Garcia-Palmer F, Wiesner RJ, Tarraga S, Harting I, Tomas P, Gomez C, Saus C, Palou A, Agusti AG. Cytochrome oxidase activity and mitochondrial gene expression in skeletal muscle of patients with chronic obstructive pulmonary disease. Am J Respir Crit Care Med 1998;157:1413-1417.

86. Schaufelberger M, Eriksson BO, Held P, Swedberg K. Skeletal muscle metabolism during exercise in patients with chronic heart failure. Heart 1996;76:29-34.

87. Conjard A, Ferrier B, Martin M, Caillette A, Carrier H, Baverel G. Effects of chronic renal failure on enzymes of energy metabolism in individual human muscle fibers. J Am Soc Nephrol 1995;6:68-74.

88. Payen JF, Wuyam B, Levy P, Reutenauer H, Stieglitz P, Paramelle B, Le Bas JF. Muscular metabolism during oxygen supplementation in patients with chronic hypoxemia. Am Rev Respir Dis 1993;147:592-598.

89. Wuyam B, Payen JF, Levy P, Bensaidane $H$, Reutenauer $H$, Le Bas JF, Benabid AL. Metabolism and aerobic capacity of skeletal muscle in chronic respiratory failure related to chronic obstructive pulmonary disease. Eur Respir J 1992;5:157-162.

90. Thompson CH, Davies RJ, Kemp GJ, Taylor DJ, Radda GK, Rajagopalan B. Skeletal muscle metabolism during exercise and recovery in patients with respiratory failure. Thorax 1993;48:486-490.

91. Evans AB, Al-Himyary AJ, Hrovat MI, Pappagianopoulos P, Wain JC, Ginns LC, Systrom DM. Abnormal skeletal muscle oxidative capacity after lung transplantation by ${ }^{31}$ P-MRS. Am J Respir Crit Care Med 1997;155:615-621.

92. Tada H, Kato H, Misawa T, Sasaki F, Hayashi S, Takahashi H, Kutsumi $Y$, Ishizaki T, Nakai T, Miyabo S. ${ }^{31} \mathrm{P}-$ nuclear magnetic resonance evidence of abnormal skeletal muscle metabolism in patients with chronic lung disease and congestive heart failure. Eur Respir J 1992;5:163-169.

93. Kutsuzawa T, Shioya S, Kurita D, Haida M, Ohta Y, Yamabayashi H. ${ }^{31} \mathrm{P}-\mathrm{NMR}$ study of skeletal muscle metabolism in patients with chronic respiratory impairment. Am Rev Respir Dis 1992;146:1019-1024.

94. Okita K, Yonezawa K, Nishijima H, Hanada A, Ohtsubo M, Kohya T, Murakami T, Kitabatake A. Skeletal muscle metabolism limits exercise capacity in patients with chronic heart failure. Circulation 1998;98:1886-1891.

95. Mancini DM, Ferraro N, Tuchler M, Chance B, Wilson JR. Detection of abnormal calf muscle metabolism in patients with heart failure using phosphorus-31 nuclear magnetic resonance. Am J Cardiol 1988;62:1234-1240. 
96. Wilson JR, Fink L, Maris J, Ferraro N, Power-Vanwart J, Eleff S, Chance B. Evaluation of energy metabolism in skeletal muscle of patients with heart failure with gated phosphorus-31 nuclear magnetic resonance. Circulation 1985;71: 57-62.

97. Massie B, Conway M, Yonge R, Frostick S, Ledingham J, Sleight P, Radda G, Rajagopalan B. Skeletal muscle metabolism in patients with congestive heart failure: relation to clinical severity and blood flow. Circulation 1987;76: 1009-1019.

98. Chati Z, Zannad F, Jeandel C, Lherbier B, Escanye JM, Robert J, Aliot E. Physical deconditioning may be a mechanism for the skeletal muscle energy phosphate metabolism abnormalities in chronic heart failure. Am Heart J 1996;131:560-566.

99. Massie BM, Conway M, Yonge R, Frostick S, Sleight P, Ledingham J, Radda G, Rajagopalan $B .{ }^{31} \mathrm{P}$ nuclear magnetic resonance evidence of abnormal skeletal muscle metabolism in patients with congestive heart failure. Am J Cardiol 1987; 60:309-315.

100. Durozard D, Pimmel P, Baretto S, Caillette A, Labeeuw M, Baverel G, Zech P. ${ }^{31} P$ NMR spectroscopy investigation of muscle metabolism in hemodialysis patients. Kidney Int 1993;43:885-892.

101. Taborsky P, Sotornik I, Kaslikova J, Schuck O, Hajek M, Horska A. ${ }^{31}$ P magnetic resonance spectroscopy investigation of skeletal muscle metabolism in uraemic patients. Nephron 1993;65:222-226.

102. Nishida A, Kubo K, Nihei H. Impaired muscle energy metabolism in uremia as monitored by ${ }^{31}$ P-NMR. Nippon Jinzo Gakkai Shi 1991;33:65-73.

103. Thompson RT, Muirhead N, Marsh GD, Gravelle D, Potwarka JJ, Driedger AA. Effect of anaemia correction on skeletal muscle metabolism in patients with endstage renal disease: ${ }^{31} \mathrm{P}$ magnetic resonance spectroscopy assessment. Nephron $1996 ; 73: 436-441$.

104. Moore GE, Bertocci LA, Painter PL. ${ }^{31} \mathrm{P}$-magnetic resonance spectroscopy assessment of subnormal oxidative metabolism in skeletal muscle of renal failure patients. J Clin Invest 1993;91:420-424.

105. Engelen MP, Schols AM, Does JD, Wouters EF. Skeletal muscle weakness is associated with wasting of extremity fat-free mass but not with airflow obstruction in patients with chronic obstructive pulmonary disease. Am J Clin Nutr $2000 ; 71: 733-738$.

106. Anker SD, Ponikowski PP, Clark AL, Leyva F, Rauchhaus M, Kemp M, Teixeira MM, Hellewell PG, Hooper J, Poole-Wilson PA, Coats AJ. Cytokines and neurohormones relating to body composition alterations in the wasting syndrome of chronic heart failure. Eur Heart J 1999;20:683-693.

107. Anker SD, Coats AJ. Cardiac cachexia: a syndrome with impaired survival and immune and neuroendocrine activation. Chest 1999;115:836-847.

108. Schols AM, Wouters EF. Nutritional considerations in the treatment of chronic obstructive pulmonary disease. Clinical Nutrition 1995;14:64-73.

109. Woodrow G, Oldroyd B, Turney JH, Tompkins L, Brownjohn AM, Smith MA. Whole body and regional body composition in patients with chronic renal failure. Nephrol Dial Transplant 1996;11:1613-1618.

110. Schols AM, Slangen J, Volovics L, Wouters EF. Weight loss is a reversible factor in the prognosis of chronic obstructive pulmonary disease. Am J Respir Crit Care Med 1998;157:1791-1797.

111. Criner GJ, Celli BR. Effect of unsupported arm exercise on ventilatory muscle recruitment in patients with severe chronic airflow obstruction. Am Rev Respir Dis $1988 ; 138: 856-861$.

112. Baarends EM, Schols AM, Slebos DJ, Mostert R, Janssen PP, Wouters EF. Metabolic and ventilatory response pattern to arm elevation in patients with COPD and healthy age-matched subjects. Eur Respir J 1995;8:1345-1351. 
113. Slettebo M, Lindboe CF, Askevold F. The neuromuscular system in patients with anorexia nervosa: electrophysiological and histologic studies. Clin Neuropathol $1984 ; 3: 217-224$.

114. Vescovo G, Serafini F, Facchin L, Tenderini P, Carraro U, Dalla Libera L, Catani C, Ambrosio GB. Specific changes in skeletal muscle myosin heavy chain composition in cardiac failure: differences compared with disuse atrophy as assessed on microbiopsies by high resolution electrophoresis. Heart 1996; 76:337-343.

115. Baldwin KM. Effect of spaceflight on the functional, biochemical, and metabolic properties of skeletal muscle. Med Sci Sports Exerc 1996;28:983-987.

116. Booth FW, Gollnick PD. Effects of disuse on the structure and function of skeletal muscle. Med Sci Sports Exerc 1983;15:415-420.

117. Jakobsson $P$, Jorfeldt $L$, Brundin A. Skeletal muscle metabolites and fiber types in patients with advanced chronic obstructive pulmonary disease (COPD), with and without chronic respiratory failure. Eur Respir J 1990;3:192-196.

118. Satta A, Migliori GB, Spanevello A, Neri M, Bottinelli R, Canepari M, Pellegrino M $A$, Reggiani C. Fiber types in skeletal muscles of chronic obstructive pulmonary disease patients related to respiratory function and exercise tolerance. Eur Respir J 1997; 10:2853-2860.

119. Maltais F, Sullivan MJ, LeBlanc P, Duscha BD, Schachat FH, Simard C, Blank JM, Jobin J. Altered expression of myosin heavy chain in the vastus lateralis muscle in patients with COPD. Eur Respir J 1999;13:850-854.

120. Sullivan MJ, Duscha BD, Klitgaard H, Kraus WE, Cobb FR, Saltin B. Altered expression of myosin heavy chain in human skeletal muscle in chronic heart failure. Med Sci Sports Exerc 1997;29:860-866.

121. Vescovo G, Volterrani M, Zennaro R, Sandri M, Ceconi C, Lorusso R, Ferrari R, Ambrosio GB, Dalla Libera L. Apoptosis in the skeletal muscle of patients with heart failure: investigation of clinical and biochemical changes. Heart 2000; 84:431-437.

122. Kouidi E, Albani M, Natsis K, Megalopoulos A, Gigis P, Guiba-Tziampiri O, Tourkantonis A, Deligiannis A. The effects of exercise training on muscle atrophy in haemodialysis patients. Nephrol Dial Transplant 1998;13:685-699.

123. Diesel W, Emms M, Knight B K, Noakes TD, Swanepoel CR, van Zyl Smit R, Kaschula RO, Sinclair-Smith CC. Morphologic features of the myopathy associated with chronic renal failure. Am J Kidney Dis 1993;22:677-684.

124. Pouw EM, Koerts-de Lang E, Gosker HR, Freling G, van der Vusse GJ, Wouters EF, Schols AM. Muscle metabolic status in patients with severe COPD with and without long-term prednisolone. Eur Respir J 2000;16:247-252. 



\section{Chapter 3}

\section{Arm mechanical efficiency and arm exercise capacity are relatively preserved in chronic obstructive pulmonary disease}

Frits M.E. Franssen, Emiel F.M. Wouters, Erica M. Baarends, Marco A. Akkermans, Annemie M.W.J. Schols

Medicine \& Science In Sports \& Exercise 2002; 34: 1570-1576 


\section{Abstract}

\section{Introduction}

Previous studies indicate that energy expenditure related to physical activity is enhanced and that mechanical efficiency of leg exercise is reduced in patients with chronic obstructive pulmonary disease (COPD). However, it is yet unclear if an inefficient energy expenditure is also present during other activities in COPD. This study was carried out to examine arm efficiency and peak arm exercise performance relative to leg exercise in 33 (23 males) patients with COPD ((mean \pm SEM) age: $61 \pm 2 \mathrm{yr} ; \mathrm{FEV}_{1}: 40 \pm 2 \%$ of predicted) and 20 sex- and age-matched healthy controls.

\section{Methods}

Body composition, pulmonary function, resting energy expenditure (REE) and peak leg and arm exercise performance were determined. To calculate mechanical efficiency, subjects performed submaximal leg and arm ergometry at $50 \%$ of achieved peak loads. During exercise testing, metabolic and ventilatory parameters were measured.

\section{Results}

In contrast to a reduced leg mechanical efficiency in patients compared to controls $(15.6 \pm 0.6 \%$ and $22.5 \pm 0.6 \%$ respectively, $p<0.001)$, arm mechanical efficiency was comparable in both groups (COPD: $18.3 \pm 0.9 \%$, controls: $21.0 \pm 1.2 \%$, NS). Arm efficiency was not related to leg efficiency, pulmonary function, work of breathing, or REE. Also, arm exercise capacity was relatively preserved in patients with COPD (ratio arm peak work rate/leg peak work rate in patients: $89 \%$ versus $53 \%$ in controls, $p<0.001)$.

\section{Conclusions}

Mechanical efficiency and exercise capacity of the upper and lower limbs are not homogeneously affected in COPD, with a relative preservation of the upper limbs. This may have implications for screening of exercise tolerance and prescription of training interventions in patients with COPD. Future studies need to elucidate the mechanism behind this observation. 


\section{Introduction}

Weight loss and depletion of fat-free mass (FFM) are common problems in patients with chronic obstructive pulmonary disease (COPD) and have been related to muscular weakness ${ }^{1}$ and exercise intolerance $^{2}$ in these patients. Moreover, nutritional depletion is associated with a decreased health status and increased mortality in $\mathrm{COPD}^{3}$. In general, weight loss occurs when total daily energy expenditure (TDE) exceeds dietary intake, whereas loss of muscle mass is mainly a consequence of a disturbed protein balance. TDE consists of resting energy expenditure (REE), diet induced thermogenesis and energy spent during daily activities. Although several studies reported an increase in REE in clinically stable patients with $\operatorname{COPD}^{4,5}$, the contribution of an elevated REE to nutritional depletion seems limited ${ }^{4}$. Also, previous studies suggest that diet induced thermogenesis is normal in patients with COPD $^{5}$ and that its contribution to total daily energy expenditure is small ${ }^{5}$. In another study, using the deuterium and oxygen labelled water technique, it was demonstrated that TDE is increased in clinically stable patients with COPD compared to healthy subjects ${ }^{6}$ under freeliving conditions. This elevation was primarily attributed to the nonresting component of TDE, i.e. an increase in energy expenditure related to physical activities. The hypothesis of an increase in activity related energy expenditure in some patients with COPD compared to controls is supported by the demonstration of a decreased mechanical efficiency (ME) of submaximal leg exercise in these patients ${ }^{7}$. Moreover, an increased oxygen cost of breathing in patients with COPD during exercise ${ }^{8}$ might contribute to the elevated energy expenditure during activities.

Although most studies on exercise in patients with COPD have focused on lower-extremity exercise, many patients report disabling dyspnoea for unsupported daily activities involving the upper extremities at work levels much lower than for lower-extremities exercise $^{9}$. This might be explained by the fact that during arm exercise, patients with COPD have to use their shoulder-girdle muscles not only for exercise, but also for breathing. This is associated with the development of a dyssynchronous breathing pattern during arm exercise in patients with severe airway obstruction ${ }^{10}$.

Based on earlier observations of a decreased mechanical efficiency of leg exercise and the impairment of unsupported arm activities in 
patients with COPD, it can be hypothesized that an inefficient energy expenditure is also present during arm exercise in COPD. As a result of the dual activity of shoulder-girdle muscles during arm exercise, arm inefficiency may be even more pronounced than leg inefficiency. Therefore the primary aim of this study was to compare the mechanical efficiency of arm exercise to the mechanical efficiency of leg exercise in patients with COPD. Since there is no method to validly and reliably measure the amount of external work performed and thus mechanical efficiency during unsupported arm exercise, supported arm exercise in the form of arm ergometry was used. In addition, peak arm exercise capacity relative to peak leg exercise capacity was compared in patients with COPD and in controls.

\section{Methods}

\section{Study population}

A group of 33 clinically stable patients with COPD consecutively admitted to a pulmonary rehabilitation centre was studied. All patients fulfilled the criteria for COPD according to American Thoracic Society guidelines ${ }^{11}$ and suffered from moderate to severe airflow obstruction (forced expiratory volume in one second; $\mathrm{FEV}_{1}: 40 \pm 2 \%$ of predicted). Patients exhibiting an increase in $\mathrm{FEV}_{1}>10 \%$ of baseline after inhalation of a $\beta_{2}$-agonist or those requiring oxygen supplementation $\left(\mathrm{PaO}_{2}\right.$ at rest $\left.<7.3 \mathrm{kPa}\right)$ were excluded. None of the patients suffered from malignancies, clinically apparent heart failure, active gastro-intestinal abnormalities, locomotor diseases or severe endocrine disorders. Patients were using one or more of the following respiratory medications: inhaled/oral short- and long-term $\beta_{2}$ sympathicomimetics, inhaled glucocorticosteroids, inhaled ipratropium bromide, oral theophyllines or low dose oral glucocorticosteroids as a maintenance therapy. From an advertisement in a local newspaper, 20 healthy age- and sex-matched control subjects were recruited. Controls did not participate in any exercise training programme. Written informed consent was obtained from all subjects and the study was approved by the medical ethics committee of the University Hospital Maastricht. The results with respect to the leg mechanical efficiency of the patients have been published earlier ${ }^{7}$. 


\section{Body composition}

Body height was determined to the nearest $0.5 \mathrm{~cm}$ (Lameris, WM 715, Breukelen, The Netherlands) with subjects standing barefoot. Body weight was measured with a beam scale (SECA, FRG, Germany) without shoes and in light clothing to the nearest $0.1 \mathrm{~kg}$. Body mass index (BMI) was calculated as the ratio of weight in kilograms to height in squared meters. Fat-free mass (FFM) was measured by bioelectrical impedance analysis at a frequency of 50 kHz (Xitron 4000b, Xitron technologies, San Diego, California, USA) and expressed in kilograms. Resistance was measured in supine position at the right side as described by Lukaski et al. ${ }^{12}$. A patient specific regression equation, described by Schols et al. ${ }^{13}$ was used to calculate FFM in the patients with COPD. Fat-free mass index (FFMI) was calculated as the ratio of FFM to height in squared meters and was expressed in $\mathrm{kg} \cdot \mathrm{m}^{-2}$.

\section{Resting energy expenditure}

Energy expenditure at rest (REE) was measured by indirect calorimetry using a ventilated hood system (Oxyconbeta, Jaeger, Würzburg, Germany). Reproducibility and validity of this method in COPD patients was shown by Schols et al. ${ }^{14}$. The system was calibrated daily at the start of the experiment. The accuracy of the system was regularly assessed using a methanol combustion test. Measurements were performed in the early morning after an overnight fast, while the subject was comfortably lying on a bed in supine position. Energy expenditure was calculated from oxygen consumption and carbon dioxide production using the abbreviated Weir formula ${ }^{15}$. Measured REE was expressed as a percentage of predicted REE, which was calculated using the linear regression equation of REE on FFM, as described by Creutzberg et al. ${ }^{4}$.

\section{Pulmonary function}

Lung function testing included $\mathrm{FEV}_{1}$ and forced vital capacity (FVC), which were calculated from the flow-volume curve using a spirometer (Masterlab, Jaeger, Würzburg, Germany). The highest value of at least three measurements was used. Diffusing capacity for carbon monoxide $\left(\mathrm{DL}_{\mathrm{CO}}\right)$ was measured by the single-breath method (Masterlab, Jaeger, Würzburg, Germany) ${ }^{16}$. Instruments were calibrated twice a day. Lung function values were expressed as a percentage of reference values ${ }^{17}$. Inspiratory muscle strength 
( $\mathrm{P}_{\mathrm{i}}$-max) was assessed by maximal inspiratory mouth pressure according to the method described by Black and Hyatt ${ }^{18}$ and was expressed in positive values. In patients a blood sample was taken from the radial artery at rest while breathing room air. Arterial oxygen tension $\left(\mathrm{P}_{\mathrm{a}} \mathrm{O}_{2}\right)$ and carbon dioxide tension $\left(\mathrm{P}_{\mathrm{a}} \mathrm{CO}_{2}\right)$ were determined on a blood gas analyzer (Radiometer $A B L$ 330, Copenhagen, Denmark).

\section{Exercise tests}

During exercise tests blood pressure (Bosotron 2, Bosch \& Sohn, Jungingen, Germany), heart rate and transcutaneous oxygen saturation (Autocorr, SIMS BCI, Waukesha, USA) were monitored. Oxygen consumption $\left(\dot{\mathrm{VO}}_{2}\right)$, carbon dioxide production $\left(\mathrm{VCO}_{2}\right)$, minute ventilation $\left(V_{E}\right)$, breathing frequency and tidal volume were investigated breath by breath through a breathing mask (Oxyconbeta, Jaeger, Würzburg, Germany). Maximal voluntary ventilation (MVV) was indirectly estimated from $\mathrm{FEV}_{1}{ }^{19}$. Heart rates were expressed as a percentage of predicted ${ }^{20}$. Equipment was calibrated before the tests. Exercise tests were performed on three separate occasions in one week.

\section{Incremental cycle ergometry test}

Patients and control subjects performed an incremental exercise test on an electrically braked cycle ergometer (Corival 400, Lode, Groningen, The Netherlands). The test was supervised by a physician and an electrocardiogram was recorded. Before the start of the test, while seated on the cycle ergometer, ventilation characteristics at rest were analysed during two minutes. After one minute of unloaded cycling, power was increased by 10 watts every minute in patients. For the control subjects, the load was increased with 15-25 watts every minute, so that the length of the exercise test was comparable for patients and controls. None of the subjects knew the exercise load and all were encouraged to cycle at 60 revolutions. $\mathrm{min}^{-1}$ until exhaustion.

\section{Incremental arm ergometry test}

Under supervision of a physician, an incremental arm exercise test was performed on an electromagnetically braked arm ergometer (Combitronic 33, Dynafit, Kaiserslautern, Germany). Subjects were seated upright on a chair in front of the ergometer, which was 
attached to the wall and was adjustable in height. The axis of rotation of the arm cycle was placed at midsternal level. The pedals of the ergometer were held by the subjects. The trunk was unsupported during testing. After a two minutes rest measurement, the test was started at 10 watts and the load was increased with 10 watts every minute in patients. In control subjects, the load was increased with 10-20 watts every minute, in order to achieve comparable duration of the test in patients and controls. The patients were encouraged to sustain the test at $60-70$ revolutions $\cdot \mathrm{min}^{-1}$ until exhaustion.

\section{Submaximal leg and arm exercise tests}

In a random order and on separate days, all subjects performed 7-minute submaximal leg and arm exercise tests at $50 \%$ of individually measured peak loads of the incremental leg and arm ergometry tests. The mean values of metabolic and ventilatory variables during the last three minutes of exercise were used for analyses. Mechanical efficiency was calculated with the following equation:

Mechanical efficiency ${ }^{21}=$ (load of exercise (watts) 0.01433 $\left(\mathrm{kcal} \cdot \mathrm{min}^{-1}\right)$ / (energy expenditure during exercise-REE) ( $\mathrm{kcal} \cdot \mathrm{min}^{-}$ $\left.\left.{ }^{1}\right)\right) \cdot 100 \%$

Energy expenditure during exercise was calculated from the steady state values of $\dot{\mathrm{VO}}_{2}$ and $\dot{\mathrm{VCO}}_{2}$ and the abbreviated Weir formula ${ }^{15}$. A good reproducibility of this method was described in a previous study in COPD patients ${ }^{7}$.

\section{Statistics}

Results are given as mean \pm standard error of the mean (SEM). Differences between patients and controls were statistically analysed using an unpaired Student's $t$-test. The paired $t$-test was used to test for differences between upper and lower extremities in both groups. Power analysis $(1-\beta=0.90)$ was performed in order to calculate minimal group sizes for determination of a statistically significant difference in mechanical efficiency between patients and controls. Effect size was estimated at $5 \%$ and standard deviation at $4 \%$, based on data of leg efficiency in healthy subjects ${ }^{22}$ and COPD patients ${ }^{7}$. Correlation coefficient analysis was performed in order to test the linear relationship between variables. A p-value $<0.05$ was 
considered statistically significant. Data were analysed with the computer program "Statistical Package for the Social Sciences" (SPSS), version 10.0.

\section{Results}

General characteristics of the two study groups are presented in Table 3.1. There were no differences in age, sex distribution and body mass index between the COPD and healthy volunteer groups. COPD patients had significantly lower values for FFM, FFMI, FEV ${ }_{1}$, FVC, diffusing capacity for carbon monoxide and $\mathrm{P}_{\mathrm{i}}$-max than controls. Resting energy expenditure expressed as a percentage of predicted REE was significantly increased in patients with COPD compared with the control group.

Table 3.1 Characteristics of study groups (mean \pm SEM).

\begin{tabular}{|c|c|c|}
\hline & Controls & COPD \\
\hline $\operatorname{Sex} \hat{0} / 9$ & $14 / 6$ & $23 / 10$ \\
\hline Age, yr & $61 \pm 1$ & $61 \pm 2$ \\
\hline Body mass index, $\mathrm{kg} \cdot \mathrm{m}^{-2}$ & $25.9 \pm 0.6$ & $24.0 \pm 0.9$ \\
\hline Fat-free mass index, $\mathrm{kg} \cdot \mathrm{m}^{-2}$ & $20.0 \pm 0.5$ & $17.0 \pm 0.4^{* *}$ \\
\hline Resting energy expenditure, \%pred & $91.8 \pm 2.4$ & $105.3 \pm 2.9^{*}$ \\
\hline $\mathrm{FEV}_{1}, \%$ pred & $108 \pm 3$ & $40 \pm 2^{* *}$ \\
\hline FVC, \%pred & $115 \pm 3$ & $86 \pm 2^{* *}$ \\
\hline Diffusing capacity for $\mathrm{CO}, \%$ pred & $112 \pm 5$ & $55 \pm 3^{* *}$ \\
\hline $\mathrm{P}_{\mathrm{i}}$-max, \%pred & $95 \pm 5$ & $77 \pm 3^{*}$ \\
\hline $\mathrm{P}_{\mathrm{a}} \mathrm{O}_{2}, \mathrm{kPa}$ & - & $9.5 \pm 0.2$ \\
\hline $\mathrm{P}_{\mathrm{a}} \mathrm{CO}_{2}, \mathrm{kPa}$ & - & $5.6 \pm 0.1$ \\
\hline
\end{tabular}

$\mathrm{FEV}_{1}$ : forced expiratory volume in one second; FVC: forced vital capacity; $\mathrm{P}_{\mathrm{i}}$-max: peak inspiratory mouth pressure; $\mathrm{P}_{\mathrm{a}} \mathrm{O}_{2}$ : arterial oxygen pressure; $\mathrm{P}_{\mathrm{a}} \mathrm{CO}_{2}$ : arterial carbon dioxide pressure; $*: p<0.05, * *: p<0.001$ COPD versus controls.

The results of incremental exercise testing of the lower and upper limbs are presented in Table 3.2. Peak load, peak $\dot{\mathrm{VO}}_{2}$, peak $\dot{\mathrm{VCO}}_{2}$, respiratory exchange ratio (RER) and end-of-exercise ventilation were significantly lower in patients with COPD, compared to healthy controls, for maximal leg as well as maximal arm exercises. The lower ventilation in patients was achieved by a combination of a smaller tidal volume and a lower breathing frequency. For both exercises, peak ventilation expressed as percentage of predicted maximal voluntary ventilation was significantly increased in COPD, 
compared to controls. Peak heart rate of incremental leg exercise, expressed as proportion of predicted maximal heart rate, was significantly lower in patients than in controls. These results indicate that in patients ventilatory limitation is the dominant contributor to exercise impairment, whereas mainly cardiovascular factors determine exercise capacity in controls. The ratio of peak $\dot{\mathrm{VO}}_{2}$ to work load during leg exercise was increased in COPD compared with controls.

Table 3.2 Results of maximal exercise testing of patients and controls (mean \pm SEM).

\begin{tabular}{|c|c|c|}
\hline & Controls & COPD \\
\hline \multicolumn{3}{|l|}{ Leg exercise } \\
\hline Peak load, watts & $205 \pm 13$ & $61 \pm 4^{* *}$ \\
\hline Peak $\dot{\mathrm{V}} \mathrm{O}_{2}, \mathrm{ml} \cdot \mathrm{min}^{-1}$ & $2079 \pm 117$ & $1006 \pm 63^{* *}$ \\
\hline Peak $\dot{\mathrm{v}} \mathrm{CO}_{2}, \mathrm{ml} \cdot \mathrm{min}^{-1}$ & $2568 \pm 149$ & $1026 \pm 75^{* *}$ \\
\hline RER & $1.23 \pm 0.02$ & $1.01 \pm 0.02^{* *}$ \\
\hline Peak $\mathrm{V}_{\mathrm{E}}, \mathrm{l} \cdot \mathrm{min}^{-1}$ & $89.0 \pm 6.2$ & $40.6 \pm 2.2^{* *}$ \\
\hline Peak VE $/ M V V, \%$ & $69 \pm 3$ & $94 \pm 5^{* *}$ \\
\hline Peak TV, I & $2.18 \pm 0.10$ & $1.25 \pm 0.06^{* *}$ \\
\hline Peak BF, $\cdot \min ^{-1}$ & $40 \pm 2$ & $33 \pm 1^{* *}$ \\
\hline Peak HR, \%pred & $100 \pm 2$ & $82 \pm 2^{* *}$ \\
\hline Peak $\dot{\mathrm{V}}_{2} /$ peak load, $\mathrm{ml} \cdot \mathrm{min}^{-1} \cdot$ watt $^{-1}$ & $10.4 \pm 0.3$ & $17.3 \pm 0.7^{* *}$ \\
\hline \multicolumn{3}{|l|}{ Arm exercise } \\
\hline Peak load, watts & $108 \pm 7^{\# \#}$ & $50 \pm 3^{* * \# \#}$ \\
\hline Peak $\dot{\mathrm{V}} \mathrm{O}_{2}, \mathrm{ml} \cdot \mathrm{min}^{-1}$ & $1637 \pm 124^{\#}$ & $851 \pm 43^{* * \# \#}$ \\
\hline Peak $\dot{\mathrm{v} C O}{ }_{2}, \mathrm{ml} \cdot \mathrm{min}^{-1}$ & $1984 \pm 147^{\# \#}$ & $875 \pm 51^{* * \# \#}$ \\
\hline RER & $1.22 \pm 0.02$ & $1.02 \pm 0.02^{* *}$ \\
\hline Peak $V_{E}, I \cdot m^{-1}$ & $75.5 \pm 6.5^{\#}$ & $36.2 \pm 1.8^{* * \# \#}$ \\
\hline Peak $V_{E} / M V V, \%$ & $60 \pm 4^{\#}$ & $85 \pm 4^{* * \# \#}$ \\
\hline Peak TV, I & $1.97 \pm 0.13^{\#}$ & $1.16 \pm 0.06^{* * \#}$ \\
\hline Peak BF, $\cdot \min ^{-1}$ & $39 \pm 3$ & $33 \pm 1^{*}$ \\
\hline Peak HR, \%pred & - & $80 \pm 2$ \\
\hline Peak $\mathrm{VO}_{2} /$ Peak load, $\mathrm{ml} \cdot \mathrm{min}^{-1} \cdot$ watt $^{-1}$ & $15.5 \pm 0.7^{\# \#}$ & $17.3 \pm 0.6$ \\
\hline
\end{tabular}

$\dot{\mathrm{VO}}_{2}$ : oxygen consumption; $\dot{\mathrm{V} C \mathrm{CO}_{2}}$ : carbon dioxide production; RER: respiratory exchange ratio; $V_{E}$ : ventilation; $M V V$ : maximal voluntary ventilation; TV: tidal volume; BF: breathing frequency; HR: heart rate; *: $\mathrm{p}<0.05, * *: \mathrm{p}<0.001$ COPD versus controls; \# : $p<0.05, \# \#: p<0.001$ arm versus leg exercise.

In patients as well as in controls, peak load, peak $\dot{\mathrm{V}} \mathrm{O}_{2}$, peak $\dot{\mathrm{V}} \mathrm{CO}_{2}$, peak $V_{E}$ and peak $V_{E} / M V V$ all were significantly higher during lower extremity exercise than during upper extremity exercise, whereas RER and peak HR (in patients) did not differ between leg and arm exercise. The difference in ventilation can be explained by lower tidal volumes during arm exercise in both groups. The ratios of peak load achieved during maximal upper limb exercise to peak load during 
maximal lower limb exercise were $89 \%$ in patients with COPD and $53 \%$ in healthy volunteers $(\mathrm{p}<0.001)$. Maximal $\mathrm{VO}_{2}$ of arm exercise was $87 \%$ of maximal $\mathrm{VO}_{2}$ during leg exercise in patients and $82 \%$ in controls $(p=0.352)$.

Table 3.3 Steady state values of exercise testing of lower and upper extremities at $50 \%$ of achieved peak load during 7 minutes (mean \pm SEM).

\begin{tabular}{|c|c|c|}
\hline & Controls & COPD \\
\hline \multicolumn{3}{|l|}{ Leg exercise } \\
\hline Load, watts & $102 \pm 6$ & $31 \pm 2^{* *}$ \\
\hline $\mathrm{v}_{2}, \mathrm{ml} \cdot \mathrm{min}^{-1}$ & $1528 \pm 82$ & $813 \pm 42^{* *}$ \\
\hline$\dot{\mathrm{v}} \mathrm{CO}_{2}, \mathrm{ml} \cdot \mathrm{min}^{-1}$ & $1426 \pm 77$ & $759 \pm 40^{* *}$ \\
\hline RER & $0.93 \pm 0.01$ & $0.94 \pm 0.01$ \\
\hline$V_{E}, I \cdot m^{-1}$ & $42.3 \pm 2.4$ & $33.3 \pm 1.2^{* *}$ \\
\hline $\mathrm{V}_{\mathrm{E}} / \mathrm{MVV}, \%$ & $33 \pm 1$ & $79 \pm 4^{* *}$ \\
\hline$\dot{\mathrm{V}} \mathrm{O}_{2} / \mathrm{V}_{\mathrm{E}}, \mathrm{ml} \cdot \mathrm{l}^{-1}$ & $36.4 \pm 0.7$ & $24.5 \pm 0.9^{* *}$ \\
\hline TV, I & $1.73 \pm 0.07$ & $1.22 \pm 0.06^{* *}$ \\
\hline$B F, \min ^{-1}$ & $24 \pm 1$ & $29 \pm 1^{*}$ \\
\hline HR, \%pred & - & $71 \pm 2$ \\
\hline \multicolumn{3}{|l|}{ Arm exercise } \\
\hline Load, watts & $54 \pm 4^{\# \#}$ & $25 \pm 1^{* * \# \#}$ \\
\hline $\mathrm{v}_{2}, \mathrm{ml} \cdot \mathrm{min}^{-1}$ & $1017 \pm 69^{\# \#}$ & $641 \pm 27^{* * \# \#}$ \\
\hline$\dot{\mathrm{V}} \mathrm{CO}_{2}, \mathrm{ml} \cdot \mathrm{min}^{-1}$ & $1003 \pm 76^{\# \#}$ & $606 \pm 27^{* * \# \#}$ \\
\hline RER & $0.98 \pm 0.01^{\#}$ & $0.95 \pm 0.01$ \\
\hline$V_{E}, 1 \cdot \min ^{-1}$ & $33.4 \pm 2.7^{\#}$ & $30.1 \pm 1.1^{\#}$ \\
\hline $\mathrm{V}_{\mathrm{E}} / \mathrm{MVV}, \%$ & $26 \pm 2^{\# \#}$ & $71 \pm 3^{* * \#}$ \\
\hline$\dot{\mathrm{V}_{2}} / \mathrm{V}_{\mathrm{E}}, \mathrm{ml} \cdot \mathrm{l}^{-1}$ & $31.2 \pm 0.9^{\# \#}$ & $21.5 \pm 0.7^{* * \# \#}$ \\
\hline TV, I & $1.43 \pm 0.10^{\#}$ & $1.10 \pm 0.05^{* \#}$ \\
\hline$B F, \min ^{-1}$ & $24 \pm 1$ & $28 \pm 1^{*}$ \\
\hline HR, \%pred & - & $68 \pm 3$ \\
\hline
\end{tabular}

$\dot{\mathrm{VO}}_{2}$ : steady state oxygen consumption; $\dot{\mathrm{V}} \mathrm{CO}_{2}$ : steady state carbon dioxide production; RER: steady state respiratory exchange ratio; $\mathrm{V}_{\mathrm{E}}$ : steady state ventilation; MVV: maximal voluntary ventilation; TV: tidal volume; $\mathrm{BF}$ : breathing frequency; HR: heart rate; $*: \mathrm{p}<0.05, * *: \mathrm{p}<0.001$ COPD versus controls; $\#: \mathrm{p}<0.05, \# \#: \mathrm{p}<0.001$ arm versus leg exercise.

Table 3.3 shows the steady state results of submaximal leg and arm exercise testing in COPD patients and controls. During submaximal lower extremity as well as during submaximal upper extremity exercise, load, $\dot{\mathrm{VO}}_{2}$ and $\dot{\mathrm{V}} \mathrm{CO}_{2}$ were significantly lower in patients compared to controls. There were no differences in RER between groups. Steady state ventilation during leg exercise, but not during arm exercise, was consistently lower in patients compared to controls. During both forms of submaximal exercise, tidal volume was decreased and breathing frequency was increased in COPD 
compared to controls. For both exercises, $V_{E} / M V V$ was increased in COPD compared to controls. In patients, steady-state heart rates were clearly below predicted peak heart rates.

In patients as well as in controls, submaximal load, $\dot{\mathrm{V}} \mathrm{O}_{2}, \dot{\mathrm{V}} \mathrm{CO}_{2}, \mathrm{~V}_{\mathrm{E}}$, $\mathrm{V}_{\mathrm{E}} / \mathrm{MVV}$ and $\dot{\mathrm{VO}}_{2} / \mathrm{V}_{\mathrm{E}}$ all were significantly higher during leg exercise than during arm exercise. Ventilation during submaximal leg exercise was increased in comparison to submaximal arm exercise as a result of a higher tidal volume during this exercise. In patients, steady state RER and heart rate did not differ between leg and arm exercise.

Mechanical efficiency of leg exercise was significantly lower in patients than in controls $(15.6 \pm 0.6 \%$ and $22.5 \pm 0.6 \%$ respectively, $\mathrm{p}<0.001$ ) (Figure 3.1). In contrast, mechanical efficiency of supported arm exercise was comparable in patients and controls (COPD: $18.3 \pm 0.9 \%$, controls: $21.0 \pm 1.2 \%$, NS). In patients with COPD, mechanical efficiency of submaximal leg exercise was significantly lower than mechanical efficiency of submaximal arm exercise $(p=0.008)$, whereas mechanical efficiency of the lower limb was comparable to that of the upper limb in control subjects $(p=0.235)$.

Figure 3.1 Bar diagram of leg and arm mechanical efficiencies in patients (grey bars) and controls (white bars). Mean values \pm SEM are shown. Significance of differences was indicated as $* *: p<0.001$ for COPD patients versus controls and $\#: p<0.05$ arm versus leg efficiency.

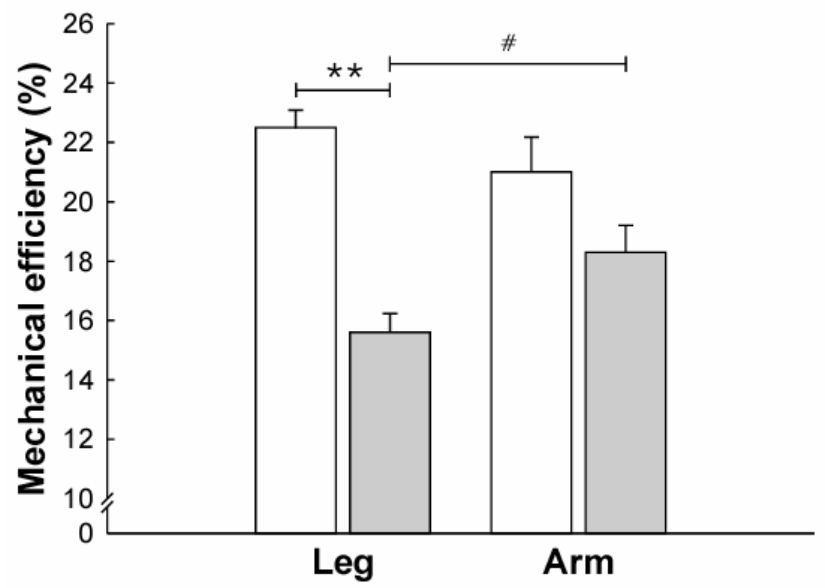

No significant relationship was found between ME of leg exercise and ME of arm exercise in patients $(r=0.286, p=0.107)$ or in controls 
$(r=0.053, p=0.828)$. In both groups, arm and leg ME were not related to variables of body composition or pulmonary function and respiratory muscle strength, or to REE or arterial blood gases. Both in COPD patients as well as in controls arm mechanical efficiency was significantly inversely related to age $(r=-0.410, p=0.018$ and $r=-0.512, p=0.025$, respectively). In the COPD group, only leg ME was correlated to measurements related to the oxygen cost of breathing, such as $\dot{\mathrm{VO}}_{2} / \mathrm{V}_{\mathrm{E}}$ ratio during maximal and submaximal leg exercise ( $r=-0.439, p=0.011$ and $r=-0.409, p=0.018$ respectively). Finally, there was an inverse relationship between the ratio peak $\mathrm{VO}_{2}$ /peak load during incremental leg exercise testing and leg $\mathrm{ME}$ calculated from results of submaximal exercise testing $(r=-0.794$. $\mathrm{p}<0.001$ ) in the COPD group (Figure 3.2). Arm mechanical efficiency was not significantly related to any of the variables of maximal or submaximal exercise testing in COPD patients.

Figure 3.2 Leg mechanical efficiency related to ratio peak $\dot{\mathrm{V}}_{2}$ /work load in COPD patients $(r=-0.794, p<0.001)$.

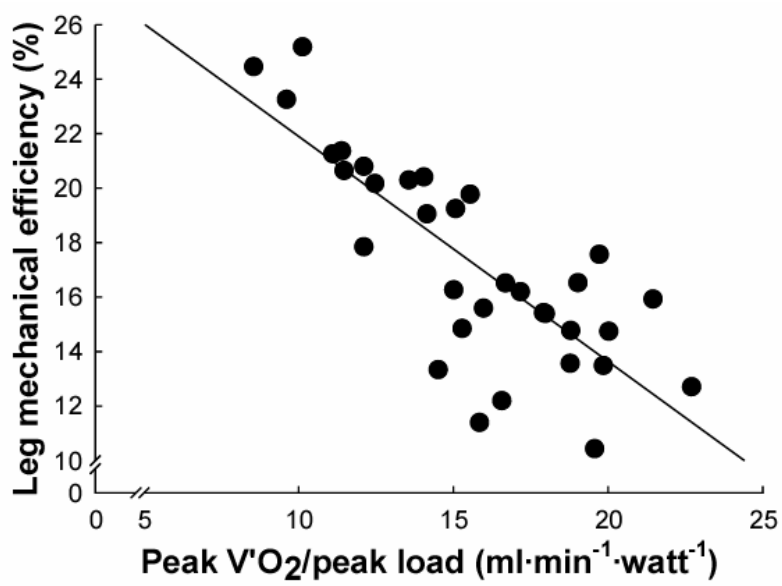




\section{Discussion}

The present study shows a preserved mechanical efficiency of submaximal arm exercise in combination with a decreased leg efficiency in clinically stable patients with COPD compared with control subjects. Moreover, exercise tolerance of the upper limbs appears to be relatively high in comparison to that of the lower limbs in patients with COPD.

It is known in healthy persons that leg mechanical efficiency generally amounts to $23-25 \%{ }^{22}$, which is higher than arm mechanical efficiency that is usually $16-19 \%{ }^{23}$. The lower mechanical efficiency of the upper limbs in healthy subjects has been attributed to a greater amount of energy expended for unmeasured work, such as torso stabilization, during arm exercise compared to leg exercise. However, this study shows that leg mechanical efficiency is significantly lower than arm mechanical efficiency in clinically stable patients with COPD. In patients, leg mechanical efficiency was reduced compared to control subjects, whereas there was no significant difference in arm mechanical efficiency between both groups. As expected, leg mechanical efficiency tended to be higher than arm mechanical efficiency in healthy controls.

It is yet unclear why arm mechanical efficiency is higher than leg mechanical efficiency in patients with COPD, but there are several possible explanations. In a previous study, the decreased mechanical efficiency of the lower limbs seemed to be associated with an increased work of breathing in COPD $^{7}$. However, in the present study, arm efficiency did not correlate with parameters related to oxygen cost of breathing, such as ratio $\mathrm{VO}_{2} / \mathrm{V}_{\mathrm{E}}$ during exercise. This suggests that arm efficiency is not affected by decreased pulmonary function per se.

Several studies have investigated the influence of different work loads on muscular efficiency in healthy subjects ${ }^{21,23,24}$, and report that mechanical efficiency is lower at lower absolute work loads ${ }^{21,23}$. The lower load during submaximal leg exercise could contribute to the decreased leg efficiency in patients compared to controls. However, this can not explain the comparable arm efficiency in patients and controls, despite lower work loads in patients.

Another possible explanation for the high arm mechanical efficiency compared to leg mechanical efficiency might be a greater reliance on anaerobic metabolism during upper limb exercise than during lower limb exercise. A non-steady state or anaerobic energy deliverance during submaximal exercise testing would result in an overestimation 
of the true mechanical efficiency. Indeed, in this study, the metabolic responses during submaximal leg as well as arm exercise relative to the peak metabolic responses were increased in patients with COPD compared with controls. However, in the COPD patients, there was no difference in the metabolic responses as percentage of peak response between submaximal leg and arm exercises. Both during leg as well as during arm submaximal exercise the metabolic response was approximately $80 \%$ of peak $\dot{\mathrm{VO}}_{2}, 93 \%$ of peak RER and $85 \%$ of peak $V_{\mathrm{E}}$. Submaximal heart rates in patients expressed as percentage of measured peak heart rates were also comparable during both tests. These similar responses during leg and arm exercise indicate that a contribution of enhanced anaerobic metabolism during arm exercise to the observed difference in leg and arm efficiency in COPD patients is unlikely.

As a result of a more sedentary lifestyle, decreased physical activity of mainly the lower limbs is likely to occur in patients with COPD. This can result in differences in training status between the lower and the upper limbs in these patients. In this way, deconditioning could contribute to the predominant loss of leg efficiency in COPD and the preservation of arm efficiency. Unfortunately, no information about the level of daily physical activity in our study groups is available. Only a few reports have investigated the relationship between training and muscular efficiency. Nickleberry et al. ${ }^{24}$ observed no difference in gross and delta efficiencies during submaximal leg ergometry between competitive and recreational cyclists, despite increased submaximal power output and endurance capacity in the group of competitive cyclists. Also, no evidence is yet available proving that mechanical efficiency is enhanced as a result of exercise training programmes in patients with COPD. Thus, it is unlikely that differences in training status between lower and upper extremities contribute to the observed difference in mechanical efficiencies between leg and arm in COPD.

Furthermore, differences in muscle fibre type composition between lower and upper extremities in patients with COPD should be considered as a possible explanation for the observed higher arm efficiency. Coyle et al. ${ }^{25}$ found a positive correlation between the percentage of type I fibres in vastus lateralis muscle and cycling efficiency during submaximal exercise in healthy subjects. In the vastus lateralis of COPD patients, a shift towards smaller fibre sizes and an increased percentage of type II fibres has been shown ${ }^{26}$. In contrast to the findings in quadriceps muscles, Gea et al. ${ }^{27}$ recently reported similar muscle fibre sizes and percentages in deltoid muscle 
biopsies in patients with COPD and controls. These observations suggest that the intrinsic skeletal muscle changes in COPD are not homogeneously distributed and that the percentage type I muscle fibres in the upper arm is preserved, in contrast to the lower limb. Future investigations need to elucidate the relationship between changes in muscle fibre types and the observed leg and arm mechanical efficiencies in patients with COPD.

A strong correlation between the ratio peak oxygen uptake to peak work rate and leg mechanical efficiency was observed in patients with COPD. In normal subjects, the slope of the relationship between peak $\dot{\mathrm{VO}}_{2}$ and work load is $10 \mathrm{ml} \cdot \mathrm{min}^{-1}$. watt $^{-1}{ }^{20}$. This value was also found in our controls. In the patient group however, the ratio was increased. Because decreased mechanical leg efficiency, in particular in active patients may contribute to elevated daily energy requirements in COPD as reported by Baarends et al. ${ }^{7}$, a maximal exercise test, commonly used in a clinical setting to detect the pathophysiology of dyspnoea and exercise limitation in COPD, may also be utilized as a diagnostic tool to detect decreased mechanical efficiency.

Furthermore, an inverse relationship between mechanical efficiency of the upper limb and age was observed in patients and in controls. The influence of aging on cycle efficiency has not been studied extensively. In a cross-sectional study that investigated ergocycle efficiency in a group of men of various age groups ${ }^{28}$, no age-related differences in gross efficiency were reported. The males in this study were younger than our subjects (mean age: $39 \pm 1.2 \mathrm{yr}$ ). No further longitudinal studies are available about the influence of aging on mechanical arm efficiency. However, other alterations in skeletal muscle are normal features of the aging process and include loss of muscle mass and function ${ }^{29}$ and changes in metabolism and muscle fibres. The alterations in muscle fibres consist of atrophy of mainly type II fibres and a proportional increase in type I muscle fibres ${ }^{29}$. Based on these changes in muscle fibres during aging and the observed correlation between the percentage of type I fibres and efficiency, one would expect an increase in mechanical efficiency with aging. However, the contrary was observed in this study.

The results of maximal exercise testing in this study further indicate that patients with COPD perform relatively better during supported upper-extremity exercise than during lower-extremity exercise. Although the achieved load during both tests was less in the patient group than in the control group, the ratio of peak load achieved during maximal upper limb exercise to peak load during maximal 
lower limb exercise was increased in patients with COPD compared with controls. Furthermore, peak oxygen consumption during arm exercise in our patients was relatively high compared to leg exercise. In a review by Franklin et al. ${ }^{30}$, it was described that maximal $\dot{\mathrm{VO}}_{2}$ of arm exercise varies between 64 and $80 \%$ of maximal $\dot{\mathrm{VO}}_{2}$ of leg exercise in healthy (younger) persons. Although this ratio seems to be increased in the COPD group, the average of the control group was also slightly higher than the reference values. At the same time, the ventilatory burden of maximal arm ergometry, as indicated by the ratio peak $V_{E} / M V V$, was less than during leg ergometry in both patients as well as controls. Furthermore, ventilatory limitation is an important determinant of exercise capacity in COPD patients, whereas mainly cardiovascular factors seem to determine exercise tolerance in controls.

The finding that arm exercise tolerance is less impaired than leg exercise tolerance in COPD, seems to be in contrast to earlier publications that reported enhanced dyspnoea, dyssynchroneous breathing ${ }^{10}$, changes in respiratory muscle recruitment ${ }^{31}$, dynamic hyperinflation ${ }^{32}$ and an inefficient metabolic and ventilatory response to arm elevation ${ }^{33}$. However it should be noted that in most of these studies unsupported arm exercise was investigated, whereas the present study measured supported arm exercise. It was demonstrated that the ventilatory response to unsupported arm elevation is enhanced in comparison to supported arm elevation in patients with COPD ${ }^{33}$. Moreover, only one study ${ }^{10}$ actually compared leg exercise and (unsupported) arm exercise in COPD.

The findings of preserved mechanical efficiency and exercise capacity of the upper extremities in COPD patients, may have significant clinical implications. Since a decreased mechanical efficiency might contribute to increased energy expenditure during exercise, a pulmonary rehabilitation programme specifically focused on training inefficient muscle groups might promote catabolism. This might negatively influence the response to nutritional therapy, which is another important component of pulmonary rehabilitation in depleted patients. In that case, endurance training interventions should in stead be preferentially aimed at more efficient muscle groups, such as the arms. As stated above, no training strategies are yet available that enhance mechanical efficiency in patients with COPD. Furthermore, the results of this study indicate that the systemic alterations related to exercise capacity and the muscular compartment must not be generalized for the lower and upper limbs, when screening patients with COPD in clinical practice. 
In summary, this study shows that arm mechanical efficiency, in contrast to leg mechanical efficiency, is normal in patients with clinically stable COPD. In addition, supported arm ergometry appears to be less impaired than leg ergometry in COPD. These observations may be important to consider in the screening and the choice of specific training interventions in patients with COPD. 


\section{References}

1. Bernard S, LeBlanc P, Whittom F, Carrier G, Jobin J, Belleau R, Maltais F. Peripheral muscle weakness in patients with chronic obstructive pulmonary disease. Am J Respir Crit Care Med 1998;158:629-634.

2. Baarends EM, Schols AM, Mostert R, Wouters EF. Peak exercise response in relation to tissue depletion in patients with chronic obstructive pulmonary disease. Eur Respir J 1997;10:2807-2813.

3. Schols AM, Slangen J, Volovics L, Wouters EF. Weight loss is a reversible factor in the prognosis of chronic obstructive pulmonary disease. Am J Respir Crit Care Med 1998;157:1791-1797.

4. Creutzberg EC, Schols AM, Bothmer-Quaedvlieg FC, Wouters EF. Prevalence of an elevated resting energy expenditure in patients with chronic obstructive pulmonary disease in relation to body composition and lung function. Eur $\mathrm{J}$ Clin Nutr 1998;52:396-401.

5. Hugli O, Frascarolo P, Schutz Y, Jequier E, Leuenberger P, Fitting JW. Dietinduced thermogenesis in chronic obstructive pulmonary disease. Am Rev Respir Dis 1993; $148: 1479-1483$.

6. Baarends EM, Schols AM, Pannemans DL, Westerterp KR, Wouters EF. Total free living energy expenditure in patients with severe chronic obstructive pulmonary disease. Am J Respir Crit Care Med 1997;155:549-554.

7. Baarends EM, Schols AM, Akkermans MA, Wouters EF. Decreased mechanical efficiency in clinically stable patients with COPD. Thorax 1997;52:981-986.

8. Levison $\mathrm{H}$, Cherniack RM. Ventilatory cost of exercise in chronic obstructive pulmonary disease. J Appl Physiol 1968;25:21-27.

9. American Thoracic Society/European Respiratory Society Statement. Skeletal muscle dysfunction in chronic obstructive pulmonary disease. Am J Respir Crit Care Med 1999;159:S1-40.

10. Celli BR, Rassulo J, Make BJ. Dyssynchronous breathing during arm but not leg exercise in patients with chronic airflow obstruction. N Engl J Med 1986;314: 1485-1490.

11. American Thoracic Society Statement. Standards for the diagnosis and care of patients with chronic obstructive pulmonary disease. Am J Respir Crit Care Med 1995; 152:S77-121.

12. Lukaski HC, Johnson PE, Bolonchuk WW, Lykken GI. Assessment of fat-free mass using bioelectrical impedance measurements of the human body. Am J Clin Nutr $1985 ; 41: 810-817$.

13. Schols AM, Wouters EF, Soeters PB, Westerterp KR. Body composition by bioelectrical-impedance analysis compared with deuterium dilution and skinfold anthropometry in patients with chronic obstructive pulmonary disease. Am J Clin Nutr 1991;53:421-424.

14. Schols AM, Schoffelen PF, Ceulemans H, Wouters EF, Saris WH. Measurement of resting energy expenditure in patients with chronic obstructive pulmonary disease in a clinical setting. JPEN J Parenter Enteral Nutr 1992;16:364-368.

15. Weir JB. New methods for calculating metabolic rate with special reference to protein metabolism. 1949. Nutrition 1990;6:213-221.

16. European Respiratory Society. Standardized lung function testing. Official statement of the European Respiratory Society. Eur Respir J Suppl 1993;16: 1-100.

17. Quanjer PH, Tammeling GJ, Cotes JE, Pedersen OF, Peslin R, Yernault JC. Lung volumes and forced ventilatory flows. Report working party standardization of lung function tests, European community for steel and coal. Official statement of the European Respiratory Society. Eur Respir J Suppl 1993;16:5-40. 
18. Black LF, Hyatt RE. Maximal respiratory pressures: Normal values and relationship to age and sex. Am Rev Respir Dis 1969;99:696-702.

19. Carter R, Peavler M, Zinkgraf S, Williams J, Fields S. Predicting maximal exercise ventilation in patients with chronic obstructive pulmonary disease. Chest 1987; $92: 253-259$.

20. Wasserman K, Hansen JE, Sue DY, Whipp BJ, Casaburi R. Principles of exercise testing and interpretation. Philadelphia: Lea \& Febiger; 1994.

21. Gaesser GA, Brooks GA. Muscular efficiency during steady-rate exercise: Effects of speed and work rate. J Appl Physiol 1975;38:1132-1139.

22. Palange $\mathbf{P}$, Galassetti P, Mannix ET, Farber MO, Manfredi F, Serra P, Carlone S. Oxygen effect on $\mathrm{O}_{2}$ deficit and $\mathrm{V}^{\prime} \mathrm{O}_{2}$ kinetics during exercise in obstructive pulmonary disease. J Appl Physiol 1995;78:2228-2234.

23. Glaser RM, Sawka MN, Laubach LL, Suryaprasad AG. Metabolic and cardiopulmonary responses to wheelchair and bicycle ergometry. J Appl Physiol 1979;46:1066-1070.

24. Nickleberry BL, Jr., Brooks GA. No effect of cycling experience on leg cycle ergometer efficiency. Medicine and science in sports and exercise 1996;28: 1396-1401.

25. Coyle EF, Sidossis LS, Horowitz JF, Beltz JD. Cycling efficiency is related to the percentage of type I muscle fibres. Medicine and science in sports and exercise $1992 ; 24: 782-788$.

26. Gosker HR, Wouters EF, van der Vusse GJ, Schols AM. Skeletal muscle dysfunction in chronic obstructive pulmonary disease and chronic heart failure: Underlying mechanisms and therapy perspectives. Am J Clin Nutr 2000;71: 1033-1047.

27. Gea JG, Pasto M, Carmona MA, Orozco-Levi M, Palomeque J, Broquetas J. Metabolic characteristics of the deltoid muscle in patients with chronic obstructive pulmonary disease. Eur Respir J 2001;17:939-945.

28. Gissane C, Corrigan DL, White JA. Gross efficiency responses to exercise conditioning in adult males of various ages. J Sports Sci 1991;9:383-391.

29. Franssen FM, Wouters EF, Schols AM. The contribution of starvation, deconditioning and ageing to the observed alterations in peripheral skeletal muscle in chronic organ diseases. Clin Nutr 2002;21:1-14.

30. Franklin BA. Exercise testing, training and arm ergometry. Sports Med 1985;2: 100-119.

31. Criner GJ, Celli BR. Effect of unsupported arm exercise on ventilatory muscle recruitment in patients with severe chronic airflow obstruction. Am Rev Respir Dis 1988; $138: 856-861$.

32. Epstein SK, Celli BR, Williams J, Tarpy S, Roa J, Shannon T. Ventilatory response to arm elevation. Its determinants and use in patients with chronic obstructive pulmonary disease. Am J Respir Crit Care Med 1995;152:211-216.

33. Dolmage TE, Maestro L, Avendano MA, Goldstein RS. The ventilatory response to arm elevation of patients with chronic obstructive pulmonary disease. Chest 1993;104:1097-1100. 



\section{Chapter 4}

\section{Limb muscle dysfunction in chronic}

obstructive pulmonary disease: effects of muscle wasting and exercise training
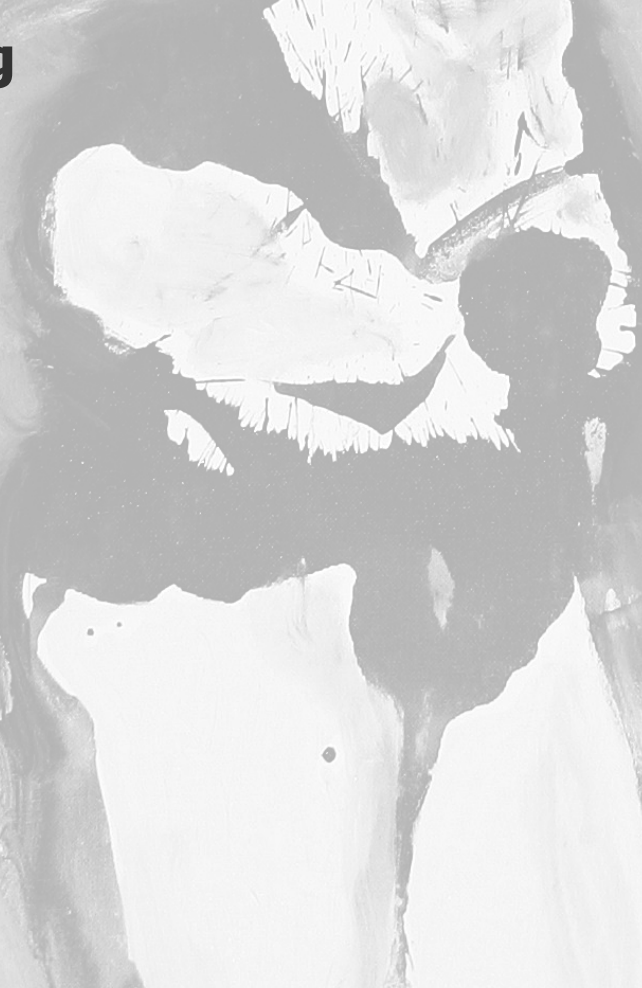

Frits M.E. Franssen, Roelinka Broekhuizen, Paul P. Janssen, Emiel F.M. Wouters, Annemie M.W.J. Schols

Medicine \& Science In Sports \& Exercise 2005; 37: 2-9 


\section{Abstract}

\section{Introduction}

Lower limb muscle weakness has often been reported in chronic obstructive pulmonary disease (COPD) and contributes to exercise intolerance. Controversial information is available regarding upper limb muscle adaptations and the influence of muscle wasting on muscle weakness. We investigated leg and arm muscle function in 59 stable COPD patients (GOLD stage III) with preserved fat-free mass (FFM) and in 28 patients with reduced FFM relative to age- and sex-matched healthy control subjects and studied the effects of 8 weeks of whole-body exercise training.

\section{Methods}

FFM was measured with bioelectrical impedance analysis. Isokinetic quadriceps (F-leg) and biceps strength (F-arm), as well as quadriceps (E-leg) and biceps endurance (E-arm) were determined with a Biodex dynamometer. Exercise training consisted of cycle ergometry, treadmill walking, weight training and gymnastics during five days $\cdot$ week $^{-1}$.

\section{Results}

F-leg $(76.2 \pm 3.6 \mathrm{~N} \cdot \mathrm{m}$ versus $118.2 \pm 6.3 \mathrm{~N} \cdot \mathrm{m}, \mathrm{p}<0.001)$ and F-arm $(25.6 \pm 1.3 \mathrm{~N} \cdot \mathrm{m}$ versus $38.1 \pm 2.1 \mathrm{~N} \cdot \mathrm{m}, \mathrm{p}<0.001$ ) were significantly and similarly reduced in the COPD patient group compared with controls. Also, E-leg $(-2.13 \pm 0.12$ versus $-1.61 \pm 0.11$, $\mathrm{p}<0.01)$, but not $\mathrm{E}$-arm $(-2.72 \pm 0.11$ and $-2.47 \pm 0.13$, NS) was decreased in patients. F-leg $(62.4 \pm 4.3 \mathrm{~N} \cdot \mathrm{m}$ versus $82.8 \pm 4.7 \mathrm{~N} \cdot \mathrm{m}, \mathrm{p}<0.01)$, but not $\mathrm{F}$-arm or muscle endurance was reduced in FFM depleted compared with non FFM depleted patients. Whereas after training, F-leg and E-leg significantly increased by $20 \%$ in the whole COPD group, biceps muscle function remained unchanged.

\section{Conclusions}

Lower and upper limb muscle dysfunction was observed in COPD patients, irrespective of the presence of FFM depletion. Generalized muscle weakness suggests systemic muscular involvement, although the preserved arm endurance and the poor response of arm performance to exercise training is indicative for intrinsic differences in muscular adaptations between leg and arm muscles. 


\section{Introduction}

Skeletal muscle weakness of the lower extremities is frequently observed in patients with chronic obstructive pulmonary disease (COPD) and contributes to exercise limitation ${ }^{1,2}$, impaired health status $^{3}$ and increased utilisation of health care services ${ }^{4}$. Peripheral muscle dysfunction in COPD has been related to muscle wasting of the extremities ${ }^{5}$, while the contribution of abnormalities in quadriceps muscle morphology ${ }^{6}$ and energy metabolism ${ }^{7}$ has not yet been elucidated. Recently, it was suggested that peripheral muscle dysfunction is absent in COPD patients with normal muscle mass, assessed by fat-free mass $(F F M)^{8}$, thus emphasizing the role of nutritional depletion in the etiology of muscle dysfunction. Muscle weakness can be approached as loss of muscle strength, muscle endurance or a combination of these. Muscle strength is defined as the capacity of the muscle to develop maximal force, while endurance is the capacity of the muscle to sustain mechanical output during (a series of) loaded contraction(s).

Although several studies reported lower limb muscle impairment in COPD, few and conflicting information is available on the function of other peripheral muscle groups, especially of the upper limbs. In addition, the relative distribution of muscle weakness between different muscle groups remains unclear. Insight in the pattern of muscular dysfunction in COPD would contribute to a better understanding of underlying local or systemic pathophysiology, such as inactivity and deconditioning, malnutrition, systemic inflammation, hypoxemia and use of systemic corticosteroids. Some studies reported a relative preservation of strength of upper limb muscles ${ }^{2,9}$, while others found a similar degree of muscle weakness for lower and upper limbs, however, with differences between proximal and distal arm muscle groups ${ }^{10}$.

Although muscle endurance was less frequently studied in COPD, both normal ${ }^{11}$ as well as decreased values for lower ${ }^{12-14}$ and upper extremities ${ }^{15}$ were described. In one study a relative preservation of muscle endurance of the upper limb was reported in comparison to the lower $\operatorname{limb}^{13}$, while in another study a combination of impaired arm muscle endurance and normal leg muscle endurance was described $^{15}$. Differences in the muscle function testing equipment, protocols and measured muscle groups together with heterogeneity in studied COPD groups probably contribute to divergent results. Therefore, the first purpose of the present study was to carefully study and compare muscle strength and endurance of the proximal 
lower and upper limbs in severe COPD patients relative to healthy subjects. Strength and endurance were measured in a single testing protocol, which was identical for lower and upper limb muscle function assessment, and the same dynamometer was used for leg and arm. To gain more insight in the mechanism and clinical implications of muscle dysfunction in COPD, this study additionally explored functional differences between muscle groups of lower and upper extremities in COPD patients with a preserved muscle mass and patients with a reduced muscle mass. Finally, this study investigated the effects of eight weeks of exercise training, consisting of a combination of whole-body endurance training and strength training of lower and upper extremities, on leg and arm muscle function in the COPD group.

\section{Methods}

\section{Subjects}

Eighty-seven patients with moderate to severe COPD ${ }^{16}$ and 35 agematched healthy volunteers were studied at baseline. All patients were in clinically stable condition and were consecutively recruited on admission to the pulmonary rehabilitation centre Hornerheide, where they participated in an intensive inpatient pulmonary rehabilitation programme. Patients exhibiting an increase in $\mathrm{FEV}_{1}>10 \%$ of baseline after inhalation of a $\beta_{2}$-agonist were excluded. Other exclusion criteria were recent surgery and chronic diseases, such as malignant disorders, clinically apparent heart failure, gastrointestinal abnormalities and insulin dependent diabetes mellitus. Within the COPD population, 28 subjects fulfilled the criteria for depletion of $\mathrm{FFM}^{17}$, while the FFM of the other 59 patients was in the normal range. The control group was recruited from an advertisement in a local newspaper for baseline comparison of body composition and muscle function. Controls did not participate in the exercise training programme. Written informed consent was obtained from all subjects and the ethical review board of the University Hospital Maastricht approved the study.

\section{Pulmonary function}

Lung function testing included forced spirometry and assessment of lung volumes by whole-body plethysmography (Masterlab, Jaeger, 
Würzburg, Germany). $\mathrm{FEV}_{1}$ and forced vital capacity (FVC) were calculated from the flow-volume curves. The highest values of at least three measurements were used. Diffusing capacity for carbon monoxide $\left(\mathrm{DL}_{\mathrm{CO}}\right)$ was measured by the single breath method (Masterlab, Jaeger, Würzburg, Germany). Instruments were calibrated twice a day. All values obtained were expressed as a percentage of reference values ${ }^{18}$. Arterial blood gas analysis was performed in all patients at rest (ABL 330, Radiometer, Copenhagen, Denmark).

\section{Anthropometric measurements}

Besides body weight and height, FFM was measured by bioelectrical impedance analysis at a frequency of $50 \mathrm{kHz}$ (Xitron 4000b, Xitron technologies, San Diego, California, USA). Resistance was measured in supine position at the right side as described by Lukaski ${ }^{19}$. A patient specific regression equation, described by Schols et al. ${ }^{20}$ was used to calculate FFM in COPD subjects. FFM index was calculated as the ratio of FFM to height in meters squared.

\section{Peripheral muscle function}

Isokinetic muscle strength and endurance of the dominant knee extensor (quadriceps) and elbow flexor (biceps) muscles were measured using a dynamometer (Biodex System II, Biodex Corporation, Shirley, New York, USA). During leg muscle function testing, subjects were seated upright on the chair of the dynamometer with support of the back. At the level of the chest, pelvis and thigh, subjects were secured with straps. The hip joint was at an angle between 90 and $100^{\circ}$ of flexion during testing. The lever arm was attached to the distal part of the tibia and its axis of rotation was visually aligned with the anatomical axis of flexion of the knee joint. Subjects were instructed to keep their hands on their thighs during testing. To assess arm muscle function, equipment was reinstalled and subjects sat upright on a chair in front of the dynamometer with their backs towards it. The shoulder of the dominant arm was placed in $90^{\circ}$ abduction. The upper arm was supported and fixed with a belt in the horizontal plane on an adjustable stand. The ventral side of the forearm was placed in the frontal plane. The handgrip of the lever arm was held by the subjects. The lateral epicondyle of the humerus was used as the axis of elbow rotation and was visually aligned with axis of rotation of the 
dynamometer. Subjects were instructed to keep their contralateral hand on their thigh.

The isokinetic testing protocol consisted of fifteen sequential volitional maximal contractions at an angular velocity of $90^{\circ} \cdot \mathrm{s}^{-1}$. Maximal isokinetic strength was defined as the highest peak torque (in Newton-meters; $\mathrm{N} \cdot \mathrm{m}$ ) in this series of fifteen (Figure 4.1). To determine isokinetic muscle endurance, the peak torques of the successive contractions were expressed as a percentage of the highest value. The first contraction was excluded from analysis. A linear curve was fitted through the calculated points. The slope of this curve, indicating the proportional decline in peak torque per contraction, was used as a measure for muscle endurance (Figure 4.1). A more negative slope indicated lower muscle endurance or increased muscle fatigue. Series in which the slope was ascending or in which the curve had a $R^{2}<0.209$ were excluded. The $R^{2}$ value of 0.209 is based on the critical value of the Pearson's correlation coefficient at a one-tailed $p$-value of 0.10 and 13 degrees of freedom. For comparison of lower and upper limb muscle function, strength and endurance were also expressed as a percentage of the mean values obtained in the control group.

Methodology of muscle function testing. Maximal isokinetic strength was defined as the highest peak torque in a series of fifteen maximal isokinetic contractions. The slope of the linear curve through the successive relative peak torques ( $r$ ) was used as measure for muscle endurance. See methods section for details.

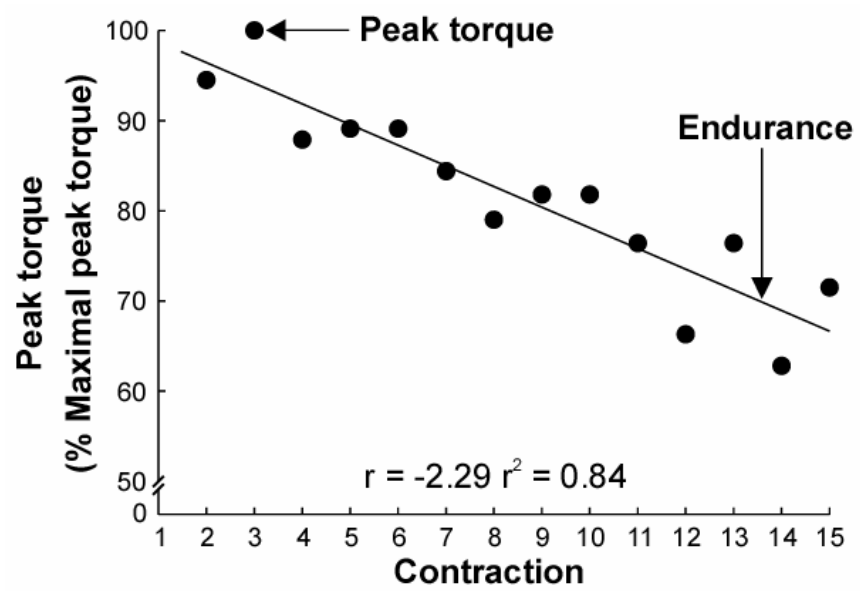


In addition to the isokinetic muscle function assessment and for comparison with other studies on muscle function in COPD, isometric handgrip force was measured with a hydraulic hand dynamometer (Jamar, Sammons Preston Rolyan, Jackson, Illinois, USA). The average value of maximal force of left and right hand during a series of three manoeuvres was used for analysis.

\section{Exercise capacity}

For characterization of the COPD patient group in terms of wholebody exercise tolerance, exercise capacity was assessed by progressive incremental exercise testing on an electrically braked cycle ergometer (Corival 400, Lode, Groningen, The Netherlands). During the entire exercise test, expired gases were investigated using breath by breath analysis through a breathing mask (Oxycon Beta, Jaeger, Würzburg, Germany). After two minutes of rest and one minute of unloaded cycling, power was increased by $10 \mathrm{~W}$ every minute in patients. In control subjects, the load was increased with 15-25 W every minute, depending on relative fitness of the subject, so as to lead to fatigue in 10-12 minutes. None of the subjects knew the exercise load and all were encouraged to cycle at 60 revolutions $\cdot \mathrm{min}^{-1}$ until exhaustion.

\section{Study design}

Inclusion, medical examination and baseline measurements of pulmonary function, body composition, peripheral muscle function and exercise performance in COPD patients were performed within the first two weeks after admission to the pulmonary rehabilitation centre. This period also allowed for familiarization with the various procedures in order to avoid learning effects. After two weeks, all patients participated in a comprehensive inpatient eight-week respiratory rehabilitation programme consisting of exercise training during five days per week, education and (when appropriate) psychosocial and behavioural intervention. During their stay in the rehabilitation centre, a standardized weight maintaining diet was offered to weight stable patients that were not eligible for nutritional supplementation ${ }^{17}$. All subjects in the FFM depleted group and eleven patients with preserved FFM but low body weight or weight loss received standardized nutritional support during rehabilitation (Respifor, Royal Numico NV, Amsterdam, The Netherlands; three times per day, $564 \mathrm{kcal} ; 20$ energy\% protein, 60 energy\% carbohydrate, 20 energy $\%$ fat). The physical exercise training 
programme consisted of a combination of endurance and strength exercise training. Submaximal cycle ergometry was performed twice a day for 20 minutes. Initial load was set at $50-60 \%$ of baseline peak work rate. Thereafter, training intensity was adapted to maintain the same relative training load during the intervention period under supervision of an exercise therapist. In addition, patients exercised on a treadmill for 20 minutes per day just below their symptomlimited rate. All patients participated in daily 30 minutes of gymnastics, focused at either strength and endurance or mobilisation and flexibility. Furthermore, patients attended daily arm exercise training sessions, consisting of 10 times one minute of unsupported arm exercise, followed by one minute of rest. Dynamic strength training exercises of the upper and lower extremities were incorporated in the programme. Muscle groups, load and number of repetitions were determined for each individual and were based on the experienced functional impairments in daily living and evaluation of the patients' muscular performance by a team of experienced physiotherapists.

Control subjects visited the pulmonary rehabilitation centre on two successive days. On the first day, a medical examination was performed and body composition and respiratory function were assessed. Furthermore, the controls practiced on the Biodex dynamometer with an exercise therapist to become familiar with the apparatus and minimize learning effects. On the second day, the actual muscle function measurement and maximal bicycle ergometry were performed.

\section{Statistical analysis}

Results are expressed as mean \pm standard error of the mean (SEM). Statistical analysis on baseline differences between patients and controls was performed using an unpaired Student's $t$-test. One-way analysis of variance (ANOVA) was used to determine differences between FFM-depleted, non-FFM-depleted patients and controls. LSD multiple comparison test was used as post hoc test. The Student's paired $t$-test for dependent samples was used to test for differences in relative muscle strength and endurance between the lower and upper limbs in COPD patients. Pearson's correlation analysis was performed in the patient group in order to investigate linear relationship between variables of body composition and muscle function. Changes in muscle function between baseline and week eight were tested with Student's paired $t$-test in the whole group of 
COPD patients. Because of the limited number of paired observations in especially the FFM depleted group, due to strict methodological criteria (as described in the section about peripheral muscle function measurement), the latter analysis was not performed for both COPD subgroups separately. All $\mathrm{p}$ values $<0.05$ were considered statistically significant.

\section{Results}

\section{Baseline characteristics}

At baseline, sex distribution, age and height were comparable in non-FFM-depleted COPD patients, FFM-depleted patients and controls (Table 4.1). Body weight was significantly lower in patients compared with controls, and in depleted compared with nondepleted patients, resulting in a reduced BMI in the patient group compared with controls $\left(22.4 \pm 0.4 \mathrm{~kg} \cdot \mathrm{m}^{-2}\right.$ versus $\left.26.3 \pm 0.4 \mathrm{~kg} \cdot \mathrm{m}^{-2}, \mathrm{p}<0.001\right)$ and in FFM-depleted versus non-FFM-depleted COPD. The reduced body weight was mainly the result of a decreased FFM in both patients groups, but a decreased fat mass also contributed to the lower body weight in the depleted patient group. Patients were characterized by severe airflow obstruction with hyperinflation and a reduced diffusing capacity for carbon monoxide (GOLD stage III). Despite comparable spirometry and blood gases, diffusing capacity for carbon monoxide was lower in FFM-depleted patients compared with nondepleted patients. Exercise capacity, measured with cycle ergometry, was markedly impaired in patients compared with controls $\left(\mathrm{VO}_{2 \max }\right.$ : $961 \pm 37 \mathrm{ml} \cdot \mathrm{min}^{-1}$ versus $\left.2134 \pm 124 \mathrm{ml} \cdot \mathrm{min}^{-1}, \mathrm{p}<0.001\right)$. Although exercise performance was lower in FFM-depleted patients compared with nondepleted patients, statistical significance was not reached.

\section{Muscle strength}

Isokinetic strength of the dominant quadriceps $(76.2 \pm 3.6 \mathrm{~N} \cdot \mathrm{m}$ versus $118.2 \pm 6.3 \mathrm{~N} \cdot \mathrm{m}, \mathrm{p}<0.001)$ and biceps $(25.6 \pm 1.3 \mathrm{~N} \cdot \mathrm{m}$ versus $38.1 \pm 2.1$ $\mathrm{N} \cdot \mathrm{m}, \mathrm{p}<0.001)$ muscles was significantly reduced in COPD patients compared with controls. Mean quadriceps and biceps strength of patients were $65 \pm 3 \%$ and $67 \pm 3 \%$ (NS) of the mean control value, indicating that lower and upper proximal limb muscle strength were equally affected. 
As shown in Figure 4.2, quadriceps and biceps strength was significantly reduced in both non-FFM-depleted as well as FFMdepleted patients. Furthermore, quadriceps strength was significantly lower in FFM-depleted compared with nondepleted patients, whereas biceps strength was comparable in both patient groups. Also after correcting for FFM, quadriceps $\left(1.57 \pm 0.06 \mathrm{~N} \cdot \mathrm{m} \cdot \mathrm{kg}^{-1}\right.$ versus $2.00 \pm 0.07$ $\left.\mathrm{N} \cdot \mathrm{m} \cdot \mathrm{kg}^{-1}\right)$ and biceps muscle strength $\left(0.53 \pm 0.02 \mathrm{~N} \cdot \mathrm{m} \cdot \mathrm{kg}^{-1}\right.$ versus $0.64 \pm 0.02 \mathrm{~N} \cdot \mathrm{m}^{\mathrm{kg}} \mathrm{kg}^{-1}$ ) were significantly reduced in COPD patients compared with controls. However, the difference in quadriceps strength between depleted and non-depleted patients disappeared

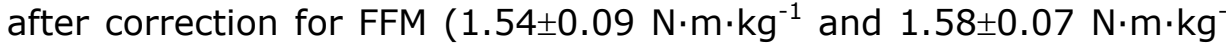
1 , respectively, NS).

Table 4.1 Baseline characteristics of the study groups (mean \pm SEM).

\begin{tabular}{|c|c|c|c|}
\hline & $\begin{array}{l}\text { Controls } \\
(n=35)\end{array}$ & $\begin{array}{c}\text { Non-FFM-depleted } \\
\text { COPD } \\
(n=59)\end{array}$ & $\begin{array}{c}\text { FFM-depleted } \\
\text { COPD } \\
(n=28)\end{array}$ \\
\hline Male/Female, No. & $24 / 11$ & $41 / 18$ & $18 / 10$ \\
\hline Age, yrs & $62 \pm 1$ & $63 \pm 1$ & $62 \pm 2$ \\
\hline \multicolumn{4}{|l|}{ Body composition } \\
\hline Height, cm & $172.2 \pm 1.6$ & $169.9 \pm 1.0$ & $168.3 \pm 1.5$ \\
\hline Weight, kg & $78.3 \pm 2.0$ & $69.6 \pm 1.4^{\#}$ & $53.6 \pm 1.6^{\# * *}$ \\
\hline $\mathrm{BMI}, \mathrm{kg} \cdot \mathrm{m}^{-2}$ & $26.3 \pm 0.4$ & $24.1 \pm 0.4^{\#}$ & $18.9 \pm 0.4^{\# * *}$ \\
\hline FFM, kg & $59.0 \pm 1.9$ & $51.1 \pm 1.0^{\#}$ & $40.7 \pm 1.0^{\# * *}$ \\
\hline FFMI, $\mathrm{kg} \cdot \mathrm{m}^{-2}$ & $19.8 \pm 0.4$ & $17.7 \pm 0.2^{\#}$ & $14.3 \pm 0.2^{\# * *}$ \\
\hline $\mathrm{FM}, \mathrm{kg}$ & $19.4 \pm 1.2$ & $18.5 \pm 0.9$ & $12.9 \pm 0.9^{\# * *}$ \\
\hline $\mathrm{FMI}, \mathrm{kg} \cdot \mathrm{m}^{-2}$ & $6.6 \pm 0.4$ & $6.4 \pm 0.3$ & $4.6 \pm 0.3^{\# * *}$ \\
\hline \multicolumn{4}{|l|}{ Lung function } \\
\hline $\mathrm{FEV}_{1}, \%$ predicted & $111 \pm 3$ & $37 \pm 22^{\#}$ & $31 \pm 3^{\#}$ \\
\hline FVC, \%predicted & $116 \pm 3$ & $76 \pm 3^{\#}$ & $70 \pm 3^{\#}$ \\
\hline $\mathrm{DL}_{\mathrm{co}}, \%$ predicted & $112 \pm 3$ & $53 \pm 3^{\#}$ & $39 \pm 3^{\# *}$ \\
\hline $\mathrm{P}_{\mathrm{a}} \mathrm{O}_{2}, \mathrm{kPa}$ & - & $9.3 \pm 0.2$ & $9.3 \pm 0.3$ \\
\hline $\mathrm{P}_{\mathrm{a}} \mathrm{CO}_{2}, \mathrm{kPa}$ & - & $5.4 \pm 0.1$ & $5.7 \pm 0.2$ \\
\hline \multicolumn{4}{|l|}{ Functional capacity } \\
\hline Peak work rate/FFM, W. $\mathrm{kg}^{-1}$ & $3.4 \pm 0.1$ & $1.2 \pm 0.1$ \# & $1.3 \pm 0.1$ \# \\
\hline $\mathrm{V}_{2 \max } / F F M, \mathrm{ml} \cdot \mathrm{min}^{-1} \cdot \mathrm{kg}^{-1}$ & $36.4 \pm 1.2$ & $19.2 \pm 0.8^{\#}$ & $21.9 \pm 1.3^{\#}$ \\
\hline Handgrip force, $\mathrm{kg}$ & $40.7 \pm 2.4$ & $33.9 \pm 1.3^{\#}$ & $31.8 \pm 1.5^{\#}$ \\
\hline
\end{tabular}

BMI: body mass index; FFM: fat-free mass, assessed by bioelectrical impedance analysis; FFMI: fat-free mass index; FM: fat mass; FMI: fat mass index; $F E V_{1}$ : forced expiratory volume in one second; FVC: forced vital capacity; $\mathrm{DL}_{\mathrm{co}}$ : diffusing capacity for carbon monoxide; $\mathrm{P}_{\mathrm{a}} \mathrm{O}_{2}$ : arterial oxygen tension; $\mathrm{P}_{\mathrm{a}} \mathrm{CO}_{2}$ : arterial carbon dioxide tension; $\mathrm{VO}_{2 \max }$ : maximal oxygen consumption. Significance of differences between patients and controls is indicated as: ${ }^{\#}: p<0.001$. Significant differences between FFMdepleted and non-FFM-depleted patients are shown as: $* * p<0.001$ and $* p<0.05$.

As shown in Figure 4.2, quadriceps and biceps strength was significantly reduced in both non-FFM-depleted as well as FFMdepleted patients. Furthermore, quadriceps strength was significantly 
lower in FFM-depleted compared with nondepleted patients, whereas biceps strength was comparable in both patient groups. Also after correcting for FFM, quadriceps $\left(1.57 \pm 0.06 \mathrm{~N} \cdot \mathrm{m} \cdot \mathrm{kg}^{-1}\right.$ versus $2.00 \pm 0.07$ $\left.\mathrm{N} \cdot \mathrm{m} \cdot \mathrm{kg}^{-1}\right)$ and biceps muscle strength $\left(0.53 \pm 0.02 \mathrm{~N} \cdot \mathrm{m} \cdot \mathrm{kg}^{-1}\right.$ versus $0.64 \pm 0.02 \mathrm{~N} \cdot \mathrm{m}^{\mathrm{kg}} \mathrm{kg}^{-1}$ ) were significantly reduced in COPD patients compared with controls. However, the difference in quadriceps strength between depleted and non-depleted patients disappeared after correction for FFM $\left(1.54 \pm 0.09 \mathrm{~N} \cdot \mathrm{m} \cdot \mathrm{kg}^{-1}\right.$ and $1.58 \pm 0.07 \mathrm{~N} \cdot \mathrm{m} \cdot \mathrm{kg}^{-}$ 1 , respectively, NS).

Figure 4.2 Baseline muscle strength (expressed as peak torque) and fatigue (expressed as proportional decline in peak torque per contraction) of the lower and upper extremities in controls (white bars), non-FFM-depleted COPD patients (light grey bars) and FFM-depleted COPD patients (dark grey bars) (mean \pm SEM). Quadriceps and biceps muscle strength were significantly reduced in both patient groups compared with controls. Quadriceps muscle strength was significantly lower in FFM-depleted than in non-FFM-depleted patients. Quadriceps fatigue, but not biceps fatigue was significantly higher in both patient groups than in controls, while fatigue was comparable in subgroups of COPD. \#\#\# $p<0.001 ; \# \#$ $\mathrm{p}<0.01 ; \# \mathrm{p}<0.05$ versus controls; ${ }^{*} \mathrm{p}<0.05$ versus non-FFM-depleted COPD.
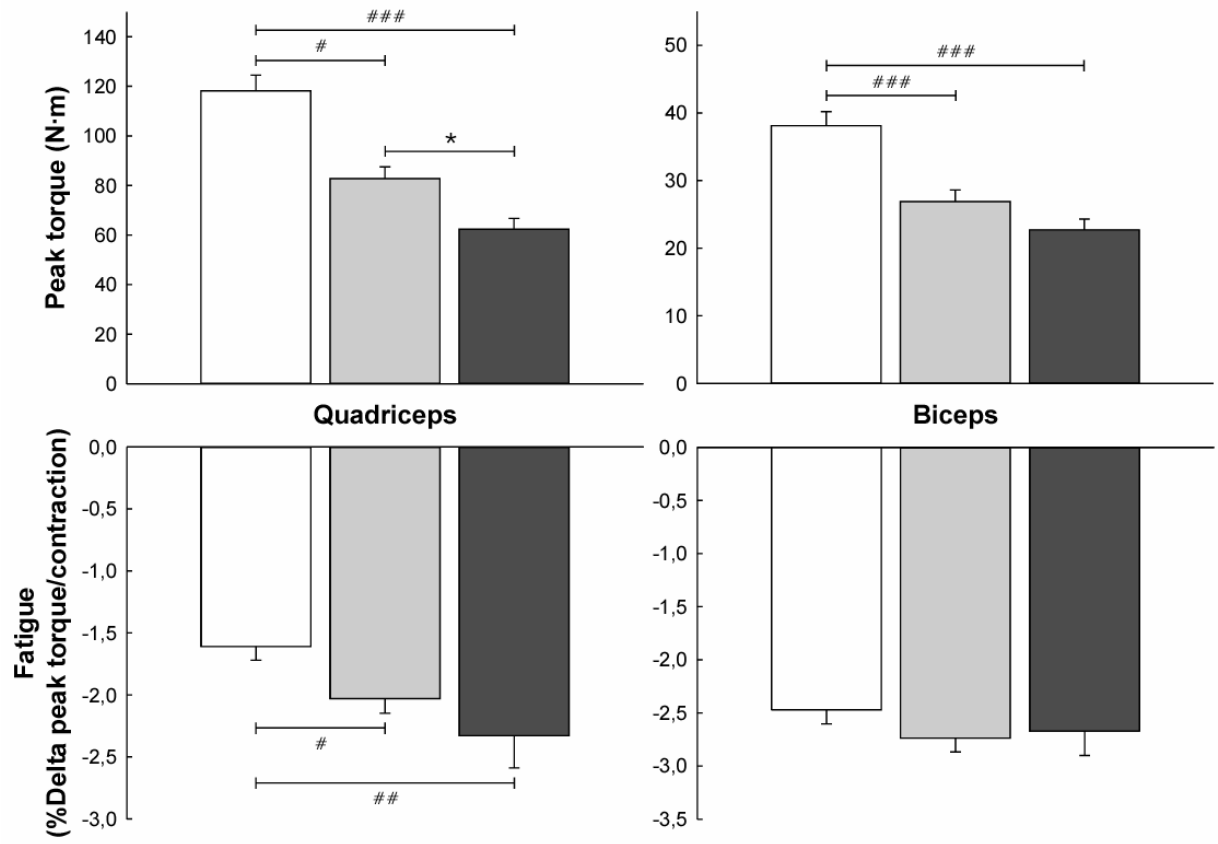
Handgrip strength was significantly lower in COPD patients than in controls $(33.2 \pm 0.9 \mathrm{~kg}$ versus $40.7 \pm 2.4 \mathrm{~kg}, \mathrm{p}<0.01)$. As shown in Table 4.1, both FFM-depleted as well as nondepleted patients had decreased handgrip strength, with no difference between these two groups.

\section{Muscle endurance}

Quadriceps muscle endurance was significantly reduced in COPD patients and both subgroups compared with controls (proportional decline in peak torque per contraction: $-2.13 \pm 0.12$ versus $-1.61 \pm 0.11, p<0.01$ ) and was $80 \pm 7 \%$ of the mean control value. Lower limb endurance was comparable in FFM-depleted and nonFFM-depleted patients, as indicated in Figure 4.2. Biceps muscle endurance was $10 \pm 4 \%$ lower in patients than in controls $(-2.72 \pm 0.11$ and $-2.47 \pm 0.13$, respectively), but the difference was not statistically significant. Also, there was no statistically significant difference in upper limb muscle endurance between non-FFM-depleted and FFMdepleted patients.

\section{Correlation analysis}

On bivariate correlation analysis in the COPD group, quadriceps strength $(r=0.43, p<0.001)$, biceps strength $(r=0.47, p<0.001)$ and handgrip force $(r=0.40, p<0.001)$ correlated strongly with FFMI, while quadriceps and biceps muscle endurance were not related to FFMI. Lower $(r=0.534, p<0.001)$ and upper extremity strength $(r=0.612, p<0.001)$ correlated strongly with $\dot{\mathrm{VO}}_{2 \max }$. Skeletal muscle function was not related to parameters of pulmonary function.

\section{Effects of exercise training}

After the exercise training programme, both strength as well as endurance of the quadriceps muscle increased with $20 \%$ in the COPD patient group $(p<0.01)$, while biceps muscle function did not significantly change (Figure 4.3). Body weight $(+1.8 \pm 0.3 \mathrm{~kg}$, $\mathrm{p}<0.001)$ and $F F M(+1.5 \pm 0.3 \mathrm{~kg}, \mathrm{p}<0.001)$ significantly increased after the pulmonary rehabilitation programme, while $F M$ remained unchanged $(+0.34 \pm 0.2 \mathrm{~kg})$. Peak cycling work rate $(+15 \pm 2 \mathrm{~W}$, $\mathrm{p}<0.001)$ and $\mathrm{VO}_{2 \max }\left(+137 \pm 26 \mathrm{ml} \cdot \mathrm{min}^{-1}, \mathrm{p}<0.001\right)$ also improved significantly, indicating an enhanced exercise capacity in patients. 
Figure 4.3 Muscle strength (expressed as peak torque) and fatigue (expressed as proportional decline in peak torque per contraction) of the lower and upper extremities in COPD before (light grey bars) and after (dark grey bars) eight weeks of whole-body exercise training in comparison to the baseline control group (white bars) (mean \pm SEM). The increase in strength and reduction in fatigue of the quadriceps muscle during training was statistically significant. Biceps muscle function did not change during eight weeks of exercise training. \#\# $p<0.001$; \#\# $p<0.01$ versus controls; ${ }^{* *} p<0.01$ versus baseline
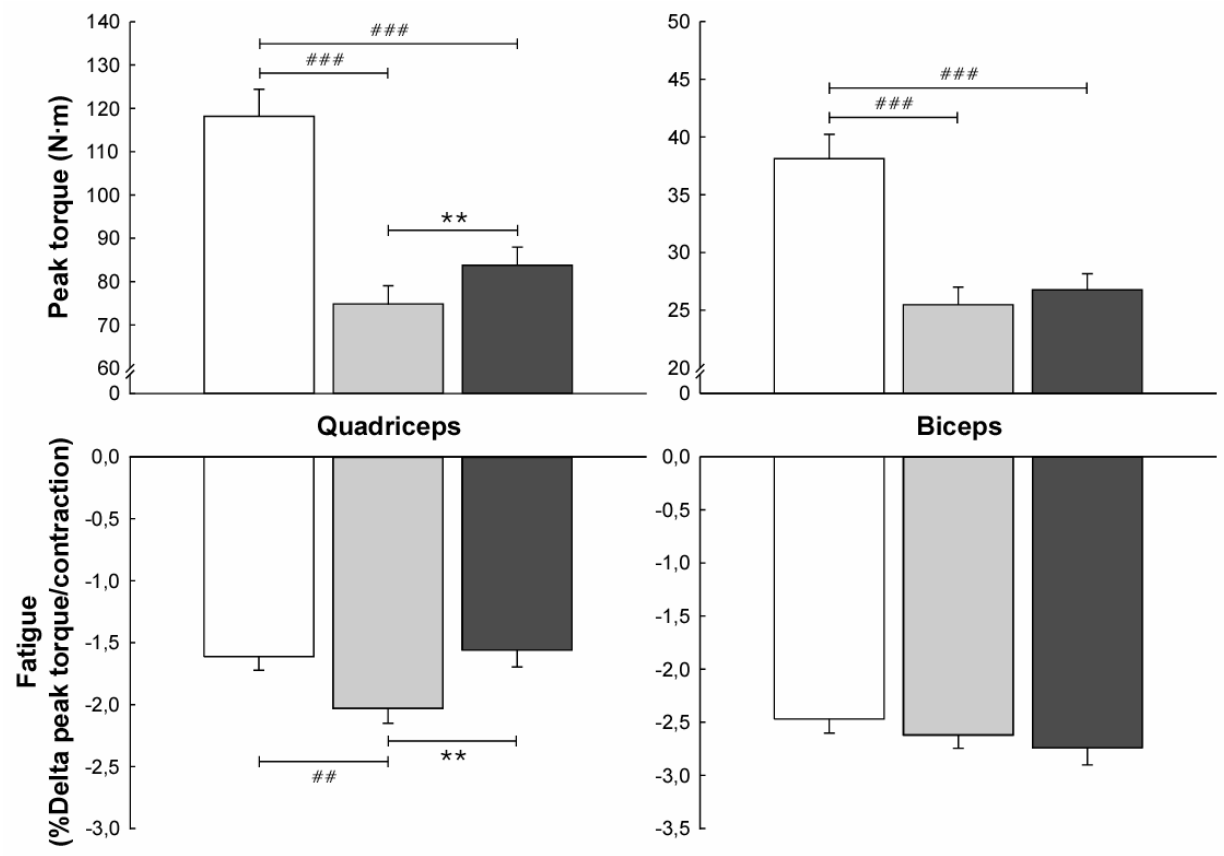

\section{Discussion}

The results of the present study can be summarized as follows. First, a reduced skeletal muscle function of the lower and upper limbs was observed in COPD patients. Quadriceps and biceps muscle strength were comparably affected, whereas the loss of muscle endurance was restricted to the lower extremities. Also, quadriceps strength was more impaired in FFM-depleted patients compared with nonFFM-depleted patients, whereas biceps strength and peripheral muscle endurance were comparable in these groups. Finally, enhanced quadriceps muscle function was observed after eight 
weeks of intensive whole-body exercise training, whereas biceps muscle function was unchanged.

Reduced muscle strength of the lower and upper extremities was previously reported in COPD $^{2,9,10,21}$ and was confirmed here. However, the relative involvement of the different muscle groups remains controversial. In this study, isokinetic muscle strength of quadriceps and biceps muscles was equally affected, indicating generalized muscle weakness. This result is not consistent with reports of a relatively preserved arm function in COPD $^{2,9,21}$. Bernard et al. ${ }^{9}$ reported a proportionally greater reduction in isokinetic quadriceps strength than that of pectoralis major and latissimus dorsi muscles in 34 normal-weight COPD patients compared with controls. In addition, Gosselink et al. ${ }^{2}$ observed lower relative values for isometric quadriceps strength compared with handgrip force in 41 COPD patients, related to reference values. However in another study, the same authors ${ }^{10}$ described a similar extent of weakness for quadriceps and arm muscles. In that study, isometric strength of proximal arm muscles was more affected than that of distal arm muscles. In a recent study of non-volitional muscle strength by Man et al. $^{21}$, quadriceps strength was substantially reduced in COPD, whereas strength of adductor pollicis muscle and diaphragm were normal. For several reasons, it is difficult to compare the results of the various studies. First, quadriceps muscle strength was used as a measure for lower limb muscle function in all studies, but numerous muscle groups of the upper limbs were investigated. Differences in the intensity of recruitment of shoulder girdle muscles, proximal arm muscle groups and distal and hand muscle groups during activities of daily living may account for various degrees of conditioning of these muscle groups and thus for relative differences in the observed degree of muscle weakness. Furthermore, the muscles of the shoulder girdle are additionally stimulated in COPD patients, because they act as accessory inspiratory muscles when ventilatory demands increase $^{22}$. Also, methods and equipment for muscle function testing differed, not only between studies, but also between lower and upper extremity in the same study ${ }^{2}$. Furthermore, both isokinetic protocols, in which the velocity of muscle contraction is constant, as well as isometric protocols, in which muscle fibre length and joint angle are constant, were used. Finally, heterogeneity regarding age, sex, severity of disease and body composition of the studied COPD patients might have contributed to the conflicting results. The present study in severe COPD patients, using the same isokinetic protocol and equipment for quadriceps and biceps muscle function 
testing, showed that lower and upper extremity strength were equally affected, which is indicative for the presence of generalized proximal muscle weakness in COPD.

This is the first study that explored differences in muscle weakness between subgroups of COPD patients with preserved and reduced FFM, independent of body weight. Lower extremity muscle strength was more impaired in FFM-depleted patients than in patients with a preserved muscle mass. After correcting for the difference in FFM between the groups, quadriceps strength was comparable, suggesting that muscle mass is the main cause of the variation in the degree of muscle weakness observed within the COPD group. It is however important to notice that significant muscle dysfunction of lower and upper extremities was present not only in COPD patients with a reduced FFM, but also in patients with a preserved FFM. This observation is in contradiction to the results of a recent study by Heijdra et al. ${ }^{8}$, who reported normal values for expiratory and handgrip muscle strength in COPD GOLD stage III outpatients with a normal FFM index and concluded that a clinically significant systemic myopathy is absent in this subset of patients. Quadriceps and biceps muscle function was not assessed. The present results, however, indicate that although muscle mass is an important determinant of muscle strength, the occurrence of muscle dysfunction is not limited to a subset of FFM-depleted COPD patients, but is already present in patients with preserved muscle mass. Others also observed muscle dysfunction in normal-weight COPD patients with a milder degree of airflow obstruction ${ }^{13}$. Since muscle dysfunction contributes to exercise intolerance ${ }^{1,2}$ and reduced quality of life ${ }^{3}$, specific therapies aimed at enhancing muscular performance, such as exercise training and nutritional and anabolic interventions, should not be limited beforehand to the subset of cachectic COPD patients. Unlike quadriceps strength, biceps muscle strength was not different between cachectic patients and those with normal FFM. Since loss of muscle mass is strongly related to muscle weakness, a comparable biceps strength in the two subgroups suggests that the additional muscular atrophy in cachectic patients is mainly restricted to the lower limb muscles. Among other factors, chronic underuse of locomotor muscles of the lower extremities is probably important in the development of this additional atrophy. Although this study included detailed measurements of body composition, the regional distribution of muscle mass was not assessed.

The ratio of muscle strength to whole-body FFM was reduced in COPD patients compared with controls. Also, differences in muscle 
strength between patients with preserved and reduced FFM disappeared after correcting for FFM. This observation is in agreement with a study by Engelen et al. ${ }^{5}$, who reported lower values for muscle function per kilogram of whole-body FFM in COPD compared with controls. In contrast, muscle function per kilogram of extremity FFM was comparable in patients and controls in that study. In addition, a normal ratio of quadriceps strength to quadriceps muscle cross-sectional area was reported in COPD ${ }^{9}$. These combined results indicate a relative redistribution of FFM in COPD with preservation of trunk FFM and predominant loss of extremity muscle mass.

In accordance with previous publications ${ }^{12-14}$, impaired quadriceps muscle endurance was perceived in this study. The observation of a comparable muscular endurance in COPD patients with normal and reduced FFM is new. In agreement with this observation, muscle mass, assessed by FFM, was not related to muscle endurance in the COPD group or in controls. This suggests that intrinsic muscular abnormalities are involved in increased skeletal muscle fatigue in COPD. These abnormalities include alterations in muscle substrate and energy metabolism and altered muscle fibre type distribution ${ }^{23}$. Although a causal relationship between morphological or metabolic alterations in skeletal muscle and muscle function has not been shown in COPD, a role for increased exercise-induced muscle oxidative stress in the development of decreased quadriceps endurance was recently suggested ${ }^{14}$. Contrary to lower extremity endurance, upper limb muscle endurance was comparable in COPD patients and controls, suggesting that this component of upper extremity muscle function is preserved. This finding is supported by the study of Clark et al. ${ }^{13}$. Despite a reduced quadriceps endurance and impaired strength for lower and upper limbs, sustained isokinetic arm function was normal in a group of normal-weight mild COPD patients. In addition to the normal upper limb muscle endurance in the present study, preserved values for arm mechanical efficiency and peak arm exercise capacity were recently reported in a comparable group of COPD patients ${ }^{24}$. These combined observations might very well be related to an uneven distribution of intrinsic alternations, such as changes in percentage type I muscle fibres and oxidative capacity, in peripheral skeletal muscles between leg and arm of COPD patients ${ }^{25}$.

The efficacy of exercise training as part of a respiratory rehabilitation programme in improving functional exercise capacity in COPD is well established $^{26,27}$. In the present group of patients with baseline 
muscle weakness, eight weeks of whole-body exercise training resulted in improvements in quadriceps strength and endurance by $20 \%$ and an increase of $16 \%$ in maximal oxygen uptake. These improvements very likely resulted from the combination of highly intensive aerobic cycling and treadmill training, which formed the major components of the physical training programme, and lower limb strengthening exercises. Significant crossover training effects between strength and endurance training were previously described and the combination of these training modalities seems an optimal strategy for COPD patients ${ }^{28,29}$. Considerable increases in quadriceps strength after aerobic training $28,30,31$ and improvements in endurance performance after resistance training ${ }^{29}$ were reported. The results of the present study confirm that muscle dysfunction in COPD is remediable with aimed therapy and that the applied methodology for measuring strength and endurance can be used to evaluate the outcome of rehabilitation. In contrast to lower extremity performance, biceps muscle weakness, which was determined with identical methodology at baseline, was not repelled during the rehabilitation period. The lack of a training effect is probably related to intensity and specificity of the exercise training. Although subjects participated in daily unsupported arm exercises, gymnastics involving arm activities and individualized upper limb resistance training, the training stimulus to the muscle groups of the upper limbs may have been insufficient. Furthermore, specificity of training effects for trained muscle groups in COPD was earlier demonstrated by Lake et al. ${ }^{32}$. Upper limb exercises resulted in improved arm performance, while lower limb training increased walking distance. No crossover training benefits were seen between arms and legs. As mentioned before, lower extremity endurance training was the main component of the exercise programme. Baseline preservation of upper extremity muscular structure, metabolism and endurance capacity may also have contributed to the lack of response of arm function to the offered comprehensive training programme.

\section{Clinical implications}

This study showed that muscular dysfunction of lower and upper extremities occurs in both cachectic COPD patients as well as patients with a relatively normal body composition. Loss of muscle mass is a main contributor to muscle weakness, but the loss of muscle endurance and the reduced strength per kilogram muscle mass suggest that other factors are also important. Limiting specific 
therapies aimed at enhancing muscle function or exercise tolerance to patients with a reduced FFM, would result in an undertreatment of the group of patients with functional impairments despite a normal body composition. Therefore, screening of COPD patients for such therapies should include not only assessments of body mass index and FFM, but also measurements of muscle function. Furthermore, the results of muscle function testing in this study indicate that strength and endurance are distinct and independent components of muscle function, which should ideally both be determined when assessing muscle performance in clinical and scientific setting in COPD. Whereas the equal distribution of strength loss between lower and upper extremities is indicative for a systemic muscle involvement, the normal endurance component of muscle function of the upper limb suggests structural and metabolic differences between leg and arm in COPD. 


\section{References}

1. Hamilton AL, Killian $\mathrm{KJ}$, Summers $\mathrm{E}$, Jones NL. Muscle strength, symptom intensity, and exercise capacity in patients with cardiorespiratory disorders. Am J Respir Crit Care Med 1995;152:2021-2031.

2. Gosselink R, Troosters T, Decramer M. Peripheral muscle weakness contributes to exercise limitation in COPD. Am J Respir Crit Care Med 1996;153:976-980.

3. Simpson K, Killian K, McCartney N, Stubbing DG, Jones NL. Randomised controlled trial of weightlifting exercise in patients with chronic airflow limitation. Thorax 1992;47:70-75.

4. Decramer M, Gosselink R, Troosters T, Verschueren M, Evers G. Muscle weakness is related to utilization of health care resources in COPD patients. Eur Respir J 1997; 10:417-423.

5. Engelen MP, Schols AM, Does JD, Wouters EF. Skeletal muscle weakness is associated with wasting of extremity fat-free mass but not with airflow obstruction in patients with chronic obstructive pulmonary disease. Am J Clin Nutr $2000 ; 71: 733-738$.

6. Whittom F, Jobin J, Simard PM, Leblanc P, Simard C, Bernard S, Belleau R, Maltais $\mathrm{F}$. Histochemical and morphological characteristics of the vastus lateralis muscle in patients with chronic obstructive pulmonary disease. Medicine and science in sports and exercise 1998;30:1467-1474.

7. Maltais F, LeBlanc $P$, Whittom F, Simard C, Marquis K, Belanger M, Breton MJ, Jobin J. Oxidative enzyme activities of the vastus lateralis muscle and the functional status in patients with COPD. Thorax 2000;55:848-853.

8. Heijdra YF, Pinto-Plata V, Frants R, Rassulo J, Kenney L, Celli BR. Muscle strength and exercise kinetics in COPD patients with a normal fat-free mass index are comparable to control subjects. Chest 2003;124:75-82.

9. Bernard S, LeBlanc P, Whittom F, Carrier G, Jobin J, Belleau R, Maltais F. Peripheral muscle weakness in patients with chronic obstructive pulmonary disease. Am J Respir Crit Care Med 1998;158:629-634.

10. Gosselink R, Troosters T, Decramer M. Distribution of muscle weakness in patients with stable chronic obstructive pulmonary disease. J Cardiopulm Rehabil 2000;20:353-360.

11. Newell SZ, McKenzie DK, Gandevia SC. Inspiratory and skeletal muscle strength and endurance and diaphragmatic activation in patients with chronic airflow limitation. Thorax 1989;44:903-912.

12. Serres I, Gautier V, Varray A, Prefaut C. Impaired skeletal muscle endurance related to physical inactivity and altered lung function in COPD patients. Chest 1998;113:900-905.

13. Clark CJ, Cochrane LM, Mackay E, Paton B. Skeletal muscle strength and endurance in patients with mild COPD and the effects of weight training. Eur Respir J 2000;15:92-97.

14. Couillard A, Maltais F, Saey D, Debigare R, Michaud A, Koechlin C, LeBlanc P, Prefaut $C$. Exercise-induced quadriceps oxidative stress and peripheral muscle dysfunction in patients with chronic obstructive pulmonary disease. Am J Respir Crit Care Med 2003;167:1664-1669.

15. Zattara-Hartmann MC, Badier M, Guillot C, Tomei C, Jammes Y. Maximal force and endurance to fatigue of respiratory and skeletal muscles in chronic hypoxemic patients: The effects of oxygen breathing. Muscle Nerve 1995;18:495502.

16. American Thoracic Society Statement. Standards for the diagnosis and care of patients with chronic obstructive pulmonary disease. Am J Respir Crit Care Med 1995; 152:S77-121. 
17. Creutzberg EC, Wouters EF, Mostert R, Weling-Scheepers CA, Schols AM. Efficacy of nutritional supplementation therapy in depleted patients with chronic obstructive pulmonary disease. Nutrition 2003;19:120-127.

18. Quanjer PH, Tammeling GJ, Cotes JE, Pedersen OF, Peslin R, Yernault JC. Lung volumes and forced ventilatory flows. Report working party standardization of lung function tests, European community for steel and coal. Official statement of the European Respiratory Society. Eur Respir J Suppl 1993;16:5-40.

19. Lukaski HC, Johnson PE, Bolonchuk WW, Lykken GI. Assessment of fat-free mass using bioelectrical impedance measurements of the human body. Am J Clin Nutr 1985;41:810-817.

20. Schols AM, Wouters EF, Soeters PB, Westerterp KR. Body composition by bioelectrical-impedance analysis compared with deuterium dilution and skinfold anthropometry in patients with chronic obstructive pulmonary disease. Am J Clin Nutr 1991;53:421-424.

21. Man WD, Soliman MG, Nikoletou D, Harris ML, Rafferty GF, Mustfa N, Polkey MI, Moxham J. Non-volitional assessment of skeletal muscle strength in patients with chronic obstructive pulmonary disease. Thorax 2003;58:665-669.

22. Orozco-Levi M, Gea J, Sauleda J, Corominas JM, Minguella J, Aran X, Broquetas JM. Structure of the latissimus dorsi muscle and respiratory function. J Appl Physiol 1995;78:1132-1139.

23. Franssen FM, Wouters EF, Schols AM. The contribution of starvation, deconditioning and ageing to the observed alterations in peripheral skeletal muscle in chronic organ diseases. Clin Nutr 2002;21:1-14.

24. Franssen FM, Wouters EF, Baarends EM, Akkermans MA, Schols AM. Arm mechanical efficiency and arm exercise capacity are relatively preserved in COPD. Medicine and science in sports and exercise 2002;34:1570-1576.

25. Gea JG, Pasto M, Carmona MA, Orozco-Levi M, Palomeque J, Broquetas J. Metabolic characteristics of the deltoid muscle in patients with chronic obstructive pulmonary disease. Eur Respir J 2001;17:939-945.

26. Lacasse $Y$, Guyatt GH, Goldstein RS. The components of a respiratory rehabilitation program: A systematic overview. Chest 1997;111:1077-1088.

27. Casaburi R. Exercise training in chronic obstructive lung disease. Philadelphia: W.B. Saunders Co.; 1993.

28. Ortega F, Toral J, Cejudo P, Villagomez R, Sanchez H, Castillo J, Montemayor T. Comparison of effects of strength and endurance training in patients with chronic obstructive pulmonary disease. Am J Respir Crit Care Med 2002;166:669-674.

29. Spruit MA, Gosselink R, Troosters T, De Paepe K, Decramer M. Resistance versus endurance training in patients with COPD and peripheral muscle weakness. Eur Respir J 2002;19:1072-1078.

30. Bernard S, Whittom F, Leblanc P, Jobin J, Belleau R, Berube C, Carrier G, Maltais $F$. Aerobic and strength training in patients with chronic obstructive pulmonary disease. Am J Respir Crit Care Med 1999;159:896-901.

31. O'Donnell DE, McGuire M, Samis L, Webb KA. General exercise training improves ventilatory and peripheral muscle strength and endurance in chronic airflow limitation. Am J Respir Crit Care Med 1998;157:1489-1497.

32. Lake FR, Henderson K, Briffa T, Openshaw J, Musk AW. Upper-limb and lowerlimb exercise training in patients with chronic airflow obstruction. Chest 1990;97:1077-1082. 


\section{Chapter 5}

Effects of whole-body exercise training on body composition and functional capacity in normal-weight patients with chronic obstructive pulmonary disease

Frits M.E. Franssen, Roelinka Broekhuizen, Paul P. Janssen, Emiel F.M. Wouters, Annemie M.W.J. Schols

Chest 2004; 125: 2021-2028 


\section{Abstract}

\section{Introduction}

Skeletal muscle wasting is related to muscle dysfunction, exercise intolerance and increased mortality risk in patients with chronic obstructive pulmonary disease (COPD). The aims of this study were to investigate the effects of whole-body exercise training on body composition in normal-weight COPD patients and to study the relationship between changes in body composition and functional capacity.

\section{Methods}

Fifty COPD patients $\left(\mathrm{FEV}_{1}: 39 \%\right.$ of predicted [SD, 16]) admitted to pulmonary rehabilitation centre Hornerheide, and 36 healthy age-matched controls (for baseline comparison) were included. Patients participated in a standardized inpatient exercise training programme consisting of daily submaximal cycle ergometry, treadmill walking, weight training and gymnastics during eight weeks. Fat-free mass (FFM) was measured by bioelectrical impedance analysis. None of the patients met the criteria for nutritional supplementation (BMI $\leq 21 \mathrm{~kg} \cdot \mathrm{m}^{-2}$ or FFM Index $\leq 15 \mathrm{~kg} \cdot \mathrm{m}^{-2}$ in females and $\leq 16 \mathrm{~kg} \cdot \mathrm{m}^{-2}$ in males). Exercise capacity was measured using incremental cycle ergometry. Isokinetic quadriceps strength was measured with a Biodex dynamometer (Biodex Medical Corporation; Shirley, New York, USA).

\section{Results}

At baseline, patients were characterized by a significantly lower FFM than the control subjects. Age and FFM were independent predictors of skeletal muscle function and exercise capacity in patients. After rehabilitation, weight $(72.4 \pm 9.8 \mathrm{~kg}$ to $73.0 \pm 9.4 \mathrm{~kg}$, $\mathrm{p}<0.05)$ significantly increased, as a result of increased FFM $(52.4 \pm 7.3 \mathrm{~kg}$ to $53.4 \pm 7.7$ $\mathrm{kg}, \mathrm{p}<0.05)$, while fat mass $(20.0 \pm 6.1 \mathrm{~kg}$ to $19.6 \pm 5.7 \mathrm{~kg})$ tended to decrease. Peak work rate $(63 \pm 29 \mathrm{~W}$ to $84 \pm 42 \mathrm{~W}, \mathrm{p}<0.001)$, maximal oxygen consumption (1028 \pm $307 \mathrm{ml} \cdot \mathrm{min}^{-1}$ to $\left.1229 \pm 421 \mathrm{ml} \cdot \mathrm{min}^{-1}, \mathrm{p}<0.001\right)$ and isokinetic quadriceps strength $(82.5 \pm 36.4 \mathrm{~N} \cdot \mathrm{m}$ to $90.3 \pm 34.9 \mathrm{~N} \cdot \mathrm{m}, \mathrm{p}<0.05)$ all improved. Changes in FFM were proportionally smaller than functional improvements, and were related to changes in maximal oxygen consumption $(r=0.361, p<0.05)$, but not to other changes in functional capacity.

\section{Conclusions}

Intensive exercise training per se is able to induce an anabolic response in normalweight COPD patients classified into GOLD stages III-IV. Improvements in exercise performance and muscle function are proportionally larger than increases in FFM. 


\section{Introduction}

Muscle wasting is a common systemic manifestation in patients with advanced chronic obstructive pulmonary disease (COPD). Reductions in fat-free mass (FFM), as an indirect measure of muscle mass, may be a result of weight loss, but may also occur disproportionate to weight loss and in a substantial proportion of patients with a normal body weight ${ }^{1,2}$. Loss of muscle mass has been related to skeletal muscle dysfunction ${ }^{3}$ and exercise intolerance ${ }^{4}$ in these patients. Moreover, weight loss and skeletal muscle mass are strong predictors of mortality risk in $\mathrm{COPD}^{5,6}$, independent of the degree of airflow limitation.

Weight loss and muscle wasting have long been considered irreversible terminal events in the progression of COPD. However, in the last decades several investigators have challenged this concept and showed positive effects of anabolic interventions such as caloric supplementation as integrated part of a pulmonary rehabilitation programme and anabolic agents. One study furthermore showed that weight gain is associated with increased survival in these patients ${ }^{5}$. Until now, most studies investigated body weight and body composition changes only in malnourished patients. Recently however, the prognostic importance of weight change was also shown in normal-weight patients ${ }^{7}$ and in another study muscle mass was even more closely related to survival than body weight in normal-weight COPD patients ${ }^{6}$. However instead of caloric intervention, exercise is the first option in normal-weight stable patients to increase muscle mass. Therefore, the first aim of the present study was to investigate if whole-body exercise per se is able to induce anabolism in these patients.

Based on the relationship between muscle wasting and functional capacity, it can be hypothesized that improvements in exercise capacity and muscle function after exercise training programmes in COPD are related to changes in body composition. This relationship however is yet unclear in COPD, due to a lack of studies on the effects of exercise training in COPD that included detailed measurements of changes in body composition. Therefore, the second aim of this study was to investigate the relationship between changes in exercise performance, muscle function and muscle mass. 


\section{Methods}

\section{Participants}

The study group consisted of 50 patients with moderate to severe COPD $^{8}$ consecutively admitted to Asthma Centre Hornerheide for an intensive inpatient pulmonary rehabilitation programme. Baseline characteristics are presented in Table 5.1. For inclusion, $\mathrm{FEV}_{1}$ had to be less than $70 \%$ of the reference value and the increase in $\mathrm{FEV}_{1}$ after inhalation of a $\beta_{2}$-agonist had to be less than $10 \%$ of the reference value. None of the patients met the criteria for nutritional supplementation, which were defined as body mass index (BMI) $\leq 21$ $\mathrm{kg} / \mathrm{m}^{2}$ and/or FFM Index $\leq 15 \mathrm{~kg} \cdot \mathrm{m}^{-2}$ in females and $\leq 16 \mathrm{~kg} \cdot \mathrm{m}^{-2}$ in males. Patients in clinically unstable condition were excluded from participation in the study. Other exclusion criteria were malignancies, clinically apparent heart failure, renal, hepatic or gastro-intestinal abnormalities, insulin dependent diabetes mellitus, inflammatory disease and recent surgery. Patients were receiving the following pulmonary maintenance medication: inhaled short- and long-acting $\beta_{2}$-adrenoceptor agonists, 76\%; anticholinergics by inhalation, $78 \%$; combined inhalers of short-acting $\beta_{2}$-adrenoceptor agonists and short-acting anticholinergics, $18 \%$; inhalation corticosteroids, $60 \%$; combined inhalers of $\beta_{2}$-sympathicomimetics and corticosteroids, $22 \%$; and oral $\mathrm{N}$-acetylcysteine, $66 \%$. At the time of admission to the pulmonary rehabilitation centre, $16 \%$ of patients were current smokers, $78 \%$ were ex-smokers and $6 \%$ were non-smokers. Smoking was not allowed during the entire rehabilitation period. Smoking history of the current smokers (52 \pm 18 packyears) was significantly increased compared to that of ex-smokers (35 \pm 20 packyears, $p<0.05)$, while there were no significant differences in age, body composition, lung function or functional capacity between these two groups. Also, the responses to exercise training were comparable in both groups.

Thirty-six age-matched healthy volunteers were recruited from an advertisement in a local newspaper for baseline comparison of body composition and functional capacity. Controls did not participate in any exercise training programme. Written informed consent was obtained from all subjects and the ethical review board of the University Hospital Maastricht approved the study. 


\section{Study design}

Patients were included within the first two weeks after admission to the pulmonary rehabilitation centre. During this period, subjects underwent medical examination by a chest physician and the baseline measurements of pulmonary function, body composition, exercise performance and muscle function were performed. Furthermore, this two-week period allowed for familiarization with the various procedures in order to avoid learning effects.

After two weeks, patients participated in a comprehensive inpatient respiratory rehabilitation programme consisting of exercise training during five days per week, education and (when appropriate) psychosocial and behavioural intervention. During their stay in the rehabilitation centre, a standardized weight maintaining diet was offered to all patients. The aimed daily dietary protein intake was 60 to $80 \mathrm{~g}$. No additional nutritional supplements or anabolic agents were used. The physical exercise-training programme consisted of a combination of endurance and strength exercise training. Submaximal cycle ergometry was performed twice a day for 20 minutes. Initial load was set at $50-60 \%$ of baseline peak work rate. Thereafter, training intensity was adapted to maintain the same relative training load during the intervention period under supervision of an exercise therapist. In addition, patients exercised on a treadmill for 20 minutes per day just below their symptomlimited rate. All patients participated in daily 30 minutes of gymnastics, focused at either strength and endurance or mobilisation and flexibility. Furthermore, patients attended daily unsupported arm exercise training sessions, consisting of 10 times one minute of exercise, followed by one minute of rest. Dynamic strength training exercises of the upper and lower extremities were incorporated in the programme. Muscle groups, load and number of repetitions were determined for each individual and were based on the experienced functional impairments in daily living and evaluation of the patients' muscular performance by a team of experienced physiotherapists.

\section{Assessments}

\section{Pulmonary function}

Lung function testing included forced spirometry and assessment of lung volumes by whole-body plethysmography (Masterlab, Jaeger, Würzburg, Germany). FEV 1 and forced vital capacity (FVC) were calculated from the flow-volume curves. The highest values of at 
least three measurements were used. Maximal voluntary ventilation was indirectly estimated from $\mathrm{FEV}_{1}{ }^{9}$. Diffusing capacity for carbon monoxide ( $\left(\mathrm{L}_{\mathrm{co}}\right)$ was measured by the single breath method (Masterlab, Jaeger, Würzburg, Germany). Instruments were calibrated twice a day. All values obtained were expressed as a percentage of reference values ${ }^{10}$. Arterial blood gas analysis was performed in all patients at rest (Radiometer ABL 330, Copenhagen, Denmark).

\section{Anthropometric measurements}

In COPD patients, anthropometric measurements were performed on admission and after 2, 4, 6 and 8 weeks of exercise training. Body height was determined to the nearest $0.5 \mathrm{~cm}$ (WM 715, Lameris, Breukelen, The Netherlands) with subjects standing barefoot. Body weight was measured with a beam scale (SECA, Hamburg, Germany) without shoes and in light clothing to the nearest $0.1 \mathrm{~kg}$. BMI was calculated as the ratio of weight to height in meters squared. FFM was measured by bioelectrical impedance analysis at a frequency of $50 \mathrm{kHz}$ (Xitron 4000b, Xitron technologies, San Diego, California, USA). Resistance was measured in supine position at the right side as described by Lukaski et al. ${ }^{11}$. A patient specific regression equation, described by Schols et al. ${ }^{12}$ was used to calculate FFM in COPD subjects. FFM index was calculated as the ratio of FFM to height in meters squared.

\section{Exercise capacity}

At baseline and after eight weeks, all patients performed an incremental exercise test on an electrically braked cycle ergometer (Corival 400, Lode, Groningen, The Netherlands) under supervision of a chest physician. Before the start of the test, while seated on the cycle ergometer, ventilation characteristics at rest were analysed during two minutes. During the entire exercise test, expired gases were investigated using breath-by-breath analysis through a breathing mask (Oxycon Beta, Jaeger, Würzburg, Germany). Heart rate, blood pressure and percutaneous oxygen saturation were monitored. After one minute of unloaded cycling, power was increased in patients by $10 \mathrm{~W}$ every minute. In control subjects, the load was increased with 15 to $25 \mathrm{~W}$ every minute, so that the duration of the test was equal in patients and controls. None of the subjects knew the exercise load and all were encouraged to cycle at 60 revolutions $\cdot \mathrm{min}^{-1}$ until exhaustion. 


\section{Skeletal muscle strength}

Isokinetic quadriceps strength of the dominant leg was measured using a Biodex dynamometer (Biodex Medical Corporation, Shirley, New York, USA) before and after the training programme. The testing protocol consisted of fifteen sequential maximal voluntary contractions at an angular velocity of $90^{\circ} \cdot \mathrm{s}^{-1}$. Quadriceps strength was defined as the highest peak torque in this series of fifteen. During the test, subjects were seated upright on the chair of the dynamometer with support of the back. At the level of the chest, pelvis and thigh, subjects were restrained with straps. The hip joint was at an angle between 90 and $100^{\circ}$ of flexion during testing. The lever arm was attached to the distal part of the tibia and its axis of rotation was visually aligned with the anatomical axis of flexion of the knee joint. Subjects were instructed to keep their hands on their thighs during testing. In order to avoid learning effects, all subjects practiced on the dynamometer under supervision of a physiotherapist the day before the actual test.

\section{Statistical analysis}

Results are expressed as mean \pm standard deviation, unless indicated otherwise. Statistical analysis on baseline differences between patients and controls was performed using an unpaired Student's $t$-test. Changes within the COPD group between baseline and week eight were tested with Student's paired $t$-test for dependent samples. Pearson's correlation analysis was performed in the patient group in order to investigate linear relationship between variables of (changes in) body composition and (changes in) exercise capacity and muscle function. Multiple stepwise regression analysis was used to identify independent predictors of exercise performance and quadriceps strength. All $p$ values $<0.05$ were considered statistically significant.

\section{Results}

Baseline characteristics of the study groups are presented in Table 5.1. Fifty patients ( 37 men and 13 women) met the selection criteria and were enrolled in the study. Mean age of the COPD patients was 64 years. BMI averaged $25.0 \mathrm{~kg} \cdot \mathrm{m}^{-2}$ and mean FFM Index was 18.1 $\mathrm{kg} \cdot \mathrm{m}^{-2}$, which indicates that the patients had a normal body weight and FFM and were not eligible for nutritional supplementation. 
However, BMI of the patients was significantly reduced in comparison to the 36 age-matched control subjects, as a result of a $6.3 \mathrm{~kg}$ difference in FFM $(p<0.01)$, despite a comparable fat mass. On average, patients suffered from moderate to severe airflow obstruction with hyperinflation and reduced diffusing capacity for carbon monoxide. Group values for $\mathrm{P}_{a} \mathrm{O}_{2}$ and $\mathrm{P}_{a} \mathrm{CO}_{2}$ were within the normal limits. Six patients received long-term oxygen therapy. At baseline, exercise capacity and quadriceps strength of patients were significantly reduced compared to controls. These differences in functional exercise capacity also existed after correction for FFM.

Table 5.1 Baseline characteristics of the study groups (mean \pm SD).

\begin{tabular}{|c|c|c|}
\hline & $\begin{array}{c}\text { Control } \\
\text { subjects }\end{array}$ & $\begin{array}{c}\text { COPD } \\
\text { patients }\end{array}$ \\
\hline Subjects $(\hat{\jmath} / P)$, No & $36(24 / 12)$ & $50(37 / 13)$ \\
\hline Age, yr & $61 \pm 6$ & $64 \pm 9$ \\
\hline \multicolumn{3}{|l|}{ Body composition } \\
\hline Height, cm & $171.9 \pm 9.3$ & $169.9 \pm 7.0$ \\
\hline Weight, kg & $78.4 \pm 11.6$ & $72.4 \pm 9.7^{\#}$ \\
\hline $\mathrm{BMI}, \mathrm{kg} \cdot \mathrm{m}^{-2}$ & $26.4 \pm 2.5$ & $25.0 \pm 2.8^{\#}$ \\
\hline FFM, kg & $58.7 \pm 10.8$ & $52.4 \pm 7.1$ \#\# \\
\hline FFMI, $\mathrm{kg} \cdot \mathrm{m}^{-2}$ & $19.7 \pm 2.1$ & $18.1 \pm 1.8^{\# \# \#}$ \\
\hline $\mathrm{FM}, \mathrm{kg}$ & $19.8 \pm 7.4$ & $20.0 \pm 6.0$ \\
\hline \multicolumn{3}{|l|}{ Pulmonary function } \\
\hline $\mathrm{FEV}_{1}, \%$ predicted & $111 \pm 17$ & $39 \pm 16$ \#\#\# \\
\hline FVC, \%predicted & $116 \pm 15$ & $77 \pm 20^{\# \# \#}$ \\
\hline TLC, \%predicted & $107 \pm 10$ & $113 \pm 17$ \\
\hline $\mathrm{DL}_{\mathrm{co}}, \%$ predicted & $112 \pm 17$ & $56 \pm 21$ \#\#\# \\
\hline $\mathrm{PaO}_{2}, \mathrm{kPa}$ & - & $9.3 \pm 1.1$ \\
\hline $\mathrm{P}_{\mathrm{a}} \mathrm{CO}_{2}, \mathrm{kPa}$ & - & $5.4 \pm 0.9$ \\
\hline \multicolumn{3}{|l|}{ Functional capacity } \\
\hline Peak work rate, W & $198 \pm 66$ & $63 \pm 29$ \#\#\# \\
\hline$\dot{\mathrm{VO}}_{2 \max }, \mathrm{ml} \cdot \mathrm{min}^{-1}$ & $2129 \pm 658$ & $1028 \pm 307$ \#\#\# \\
\hline$\dot{\mathrm{V}}_{2 \max } / \mathrm{FFM}, \mathrm{ml} \cdot \mathrm{kg}^{-1} \cdot \mathrm{min}^{-1}$ & $36.5 \pm 6.5$ & $19.3 \pm 4.7^{\# \# \#}$ \\
\hline $\mathrm{QF}, \mathrm{N} \cdot \mathrm{m}$ & $118 \pm 37$ & $83 \pm 36^{\# \# \#}$ \\
\hline $\mathrm{QF} / \mathrm{FFM}, \mathrm{N} \cdot \mathrm{m} \cdot \mathrm{kg}^{-1}$ & $2.00 \pm 0.42$ & $1.55 \pm 0.57$ \#\#\# \\
\hline
\end{tabular}

BMI: body mass index; FFM: fat-free mass, assessed by bioelectrical impedance analysis; FFMI: fat-free mass index; FM: fat mass; FEV $_{1}$ : forced expiratory volume in one second; FVC: forced vital capacity; TLC: total lung capacity; $\mathrm{DL}_{\mathrm{co}}$ : diffusing capacity for carbon monoxide. $\mathrm{P}_{\mathrm{a}} \mathrm{O}_{2}$ : arterial oxygen tension; $\mathrm{P}_{\mathrm{a}} \mathrm{CO}_{2}$ : arterial carbon dioxide tension; $\dot{\mathrm{V}}_{2 \text { max }}$ : maximal oxygen consumption; $\mathrm{QF}$ : isokinetic quadriceps strength. Significance of differences between patients and controls is indicated as: ${ }^{*}$ : $\mathrm{p}<0.05 ;{ }^{\# \#}: \mathrm{p}<0.01 ;{ }^{\# \# \#}: \mathrm{p}<0.001$.

In bivariate correlation analysis in the COPD group, age, FFM, FEV ${ }_{1}$, $D L_{C O}$ and $\mathrm{P}_{\mathrm{a}} \mathrm{O}_{2}$ all significantly correlated with maximal oxygen consumption $\left(\mathrm{V}_{2 \max }\right)$ and peak work load $\left(\mathrm{W}_{\max }\right)$ (data not shown). 
These parameters were entered in a stepwise regression model with $\mathrm{VO}_{2 \max }$ as dependent variable (Table 5.2). FFM alone accounted for $38 \%$ of the variation in $\mathrm{VO}_{2 \max }$ and in combination with age and $\mathrm{DL}_{\mathrm{CO}}$ explained $56 \%$ of variation in $\dot{\mathrm{VO}}_{2 \max }$. $\mathrm{FEV}_{1}$ and $\mathrm{P}_{\mathrm{a}} \mathrm{O}_{2}$ were excluded. When entering $\mathrm{W}_{\max }$ as dependent variable, FFM, age, $\mathrm{FEV}_{1}$ and $\mathrm{DL}_{\mathrm{co}}$ all individually contributed and explained $49 \%$ of variation. Furthermore, FFM and age of patients, but none of the variables of pulmonary function, were independently related to isokinetic quadriceps strength with a total adjusted $r^{2}$ of 0.50 . FFM and age were not mutually correlated $(r=-0.024, p=0.868)$. Also, isokinetic quadriceps strength was related to $\dot{\mathrm{VO}}_{2 \max }$ and $\mathrm{W}_{\max }(r=0.54$ and $r=0.40$ respectively, $p<0.01$ ) at baseline.

Table 5.2 Results of stepwise regression analysis for baseline exercise capacity and quadriceps strength in COPD patients.

\begin{tabular}{lccc}
\hline & $\mathrm{VO}_{2 \max }, \mathrm{ml} \cdot \mathrm{min}^{-1}$ & $\mathrm{~W}_{\max }, \mathrm{W}$ & $\mathrm{QF}, \mathrm{N} \cdot \mathrm{m}$ \\
\hline $\mathrm{Age}, \mathrm{yr}$ & $-0.37^{* *}$ & $-0.43^{* * *}$ & $-0.33^{* * *}$ \\
$\mathrm{FFM}, \mathrm{kg}$ & $0.55^{* * *}$ & $0.22^{*}$ & $0.63^{* *}$ \\
$\mathrm{FEV}_{1}, \mathrm{l}$ & $\mathrm{NS}$ & $0.37^{* *}$ & $\mathrm{NS}$ \\
$\mathrm{DL}_{\mathrm{CO}}, \%$ predicted & $0.33^{* *}$ & $0.25^{*}$ & $\mathrm{NS}$ \\
$\mathrm{P}_{\mathrm{a}} \mathrm{O}_{2}, \mathrm{kPa}$ & $\mathrm{NS}$ & $\mathrm{NS}$ & $\mathrm{NS}$ \\
\hline
\end{tabular}

$\mathrm{V}_{2 \text { max }}$ : maximal oxygen consumption; $\mathrm{W}_{\max }$ : peak work rate; $\mathrm{QF}$ : isokinetic quadriceps stength; FFM: fat-free mass; $\mathrm{FEV}_{1}$ : forced expiratory volume in one second; $\mathrm{DL}_{\mathrm{co}}$ : diffusing capacity for carbon monoxide. $\mathrm{P}_{\mathrm{a}} \mathrm{O}_{2}$ : arterial oxygen tension. Partial $r$ values are shown. Significance of relationships is indicated as: ${ }^{*}: p<0.05 ;{ }^{* *}$ : $p<0.01 ;^{* * *}: p<0.001$. NS: not statistically significant.

Changes in body composition after eight weeks of exercise training are shown in Figure 5.1. After training, body weight significantly increased from $72.4 \pm 9.8 \mathrm{~kg}$ to $73.0 \pm 9.4 \mathrm{~kg}(p<0.05)$, as a result of an increase in FFM from $52.4 \pm 7.3 \mathrm{~kg}$ to $53.4 \pm 7.7 \mathrm{~kg}(p<0.05)$. There was a slight decrease in fat mass by $0.4 \mathrm{~kg}$ (NS). Forty-six percent and $58 \%$ of the gain in body weight and FFM, respectively, were achieved in the last two weeks of the intervention period. Exercise performance was significantly enhanced during the training period, as indicated by the $35 \%$ increase in peak work rate $(p<0.001)$ and $17 \%$ increase in $\mathrm{VO}_{2 \max }(p<0.001)$ (Figure 5.2, panels $A$ and $B$ ). The relative increase in peak work rate was greater than the improvement in $\dot{\mathrm{VO}}_{2 \max }(p<0.01)$. COPD patients demonstrated a $30 \%$ improvement in quadriceps strength $(p<0.05)$, as shown in panel $\mathrm{C}$ of Figure 5.2. 
Figure 5.1 Changes in anthropometric measurements in nondepleted COPD patients during eight weeks of whole-body physical exercise training embedded in an inpatient respiratory rehabilitation programme (mean \pm SEM). A) Change in body weight. Weight after eight weeks of intervention was significantly increased, compared to baseline. B) Change in FFM. A consistent and significant increase in FFM was observed during exercise training. C) Change in fat mass. Fat mass tended to decrease during the training programme. Significant within-group differences were detectable at eight weeks. ${ }^{*}: \mathrm{p}<0.05$ versus baseline.
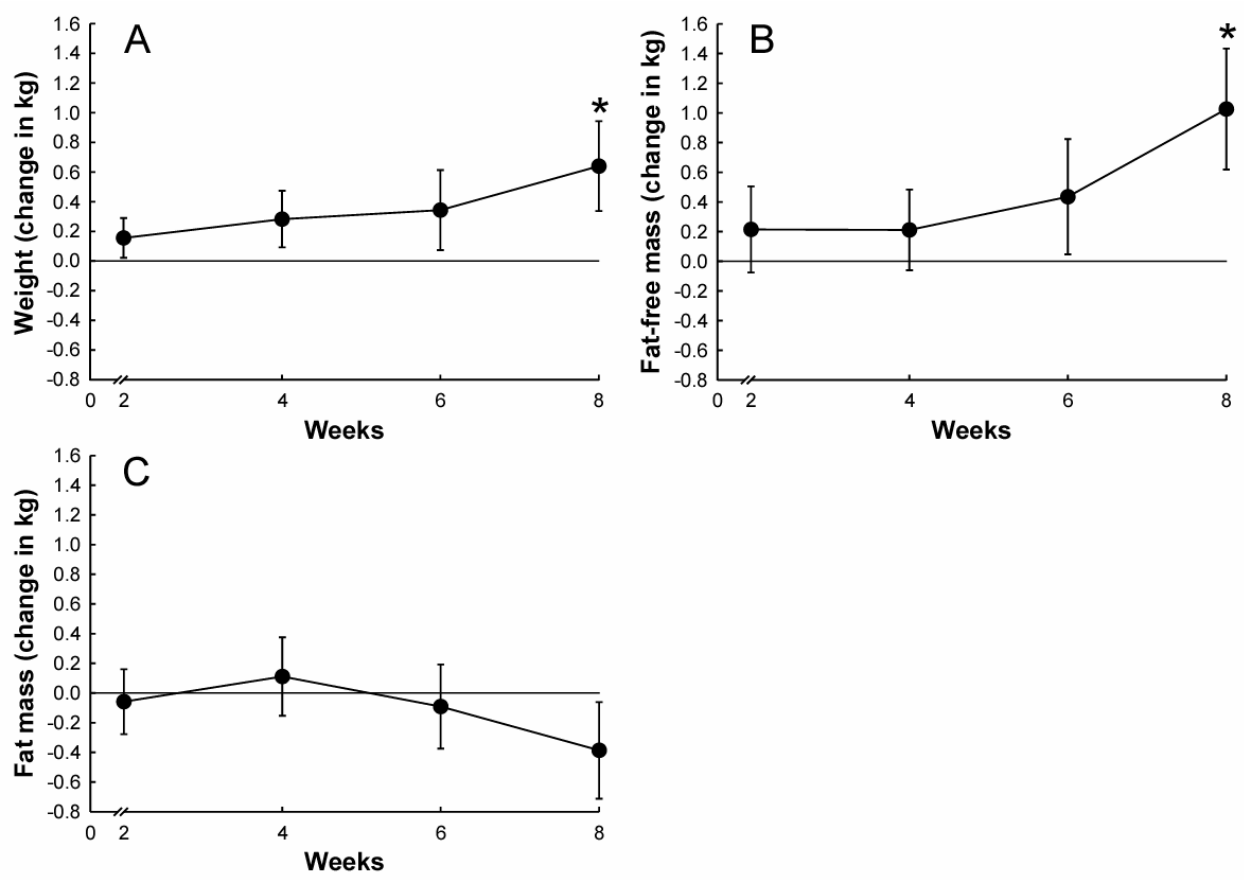
Figure 5.2 Individual and mean responses of functional exercise capacity and muscle strength during eight weeks of whole-body exercise training. A) Change in $\dot{\mathrm{V}}_{2 \max }$. B) Response of $\mathrm{W}_{\max }$. C) Change in isokinetic quadriceps strength. All variables improved significantly. Closed circles and lines are individual values at baseline and after eight weeks. Open circles represent mean values and SEM. ${ }^{*}: p<0.05 ;{ }^{* * *}: p<0.001$ versus baseline.
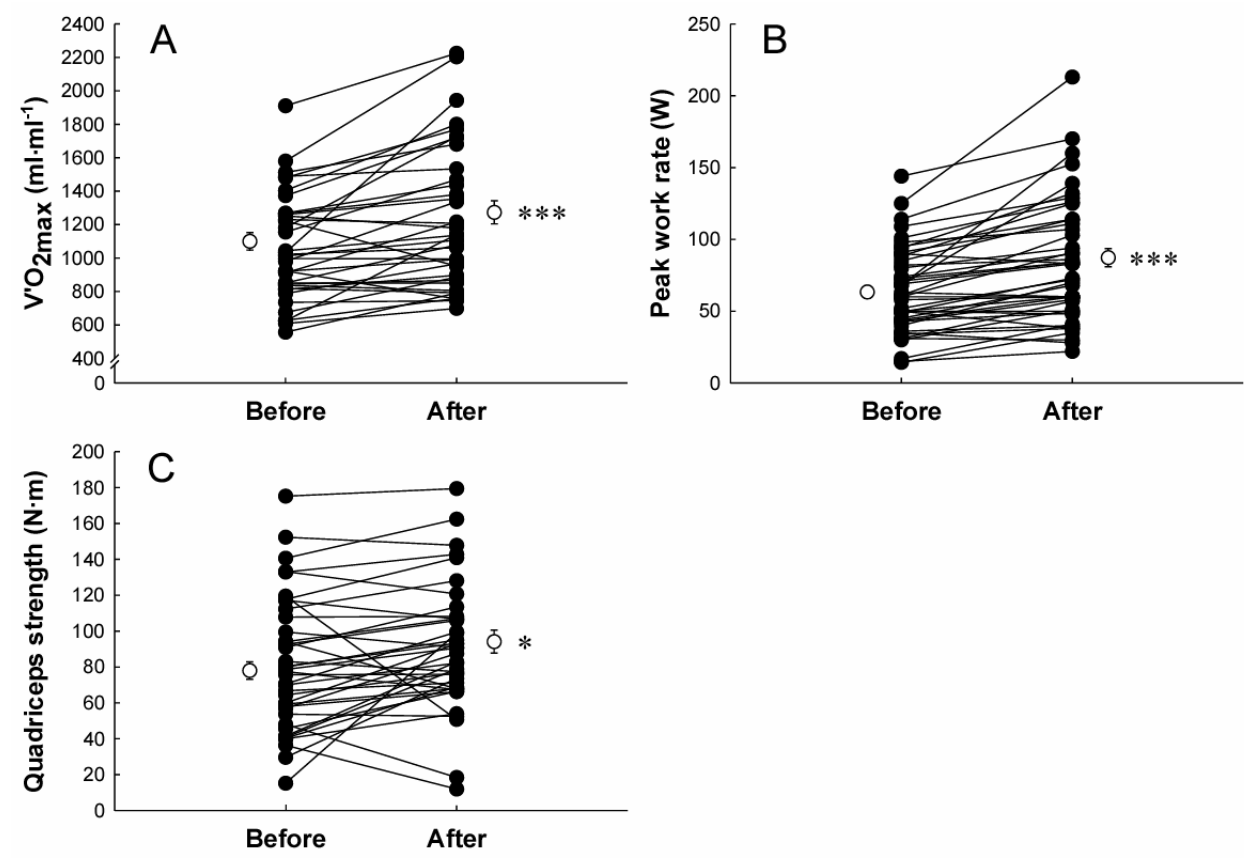

Changes in FFM correlated significantly with changes in $\dot{\mathrm{VO}}_{2 \max }$, but not with changes of $W_{\max }$ or quadriceps strength (Figure 5.3). Changes in $\dot{\mathrm{VO}}_{2 \max }$ and $\mathrm{W}_{\max }$ were mutually related $(r=0.644$, $\mathrm{p}<0.001)$. Changes in $\dot{\mathrm{VO}}_{2 \max }, \mathrm{W}_{\max }$ or quadriceps strength were not related to age of the COPD patients, i.e. older patients showed a comparable anabolic response than younger patients (data not shown). 
Figure 5.3 Bivariate correlations between changes in FFM and changes in functional exercise capacity and muscle function. A) Change in $\mathrm{VO}_{2 \max }$ is related to change in FFM $(r=0.361, p<0.05, n=36)$. B) Change in $W_{\max }$ is not related to change in FFM ( $r=-0.080, N S, n=43)$. C) Change in quadriceps strength is not related to change in FFM $(r=-0.009$, NS, $n=39)$.
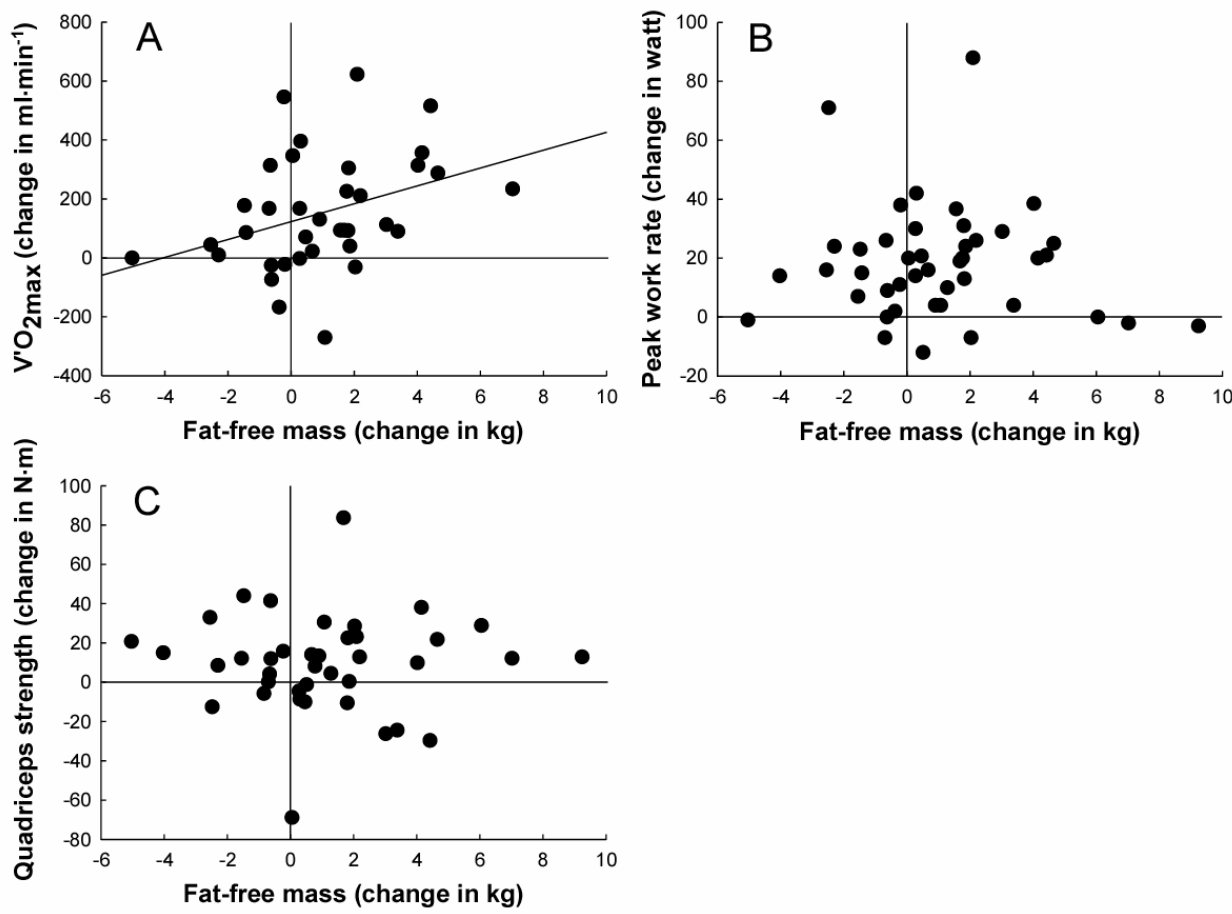

\section{Discussion}

The results of the present study indicated that intensive exercise training per se is able to induce an anabolic response in normalweight COPD patients. After eight weeks of whole-body exercise training, body weight increased as a result of increased FFM, while body fat tended to decrease. Although exercise performance and muscle strength were strongly related to skeletal muscle mass at baseline, changes in functional capacity after the training programme were only partially related to changes in body composition. Finally, it was shown that age is a predictor of baseline functional capacity in COPD patients, independent of FFM and pulmonary function, but not of the response to rehabilitation. 


\section{Exercise as anabolic stimulus}

Improvements in exercise performance, peripheral muscle function and quality of life after exercise training in patients with COPD are well documented ${ }^{13,14}$. However, the influence of exercise training per se on body composition has rarely been studied in COPD. In the present study, body weight and FFM increased in normal-weight patients after a balanced exercise training programme of both endurance as well as strength training. This suggests that exercise training can act as an anabolic stimulus in these patients. These results are in accordance with a study by Bernard et al. ${ }^{13}$, who reported enhanced bilateral midthigh muscle cross-sectional area, a measure of skeletal muscle mass, assessed by computed tomography after 12 weeks of aerobic training combined with strength training in normal-weight COPD patients. However, BMI did not change in their group. The changes in body composition reported in this study are similar to those reported after exercise conditioning in healthy elderly subjects. Besides improved muscle function, Frontera et al. ${ }^{15}$ described a 0.5 and $1.0 \mathrm{~kg}$ increase in body weight and FFM, respectively, after 12 weeks of strength training in untrained healthy older men. In general, the ability of exercise to induce changes in body weight, FFM and fat mass is affected by various factors, including the type, intensity, frequency and duration of exercise ${ }^{16}$. Traditionally, whole-body endurance training played a central role in pulmonary rehabilitation. In order to reverse muscle weakness and increase muscle mass, however, resistance training might be more effective and various combined training regimens are currently being implemented in respiratory rehabilitation in patients with COPD. The results of this study confirm that a combination of whole-body endurance training and strength training results in improved physiological function, but may also increase FFM.

\section{Clinical implications of muscle wasting in normal-weight COPD patients}

The results of this study in normal-weight patients are different from findings in depleted patients with COPD. Schols et al. ${ }^{17}$ studied the effects of nutrition intervention versus placebo treatment embedded in the same pulmonary rehabilitation programme in both depleted as well as nondepleted patients with COPD. Depleted patients who did not receive nutritional support showed no significant changes in body weight, FFM or respiratory muscle function after eight weeks of whole-body exercise training. In this group FFM even tended to 
decrease by $0.6 \mathrm{~kg}$. A subsequent study by Creutzberg et al. ${ }^{18}$ showed that nutritional supplementation therapy implemented in a pulmonary rehabilitation programme resulted in improved body composition, exercise performance, muscle function and quality of life in depleted or weight-losing patients with COPD. The discrepancy in response to exercise training between depleted and nondepleted patients might be related to enhanced protein catabolism in depleted patients with COPD $^{19}$. In order to induce an anabolic response in depleted patients, extensive nutritional support, including caloric supplements and anabolic agents is probably indicated, whereas this study shows that less intervening physiologic interventions are sufficient in normal-weight patients.

Although the patients with COPD in this study had a normal body weight and were not eligible for nutritional support, their body mass index was significantly lower than that of the age-matched control subjects. This difference in body weight resulted from a significantly lower FFM in patients, despite a comparable fat mass. These baseline results once again indicate that loss of FFM may occur in normalweight patients and that nutritional assessment in patients with COPD should include measurements of both body weight and FFM.

\section{Relationship between functional improvements and changes in body composition}

In the present study, changes in functional capacity were only in part related to changes in FFM, although at baseline FFM was a strong predictor of cycling performance and quadriceps strength. Also, the increase in FFM $(2 \%, p<0.05)$ was insufficient to account for the increases in $\dot{\mathrm{VO}}_{2 \max }, \mathrm{W}_{\max }$ and strength. Despite the lack of correlation, the vast majority of patients showed enhanced functional capacity, FFM, or both (Figure 5.3). Several possible explanations may account for the absence of a direct relationship between improvements in muscle mass and functional capacity. In the present study whole-body FFM was used as an indirect measure of muscle mass. Local increase in quadriceps muscle bulk as a result of exercise training was not assessed and may have been underestimated by the use of bio-electrical impedance analysis. It was previously reported that quadriceps muscle quantity and strength are directly related to cycling capacity and walking distance ${ }^{20,21}$. In the previously mentioned study of Bernard et al. ${ }^{13}$ quadriceps muscle mass was assessed before and after exercise training. Correlations between changes in quadriceps muscle cross- 
sectional area and functional improvements however were not mentioned. Low sensitivity of bioelectrical impedance analysis to detect local changes and redistributions in muscle mass probably plays a minor role in the nonexistence of a relationship between changes in muscle structure and functional capacity. In accordance with the present results, several investigations in healthy subjects showed that gains in muscle strength after resistance training were not related to local muscle hypertrophy ${ }^{15,22}$ and that increments in strength were proportionally greater than increases in muscle bulk.

In addition to an increase in FFM, exercise training induces intrinsic alterations in skeletal muscle, such as increments in mitochondria or oxidative enzymes, which contribute to the improved physiologic function and may explain the lack of correlation between increased FFM and functional capacity. Furthermore, as a result of exercise training, patients with COPD might have developed the ability to increase motor-unit recruitment during exercise and thereby performance might have increased more than muscle mass ${ }^{22}$. Others also suggested a contribution of neurological factors to functional improvements after training in elderly ${ }^{15}$. Finally, decreased exertional dyspnea and anxiety to engage in exercise and increased motivation after pulmonary rehabilitation may also have contributed to the disproportionate gain in functional capacity, compared with FFM. In order to further investigate the possible mechanisms whereby functional capacity might be increased more than muscle mass future studies are necessary. A prospective study consisting of a combination of local assessments of muscle mass, muscle biopsies and non-volitional strength measurements before and after an exercise training programme would be able to discriminate between the mentioned factors.

Changes in FFM were positively related to changes in $\dot{\mathrm{VO}}_{2 \max }$, but not with changes in $W_{\max }$, although improvements in functional parameters were strongly correlated. The reason for this discrepancy is not readily apparent. The facts that muscle mass is the metabolically active tissue and that the effort to exercise influences peak work rate more than oxygen consumption probably contribute to this observation.

\section{Determinants of functional capacity}

FFM was strongly related to exercise capacity and muscle strength, which is in accordance with earlier studies ${ }^{1,3,4}$. In keeping with the conclusions of Hamilton et al. ${ }^{20}$, quadriceps strength was related to 
maximal work capacity. Loss of muscle mass and redistribution of fat mass with age have been demonstrated and are referred to as sarcopenia. Also, the normal aging process is accompanied by a decline in functional capacity ${ }^{23}$. Frontera et al. ${ }^{24}$ observed reduced muscle strength in 65- to 78-year-old men and women compared to younger subjects. When adjusted for FFM, estimated from hydrostatic weighing, age-related differences disappeared, indicating that loss of muscle mass is the most important determinant of agerelated differences in skeletal muscle strength. Reduced muscle mass and strength also contribute to the decrease in maximal aerobic exercise capacity that occurs during aging ${ }^{25}$. In the present crosssectional study in 43- to 78-year-old patients with COPD, advanced age was negatively related to muscle function and exercise capacity. Moreover, stepwise regression analysis showed that the relationship between age and functional capacity was independent of the influence of FFM. Also, no mutual correlation was observed between FFM and age. These results suggest that age-related factors, other than loss of FFM, contribute to disability in patients with advanced COPD and that the course of the aging process may be different in COPD compared with healthy subjects. Potential factors contributing to age-related functional impairment in COPD include changes in muscle morphology and energy metabolism and reduced activity of motor neurons. Larsson et al. ${ }^{26}$ observed a selective atrophy of type II muscle fibres and a decreased proportion of type II fibres in biopsies of the vastus lateralis muscle with increasing age in 51 healthy male subjects of different ages. In the same study, it was found that age, FFM and type II fibre area were independent predictors of the age-related decline in strength. In accordance with these findings, a preferential muscle fibre type IIX atrophy was recently reported in vastus lateralis biopsies of COPD patients ${ }^{27}$. Thus, muscular type II fibre atrophy may partially explain muscular weakness with increasing age, independent of the loss of lean body mass in COPD. Reduced oxidative capacity of vastus lateralis muscle has been reported in COPD ${ }^{28}$ and is related to peak exercise capacity. However, no major alterations in the activities of oxidative or glycolytic enzymes in skeletal muscles were described in relation to age in healthy subjects ${ }^{29}$. Thus, it is unlikely that changes in muscle energy metabolism in COPD result from accelerated aging. Studies have shown that both the number and size of active motor units are affected during aging ${ }^{30}$, but the prevalence and role of these and other neuropathic changes in age-related functional impairment in patients with COPD is unknown. Although advancing age was 
independently related with reduced functional capacity in COPD, the exact mechanism behind this observation remains unclear. The effects of the exercise training programme on weight, FFM and exercise performance were not related to age of the participants, indicating that the ability to adapt to an anabolic stimulus is maintained in older COPD patients.

In conclusion, normal-weight COPD patients classified into GOLD stages III-IV show an anabolic response to physical exercise training, which together with other training-induced adaptations contributes to functional improvements. The influence of changes in FFM on prognosis in normal-weight patients needs to be studied. 


\section{References}

1. Schols AM, Soeters PB, Dingemans AM, Mostert R, Frantzen PJ, Wouters EF. Prevalence and characteristics of nutritional depletion in patients with stable COPD eligible for pulmonary rehabilitation. Am Rev Respir Dis 1993;147:11511156.

2. Schwebel C, Pin I, Barnoud D, Devouassoux G, Brichon PY, Chaffanjon P, Chavanon O, Sessa C, Blin D, Guignier M, et al. Prevalence and consequences of nutritional depletion in lung transplant candidates. Eur Respir J 2000;16: 1050-1055.

3. Engelen MP, Schols AM, Baken WC, Wesseling GJ, Wouters EF. Nutritional depletion in relation to respiratory and peripheral skeletal muscle function in outpatients with COPD. Eur Respir J 1994;7:1793-1797.

4. Baarends EM, Schols AM, Mostert R, Wouters EF. Peak exercise response in relation to tissue depletion in patients with chronic obstructive pulmonary disease. Eur Respir J 1997;10:2807-2813.

5. Schols AM, Slangen J, Volovics L, Wouters EF. Weight loss is a reversible factor in the prognosis of chronic obstructive pulmonary disease. Am J Respir Crit Care Med 1998;157:1791-1797.

6. Marquis K, Debigare R, Lacasse $\mathrm{Y}$, LeBlanc P, Jobin J, Carrier G, Maltais F. Midthigh muscle cross-sectional area is a better predictor of mortality than body mass index in patients with chronic obstructive pulmonary disease. Am J Respir Crit Care Med 2002;166:809-813.

7. Prescott $\mathrm{E}$, Almdal T, Mikkelsen $\mathrm{KL}$, Tofteng $\mathrm{CL}$, Vestbo J, Lange P. Prognostic value of weight change in chronic obstructive pulmonary disease: Results from the Copenhagen City Heart Study. Eur Respir J 2002;20:539-544.

8. American Thoracic Society Statement. Standards for the diagnosis and care of patients with chronic obstructive pulmonary disease. Am J Respir Crit Care Med 1995;152:S77-121.

9. Wasserman K, Hansen JE, Sue DY, Whipp BJ, Casaburi R. Principles of exercise testing and interpretation. Philadelphia: Lea \& Febiger; 1994.

10. Quanjer PH, Tammeling GJ, Cotes JE, Pedersen OF, Peslin R, Yernault JC. Lung volumes and forced ventilatory flows. Report working party standardization of lung function tests, European community for steel and coal. Official statement of the European Respiratory Society. Eur Respir J Suppl 1993;16:5-40.

11. Lukaski HC, Johnson PE, Bolonchuk WW, Lykken GI. Assessment of fat-free mass using bioelectrical impedance measurements of the human body. Am J Clin Nutr 1985;41:810-817.

12. Schols AM, Wouters EF, Soeters PB, Westerterp KR. Body composition by bioelectrical-impedance analysis compared with deuterium dilution and skinfold anthropometry in patients with chronic obstructive pulmonary disease. Am J Clin Nutr 1991;53:421-424.

13. Bernard S, Whittom F, Leblanc P, Jobin J, Belleau R, Berube C, Carrier G, Maltais F. Aerobic and strength training in patients with chronic obstructive pulmonary disease. Am J Respir Crit Care Med 1999;159:896-901.

14. Lacasse Y, Guyatt GH, Goldstein RS. The components of a respiratory rehabilitation programme: A systematic overview. Chest 1997;111:1077-1088.

15. Frontera WR, Meredith CN, O'Reilly KP, Knuttgen HG, Evans WJ. Strength conditioning in older men: Skeletal muscle hypertrophy and improved function. $J$ Appl Physiol 1988;64:1038-1044.

16. Ballor DL, Keesey RE. A meta-analysis of the factors affecting exercise-induced changes in body mass, fat mass and fat-free mass in males and females. Int $J$ Obes $1991 ; 15: 717-726$. 
17. Schols AM, Soeters PB, Mostert R, Pluymers RJ, Wouters EF. Physiologic effects of nutritional support and anabolic steroids in patients with chronic obstructive pulmonary disease. A placebo- controlled randomized trial. Am J Respir Crit Care Med 1995;152:1268-1274.

18. Creutzberg EC, Wouters EF, Mostert R, Weling-Scheepers CA, Schols AMWJ. Efficacy of nutritional supplementation therapy in depleted patients with chronic obstructive pulmonary disease. Nutrition 2003;19:120-127.

19. Engelen MP, Wouters EF, Deutz NE, Menheere PP, Schols AM. Factors contributing to alterations in skeletal muscle and plasma amino acid profile in patients with chronic obstructive pulmonary disease. Am J Clin Nutr 2000;72:1480-1487.

20. Hamilton AL, Killian KJ, Summers $\mathrm{E}$, Jones NL. Muscle strength, symptom intensity, and exercise capacity in patients with cardiorespiratory disorders. Am J Respir Crit Care Med 1995;152:2021-2031.

21. Frontera WR, Meredith CN, O'Reilly KP, Evans WJ. Strength training and determinants of vo2max in older men. J Appl Physiol 1990;68:329-333.

22. Young $A$, Stokes $M$, Round JM, Edwards RH. The effect of high-resistance training on the strength and cross-sectional area of the human quadriceps. Eur J Clin Invest 1983;13:411-417.

23. Evans W. Functional and metabolic consequences of sarcopenia. $J$ Nutr 1997; 127:998S-1003S.

24. Frontera WR, Hughes VA, Lutz KJ, Evans WJ. A cross-sectional study of muscle strength and mass in 45- to 78-yr-old men and women. $J$ Appl Physiol 1991;71:644-650.

25. Fleg JL, Lakatta EG. Role of muscle loss in the age-associated reduction in $\mathrm{V}^{\prime} \mathrm{O}_{2}$ max. J Appl Physiol 1988;65:1147-1151.

26. Larsson L, Grimby G, Karlsson J. Muscle strength and speed of movement in relation to age and muscle morphology. J Appl Physiol 1979;46:451-456.

27. Gosker HR, Engelen MP, van Mameren H, van Dijk PJ, van der Vusse GJ, Wouters $\mathrm{EF}$, Schols AM. Muscle fibre type IIx atrophy is involved in the loss of fat-free mass in chronic obstructive pulmonary disease. Am J Clin Nutr 2002;76:113-119.

28. Maltais F, Simard AA, Simard C, Jobin J, Desgagnes P, LeBlanc P. Oxidative capacity of the skeletal muscle and lactic acid kinetics during exercise in normal subjects and in patients with COPD. Am J Respir Crit Care Med 1996;153:288293.

29. Franssen FM, Wouters EF, Schols AM. The contribution of starvation, deconditioning and ageing to the observed alterations in peripheral skeletal muscle in chronic organ diseases. Clin Nutr 2002;21:1-14.

30. Rogers MA, Evans WJ. Changes in skeletal muscle with aging: Effects of exercise training. Exerc Sport Sci Rev 1993;21:65-102. 



\section{Chapter 6}

Summary and discussion on part 1 of the thesis 



\section{Introduction}

In the last decades it has become clear that COPD is more than a chronic disease affecting the lungs. Peripheral skeletal muscle dysfunction and loss of fat-free mass have been identified as extrapulmonary manifestations of the disease with significant clinical implications. The recognition of the role of abnormal muscle function and body composition in symptomatology and prognosis of COPD patients has offered new treatment opportunities, including pulmonary rehabilitation. It is important to understand the pathophysiology of skeletal muscle dysfunction, in order to design strategies for intervention. A systematic review of the literature (chapter 2) revealed a shift from type I to type II skeletal muscle fibres and an impaired skeletal muscle oxidative capacity of the lower extremities in COPD and other chronic organ diseases. The etiology of skeletal muscle dysfunction is complex and only partially understood. Instead of one leading mechanism, a combination of several disease-related factors and comorbid conditions probably accounts for the alterations described in chapter 2 . These COPDrelated factors include chronic hypoxia ${ }^{1-3}$, oxidative stress ${ }^{4}$, acute and chronic hypercapnia ${ }^{5-7}$ and persistent low-grade systemic inflammation ${ }^{8-10}$. In addition, semi-starvation and deconditioning are two conditions that may very well contribute to skeletal muscle dysfunction in COPD, as was extensively reviewed in chapter 2 . The following section will focus on implications of sarcopenia in COPD.

\section{COPD and sarcopenia: common traits}

\section{Body composition and functional implications}

Sarcopenia, which literally means "poverty of the flesh" in Greek, is used to describe age-related loss in skeletal muscle mass and functioning ${ }^{11}$. Multiple factors are considered to contribute to sarcopenia, including loss of a-motoneuron activity, alterations in endocrine function, a sedentary lifestyle and changes in protein metabolism ${ }^{12}$. Although basal rate of muscle protein synthesis was not reduced in elderly men with muscle loss and net muscle protein balance was similar compared with younger $\operatorname{men}^{13}$, the response of skeletal muscle to endocrine and nutritional stimuli seems impaired 
at advanced age. Insulin is a potent anabolic stimulus for skeletal muscle, primarily by promoting protein synthesis ${ }^{14}$. In the elderly however, muscle protein synthesis is resistant to the anabolic action of insulin, independent of glucose tolerance ${ }^{15}$. Also, responsiveness of muscle protein synthesis to essential amino acid ingestion is diminished in advanced age, independent of insulin signaling ${ }^{16}$. Similar to the age-related adaptations, a substantial proportion of COPD patients suffers from reduced fat-free mass, despite a normal body weight ${ }^{17}$. This subgroup of patients is often referred to as the sarcopenic phenotype of COPD and is characterized by impaired muscle strength ${ }^{18}$, exercise intolerance ${ }^{17}$, poor health status ${ }^{19}$ and increased mortality risk $^{20}$ in comparison to patients with relatively preserved fat-free mass. Since most cross-sectional studies in COPD included age-matched controls, it was hypothesized that an increased rate of aging contributes to the quantitative change in muscle mass in patients with chronic airflow limitation ${ }^{21}$. However, no longitudinal studies have investigated potential differences in rate of development of sarcopenic changes in skeletal muscle between COPD patients and healthy subjects. Considering the possible etiology of accelerated muscle wasting in weight stable COPD patients, a potential role for reduced insulin action on protein metabolism is intriguing. Although hardly studied, available data suggest increased circulating insulin levels in normal-weight COPD patients ${ }^{22,23}$ and decreased insulin sensitivity of glucose metabolism was reported in some of these patients ${ }^{23,24}$. Also, significant disturbances in protein metabolism were observed in patients with COPD. In normal-weight patients, increased whole-body protein breakdown and synthesis were observed ${ }^{25}$, while enhanced myofibrillar protein breakdown was shown in cachectic COPD patients ${ }^{26}$ (chapter 9). The relationship between insulin and protein turnover however has not yet been studied in patients with COPD.

\section{Skeletal muscle morphology and energy metabolism}

As reviewed in chapter 2, pathophysiologic alterations in skeletal muscle in sarcopenia include a decline in the total number of muscle fibres and specific atrophy of type II fibres. Within the group of type II muscle fibres, especially type IIX fibres are subject to age-related atrophy ${ }^{27,28}$. In addition, alterations in the proportion of type I and II muscle fibres have been reported in healthy elderly. However, the exact direction of this shift in fibre type distribution in sarcopenia remains uncertain ${ }^{29,30}$. Furthermore, there is growing evidence for 
reduced oxidative enzyme activity and decline in the rate of mitochondrial protein synthesis with aging ${ }^{31-34}$. Decreased agerelated muscle mitochondrial respiratory capacity ${ }^{35}$ is correlated with a greater increase in the ratio of inorganic phosphate to phosphocreatinine during exercise in elderly compared to younger persons ${ }^{31}$. Also, an age-related shift in fuel use during exercise has also been reported ${ }^{35,36}$. It seems that fat oxidation during moderate intensity exercise is reduced in healthy elderly, while carbohydrate oxidation rate is increased ${ }^{36,37}$.

While substrate metabolism during exercise in patients with COPD will be subject of the second part of this thesis, alterations in skeletal muscle morphology and oxidative capacity that occur in patients with COPD thus show much resemblance to the changes that occur in healthy elderly. These alterations include atrophy of type IIX muscle fibres $^{38}$, a type I-to-II fibre type shift ${ }^{39}$ and reduced oxidative capacity $^{40}$ (chapter 2).

\section{Definition of sarcopenia in COPD}

In patients with COPD, the sarcopenic phenotype is usually defined by reduced fat-free mass in combination with normal or increased body weight, resulting in a relative or absolute increase in body fat mass. The prevalence of fat-free mass depletion in COPD depends on the choice of cut-off values for fat-free mass index (FFMI), defined as fat-free mass standardized for height. Until now, no official guidance for the use of cut-offs for FFMI in COPD patients is available. The traditional Dutch criteria by Schols et al. ${ }^{17}$ suggested a cut point of $15 \mathrm{~kg} \cdot \mathrm{m}^{-2}$ for women and $16 \mathrm{~kg} \cdot \mathrm{m}^{-2}$ for men with COPD. In a more recent study, the lowest 10th percentile of the general COPD population of the Copenhagen City Heart Study was defined as depleted, resulting in a cut-off value of $14.62 \mathrm{~kg} \cdot \mathrm{m}^{-2}$ for women and $17.05 \mathrm{~kg} \cdot \mathrm{m}^{-2}$ for men with COPD ${ }^{20}$. These values compare with the lower limits of normal in the healthy adult Caucasian population, where lower limits of normal of $14.6 \mathrm{~kg} \cdot \mathrm{m}^{-2}$ for women and 16.7 $\mathrm{kg} \cdot \mathrm{m}^{-2}$ for men were identified in subjects with normal body mass index ${ }^{41}$. Compared to the Dutch criteria, the use of the Danish cut-off values results in a decreased prevalence of fat-free mass depletion in female patients and a substantially increased prevalence of low fatfree mass in male patients ${ }^{20}$. In this thesis, the Dutch criteria were used to discriminate between COPD patients with normal and reduced fat-free mass. That may explain some discrepancies in 
description of the COPD phenotypes ranging from cachexia to hidden loss of fat-free mass and sarcopenia.

In addition to a sarcopenic body composition, characterized by low fat-free mass combined with preserved body weight, pulmonary cachexia is commonly observed in patients with COPD and is defined as low fat-free mass in combination with low body weight. Since longitudinal studies on changes in body composition are lacking in COPD, it is currently unknown if sarcopenia and cachexia are truly two different phenotypes of this disease. Also, it is unclear if the mechanisms underlying the loss of fat-free mass are the same in both conditions. Alternatively to the existence of two distinct phenotypes, sarcopenia and cachexia might be different stages in the natural progression of changes in body composition in COPD. Thus, loss of fat-free mass may represent the early stage of pulmonary cachexia, with weight loss as a terminal event.

\section{Accelerated aging in COPD?}

It was earlier hypothesized that accelerated aging contributes to skeletal muscle dysfunction and loss of fat-free mass in COPD $^{21,42}$, but only a few studies directly investigated the relationship between aging and COPD until now. Accelerated senescence of alveolar epithelial and endothelial cells was observed in emphysema patients in comparison to asymptomatic smokers and nonsmokers ${ }^{43}$. Length of telomeres, which are DNA-protein structures located at the end of chromosomes, is considered a marker of cell aging and senescence ${ }^{44}$. Although cigarette smoking causes enhanced shortening of telomere length, no differential effect of smoking on telomere length in circulating lymphocytes was observed in COPD patients and healthy smokers $^{45}$. In addition, decreased levels of human sirtuin (SIRT1) were observed in macrophages and lungs of COPD patients and healthy smokers ${ }^{46}$. Sirtuins are $\mathrm{NAD}^{+}$-dependent deacetylases and mono-ADP-ribosyl transferases that regulate a wide array of proteins involved in energy metabolism, cell survival and DNA repair ${ }^{47,48}$. There is growing evidence for a role of sirtuins in regulation of human aging ${ }^{49}$. Finally, impaired skeletal muscle mitochondrial respiratory function ${ }^{50}$ and reduced mitochondrial number and fractional area in vastus lateralis muscle were reported in COPD patients in comparison to age-matched controls ${ }^{51}$. Decreased activities of the mitochondrial electron transport chain complexes and an increased release of reactive oxygen species from 
mitochondria are well documented with $\mathrm{age}^{52}$. Consequently, mitochondrial dysfunction is considered one of the possible mechanisms underlying biological aging ${ }^{53}$. The observation of disturbed mitochondrial function in patients with COPD enforces the hypothesis of accelerated aging in this disease. However, until now no studies investigated biomarkers of aging in skeletal muscle samples of patients with COPD. In addition, no longitudinal studies comparing changes in skeletal muscle mass or function between healthy elderly and patients with COPD have been performed. In the absence of these studies, the contribution of premature aging to skeletal muscle dysfunction and disturbed energy metabolism in COPD remains hypothetical but intruiging.

\section{Upper versus lower extremity functional capacity in COPD}

The distribution of skeletal muscle dysfunction and exercise intolerance between lower and upper limbs in COPD is yet unknown, since most studies focused on the lower extremities. This is surprising, since many patients experience disabling dyspnoea when performing arm activities. This was partly attributed to dyssynchronous breathing during upper extremity exercise ${ }^{54}$. Differentiation between the various features of upper and lower extremity performance and investigation of the role of body composition may contribute to the understanding of skeletal muscle dysfunction and to the development of muscle group specific interventions in COPD. In chapter 4 upper and lower limb muscle strength and endurance and the relationship with fat-free mass were carefully studied, using a volitional isokinetic testing protocol. Both quadriceps and biceps muscle strength were reduced in COPD patients compared to controls and were equally affected. Fat-free mass was an important predictor of muscle strength, although loss of muscle strength was not limited to cachectic patients. Determinants of functional capacity in COPD were further explored in chapter 5. Independent of fat-free mass, advanced age was negatively related to quadriceps strength and exercise performance. These are important observations, since it was previously suggested that muscle dysfunction is absent in COPD patients with normal fat-free mass $^{55}$. The observation of muscle weakness in COPD patients with normal fat-free mass indicates that screening for skeletal muscle dysfunction should not be restricted to cachectic patients. Since 
muscle dysfunction is associated with poor exercise capacity ${ }^{56}$ and impaired health status ${ }^{57}$, therapies aimed at increasing muscle function should be available not only for patients with low fat-free mass. In particular, sarcopenic COPD patients are at increased risk for undertreatment, since the shift towards reduced fat-free mass and increased fat mass is not easily recognized with traditional anthropometric measurements, consisting of height and weight. Furthermore, the association between age and functional capacity, independent of body composition (chapter 5) suggests a role for aging in the etiology of skeletal muscle dysfunction in COPD.

A preservation of mechanical efficiency and exercise capacity of the upper limbs in patients with COPD was observed in chapter 3. In line with these observations, normal upper limb muscle endurance in COPD was found in chapter 4, while lower limb muscle endurance was impaired. In contrast to muscle strength, endurance and mechanical efficiency of leg and arm muscles were not related to fatfree mass. This suggests that other factors determine muscle endurance and mechanical efficiency in COPD. Indeed, quadriceps endurance correlated with muscle citrate synthase activity and proportion of type I muscle fibres in patients with COPD, indicating that muscular endurance is related to muscle oxidative capacity ${ }^{58}$. Also, cycling efficiency was positively related to the percentage of type I muscle fibres in healthy subjects ${ }^{59,60}$. In COPD patients, a link between decreased mechanical efficiency during maximal single leg knee-extensor and bicycle exercise and increased proportion of type II muscle fibres was also suggested ${ }^{61}$. The potential role of skeletal muscle mitochondrial dysfunction ${ }^{50}$ in metabolic inefficiency in patients with COPD has not been studied.

The uneven distribution of skeletal muscle dysfunction between upper and lower limbs suggests a role for local or muscle specific etiologic factors. A preservation of oxidative capacity and proportion of type I muscle fibres in the upper limbs of patients with COPD $^{62}$ might be the explanation for the maintained muscle endurance and mechanical efficiency in these patients. With regard to this observation, a different training status of lower and upper limb, resulting from a more sedentary lifestyle is probably an important factor and thus exercise training might be beneficial. Indeed, eight weeks of strength training focused on the quadriceps muscle resulted in a significant improvement in mechanical efficiency during submaximal cycle ergometry in patients with severe COPD ${ }^{63}$. It is yet unknown if this increase in mechanical efficiency is the result of a training-induced shift in muscle fibre type distribution towards the 
more fatigue resistant type ${ }^{64}$. Also, Also, the clinical implications of improving mechanical efficiency in COPD have yet to be established. The results of chapter $\mathbf{3}$ and $\mathbf{4}$ clearly indicate a preservation of upper limb functional capacity in patients with COPD. This suggests that in addition to systemic causes of skeletal muscle dysfunction in COPD, such as gas exchange abnormalities and low-grade inflammation, muscle specific adaptations in energy metabolism are important.

\section{Management of sarcopenia in COPD}

Loss of fat-free mass is the result of an imbalance between muscle protein synthesis and breakdown. Several studies suggested a link between increased muscular protein breakdown and reduced fat-free mass in patients with COPD $^{65}$. Increased urinary excretion of pseudouridine, a measure for cellular protein breakdown, was observed in COPD patients with a sarcopenic phenotype in comparison to controls and was related to fat-free mass ${ }^{65}$. In addition, increased expression of atrogin-1 and MuRF1 mRNA in quadriceps muscle of COPD patients with muscle atrophy suggests activation of the ubiquitin-proteasome pathway in these subjects ${ }^{66}$. In the absence of anticatabolic therapies, sarcopenic COPD patients may benefit from anabolic interventions aimed at restoration of fatfree mass and functional capacity. Pulmonary rehabilitation is an evidence-based non-pharmacological treatment for patients with $\mathrm{COPD}^{67}$, aimed at reducing symptoms, improving quality of life and increasing physical and emotional participation in activities of daily life. Physical exercise training, education, nutritional intervention, psychosocial support and patient assessments are essential components of pulmonary rehabilitation ${ }^{68}$.

Traditionally, pulmonary rehabilitation was reserved for COPD patients with severe disease, suffering from disabling dyspnoea, poor exercise tolerance and pulmonary cachexia. However, the results of chapter $\mathbf{4}$ and $\mathbf{5}$ of this thesis indicate that pulmonary rehabilitation should be integrated in the clinical management of all COPD patients with moderate and more severe disease. Significant increases in fatfree mass and body weight were demonstrated after eight weeks of intensive exercise training in normal-weight COPD patients, indicating that whole-body aerobic and muscle exercise induces an anabolic response in these patients (chapter 5). Since fat-free mass is an important determinant of muscle strength (chapter 4) and 
muscle weakness is not restricted to cachectic COPD patients (chapter 4), increasing fat-free mass is expected to be beneficial for all patients. Furthermore, weight gain was previously associated with reduced mortality in low to normal-weight severe COPD patients ${ }^{69}$. The long-term effects of the increase in fat-free mass and body weight observed in chapter $\mathbf{5}$ on functional capacity and prognosis are currently unknown. In addition, the impact on clinically important co-morbid conditions of COPD, including alterations in insulin sensitivity (chapter 7 ) and cardiovascular risk $^{70}$, remains to be studied.

In contrast to "normal" sarcopenia, the contribution of decreased muscle protein synthesis to loss of fat-free mass in normal-weight COPD patients has not been demonstrated. Also, the effects of amino acid suppletion alone or in combination with insulin therapy on skeletal muscle protein turnover are yet unexplored. This kind of intervention may be an interesting supplement to exercise training as an anabolic stimulus in sarcopenic COPD patients.

In chapter $\mathbf{3}$ and $\mathbf{4}$ of this thesis, it was shown that skeletal muscles of the upper limb are less affected by dysfunction and inefficiency than lower limb muscles in COPD. This is an important finding in the wake of pulmonary rehabilitation. Possibly, upper extremities are less deconditioned in COPD patients as a result of competitive recruitment of upper limb and shoulder girdle muscle groups for extremity movement and ventilation. However, the observation of reduced biceps muscle strength in COPD in chapter 4 indicates that these patients may benefit from tailored upper extremity training or occupational therapy embedded in pulmonary rehabilitation. The need for upper extremity conditioning is further emphasized by the impairment of unsupported arm activities in COPD patients ${ }^{71}$ and the importance of arm muscles for many activities of daily living including lifting, washing and combing hair ${ }^{72}$.

Exercise training in combination with dynamic strength training resulted in significant improvements in lower extremity muscle strength and endurance (chapter 4) and peak exercise capacity (chapter 5). However, the impairment in upper extremity muscle strength was not reversed by the comprehensive exercise training programme. This lack of effect on biceps muscle function indicates the specificity of training effects for the muscle groups trained. It was previously shown that lower limb exercise training increased walking distance, while upper limb exercises improved the maximum work load achieved on arm ergometry in patients with COPD ${ }^{72}$. 
In the first part of this thesis, physiological implications of sarcopenia in COPD were demonstrated. In the next part, relationship between substrate metabolism and body composition will be presented. 


\section{References}

1. Hoppeler H, Kleinert E, Schlegel C, Claassen H, Howald H, Kayar SR, Cerretelli P. Morphological adaptations of human skeletal muscle to chronic hypoxia. Int $\mathrm{J}$ Sports Med 1990;11 Suppl 1:S3-9.

2. Hoppeler $\mathrm{H}$, Desplanches $\mathrm{D}$. Muscle structural modifications in hypoxia. Int $J$ Sports Med 1992;13 Suppl 1:S166-168.

3. Howald H, Pette D, Simoneau JA, Uber A, Hoppeler H, Cerretelli P. Effects of chronic hypoxia on muscle enzyme activities. Int J Sports Med 1990;11 Suppl $1: \mathrm{S} 10-14$.

4. Boots AW, Haenen GR, Bast A. Oxidant metabolism in chronic obstructive pulmonary disease. Eur Respir J Supp/ 2003;46:14s-27s.

5. Vianna LG, Koulouris N, Lanigan C, Moxham J. Effect of acute hypercapnia on limb muscle contractility in humans. J Appl Physiol 1990;69:1486-1493.

6. Mador MJ, Wendel T, Kufel TJ. Effect of acute hypercapnia on diaphragmatic and limb muscle contractility. Am J Respir Crit Care Med 1997;155:1590-1595.

7. Gertz I, Hedenstierna G, Hellers G, Wahren J. Muscle metabolism in patients with chronic obstructive lung disease and acute respiratory failure. Clin Sci Mol Med 1977;52:396-403.

8. Yende S, Waterer GW, Tolley EA, Newman AB, Bauer DC, Taaffe DR, Jensen R, Crapo $R$, Rubin $S$, Nevitt $M$, et al. Inflammatory markers are associated with ventilatory limitation and muscle dysfunction in obstructive lung disease in well functioning elderly subjects. Thorax 2006;61:10-16.

9. Broekhuizen R, Wouters EF, Creutzberg EC, Schols AM. Raised CRP levels mark metabolic and functional impairment in advanced COPD. Thorax 2006;61:17-22.

10. Pinto-Plata VM, Mullerova H, Toso JF, Feudjo-Tepie M, Soriano JB, Vessey RS, Celli BR. C-reactive protein in patients with COPD, control smokers and nonsmokers. Thorax 2006;61:23-28.

11. Morley JE, Baumgartner RN, Roubenoff R, Mayer J, Nair KS. Sarcopenia. J Lab Clin Med 2001;137:231-243.

12. Thomas DR. Loss of skeletal muscle mass in aging: Examining the relationship of starvation, sarcopenia and cachexia. Clin Nutr 2007;26:389-399.

13. Volpi E, Sheffield-Moore M, Rasmussen BB, Wolfe RR. Basal muscle amino acid kinetics and protein synthesis in healthy young and older men. Jama 2001;286:1206-1212.

14. Biolo G, Declan Fleming RY, Wolfe RR. Physiologic hyperinsulinemia stimulates protein synthesis and enhances transport of selected amino acids in human skeletal muscle. J Clin Invest 1995;95:811-819.

15. Rasmussen BB, Fujita S, Wolfe RR, Mittendorfer B, Roy M, Rowe VL, Volpi E. Insulin resistance of muscle protein metabolism in aging. Faseb $J$ 2006;20: 768-769.

16. Cuthbertson D, Smith K, Babraj J, Leese G, Waddell T, Atherton P, Wackerhage $\mathrm{H}$, Taylor PM, Rennie MJ. Anabolic signaling deficits underlie amino acid resistance of wasting, aging muscle. Faseb J 2005;19:422-424.

17. Schols AM, Soeters PB, Dingemans AM, Mostert R, Frantzen PJ, Wouters EF. Prevalence and characteristics of nutritional depletion in patients with stable COPD eligible for pulmonary rehabilitation. Am Rev Respir Dis 1993;147:11511156.

18. Engelen MP, Schols AM, Does JD, Wouters EF. Skeletal muscle weakness is associated with wasting of extremity fat- free mass but not with airflow obstruction in patients with chronic obstructive pulmonary disease. Am J Clin Nutr $2000 ; 71: 733-738$. 
19. Mostert R, Goris A, Weling-Scheepers C, Wouters EF, Schols AM. Tissue depletion and health related quality of life in patients with chronic obstructive pulmonary disease. Respir Med 2000;94:859-867.

20. Vestbo J, Prescott E, Almdal T, Dahl M, Nordestgaard BG, Andersen T, Sorensen TI, Lange P. Body mass, fat-free body mass, and prognosis in patients with chronic obstructive pulmonary disease from a random population sample: Findings from the Copenhagen City Heart Study. Am J Respir Crit Care Med 2006;173:79-83.

21. Steiner MC. Sarcopaenia in chronic obstructive pulmonary disease. Thorax 2007;62:101-103.

22. Engelen MP, Wouters EF, Deutz NE, Menheere PP, Schols AM. Factors contributing to alterations in skeletal muscle and plasma amino acid profile in patients with chronic obstructive pulmonary disease. Am J Clin Nutr 2000;72:1480-1487.

23. Koehler F, Doehner W, Hoernig S, Witt C, Anker SD, John M. Anorexia in chronic obstructive pulmonary disease - association to cachexia and hormonal derangement. Int J Cardiol 2007;119:83-89.

24. Bolton CE, Evans M, Ionescu AA, Edwards SM, Morris RH, Dunseath G, Luzio SD, Owens DR, Shale DJ. Insulin resistance and inflammation - a further systemic complication of COPD. COPD 2007;4:121-126.

25. Engelen MP, Deutz NE, Wouters EF, Schols AM. Enhanced levels of whole-body protein turnover in patients with chronic obstructive pulmonary disease. Am J Respir Crit Care Med 2000;162:1488-1492.

26. Rutten EP, Franssen FM, Engelen MP, Wouters EF, Deutz NE, Schols AM. Greater whole-body myofibrillar protein breakdown in cachectic patients with chronic obstructive pulmonary disease. Am J Clin Nutr 2006;83:829-834.

27. Grimby G, Danneskiold-Samsoe B, Hvid K, Saltin B. Morphology and enzymatic capacity in arm and leg muscles in 78-81 year old men and women. Acta Physiol Scand 1982;115:125-134.

28. Aniansson A, Hedberg M, Henning GB, Grimby G. Muscle morphology, enzymatic activity, and muscle strength in elderly men: A follow-up study. Muscle Nerve 1986;9:585-591.

29. Larsson L, Sjodin B, Karlsson J. Histochemical and biochemical changes in human skeletal muscle with age in sedentary males, age 22--65 years. Acta Physiol Scand 1978;103:31-39.

30. Frontera WR, Hughes VA, Fielding RA, Fiatarone MA, Evans WJ, Roubenoff R. Aging of skeletal muscle: A 12-yr longitudinal study. J Appl Physiol 2000;88:1321-1326.

31. Coggan AR, Abduljalil AM, Swanson SC, Earle MS, Farris JW, Mendenhall LA, Robitaille PM. Muscle metabolism during exercise in young and older untrained and endurance-trained men. J Appl Physiol 1993;75:2125-2133.

32. Houmard JA, Weidner ML, Gavigan KE, Tyndall GL, Hickey MS, Alshami A. Fiber type and citrate synthase activity in the human gastrocnemius and vastus lateralis with aging. J Appl Physiol 1998;85:1337-1341.

33. Rooyackers OE, Adey DB, Ades PA, Nair KS. Effect of age on in vivo rates of mitochondrial protein synthesis in human skeletal muscle. Proc Natl Acad Sci U S A 1996;93:15364-15369.

34. Papa S. Mitochondrial oxidative phosphorylation changes in the life span. Molecular aspects and physiopathological implications. Biochim Biophys Acta 1996;1276:87-105.

35. Meredith CN, Frontera WR, Fisher EC, Hughes VA, Herland JC, Edwards J, Evans WJ. Peripheral effects of endurance training in young and old subjects. $J$ Appl Physiol 1989;66:2844-2849.

36. Sial S, Coggan AR, Carroll R, Goodwin J, Klein S. Fat and carbohydrate metabolism during exercise in elderly and young subjects. Am J Physiol 1996;271:E983-989. 
37. Mittendorfer B, Klein S. Effect of aging on glucose and lipid metabolism during endurance exercise. Int J Sport Nutr Exerc Metab 2001;11 Suppl:S86-91.

38. Gosker HR, Engelen MP, van Mameren H, van Dijk PJ, van der Vusse GJ, Wouters $E F$, Schols AM. Muscle fibre type IIx atrophy is involved in the loss of fat-free mass in chronic obstructive pulmonary disease. Am J Clin Nutr 2002;76:113-119.

39. Whittom F, Jobin J, Simard PM, Leblanc P, Simard C, Bernard S, Belleau R, Maltais F. Histochemical and morphological characteristics of the vastus lateralis muscle in patients with chronic obstructive pulmonary disease. Medicine and science in sports and exercise 1998;30:1467-1474.

40. Maltais F, Simard AA, Simard C, Jobin J, Desgagnes P, LeBlanc P. Oxidative capacity of the skeletal muscle and lactic acid kinetics during exercise in normal subjects and in patients with COPD. Am J Respir Crit Care Med 1996;153: 288-293.

41. Kyle UG, Schutz Y, Dupertuis YM, Pichard C. Body composition interpretation. Contributions of the fat-free mass index and the body fat mass index. Nutrition 2003;19:597-604.

42. Vogelmeier C, Bals R. Chronic obstructive pulmonary disease and premature aging. Am J Respir Crit Care Med 2007;175:1217-1218.

43. Tsuji T, Aoshiba K, Nagai A. Alveolar cell senescence in patients with pulmonary emphysema. Am J Respir Crit Care Med 2006;174:886-893.

44. Epel ES, Blackburn EH, Lin J, Dhabhar FS, Adler NE, Morrow JD, Cawthon RM. Accelerated telomere shortening in response to life stress. Proc Natl Acad Sci U S A 2004;101:17312-17315.

45. Morla M, Busquets X, Pons J, Sauleda J, MacNee W, Agusti AG. Telomere shortening in smokers with and without COPD. Eur Respir J 2006;27:525-528.

46. Rajendrasozhan S, Yang SR, Kinnula VL, Rahman I. Sirt1, an antiinflammatory and antiaging protein, is decreased in lungs of patients with chronic obstructive pulmonary disease. Am J Respir Crit Care Med 2008;177:861-870.

47. Michan S, Sinclair D. Sirtuins in mammals: Insights into their biological function. Biochem J 2007;404:1-13.

48. Whittle JR, Powell MJ, Popov VM, Shirley LA, Wang C, Pestell RG. Sirtuins, nuclear hormone receptor acetylation and transcriptional regulation. Trends Endocrinol Metab 2007; 18:356-364.

49. Bellizzi D, Rose G, Cavalcante P, Covello G, Dato S, De Rango F, Greco V, Maggiolini M, Feraco E, Mari V, et al. A novel VNTR enhancer within the sirt3 gene, a human homologue of sir2, is associated with survival at oldest ages. Genomics 2005;85:258-263.

50. Rabinovich RA, Bastos R, Ardite E, Llinas L, Orozco-Levi M, Gea J, Vilaro J, Barbera JA, Rodriguez-Roisin R, Fernandez-Checa JC, et al. Mitochondrial dysfunction in COPD patients with low body mass index. Eur Respir $J$ 2007;29:643-650.

51. Gosker HR, Hesselink MK, Duimel H, Ward KA, Schols AM. Reduced mitochondrial density in the vastus lateralis muscle of patients with COPD. Eur Respir $J$ 2007;30:73-79.

52. Conley KE, Marcinek DJ, Villarin J. Mitochondrial dysfunction and age. Curr Opin Clin Nutr Metab Care 2007;10:688-692.

53. Figueiredo PA, Mota MP, Appell HJ, Duarte JA. The role of mitochondria in aging of skeletal muscle. Biogerontology 2008;9:67-84.

54. Celli BR, Rassulo J, Make BJ. Dyssynchronous breathing during arm but not leg exercise in patients with chronic airflow obstruction. N Engl J Med 1986; 314:1485-1490.

55. Heijdra YF, Pinto-Plata V, Frants R, Rassulo J, Kenney L, Celli BR. Muscle strength and exercise kinetics in COPD patients with a normal fat-free mass index are comparable to control subjects. Chest 2003;124:75-82. 
56. Gosselink R, Troosters $T$, Decramer M. Peripheral muscle weakness contributes to exercise limitation in COPD. Am J Respir Crit Care Med 1996;153:976-980.

57. Simpson K, Killian K, McCartney N, Stubbing DG, Jones NL. Randomised controlled trial of weightlifting exercise in patients with chronic airflow limitation. Thorax 1992;47:70-75.

58. Allaire J, Maltais F, Doyon JF, Noel M, LeBlanc P, Carrier G, Simard C, Jobin J. Peripheral muscle endurance and the oxidative profile of the quadriceps in patients with COPD. Thorax 2004;59:673-678.

59. Coyle EF, Sidossis LS, Horowitz JF, Beltz JD. Cycling efficiency is related to the percentage of type I muscle fibres. Medicine and science in sports and exercise $1992 ; 24: 782-788$.

60. Umberger BR, Gerritsen KG, Martin PE. Muscle fibre type effects on energetically optimal cadences in cycling. Journal of biomechanics 2006;39:1472-1479.

61. Richardson RS, Leek BT, Gavin TP, Haseler LJ, Mudaliar SR, Henry R, MathieuCostello $\mathrm{O}$, Wagner PD. Reduced mechanical efficiency in chronic obstructive pulmonary disease but normal peak $\mathrm{V}^{\prime} \mathrm{O}_{2}$ with small muscle mass exercise. $A m \mathrm{~J}$ Respir Crit Care Med 2004;169:89-96.

62. Gea JG, Pasto M, Carmona MA, Orozco-Levi M, Palomeque J, Broquetas J. Metabolic characteristics of the deltoid muscle in patients with chronic obstructive pulmonary disease. Eur Respir J 2001;17:939-945.

63. Hoff J, Tjonna AE, Steinshamn S, Hoydal M, Richardson RS, Helgerud J. Maximal strength training of the legs in COPD: A therapy for mechanical inefficiency. Medicine and science in sports and exercise 2007;39:220-226.

64. Staron RS, Karapondo DL, Kraemer WJ, Fry AC, Gordon SE, Falkel JE, Hagerman FC, Hikida RS. Skeletal muscle adaptations during early phase of heavyresistance training in men and women. J Appl Physiol 1994;76:1247-1255.

65. Bolton CE, Broekhuizen R, Ionescu AA, Nixon LS, Wouters EF, Shale DJ, Schols AM. Cellular protein breakdown and systemic inflammation are unaffected by pulmonary rehabilitation in COPD. Thorax 2007;62:109-114.

66. Doucet $M$, Russell AP, Leger $B$, Debigare $R$, Joanisse DR, Caron MA, Leblanc $P$, Maltais $\mathrm{F}$. Muscle atrophy and hypertrophy signalling in patients with chronic obstructive pulmonary disease. Am J Respir Crit Care Med 2007.

67. Rabe KF, Hurd S, Anzueto A, Barnes PJ, Buist SA, Calverley P, Fukuchi Y, Jenkins $C$, Rodriguez-Roisin $R$, van Weel $C$, et al. Global strategy for the diagnosis, management, and prevention of chronic obstructive pulmonary disease: GOLD executive summary. Am J Respir Crit Care Med 2007;176:532-555.

68. Nici L, Donner C, Wouters E, Zuwallack R, Ambrosino N, Bourbeau J, Carone M, Celli B, Engelen M, Fahy B, et al. American Thoracic Society/European Respiratory Society statement on pulmonary rehabilitation. Am J Respir Crit Care Med 2006;173:1390-1413.

69. Prescott $\mathrm{E}$, Almdal T, Mikkelsen $\mathrm{KL}$, Tofteng $\mathrm{CL}$, Vestbo J, Lange P. Prognostic value of weight change in chronic obstructive pulmonary disease: Results from the Copenhagen City Heart Study. Eur Respir J 2002;20:539-544.

70. Sin DD, Wu L, Man SF. The relationship between reduced lung function and cardiovascular mortality: A population-based study and a systematic review of the literature. Chest 2005;127:1952-1959.

71. Baarends EM, Schols AM, Slebos DJ, Mostert R, Janssen PP, Wouters EF. Metabolic and ventilatory response pattern to arm elevation in patients with COPD and healthy age-matched subjects. Eur Respir J 1995;8:1345-1351.

72. Lake FR, Henderson K, Briffa T, Openshaw J, Musk AW. Upper-limb and lowerlimb exercise training in patients with chronic airflow obstruction. Chest 1990; 97:1077-1082. 



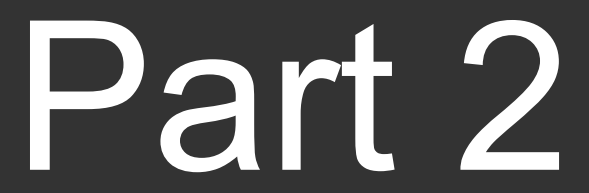

Substrate metabolism in relation to sarcopenia in COPD 



\section{Chapter 7}

\section{Increased postabsorptive and}

exercise-induced whole-body glucose production in patients with chronic obstructive pulmonary disease
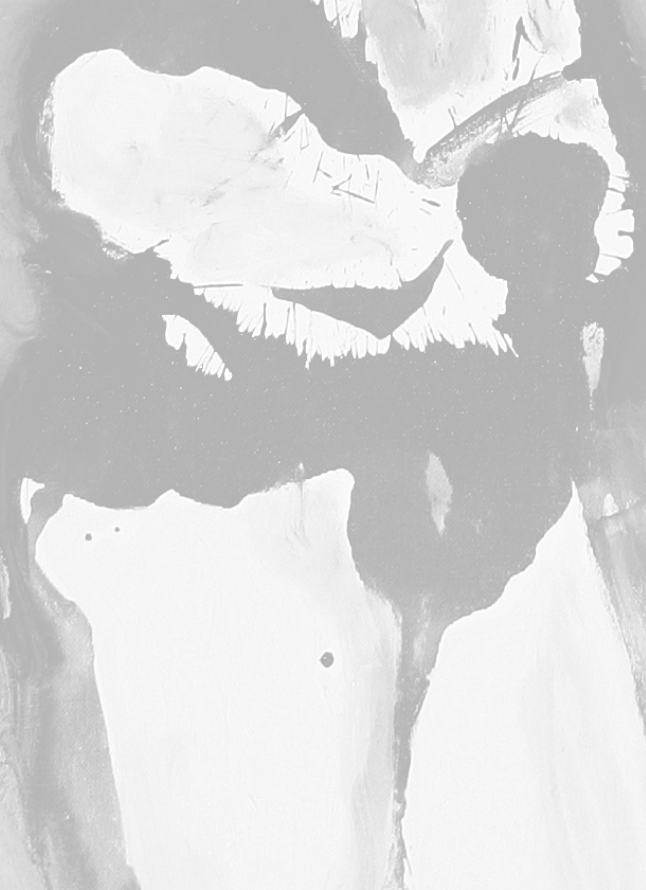

Frits M.E. Franssen, Hans P. Sauerwein, Mariette T. Ackermans, Erica P.A. Rutten, Emiel F.M. Wouters, Annemie M.W.J. Schols Submitted 


\section{Abstract}

\section{Introduction}

Muscle biopsy and ${ }^{31} \mathrm{P}$-nuclear magnetic resonance studies have consistently shown decreased oxidative capacity in patients with moderate to severe chronic obstructive pulmonary disease (COPD). Limited information is available regarding potential adaptations or abnormalities in anaerobic metabolism and intermediary glucose metabolism.

\section{Methods}

Using stable isotope tracer methodology, glucose metabolism was assessed at rest and during exercise in COPD patients with moderate disease severity ( $\mathrm{FEV}_{1}: 52 \pm 3 \%$ ), prestratified into normal $\left(n=7, B M I: 27.5 \pm 0.9 \mathrm{~kg} \cdot \mathrm{m}^{-2}\right)$ and underweight subjects $(n=6$, BMI: $20.6 \pm 0.7 \mathrm{~kg} \cdot \mathrm{m}^{-2}$ ) and in 8 healthy controls matched for age and BMI with the normal-weight COPD group. Glucose tolerance was normal in all subjects. Rate of appearance $\left(R_{a}\right)$ of glucose at rest and during submaximal cycling exercise was measured by infusion of $\left[6,6-{ }^{2} \mathrm{H}_{2}\right]$ glucose in postabsorptive state and expressed per $\mathrm{kg}$ fat-free mass.

\section{Results}

Resting glucose $R_{a}$ was significantly enhanced in COPD compared to controls $\left(16.4 \pm 0.4 \mu \mathrm{mol} \cdot \mathrm{kgFFM}^{-1} \cdot \mathrm{min}^{-1}\right.$ versus $\left.15.1 \pm 0.4 \mu \mathrm{mol} \cdot \mathrm{kgFFM}^{-1} \cdot \mathrm{min}^{-1}, \mathrm{p}<0.05\right)$ and was inversely related to fat-free mass $(r=-0.75, p<0.01)$ Also, the exercise-induced increase in glucose $R_{a}$ was enhanced in COPD $(81.9 \pm 3.4 \%$ versus $72.1 \pm 2.0 \%$, $p=0.05)$, resulting in elevated end-of-exercise glucose output. Differences were most pronounced in the underweight COPD group, which was characterized by enhanced plasma catecholamine levels and decreased insulin concentrations (all: $p<0.05$ ). In normal-weight patients, there was evidence for decreased insulin sensitivity assessed by homeostatic modelling technique.

\section{Conclusions}

Whole-body glucose production is increased in clinically stable COPD patients with normal glucose tolerance. It is hypothesized that epiphenomena of COPD such as reduced skeletal muscle oxidative capacity, relative hypoxemia and sympathetic activation contribute to this observation. 


\section{Introduction}

${ }^{31} \mathrm{P}$-Nuclear magnetic resonance ${ }^{1}$ as well as muscle biopsy studies ${ }^{2}$ have shown a reduced skeletal muscle fat oxidative capacity and abnormal mitochondrial function in patients with chronic obstructive pulmonary disease (COPD) but implications for glucose metabolism are yet unknown. These may be relevant since the risk for cardiovascular mortality is significantly increased in COPD $^{3}$, which could be related to insulin resistance in these patients, as was recently suggested ${ }^{4}$. Hypoxemia ${ }^{5}$, loss of lean body mass $^{6}$, neurohumoral activation ${ }^{7}$, a pro-inflammatory state $^{8}$ and medications, such as glucocorticosteroids, are known to influence glucose metabolism. We therefore hypothesized that COPD patients, even with normal glucose tolerance, are at increased risk for disturbances in intermediary glucose metabolism.

In the present study, glucose metabolism, measured by whole-body glucose production and concentration and plasma levels of hormones involved in glucose homeostasis, was assessed in COPD patients and controls. Since disturbances in intermediary metabolism might contribute to changes in body composition in COPD (i.e. ratio of fat versus fat-free mass) and body composition itself is a determinant of glucose output, potential alterations in glucose metabolism were studied in both normal-weight as well as underweight COPD patients. Submaximal bicycle exercise was used as a stimulus to endogenous glucose production in order to augment potential small disturbances at rest.

\section{Methods}

\section{Study population}

Patients were recruited at the outpatient department for respiratory disease of the University Hospital Maastricht, while the control group was recruited from an advertisement in a local newspaper. All subjects were men. Patients fulfilled the criteria for COPD according to American Thoracic Society guidelines ${ }^{9}$ and suffered from chronic irreversible airflow obstruction, defined as forced expiratory volume in one second $\left(\mathrm{FEV}_{1}\right)$ less than $70 \%$ of predicted and less than $10 \%$ improvement in $\mathrm{FEV}_{1}$ compared to baseline after inhalation of a $\beta_{2}-$ agonist. An oral glucose tolerance test was performed in 16 COPD patients and nine controls. Three patients and one control subject 
dropped out of the study because of abnormal values, as defined below. For subgroup analysis, the COPD group was divided into a group of seven patients with a body mass index (BMI) comparable to the control group and a comparable group of patients with a significantly lower BMI. None of the patients exhibited chronic respiratory insufficiency, defined as $\mathrm{P}_{\mathrm{a}} \mathrm{O}_{2}<7,3 \mathrm{kPa}$, or received supplemental oxygen therapy. To ensure a homogeneous group of COPD patients without comorbidity in order to study altered glucose metabolism as primary defect, subjects with a history of diabetes mellitus type I or II, thyroid or other endocrine disorders, recent weight loss, malignancies, clinically apparent heart failure, renal, hepatic or other gastro-intestinal disease or recent surgery were excluded. Furthermore, none of the subjects used oral glucocorticosteroids as maintenance treatment or suffered from respiratory tract infection or exacerbation within a 4-week period prior to the study. Patients were using the following pulmonary maintenance medications: inhaled short- and long-acting $B_{2}$-adrenoceptor agonists, 54\%; anticholinergics by inhalation, 54\%; combined inhalers of short-acting $B_{2}$-adrenoceptor agonists and short-acting anticholinergics, $8 \%$; inhalation corticosteroids, $8 \%$; combined inhalers of sympathicomimetics and corticosteroids, $46 \%$; xanthines, $31 \%$; and oral $\mathrm{N}$-acetylcysteine, $23 \%$. There was no significant difference in the use of pulmonary medications between COPD subgroups. Written informed consent was obtained from all subjects and the study was approved by the medical ethical committee of the University Hospital Maastricht.

\section{Study design}

The study was performed at the outpatient metabolic ward on two separate mornings in all subjects. On the first visit, an oral glucose tolerance test was carried out, followed by a medical history and examination, measurement of body composition, lung function testing and determination of exercise capacity. The second part of the study consisted of the glucose stable isotope tracer protocol, as described below. On this second morning of the study, pulmonary maintenance medications were suspended in order to avoid potential acute medication effects on glucose metabolism.

\section{Oral glucose tolerance test}

After an overnight fast, an oral glucose tolerance test (OGTT) was performed in 16 COPD patients and nine controls. On the three days 
prior to testing, subjects were allowed unrestricted diet with a minimal carbohydrate intake of $150 \mathrm{~g} \cdot \mathrm{day}^{-1}$, in order to obtain the best reproducibility of the test and to minimize falsely abnormal results. Dietary history of the previous days was obtained on the morning of the test. A cannula was placed in an anticubital vein of the arm for blood sampling in the fasting state and 120 minutes after ingestion of a standardized dose of $83.5 \mathrm{gram}$ of dextrose monohydrate diluted to $250 \mathrm{ml}$ with water. The solution was consumed within a 5 minute period. During the OGTT no physical activity was allowed and subjects rested on a chair. According to WHO criteria for diagnosis of diabetes mellitus and glucose intolerance ${ }^{10}$, a fasting blood glucose level $>7,8 \mathrm{mmol} \cdot \cdot^{-1}$ or a two hours postload glucose concentration $>11,1 \mathrm{mmol}^{-1}$ were considered as an indication for the presence of diabetes mellitus. Glucose intolerance was defined as a two hours post load glucose concentration in the range $7,8-11,1 \mathrm{mmol}^{-1}$. Only subjects with normal glucose tolerance were allowed to participate in the second part of the study (Table 7.1).

\section{Body composition}

Body height was determined to the nearest $0.5 \mathrm{~cm}$ with subjects standing barefoot. Body weight (BW) was measured with a beam scale (SECA, Hamburg, Germany) without shoes and in light clothing to the nearest $0.1 \mathrm{~kg}$. Body mass index was calculated as the ratio of weight to height in meters squared. Fat-free mass (FFM) was measured by bioelectrical impedance analysis at a spectrum of 48 frequencies ranging from 5 to $500 \mathrm{kHz}$ (Xitron 4000b, Xitron technologies, San Diego, California, USA). Resistance was measured in supine position at the right side as described by Lukaski ${ }^{11}$. In subjects with COPD, FFM was estimated from impedance measurements using the sex-specific regression equation described by Steiner ${ }^{12}$, while the equation of Dey ${ }^{13}$ was used for the healthy elderly controls. Fat-free mass index (FFMI) was calculated as the ratio of FFM to height in meters squared.

\section{Pulmonary function}

Lung function testing included spirometry before and after inhalation of a $B_{2}$-agonist for determination of $\mathrm{FEV}_{1}$ and forced vital capacity (FVC). The highest value of at least three measurements was used. Diffusing capacity for carbon monoxide $\left(\mathrm{DL}_{\mathrm{co}}\right)$ was measured by the single-breath method (MasterLab Transfer, Jaeger, Würzburg, 
Germany). Total lung capacity (TLC) and residual volume (RV) were measured by whole-body plethysmography (MasterLab Body, Jaeger, Würzburg, Germany). All values were expressed as a percentage of predicted ${ }^{14}$. In patients blood was drawn from the radial artery at rest on the morning of the tracer study. Arterial oxygen tension $\left(\mathrm{P}_{\mathrm{a}} \mathrm{O}_{2}\right)$ and carbon dioxide tension $\left(\mathrm{P}_{\mathrm{a}} \mathrm{CO}_{2}\right)$ were determined on a blood gas analyzer (ABL 700, Radiometer, Copenhagen, Denmark).

Table 7.1. Baseline characteristics of the study groups (mean \pm SEM).

\begin{tabular}{|c|c|c|c|c|}
\hline & $\begin{array}{l}\text { Controls } \\
\qquad(n=8)\end{array}$ & $\begin{array}{c}\text { COPD } \\
\text { All } \\
(n=13)\end{array}$ & $\begin{array}{c}\text { COPD } \\
\text { normal BMI } \\
(n=7)\end{array}$ & $\begin{array}{c}\text { COPD } \\
\text { reduced BMI } \\
(n=6)\end{array}$ \\
\hline Age, yr & $65 \pm 2$ & $67 \pm 3$ & $64 \pm 4$ & $70 \pm 4$ \\
\hline \multicolumn{5}{|l|}{ Body composition } \\
\hline Height, cm & $175.1 \pm 2.3$ & $170.7 \pm 1.4$ & $172.9 \pm 1.9$ & $168.1 \pm 1.5^{\mathrm{a}}$ \\
\hline Weight, kg & $83.9 \pm 5.1$ & $71.3 \pm 4.0$ & $82.5 \pm 3.5$ & $58.2 \pm 2.1^{\mathrm{c}, \mathrm{e}}$ \\
\hline $\mathrm{BMI}, \mathrm{kg} \cdot \mathrm{m}^{-2}$ & $27.3 \pm 1.4$ & $24.3 \pm 1.1$ & $27.5 \pm 0.9$ & $20.6 \pm 0.7^{c, f}$ \\
\hline FFM, kg & $61.8 \pm 2.5$ & $51.1 \pm 2.1^{b}$ & $56.1 \pm 2.4$ & $45.3 \pm 1.5^{c, e}$ \\
\hline $\mathrm{FFMI}, \mathrm{kg} \cdot \mathrm{m}^{-2}$ & $20.1 \pm 0.7$ & $17.5 \pm 0.6^{a}$ & $18.8 \pm 0.8$ & $16.0 \pm 0.4^{c, d}$ \\
\hline $\mathrm{FM}, \mathrm{kg}$ & $22.1 \pm 3.0$ & $20.2 \pm 2.5$ & $26.4 \pm 2.9$ & $12.9 \pm 0.8^{\mathrm{a}, \mathrm{e}}$ \\
\hline $\mathrm{FMI}, \mathrm{kg} \cdot \mathrm{m}^{-2}$ & $7.1 \pm 0.9$ & $6.8 \pm 0.8$ & $8.8 \pm 0.9$ & $4.6 \pm 0.3^{a, e}$ \\
\hline \multicolumn{5}{|l|}{ Lung function } \\
\hline $\mathrm{FEV}_{1}, \%$ predicted & $103 \pm 4$ & $52 \pm 3^{c}$ & $53 \pm 5^{c}$ & $51 \pm 5^{c}$ \\
\hline $\mathrm{DL}_{\mathrm{co}}, \%$ predicted & $113 \pm 6$ & $62 \pm 4^{c}$ & $62 \pm 7^{c}$ & $62 \pm 4^{c}$ \\
\hline RV, \%predicted & $111 \pm 8$ & $150 \pm 11^{\mathrm{a}}$ & $124 \pm 10$ & $180 \pm 12^{\mathrm{c}, \mathrm{e}}$ \\
\hline $\mathrm{P}_{\mathrm{a}} \mathrm{O}_{2}, \mathrm{kPa}$ & - & $8.5 \pm 7.4$ & $8.5 \pm 7.4$ & $8.5 \pm 7.8$ \\
\hline $\mathrm{P}_{\mathrm{a}} \mathrm{CO}_{2}, \mathrm{kPa}$ & - & $5.1 \pm 0.2$ & $5.1 \pm 0.2$ & $5.1 \pm 0.1$ \\
\hline \multicolumn{5}{|l|}{ Functional capacity } \\
\hline Peak work rate, $\mathrm{W}$ & $220 \pm 23$ & $74 \pm 7^{c}$ & $83 \pm 11^{c}$ & $65 \pm 6^{c}$ \\
\hline$\dot{\mathrm{V}}_{2 \max }, \mathrm{ml} \cdot \mathrm{min}^{-1}$ & $2522 \pm 167$ & $1266 \pm 86^{c}$ & $1409 \pm 133^{c}$ & $1099 \pm 55^{c}$ \\
\hline \multicolumn{5}{|l|}{ OGTT } \\
\hline Glucose $T_{0}, \mathrm{mmol}^{-1}$ & $5.8 \pm 0.2$ & $5.7 \pm 0.3$ & $5.9 \pm 0.5$ & $5.4 \pm 0.3$ \\
\hline Glucose $T_{2}, \mathrm{mmol} \cdot \mathrm{l}^{-1}$ & $4.8 \pm 0.6$ & $6.4 \pm 1.0$ & $7.1 \pm 1.7$ & $5.6 \pm 0.5$ \\
\hline
\end{tabular}

BMI: body mass index; FFM: fat-free mass, assessed by bioelectrical impedance analysis; FFMI: fat-free mass index; FM: fat mass; FMI: fat mass index; $F E V_{1}$ : forced expiratory volume in one second; $\mathrm{DL}_{\mathrm{co}}$ : diffusing capacity for carbon monoxide; RV: residual volume; $\mathrm{P}_{\mathrm{a}} \mathrm{O}_{2}$ : arterial oxygen tension; $\mathrm{P}_{\mathrm{a}} \mathrm{CO}_{2}$ : arterial carbon dioxide tension; $\dot{\mathrm{V}}_{2 \text { max }}$ : maximal oxygen consumption. OGTT: oral glucose tolerance test. $\mathrm{T}_{0}$ : fasting plasma concentration; $\mathrm{T}_{2}$ : plasma concentration two hours after oral glucose load. Significance of differences between COPD patients and controls is indicated as: ${ }^{a}$ : $\mathrm{p}<0.05,{ }^{b}: \mathrm{p}<0.01,{ }^{c}$ : $\mathrm{p}<0.001$. Significant differences between COPD patients matched for BMI and patients with a reduced BMI are shown as: ${ }^{d}: p<0.05,{ }^{e} p<0.01$ and ${ }^{\mathrm{f}} \mathrm{p}<0.001$. 


\section{Exercise capacity}

All subjects performed an incremental exercise test on an electrically braked cycle ergometer (Corival 400, Lode, Groningen, The Netherlands) under supervision of a physician. Before the start of the test, while seated on the cycle ergometer, ventilation characteristics at rest were analysed during two minutes. During the entire exercise test, expired gases were investigated using breath-by-breath analysis through a breathing mask (Oxycon Beta, Jaeger, Würzburg, Germany). Heart rate, blood pressure and percutaneous oxygen saturation were monitored. After one minute of unloaded cycling, power was increased by $10 \mathrm{~W}$ every minute in patients. For the control subjects, the load was increased with 15 to $25 \mathrm{~W}$ every minute, so that the length of the exercise test was comparable for patients and controls. None of the subjects knew the exercise load and all were encouraged to cycle at 60 revolutions $\cdot \mathrm{min}^{-1}$ until exhaustion. Peak work load $\left(\mathrm{W}_{\max }\right)$ and peak oxygen consumption $\left(\dot{\mathrm{VO}}_{2 \max }\right)$ were used in the analysis.

\section{Basic principles of stable isotope tracer methodology}

Isotopes are atoms with a slightly different weight than the naturally abundant atoms of a chemical element, due to a differing number of neutrons. For example, the $\left[6,6-{ }^{2} \mathrm{H}_{2}\right]$ glucose isotope refers to a stable molecule of glucose in which the 6 carbon position is labelled with two hydrogens that are enriched with atoms of mass two (deuterium). Since the different number of neutrons in the atom does not affect the chemical properties of the molecule, a stable isotope will show identical endogenous kinetics as the naturally abundant form of the molecule. The difference in molecule weight enables detection by mass spectrometry and determination of plasma substrate enrichment, i.e. the ratio between stable isotope tracer and tracee (endogenous substrate). Continuous infusion of a stable isotope tracer in steady state conditions in vivo enables calculation of substrate kinetics, i.e. rate of appearance (endogenous production and exogenous infusion) and rate of disappearance (irreversible tissue uptake and loss) by analysis of plasma substrate enrichment.

\section{Glucose stable isotope tracer protocol}

After an overnight fast, subjects reported at the laboratory at 07.30 $\mathrm{h}$ and were studied at rest in the supine position. A teflon catheter 
was inserted into a forearm vein for isotope infusion and a second catheter for sampling of arterialized venous blood was placed retrograde in a dorsal hand vein of the contralateral arm and maintained at $60^{\circ} \mathrm{C}$ in a thermoregulated box. At $08.00 \mathrm{~h}$, after taking a blood sample for background enrichment of plasma glucose, subjects were administered a single intravenous dose of [6,6${ }^{2} \mathrm{H}_{2}$ ]glucose $\left(17.6 \mu \mathrm{mol} \cdot \mathrm{kgBW}^{-1}\right.$, >99\% enriched; Cambridge Isotopes Inc, Andover, Massachusetts, USA) in order to prime the glucose pool. Thereafter $(t=0)$, a continuous infusion of $\left[6,6-{ }^{2} \mathrm{H}_{2}\right]$ glucose $\left(0.22 \mu \mathrm{mol} \cdot \mathrm{kgBW}^{-1} \cdot \mathrm{min}^{-1}\right)$ dissolved in $0.9 \%$ saline was started via a calibrated pump (IVAC 560, San Diego, California, USA). Blood samples were taken at $\mathrm{t}=110$ and 120 minutes. The exact infusion rate in each experiment was determined by measuring the glucose concentration and enrichment in the infusate. At $t=120$ minutes COPD patients started to exercise on a cycle ergometer at a workload of $50 \% \mathrm{~W}_{\max }$ for 20 minutes, while controls exercised at an identical absolute work load $\left(30 \mathrm{~W}=50 \%\right.$ of mean $\mathrm{W}_{\max }$ in COPD patients) for the same duration. Blood samples were drawn at $t=125,130,135$ and 140 minutes. The protocol continued with one hour recovery period, during which blood samples were taken at $\mathrm{t}=155,170,185$ and 200 minutes. Thereafter, controls performed a second 20 minute exercise test at $50 \%$ of their individual $W_{\max }$ in order to study potential alterations in glucose kinetics at identical relative submaximal work load. Blood samples were taken at $\mathrm{t}=205$, 210, 215 and 220 minutes during exercise and at $\mathrm{t}=235,250,265$ and 280 minutes during a second recovery period of one hour. Plasma levels of glucoregulatory hormones were determined at $\mathrm{t}=110,140,200,220$ and 280 minutes. To minimize changes in substrate isotopic enrichment, infusion rate of glucose tracer was doubled $\left(0.44 \mu \mathrm{mol} \cdot \mathrm{kgBW}^{-1} \cdot \mathrm{min}^{-1}\right)$ during submaximal exercise ${ }^{15}$. During the study, subjects were allowed to drink water only.

\section{Sample collection and analysis}

During the OGTT, venous blood samples were collected in sodium fluoride containing tubes and immediately placed on ice. Within 15 minutes, blood glucose was analysed by the glucose oxidase method with a YSI 2300 STAT Plus analyzer (YSI Incorporated, Yellow Springs, Ohio, USA).

Blood samples $(5 \mathrm{ml})$ for $\left[6,6-{ }^{2} \mathrm{H}_{2}\right]$ glucose enrichment and glucose and glycerol concentrations were collected on heparin, immediately put on ice, and centrifuged at $4000 \mathrm{rpm}$ at $+4^{\circ} \mathrm{C}$ for 10 minutes. For 
determination of insulin and cortisol, $3 \mathrm{ml}$ of arterialized-venous blood were put into a coagulation tube, which was centrifuged for ten minutes at $3000 \mathrm{rpm}$ at room temperature. Serum was separated and centrifuged again for five minutes at $3000 \mathrm{rpm}$. An iced EDTA and trasylol containing tube was used to collect blood for the measurements of glucagon. After mixing, plasma was separated from cells by centrifugation at $4000 \mathrm{rpm}$ for 10 minutes at $+4^{\circ} \mathrm{C}$. Samples for catecholamines were collected in iced EDTA tubes, centrifuged at $4000 \mathrm{rpm}$ for 10 minutes at $+4^{\circ} \mathrm{C}$ and stored in a glutathione containing tube. All aliquots of plasma and serum were frozen immediately in liquid nitrogen, stored $-80^{\circ} \mathrm{C}$ and transported on dry ice before assay.

Plasma insulin concentrations were determined by a chemiluminescent immunometric assay and plasma cortisol concentrations were measured by a chemiluminescent immunoassay, both on an Immulite 2000 system (Diagnostic Products Corporation, Los Angeles, California, USA). Glucagon was determined by RIA (125-I Glucagon RIA, LINCO Research, St. Charles, Missouri, USA). Serum free fatty acids (FFA) were measured by an enzymatic colorimetric method (NEFAC; Wako Chemicals GmbH, Neuss, Germany).Catecholamines were determined by an in-house reversed phase HPLC method with fluorescence detection.

\section{Gas chromatography-mass spectrometry}

$\left[6,6-{ }^{2} \mathrm{H}_{2}\right]$ glucose enrichment and glucose and glycerol concentration were measured as described earlier ${ }^{16,17}$. Briefly, plasma samples were deproteinized with methanol. The aldonitril penta-acetate derivative of glucose was injected into a gas chromatograph/mass spectrometer system (model 6890 gas chromatograph coupled to a model 5973 mass selective detector, equipped with an electron impact ionization mode; Hewlett-Packard, Palo Alto, California, USA). Separation was achieved on a J\&W DB17 column ( $30 \mathrm{~m} \times 0.25 \mathrm{~mm}$, df $0.25 \mu \mathrm{m}$; Agilent Technologies Nederland BV, Amstelveen, The Netherlands). Glucose concentrations were determined by gas chromatography using xylose as an internal standard. Glucose was monitored at mass-to-charge ratio 187, 188, and 189. The enrichment of $\left[6,6-{ }^{2} \mathrm{H}_{2}\right]$ glucose was determined by dividing the peak area of mass-to-charge ratio 189 by the peak area of mass-tocharge ratio 187 and correcting for natural enrichments. 


\section{Calculations}

The rate of glucose appearance $\left(R_{a}\right)$ at rest was calculated by dividing the infusion rate of $\left[6,6-{ }^{2} \mathrm{H}_{2}\right]$ glucose by the resulting enrichment of plasma aldenotril pentaacetate glucose. Glucose $R_{a}$ is composed of endogenous glucose production and exogenous tracer infusion. During submaximal exercise glucose $R_{a}$ was calculated using the single-pool non-steady state Steele equation, adapted for stable isotope methodology as described elsewhere ${ }^{18}$ :

$\mathrm{R}_{\mathrm{a}}=\left(F-V_{d}\left[\left(C_{2}+C_{1}\right) / 2\right]\left[\left(E_{2}-E_{1}\right) /\left(t_{2}-t_{1}\right)\right]\right) /\left(\left(E_{2}+E_{1}\right) / 2\right)$,

where $F$ is the infusion rate $\left(\mu \mathrm{mol} \cdot \mathrm{kgFFM}^{-1} \cdot \mathrm{min}^{-1}\right), V_{d}$ is the distribution volume of glucose, $C_{1}$ and $C_{2}$ are glucose concentrations at times $1\left(t_{1}\right)$ and $2\left(t_{2}\right)$, respectively, and $E_{1}$ and $E_{2}$ are the glucose enrichments at $t_{1}$ and $t_{2}$, respectively. Because of the short duration of submaximal exercise, the volume of distribution of glucose was assumed to be $100 \mathrm{ml} \cdot \mathrm{kgBW}^{-1}$ (Personal communication with prof. dr. Robert R. Wolfe ${ }^{18}$ ).

Insulin sensitivity was assessed using the homeostatic modelling technique $(\mathrm{HOMA})^{19}$, based on fasting plasma glucose and insulin levels.

\section{Statistics}

Results are expressed as mean \pm standard error of the mean (SEM). Statistical analysis on baseline differences between COPD patients and controls was performed using an unpaired Student's $t$-test. One way analysis of variance (ANOVA) was used to determine differences in rate of appearance of glucose, substrate and hormone concentrations and functional parameters between patients with a reduced BMI, patients with a normal BMI and controls. LSD multiple comparison test was used as post hoc test. Pearson's correlation analysis was performed in order to investigate linear relationship between variables of glucose metabolism, glucoregulatory hormones, body composition, lung function and exercise performance. All $p$ values $<0.05$ were considered statistically significant.

\section{Results}

Thirteen male COPD patients and eight male healthy volunteers participated in the glucose stable isotope tracer protocol (Table 7.1). 
Fat-free mass was significantly reduced in COPD patients compared to controls, while fat mass was comparable. Patients were characterized by moderate airflow obstruction, a moderately reduced diffusing capacity and normoxaemia at rest. Exercise capacity was significantly reduced in COPD versus controls, while peripheral oxygen saturation at rest was comparable and no significant exercise-induced desaturation occurred in any of the groups (data not shown). Underweight COPD patients were characterized by reduced fat-free mass and fat mass in comparison to normal-weight patients and increased residual volumes but the severity of airflow limitation and arterial blood gases were comparable in both COPD groups. Also, exercise capacity was equally impaired in both COPD groups.

Glucose $R_{a}$ at rest was significantly increased in COPD patients compared to controls $\left(16.4 \pm 0.4 \mu \mathrm{mol} \cdot \mathrm{kgFFM}^{-1} \cdot \mathrm{min}^{-1}\right.$ versus $15.1 \pm 0.4$ $\left.\mu \mathrm{mol} \cdot \mathrm{kgFFM}^{-1} \cdot \mathrm{min}^{-1}, \mathrm{p}<0.05\right)$. Only in patients, glucose $R_{a}$ was inversely related to fat-free mass $(r=-0.75, p<0.01)$. Resting glucose $\mathrm{R}_{\mathrm{a}}$ of underweight COPD patients $\left(16.6 \pm 0.4 \mu \mathrm{mol} \cdot \mathrm{kgFFM}^{-1} \cdot \mathrm{min}^{-1}\right)$ was significantly enhanced compared to controls $\left(15.0 \pm 0.4 \mu \mathrm{mol}^{\prime} \mathrm{kgFFM}^{-}\right.$ $\left.{ }^{1} \cdot \mathrm{min}^{-1}, \mathrm{p}<0.05\right)$, while glucose $R_{a}$ at rest of normal-weight patients $\left(16.1 \pm 0.6 \mu \mathrm{mol} \cdot \mathrm{kgFFM}^{-1} \cdot \mathrm{min}^{-1}, \mathrm{NS}\right)$ was not statistically increased (Figure 7.1).

There was a physiological increase in glucose $R_{a}$ during submaximal exercise in both COPD patients as well as controls ( $p$ values for paired samples $<0.001$ ), but the proportional increase in glucose $R_{a}$ during submaximal exercise at identical workload was enhanced in COPD compared to controls $(81.9 \pm 3.4 \%$ versus $72.1 \pm 2.0 \%$, $\mathrm{p}=0.05)$. The relative increase in glucose production was related to norepinephrine concentrations in COPD $(r=0.61, p<0.05)$. Also, the proportional increase in glucose $R_{a}$ was significantly enhanced in COPD patients with a reduced BMI $(+90.4 \pm 5.3 \%)$ compared to normal BMI patients $(+74.7 \pm 2.2 \%, \mathrm{p}<0.01)$. Consequently, glucose $\mathrm{R}_{\mathrm{a}}$ was significantly elevated in patients compared to controls during submaximal exercise at both identical absolute and relative workloads and during the following recovery periods. End-of-exercise glucose $R_{a}$ of underweight patients $\left(31.6 \pm 0.8 \mu \mathrm{mol} \cdot \mathrm{kgFFM}^{-1} \cdot \mathrm{min}^{-1}\right)$ was significantly enhanced in comparison to controls after submaximal exercise at both identical absolute $(25.8 \pm 0.6$ $\left.\mu \mathrm{mol} \cdot \mathrm{kgFFM}^{-1} \cdot \mathrm{min}^{-1}, \mathrm{p}<0.001\right)$ as well as identical relative work load $\left(24.1 \pm 0.7 \mu \mathrm{mol} \cdot \mathrm{kgFFM}^{-1} \cdot \mathrm{min}^{-1}, \mathrm{p}<0.001\right)$ (Figure 7.1). Also, normal 
BMI patients showed significantly elevated glucose $R_{a}(28.0 \pm 1.0$ $\mu \mathrm{mol} \cdot \mathrm{kgFFM}^{-1} \cdot \mathrm{min}^{-1}$ ) after submaximal exercise in comparison to controls.

Figure 7.1 Rate of appearance $\left(R_{a}\right)$ of glucose at rest, during exercise at $30 \mathrm{~W}$ ( $=50 \%$ of peak work load of COPD patients), exercise at $50 \%$ of individual peak work loads and recovery (mean \pm SEM). COPD patients with a reduced BMI are represented by closed circles. Values of COPD patients with a normal BMI are shown as open circles and control values are depicted by closed triangles. Glucose $R_{a}$ was significantly increased during the entire protocol in COPD patients with a reduced BMI, in comparison to controls. During exercise, glucose $R_{a}$ of normal BMI patients was also significantly enhanced compared to controls.

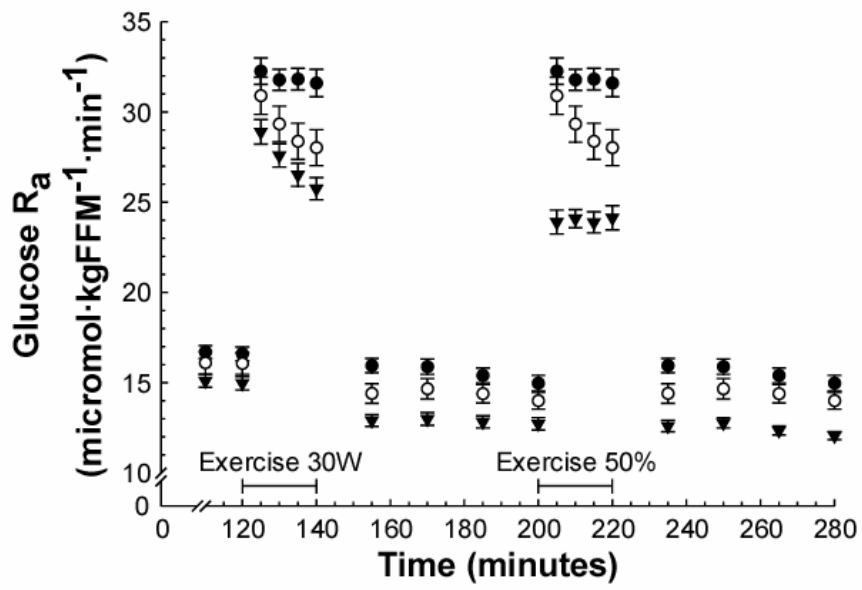

Fasting plasma levels of glucose, insulin, glucagon, cortisol, FFA and glycerol were comparable in COPD patients and controls, while concentrations of epinephrine and norepinephrine tended to be increased in COPD patients ( $p=0.05$ and $p=0.07$, respectively) (Table 7.2). Plasma levels of glucose remained constant during submaximal exercise and recovery in comparison to fasting levels and were comparable in both groups. As expected, end-of-exercise glucagon and catecholamine concentrations were significantly enhanced in COPD patients and controls in comparison to baseline values, while insulin levels were significantly suppressed (data not shown).

As shown in Table 7.2, low BMI patients were characterized by reduced plasma insulin concentrations and elevated catecholamine 
levels in comparison to patients with a normal BMI and controls. Normal BMI patients showed an increase in insulin levels compared to controls. Plasma concentrations of glucose, glucagon, cortisol, FFA and glycerol were comparable in all groups.

Table 7.2 Post-absorptive resting and end-of-exercise plasma substrate and hormone concentrations (mean \pm SEM).

\begin{tabular}{|c|c|c|c|c|}
\hline & $\begin{array}{l}\text { Controls } \\
\qquad(n=8)\end{array}$ & $\begin{array}{c}\text { COPD } \\
\text { All } \\
(n=13)\end{array}$ & $\begin{array}{c}\text { COPD } \\
\text { normal BMI } \\
(n=7)\end{array}$ & $\begin{array}{l}\text { COPD } \\
\text { reduced BMI } \\
(n=6)\end{array}$ \\
\hline \multicolumn{5}{|l|}{ Resting state } \\
\hline Glucose, $\mathrm{mmol} \cdot \mathrm{l}^{-1}$ & $5.79 \pm 0.19$ & $5.65 \pm 0.29$ & $5.90 \pm 0.48$ & $5.37 \pm 0.26$ \\
\hline Insulin, $\mathrm{pmol} \cdot \mathrm{I}^{-1}$ & $49 \pm 8$ & $51 \pm 10$ & $76 \pm 12 \#$ & $22 \pm 6 * *$ \\
\hline HOMA score & $13.4 \pm 2.5$ & $14.3 \pm 3.2$ & $21.5 \pm 4.1^{\$}$ & $5.8 \pm 1.5 * * \$ \$$ \\
\hline Glucagon, $\mathrm{pmol} \cdot \mathrm{l}^{-1}$ & $63 \pm 6$ & $68 \pm 4$ & $71 \pm 7$ & $65 \pm 5$ \\
\hline Cortisol, $\mathrm{nmol} \cdot \mathrm{I}^{-1}$ & $292 \pm 31$ & $306 \pm 28$ & $303 \pm 36$ & $310 \pm 49$ \\
\hline $\mathrm{FFA}, \mathrm{mmol} \cdot \mathrm{l}^{-1}$ & $1.12 \pm 0.14$ & $1.04 \pm 0.08$ & $1.08 \pm 0.13$ & $0.99 \pm 0.11$ \\
\hline Glycerol, $\left.\mathrm{mmol} \cdot\right|^{-1}$ & $83.3 \pm 6.5$ & $90.6 \pm 7.1$ & $85.0 \pm 9.5$ & $97.1 \pm 11.1$ \\
\hline Epinephrine, $\mathrm{nmol}^{-1} \mathrm{I}^{-1}$ & $0.42 \pm 0.07$ & $0.74 \pm 0.14$ & $0.52 \pm 0.12$ & $1.01 \pm 0.24 \# *$ \\
\hline Norepinephrine, $\mathrm{nmol} \cdot \mathrm{I}^{-1}$ & $0.42 \pm 0.10$ & $1.02 \pm 0.24$ & $0.85 \pm 0.21$ & $1.22 \pm 0.46 \#$ \\
\hline \multicolumn{5}{|l|}{ End-of-exercise } \\
\hline Glucose, $\left.\mathrm{mmol} \cdot\right|^{-1}$ & $6.19 \pm 0.19$ & $6.30 \pm 0.21$ & $6.21 \pm 0.27$ & $6.41 \pm 0.36$ \\
\hline Insulin, $\mathrm{pmol} \cdot \mathrm{I}^{-1}$ & $51 \pm 8$ & $55 \pm 10$ & $66 \pm 13$ & $19 \pm 3 \# * *$ \\
\hline Glucagon, $\mathrm{pmol} \cdot \mathrm{l}^{-1}$ & $62 \pm 7$ & $71 \pm 6$ & $79 \pm 10$ & $64 \pm 4$ \\
\hline Cortisol, $\mathrm{nmol} \cdot \mathrm{I}^{-1}$ & $285 \pm 23$ & $394 \pm 30$ & $386 \pm 37$ & $404 \pm 52 \#$ \\
\hline $\mathrm{FFA}, \mathrm{mmol} \cdot \mathrm{l}^{-1}$ & $1.75 \pm 0.24$ & $1.44 \pm 0.13$ & $1.45 \pm 0.15$ & $1.42 \pm 0.25$ \\
\hline Glycerol, $\mathrm{mmol}^{-1}$ & $223.1 \pm 36.5$ & $217.6 \pm 30.4$ & $207.7 \pm 40.5$ & $229.1 \pm 49.7$ \\
\hline Epinephrine, $\mathrm{nmol}^{-1} \mathrm{I}^{-1}$ & $0.79 \pm 0.16$ & $3.28 \pm 1.23$ & $3.68 \pm 2.40$ & $2.88 \pm 1.00$ \\
\hline Norepinephrine, $\mathrm{nmol} \cdot \mathrm{I}^{-1}$ & $1.32 \pm 0.18$ & $2.30 \pm 0.45$ & $2.41 \pm 0.51$ & $2.18 \pm 0.86$ \\
\hline
\end{tabular}

Significance of differences between patients and controls is indicated as: $\#: p<0.05$; $\$: p=0.06 ; \$ \$ p=0.09$. Significant differences between COPD patients with normal BMI and patients with a reduced BMI are shown as: $*: \mathrm{p}<0.05$ and $* *: \mathrm{p}<0.01$.

HOMA score was comparable in COPD patients and controls (Table 7.2), but was significantly reduced in patients with a reduced BMI in comparison to normal-weight patients (Figure 7.2). In normal-weight patients HOMA score tended to be increased in comparison to controls, indicating reduced insulin sensitivity this patient group. HOMA score was significantly related to BMI $(r=0.57, p<0.05)$ and fat-mass index $(r=0.74, p<0.01)$ (Figure 7.3$)$ in bivariate regression analysis. 
Figure 7.2 Homeostasis model assessment (HOMA) index for insulin sensitivity in subgroups of COPD patients with normal and reduced body mass index (BMI) and controls. Insulin sensitivity was significantly reduced in COPD patients with normal BMI in comparison to patients with reduced BMI (\#: $\mathrm{p}<0.01$ ). Also, there was a strong tendency towards decreased insulin sensitivity in normal-weight COPD patients in comparison to controls matched for BMI $(\$: p=0.06)$.

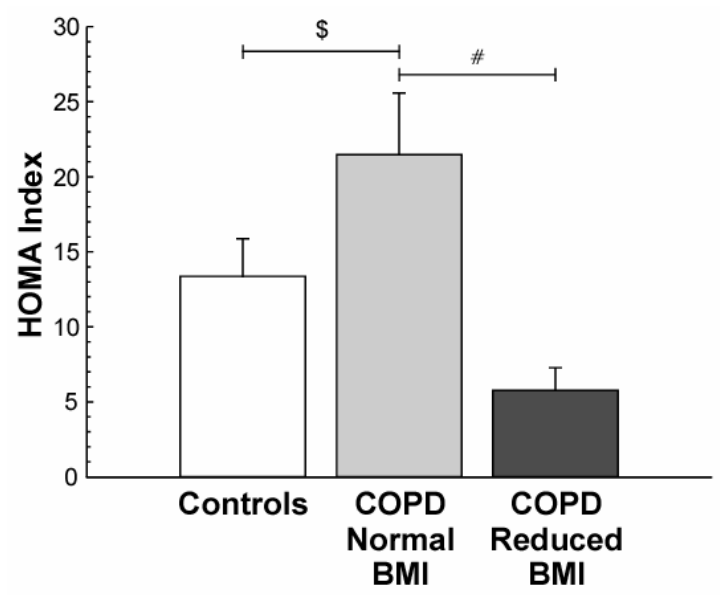

Figure 7.3 Bivariate correlation between fat-mass index and homeostasis model assessment (HOMA) index for insulin sensitivity in COPD patients. COPD patients with reduced BMI are depicted by closed circles, while open circles represent normal-weight COPD patients. A significant positive correlation was observed $(r=0.74, p<0.01)$.

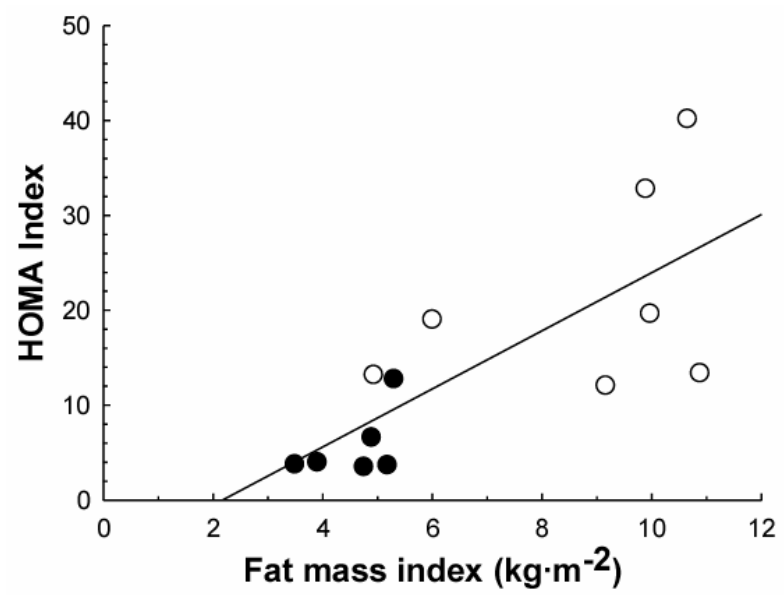




\section{Discussion}

The results of this first study on glucose kinetics in COPD can be summarized as follows. Post-absorptive whole-body glucose production is enhanced in COPD patients with moderate disease severity compared to healthy subjects. The increased glucose turnover is present in the resting state and is amplified during submaximal exercise. COPD subgroup analysis shows that alterations in glucose production are predominantly present in underweight patients, although submaximal exercise revealed enhanced intermediary carbohydrate metabolism in normal-weight COPD patients as well. Finally, there is indirect evidence for insulin resistance in normal-weight patients. Possible explanations for these observations and the clinical implications are discussed here.

\section{Glucose production in COPD}

Whole-body resting post-absorptive glucose production was enhanced in glucose tolerant COPD patients. After an overnight fast (as in the present study), the major part of total glucose production constitutes of hepatic glycogenolysis, while the contribution of gluconeogenesis, in which glucose is formed from especially lactate, alanine and glycerol, increases during exercise or prolonged starvation.

There are several possible pathophysiological explanations for the increased glucose production in COPD. Acute and chronic hypoxemia, which may be chronically present in end-stage COPD or intermittently during exercise in less severe COPD, cause an increment in glucose production in normal subjects ${ }^{5}$. Although chronic respiratory failure was an exclusion factor in the present study and exercise-related oxygen desaturation did not occur, resting arterial oxygen tension of the COPD patients was below reference values for healthy subjects.

Furthermore, decreased skeletal muscle oxidative capacity may result in enhanced endogenous glucose production in COPD. The observation of an increased glucose production in combination with normoglycemia implicates an increased glucose tissue uptake. After uptake, glucose can be either stored as glycogen, lactate or fat or it can be oxidized. No muscle biopsies were performed in the present study, since the protocol was already quite invasive. Jakobsson et al. ${ }^{5}$ reported reduced resting glycogen concentrations in quadriceps muscle of normal-weight COPD patients with chronic respiratory 
failure. In another study by Engelen et al. ${ }^{20}$ muscle glycogen content was comparable in COPD patients and controls, but resting lactate and pyruvate concentrations were enhanced in quadriceps muscle of patients with COPD. In the presence of adequate oxygen delivery, muscle pyruvate and lactate increase when the rate of pyruvate production by glycolysis exceeds the oxidative capacity of the tricarboxylic acid pathway. Indeed, COPD patients are characterized by an impaired skeletal muscle oxidative capacity and this is associated with disturbed lactic acid kinetics ${ }^{21}$. Furthermore, an increased proportion of type 2 muscle fibres, with a reduced oxidative enzyme activity, is observed in $\mathrm{COPD}^{22}$, indicating a shift toward a glycolytic energy production in these patients. The finding of an increased glucose turnover in the present study might very well be an adaptation to an increased dependence on glucose for energy provision, as a result of decreased oxidative capacity in COPD. The fact that enhanced glucose production was accompanied by a reduced fat mass and the finding of non-elevated muscle glycogen content in previous studies supports this hypothesis of increased muscle glucose use for high energy phoshate production at the cost of increased glucose storage. In line with this hypothesis, an increased carbohydrate oxidation was previously reported in malnourished COPD patients and contributed to a hypermetabolic state $^{23}$.

Neurohumoral activation, reflected by elevated catecholamines, is consistently found in COPD patients and may contribute to the systemic manifestations of the disease ${ }^{7}$. Catecholamines increase glucose production by stimulating glycogenolysis and gluconeogenesis, and elevated levels of these were indeed observed in the present study. However, no linear relationship between catecholamine levels and resting glucose production was found in the present study, possibly due to the small group size.

The systemic use of corticosteroids in COPD may lead to hyperglycemia by increasing hepatic glucose production and inhibiting glucose uptake and utilization by peripheral tissues. Also, B-adrenoceptor agonists are able to induce hyperglycemia in humans. Since none of the patients in the study used oral glucocorticosteroids and daily inhalations of $B_{2}$-adrenoceptor agonists were suspended until after the study and equally distributed between patient groups, a role for medication in the observed results is unlikely. 


\section{Glucose production and body composition in COPD}

Basal and exercise-induced glucose output of underweight patients was slightly increased in comparison to normal-weight patients and was evidently elevated compared to healthy subjects. Although glucose production was inversely related to fat-free mass, differences in body composition between COPD subgroups cannot explain these results. Studies in healthy non-diabetic individuals showed that lean body mass was a positive predictor of postabsorptive endogenous glucose output, irrespective of body weight ${ }^{6,24}$. Thus, disease specific factors related to cachexia, such as more pronounced hypoxemia, reduced oxidative capacity or skeletal muscle fibre type redistribution may account for the predominant disturbance of glucose output in the underweight COPD patients. Moreover, preferential atrophy of type IIX glycolytic muscle fibres in COPD might affect the relationship between whole-body glucose production and fat-free mass $^{25}$. Also, increased levels of catecholamines in underweight patients could contribute, since catecholamines are considered the primary drive behind stimulation of exercise-induced glucose production in healthy subjects ${ }^{26}$ and a positive correlation between norepinephrine levels and delta glucose production was observed in this study.

\section{Insulin sensitivity}

Fasting plasma levels of glucose and insulin were comparable in COPD patients and controls in the present study, resulting in a similar index of insulin sensitivity estimated by homeostasis model assessment (HOMA). HOMA is a simple and validated alternative to the euglycemic hyperinsulinemic clamp technique, which is regarded the reference method for assessment of insulin sensitivity in vivo ${ }^{27}$. In COPD patients, only one study used this glucose clamp technique to determine insulin sensitivity. In line with the observation in the present study, Jakobsson et al. ${ }^{28}$ reported normal insulin sensitivity in advanced normal-weight patients with chronic respiratory failure in comparison to controls.

In contrast to the present results, Bolton et al. ${ }^{4}$ recently reported insulin resistance in a group of normal-weight COPD patients with normal oxygen saturation compared to healthy subjects. Circulating levels of inflammatory mediators were increased in these patients and both BMI as well as interleukin 6 levels were predictive variables of insulin resistance in these COPD patients. Although the results by Bolton et al. may have been confounded by the fact that some of the 
patients were glucose intolerant, as indicated by slight fasting hyperglycemia, the possible association between BMI and insulin resistance in COPD is interesting. In the present study, insulin sensitivity was significantly decreased in normal-weight COPD patients compared to underweight patients and HOMA score was related to BMI and fat mass. Furthermore, in comparison to controls, insulin sensitivity of normal-weight patients tended to be decreased, whereas there was a trend towards increased insulin sensitivity in underweight COPD patients. Regarding this observation, several points must be emphasized. First of all, in contrast to the study by Bolton et al., the present study actively excluded patients with glucose intolerance, so results cannot have not been confounded by this factor. Secondly, normal-weight COPD patients and controls were matched for BMI (see Table 7.1), so a discrepancy in body composition did not account for the lower insulin sensitivity in normal-weight COPD patients. Finally, the observations in the present study are in accordance with recently published data on insulin sensitivity in COPD by Koehler et al. ${ }^{29}$. In their study, insulin sensitivity, measured by HOMA score, was significantly reduced in a large group of normal-weight patients compared to underweight COPD patients. Interestingly, similar to the present results, insulin sensitivity tended to be decreased in normal-weight patients in comparison to controls with an identical BMI. Regarding the possibility of increased insulin sensitivity in underweight versus normal-weight COPD patients, it is important to notice that being underweight is associated with increased insulin sensitivity in healthy subjects $^{30}$, so this is not a unique feature in COPD. However, as stated before, the decrease in insulin resistance in normal-weight patients compared to controls cannot be explained by any difference in body composition.

Although assessment of insulin sensitivity in COPD was not the primary goal of the present study, the combination of observations in this and other recent studies suggest that a certain degree of insulin resistance may already occur in normal-weight COPD patients. The underlying pathophysiological mechanism(s) are yet unknown, but there are several possible explanations. Jakobsson et al. ${ }^{31}$ observed a significant increase in glucose tolerance and insulin sensitivity during oxygen supplementation in chronic hypoxemic COPD patients. Although the degree of insulin resistance was not compared to controls, their study suggests that hypoxemia plays a role in insulin resistance in COPD. Fascinatingly, the authors described a positive correlation between the change in glucose uptake with and without 
supplemental oxygen and BMI, suggesting that insulin sensitivity is more impaired in more obese COPD patients. Again, this observation is in line with the present study.

Before drawing conclusions on the issue of insulin resistance in (subgroups of) COPD patients, a study using the "gold standard" method to measure insulin sensitivity, i.e. the hyperinsulinaemic euglycaemic glucose clamp procedure, is needed. Preferentially such a study will include well-stratified COPD subgroups, such as normalweight versus underweight patients and normoxaemic versus hypoxemic patients in order to investigate the potentially opposite effects of body composition and hypoxemia in COPD on insulin sensitivity and glucose uptake. Until then, also the contribution of insulin resistance to increased cardiovascular mortality in $\mathrm{COPD}^{3}$ remains speculative.

\section{Clinical implications}

In contrast to underweight COPD patients, who showed clear disturbances in resting glucose production, endogenous glucose production of normal-weight COPD patients was comparable to controls at rest. However, short-term submaximal bicycle exercise revealed an enhanced glucose turnover in this group. This observation is relevant to daily living conditions in these patients. Early lactic acidosis is a common finding in COPD $^{32}$, indicating increased metabolic stress during relatively low intensity exercise. The metabolic demands of specific physical activities are usually quantified in metabolic equivalents (METS), defined as the ratio of work to resting metabolic rate. The calculated energy cost of the submaximal bicycle exercise in the present study is approximately three METS, which is comparable to home activities such as sweeping, downstairs and implied walking, walking the dog and carrying small children in healthy subjects ${ }^{33}$. Performance of these or more intense activities of daily living by both underweight as well as normal-weight COPD patients might thus result in temporary enhancements in glucose turnover. The clinical implications of these daily bursts of metabolic stress and especially the effects on energy balance, body composition and cardiovascular risk are unknown and subject of future investigations.

\section{Limitations of the study}

The individual contribution of gluconeogenesis and glycogenolysis to total glucose production was not determined in the present study. In 
further studies on glucose kinetics in COPD, quantification of fractional gluconeogenesis can be achieved by the use of a deuterium labeled water tracer in addition to $\left[6,6-{ }^{2} \mathrm{H}_{2}\right]$ glucose. Furthermore, a relationship between increased glucose production and reduced oxidative capacity cannot be proven based on the present results, since no muscle biopsies were taken.

\section{Conclusions}

Postabsorptive resting and exercise-induced whole-body glucose production is increased in clinically stable patients with COPD GOLD stage II-III. Enhanced glucose output is observed in both underweight as well as normal-weight patients, but predominantly in the first group. It was hypothesized that epiphenomena of COPD such as reduced skeletal muscle oxidative capacity, relative hypoxemia and sympathetic and inflammatory activation contribute to this increased glucose production. Additional research is warranted to further clarify the relationships between whole-body substrate metabolism, muscle energy supply and pulmonary cachexia and the clinical implications of the present findings. Nevertheless, this study provides a strong rational to investigate the value of nutritional and pharmacological interventions targeting intermediary glucose metabolism in moderate COPD. 


\section{References}

1. Kutsuzawa T, Shioya S, Kurita D, Haida M, Ohta $Y$, Yamabayashi H. ${ }^{31} \mathrm{P}$ NMR study of skeletal muscle metabolism in patients with chronic respiratory impairment. Am Rev Respir Dis 1992;146:1019-1024.

2. Maltais F, LeBlanc P, Whittom F, Simard C, Marquis K, Belanger M, Breton MJ, Jobin J. Oxidative enzyme activities of the vastus lateralis muscle and the functional status in patients with COPD. Thorax 2000;55:848-853.

3. Sin DD, Wu L, Man SF. The relationship between reduced lung function and cardiovascular mortality: A population-based study and a systematic review of the literature. Chest 2005;127:1952-1959.

4. Bolton CE, Evans M, Ionescu AA, Edwards SM, Morris RH, Dunseath G, Luzio SD, Owens DR, Shale DJ. Insulin resistance and inflammation - a further systemic complication of COPD. COPD 2007;4:121-126.

5. Jakobsson $P$, Jorfeldt $L$, Brundin A. Skeletal muscle metabolites and fibre types in patients with advanced chronic obstructive pulmonary disease, with and without chronic respiratory failure. Eur Respir J 1990;3:192-196.

6. Natali A, Toschi E, Camastra S, Gastaldelli A, Groop L, Ferrannini E. Determinants of postabsorptive endogenous glucose output in non-diabetic subjects. European group for the study of insulin resistance. Diabetologia 2000;43:1266-1272.

7. Andreas S, Anker SD, Scanlon PD, Somers VK. Neurohumoral activation as a link to systemic manifestations of chronic lung disease. Chest 2005;128:3618-3624.

8. Duncan BB, Schmidt MI, Pankow JS, Ballantyne CM, Couper D, Vigo A, Hoogeveen R, Folsom AR, Heiss G. Low-grade systemic inflammation and the development of type 2 diabetes: The atherosclerosis risk in communities study. Diabetes 2003;52:1799-1805.

9. American Thoracic Society Statement. Standards for the diagnosis and care of patients with chronic obstructive pulmonary disease. Am J Respir Crit Care Med 1995;152:S77-121.

10. WHO expert committee on diabetes mellitus: Second report. World Health Organ Tech Rep Ser 1980;646:1-80.

11. Lukaski HC, Johnson PE, Bolonchuk WW, Lykken GI. Assessment of fat-free mass using bioelectrical impedance measurements of the human body. Am J Clin Nutr 1985;41:810-817.

12. Steiner MC, Barton RL, Singh SJ, Morgan MD. Bedside methods versus dual energy x-ray absorptiometry for body composition measurement in COPD. Eur Respir J 2002;19:626-631.

13. Kyle UG, Bosaeus I, De Lorenzo AD, Deurenberg P, Elia M, Gómez JM, Heitmann BL, Kent-Smith L, Melchior JC, Pirlich M, Scharfetter H, Schols AM, Pichard C; Composition of the ESPEN Working Group. Bioelectrical impedance analysis-part i: Review of principles and methods. Clin Nutr 2004;23:1226-1243.

14. Quanjer PH, Tammeling GJ, Cotes JE, Pedersen OF, Peslin R, Yernault JC. Lung volumes and forced ventilatory flows. Report working party standardization of lung function tests, European community for steel and coal. Official statement of the European Respiratory Society. Eur Respir J Suppl 1993;16:5-40.

15. Romijn JA, Coyle EF, Sidossis LS, Gastaldelli A, Horowitz JF, Endert E, Wolfe RR. Regulation of endogenous fat and carbohydrate metabolism in relation to exercise intensity and duration. Am J Physiol 1993;265:E380-391.

16. Ackermans MT, Pereira Arias AM, Bisschop PH, Endert E, Sauerwein HP, Romijn JA. The quantification of gluconeogenesis in healthy men by ${ }^{2} \mathrm{H}_{2} \mathrm{O}$ and [2${ }^{13} \mathrm{C}$ ]glycerol yields different results: Rates of gluconeogenesis in healthy men measured with ${ }^{2} \mathrm{H}_{2} \mathrm{O}$ are higher than those measured with $\left[2-{ }^{13} \mathrm{C}\right]$ glycerol. $\mathrm{J}$ Clin Endocrinol Metab 2001;86:2220-2226. 
17. Ackermans MT, Ruiter AF, Endert E. Determination of glycerol concentrations and glycerol isotopic enrichments in human plasma by gas chromatography/mass spectrometry. Anal Biochem 1998;258:80-86.

18. Wolfe RR. Radioactive and stable isotope tracers in biomedicine : Principles and practice of kinetic analysis. New York: Wiley-Liss; 1992.

19. Matthews DR, Hosker JP, Rudenski AS, Naylor BA, Treacher DF, Turner RC. Homeostasis model assessment: Insulin resistance and beta-cell function from fasting plasma glucose and insulin concentrations in man. Diabetologia $1985 ; 28: 412-419$.

20. Engelen MP, Schols AM, Does JD, Gosker HR, Deutz NE, Wouters EF. Exerciseinduced lactate increase in relation to muscle substrates in patients with chronic obstructive pulmonary disease. Am J Respir Crit Care Med 2000;162:1697-1704.

21. Maltais F, Simard AA, Simard C, Jobin J, Desgagnes P, LeBlanc P. Oxidative capacity of the skeletal muscle and lactic acid kinetics during exercise in normal subjects and in patients with COPD. Am J Respir Crit Care Med 1996;153:288293.

22. Gosker HR, van Mameren $H$, van Dijk PJ, Engelen MP, van der Vusse GJ, Wouters $E F$, Schols AM. Skeletal muscle fibre-type shifting and metabolic profile in patients with chronic obstructive pulmonary disease. Eur Respir J 2002;19: 617-625.

23. Goldstein SA, Thomashow BM, Kvetan V, Askanazi J, Kinney JM, Elwyn DH. Nitrogen and energy relationships in malnourished patients with emphysema. Am Rev Respir Dis 1988;138:636-644.

24. Giusti V, Schneiter P, Thiebaud D, Landry M, Burckhardt P, Jequier E, Tappy L. Influences of body weight, body composition, and substrate oxidation rate on resting postabsorptive glucose production and gluconeogenesis. Int J Obes Relat Metab Disord 1996;20:842-847.

25. Gosker HR, Engelen MP, van Mameren H, van Dijk PJ, van der Vusse GJ, Wouters $E F$, Schols AM. Muscle fibre type IIx atrophy is involved in the loss of fat-free mass in chronic obstructive pulmonary disease. Am J Clin Nutr 2002;76:113-119.

26. Kreisman SH, Ah Mew N, Arsenault M, Nessim SJ, Halter JB, Vranic M, Marliss EB. Epinephrine infusion during moderate intensity exercise increases glucose production and uptake. Am J Physiol Endocrinol Metab 2000;278:E949-957.

27. Bonora E, Targher G, Alberiche M, Bonadonna RC, Saggiani F, Zenere MB, Monauni T, Muggeo M. Homeostasis model assessment closely mirrors the glucose clamp technique in the assessment of insulin sensitivity: Studies in subjects with various degrees of glucose tolerance and insulin sensitivity. Diabetes Care 2000;23:57-63.

28. Jakobsson $P$, Jorfeldt $L$, von Schenck $H$. Insulin resistance is not exhibited by advanced chronic obstructive pulmonary disease patients. Clin Physiol 1995;15: 547-555.

29. Koehler F, Doehner W, Hoernig S, Witt C, Anker SD, John M. Anorexia in chronic obstructive pulmonary disease - association to cachexia and hormonal derangement. Int J Cardiol 2007;119:83-89.

30. Tayek JA, Manglik S, Abemayor E. Insulin secretion, glucose production, and insulin sensitivity in underweight and normal-weight volunteers, and in underweight and normal-weight cancer patients: A clinical research center study. Metabolism 1997;46:140-145.

31. Jakobsson $\mathrm{P}$, Jorfeldt $\mathrm{L}$. Oxygen supplementation increases glucose tolerance during euglycaemic hyperinsulinaemic glucose clamp procedure in patients with severe COPD and chronic hypoxaemia. Clin Physiol Funct Imaging 2006;26: 271-274.

32. Casaburi R, Patessio A, Ioli F, Zanaboni S, Donner CF, Wasserman K. Reductions in exercise lactic acidosis and ventilation as a result of exercise training in patients with obstructive lung disease. Am Rev Respir Dis 1991;143:9-18. 
33. Ainsworth BE, Haskell WL, Whitt MC, Irwin ML, Swartz AM, Strath SJ, O'Brien WL, Bassett DR Jr, Schmitz KH, Emplaincourt PO, Jacobs DR Jr, Leon AS. Compendium of physical activities: An update of activity codes and met intensities. Med Sci Sports Exerc 2000;32:S498-504. 



\section{Chapter 8}

Whole-body resting and exerciseinduced lipolysis in sarcopenic patients with chronic obstructive pulmonary disease

Frits M.E. Franssen, Hans P. Sauerwein, Erica P.A. Rutten, Emiel F.M. Wouters, Annemie M.W.J. Schols European Respiratory Journal 2008; 32: 1466-1471 


\section{Abstract}

\section{Introduction}

An impaired $\beta$-adrenoceptor-mediated lipolysis was reported in sarcopenic patients with chronic obstructive pulmonary disease (COPD). This could play a role in the shift in body composition towards decreased fat-free mass (FFM) and relative maintenance of fat mass (FM). Lipolysis could be affected by chronic treatment with $\beta_{2}$-agonists or disease-related factors. Therefore, whole-body resting and exercise-induced lipolysis was investigated in sarcopenic COPD patients with moderate disease severity.

\section{Methods}

Seven sarcopenic COPD patients $\left(\mathrm{FEV}_{1}: 53 \pm 5 \%\right.$, BMI: $\left.27.5 \pm 0.9 \mathrm{~kg} \cdot \mathrm{m}^{-2}\right)$ and 7 controls matched for age, gender and BMI were studied. In addition, 6 underweight COPD patients $\left(\mathrm{FEV}_{1}\right.$ : $\left.51 \pm 5 \%, \mathrm{BMI}: 20.6 \pm 0.7 \mathrm{~kg} \cdot \mathrm{m}^{-2}\right)$ matched for disease severity were recruited. Lipolysis and plasma levels of catecholamines were assessed during infusion of $\left[{ }^{2} \mathrm{H}_{5}\right]$ glycerol at rest and during submaximal cycling exercise.

\section{Results}

Proportional FM was comparable between sarcopenic patients and controls, while FFMindex was significantly reduced in patients. At rest, the rate of appearance $\left(R_{a}\right)$ of glycerol $\left(4.1 \pm 0.6 \mu \mathrm{mol} \cdot \mathrm{kgFFM}^{-1} \cdot \mathrm{min}^{-1}\right.$ and $3.3 \pm 0.2 \mu \mathrm{mol} \cdot \mathrm{kgFFM}^{-1} \cdot \mathrm{min}^{-1}$, respectively) was not significantly different. In underweight patients, glycerol $R_{a}(4.3 \pm 0.5$ $\mu \mathrm{mol} \cdot \mathrm{kgFFM}^{-1} \cdot \mathrm{min}^{-1}$ ) was also comparable. End-of-exercise lipolytic rates were not significantly different between groups. Glycerol $R_{a}$ was not related to fat mass. Resting epinephrine levels were significantly increased in underweight COPD patients and were related to resting lipolysis $(r=0.520, p<0.05)$.

\section{Conclusions}

Sarcopenia in COPD patients with moderate disease severity is not characterized by abnormal lipolytic rate. Altered regulation of muscle protein turnover seems to be the trigger in the body compositional shift observed in these patients. 


\section{Introduction}

Cachexia, defined as weight loss with a disproportional loss of fatfree mass (FFM), occurs in a substantial number of patients with chronic obstructive pulmonary disease (COPD) and is an independent predictor of mortality ${ }^{1}$. Its prevalence depends on the population analysed and varies from $11 \%$ in moderate to severe COPD outpatients $^{2}$ to $26 \%$ in severe patients eligible for pulmonary rehabilitation $^{3}$. Furthermore, in a substantial proportion of normalweight COPD patients $(10-15 \%)^{3,4}$ hidden depletion of fat-free mass occurs, also referred to as sarcopenia. The clinical implications of this body compositional shift towards decreased FFM and relative or even absolute abundance of fat mass were illustrated in a study showing a greater degree of physical impairment in normal-weight COPD patients with low FFM compared to underweight patients with preserved fat-free mass ${ }^{3}$. We hypothesized that sarcopenia in COPD is associated with alterations in intermediary metabolism, towards accelerated net muscle protein breakdown and/or impaired fat oxidation or decreased lipolysis. There are some indications that depletion of FFM is indeed associated with altered regulation of protein turnover towards increased protein breakdown $n^{5-7}$. Also, reduced skeletal muscle activity of 3-hydroxyacyl CoA dehydrogenase $(\mathrm{HADH})$, which regulates the $\beta$-oxidation of fatty acids, has consistently been shown in normal-weight COPD patients ${ }^{8}$. Finally, an impaired $\beta$-adrenoceptor-mediated increase in plasma levels of nonesterified fatty acids was reported in sarcopenic COPD patients ${ }^{9}$, which is suggestive for a reduced lipolysis. However, whole-body lipolytic rate and differences in lipid kinetics between sarcopenic and underweight COPD patients have not been studied until now.

The primary aim of the present study was to investigate resting whole-body lipolysis in sarcopenic COPD patients versus healthy controls, matched for age and BMI. Secondary, potential differences in lipolytic rate between normal and underweight COPD patients matched for disease severity were explored, since loss of fat mass may be due to increased lipolysis, as previously observed in cancer patients ${ }^{10}$. Since oxidation of free fatty acids accounts for the major portion of energy requirements during low intensity exercise, submaximal bicycle exercise was used as metabolic stressor for whole-body lipolysis. 


\section{Methods}

\section{Study population}

Seven male and clinically stable COPD out-patients ${ }^{11}$ with moderate airflow obstruction and seven healthy controls, matched for age, sex and body mass index (BMI) volunteered for this study. Additionally, six COPD patients with low BMI were recruited, matched for FEV ${ }_{1}$. Details on body composition of the groups are shown in Figure 8.1. Exclusion criteria for participation were glucose intolerance, diabetes mellitus, thyroid or other endocrine disorders, recent involuntary weight loss, malignancies, chronic heart failure, renal, hepatic or other gastro-intestinal disease or recent surgery. Patients did not exhibit chronic respiratory insufficiency or receive supplemental oxygen therapy. The following pulmonary maintenance medications were used: inhaled short- and long-acting $\beta_{2}$-adrenoceptor agonists, $54 \%$; anticholinergics by inhalation, 54\%; combined inhalers of short-acting $\beta_{2}$-adrenoceptor agonists and short-acting anticholinergics, $8 \%$; inhalation corticosteroids, 8\%; combined inhalers of sympathicomimetics and corticosteroids, $46 \%$; xanthines, $31 \%$; and oral $\mathrm{N}$-acetylcysteine, $23 \%$. The use of pulmonary medications was equally distributed between COPD subgroups. On the evening before the test day and on the morning of the study, pulmonary maintenance medications were suspended in order to avoid potential acute effects of these on lipolysis. Written informed consent was obtained from all subjects and the study was approved by the medical ethical committee of the University Hospital Maastricht.

\section{Study design}

The study was performed at the out-patient metabolic ward of the University Hospital Maastricht on two separate occasions. During the first visit, medical history was checked and physical examination was performed by a physician. Furthermore, body composition was measured and lung function and incremental exercise tests were carried out. Eligible subjects subsequently participated in the glycerol stable isotope tracer protocol, as described below.

\section{Lung function tests}

Subjects underwent spirometry for measurement of forced expiratory volume in one second $\left(\mathrm{FEV}_{1}\right)$ and forced vital capacity (FVC). The 
highest value of at least three technically acceptable maneuvers was used. Total lung capacity (TLC) and residual volume (RV) were determined by whole-body plethysmography (MasterLab Body, Jaeger, Würzburg, Germany). Diffusing capacity for carbon monoxide $\left(\mathrm{DL}_{\mathrm{co}}\right)$ was assessed by the single-breath method (MasterLab Transfer, Jaeger, Würzburg, Germany). All values obtained were related to a reference value and expressed as a percentage of the predicted value. In patients, arterial blood gases were determined on a blood gas analyzer (ABL 700, Radiometer, Copenhagen, Denmark).

\section{Body composition}

Body height was determined to the nearest $0.5 \mathrm{~cm}$ with subjects standing barefoot. Body weight (BW) was measured with a beam scale (SECA, Hamburg, Germany) without shoes and in light clothing to the nearest $0.1 \mathrm{~kg}$. Body mass index was calculated as the ratio of weight to height in meters squared. FFM was measured by bioelectrical impedance analysis at a spectrum of 48 frequencies ranging from 5 to $500 \mathrm{kHz}$ (Xitron 4000b, Xitron technologies, San Diego, California, USA). Resistance was measured in supine position at the right side as described by Lukaski ${ }^{12}$. In subjects with COPD, FFM was estimated from impedance measurements using the sexspecific regression equation described by Steiner $^{13}$, while the equation of Dey ${ }^{14}$ was used for the healthy elderly controls. Fat-free mass index (FFMI) was calculated as the ratio of FFM to height in meters squared.

\section{Exercise capacity}

In order to determine the submaximal bicycle exercise load for each individual, subjects performed a standardized incremental exhaustive exercise test on an electrically braked cycle ergometer, as previously published $^{15}$.

\section{Glycerol stable isotope tracer protocol}

After an overnight fast, subjects reported at the laboratory at 07.30 $\mathrm{h}$ and were studied at rest in the supine position. A catheter was placed in an antecubital vein of the arm for stable isotope infusion. A second catheter for sampling of arterialized venous blood was placed retrograde in a dorsal hand vein of the contralateral arm and maintained at $60^{\circ} \mathrm{C}$ in a thermoregulated box. At $08.00 \mathrm{~h}$, after taking a blood sample for background enrichment of plasma glycerol, 
subjects were administered a single intravenous dose of $\left[{ }^{2} \mathrm{H}_{5}\right]$ glycerol (1.5 $\mu \mathrm{mol} \cdot \mathrm{kgBW}^{-1}, \quad>99 \%$ enriched; Cambridge Isotopes Inc, Andover, Massachusetts, USA) in order to prime the glycerol pool.

Thereafter $(t=0)$, a continuous infusion of $\left[{ }^{2} \mathrm{H}_{5}\right]$ glycerol $(0.1$ $\mu \mathrm{mol} \cdot \mathrm{kgBW}^{-1} \cdot \mathrm{min}^{-1}$ ) dissolved in $0.9 \%$ saline was started via a calibrated pump (IVAC 560, San Diego, California, USA). Resting blood samples were taken at $t=110$ and 120 minutes. In each experiment, the exact $\left[{ }^{2} \mathrm{H}_{5}\right]$ glycerol infusion rate was determined from the glycerol concentration and enrichment in the infusate. At $t=120$ minutes COPD patients started to exercise on a cycle ergometer at a workload of $50 \%$ maximal workload $\left(\mathrm{W}_{\max }\right)$ for 20 minutes, while controls exercised at an identical absolute work load (30 $\mathrm{W}=50 \%$ of mean $\mathrm{W}_{\max }$ in COPD patients) for the same duration. Blood samples were drawn at $t=125,130,135$ and 140 minutes. The protocol continued with one hour recovery period, during which blood samples were taken at $t=155,170,185$ and 200 minutes. Thereafter, controls performed a second 20 minute exercise test at $50 \%$ of their individual $W_{\max }$ in order to study potential alterations in glycerol kinetics at identical relative submaximal work load. Blood samples were taken at $\mathrm{t}=205,210,215$ and 220 minutes during exercise and at $\mathrm{t}=235,250,265$ and 280 minutes during a second recovery period of one hour. Plasma levels of regulatory hormones were determined at $\mathrm{t}=110,140,200,220$ and 280 minutes. During the study, subjects were allowed to drink water only.

\section{Analytic procedures}

Blood samples $(5 \mathrm{ml})$ for $\left[{ }^{2} \mathrm{H}_{5}\right]$ glycerol enrichment and glycerol concentration were collected on heparin, immediately put on ice, and centrifuged at $4000 \mathrm{rpm}$ at $+4^{\circ} \mathrm{C}$ for 10 minutes. Samples for catecholamines were collected in iced EDTA tubes, centrifuged at $4000 \mathrm{rpm}$ for 10 minutes at $+4^{\circ} \mathrm{C}$ and stored in a glutathione containing tube. For determination of insulin, $3 \mathrm{ml}$ of arterializedvenous blood were put into a coagulation tube, which was centrifuged for 10 minutes at $3000 \mathrm{rpm}$ at room temperature. Serum was separated and centrifuged again for 5 minutes at $3000 \mathrm{rpm}$. All aliquots of plasma and serum were frozen immediately in liquid nitrogen, stored $-80^{\circ} \mathrm{C}$ and transported on dry ice before assay.

Isotope enrichment of glycerol in plasma was determined by gas chromatography-mass spectrometry, as described by Ackermans et al. ${ }^{16}$. Serum free fatty acids (FFA) were measured by an enzymatic colorimetric method (NEFAC; Wako Chemicals GmbH, Neuss, 
Germany). Catecholamines were determined by an in-house reversed phase HPLC method with fluorescence detection. Plasma insulin concentrations were determined by radioimmunoassay (RIA) (Immulite, Diagnostic Products Corporation, Los Angeles, California, USA).

\section{Calculations}

Rate of appearance $\left(R_{a}\right)$ of glycerol at rest was calculated by dividing the infusion rate of $\left[{ }^{2} \mathrm{H}_{5}\right]$ glycerol by the plasma glycerol enrichment. During submaximal exercise glycerol $R_{a}$ was calculated using the single-pool non-steady state Steele equation, adapted for stable isotope methodology as described elsewhere ${ }^{17}$ :

$\mathrm{R}_{\mathrm{a}}=\left(F-V_{d}\left[\left(C_{2}+C_{1}\right) / 2\right]\left[\left(E_{2}-E_{1}\right) /\left(t_{2}-t_{1}\right)\right]\right) /\left(\left(E_{2}+E_{1}\right) / 2\right)$,

where $F$ is the infusion rate $\left(\mu \mathrm{mol} \cdot \mathrm{kgFFM}{ }^{-1} \cdot \mathrm{min}^{-1}\right), V_{d}$ is the distribution volume of glycerol, $C_{1}$ and $C_{2}$ are glycerol concentrations at times $1\left(t_{1}\right)$ and $2\left(t_{2}\right)$, respectively, and $E_{1}$ and $E_{2}$ are the glycerol enrichments at $t_{1}$ and $t_{2}$, respectively. The effective $V_{d}$ was assumed to be $230 \mathrm{ml}^{\circ} \mathrm{kgBW}^{-1} 18$.

\section{Statistics}

Results are expressed as mean \pm standard error of the mean (SEM). One way analysis of variance (ANOVA) was used to determine differences in baseline characteristics and substrate and hormone concentrations between normal-weight patients, underweight patients and controls. LSD multiple comparison test was used as post hoc test. Mixed design ANOVA for repeated measures was performed in order to analyse potential differences in glycerol $R_{a}$ between the three study groups. Groups were entered as between-group variables, while individual glycerol $R_{a}$ 's at various timepoints of the protocol were used as within-group variables. This analysis was performed for each of the phases of the protocol (rest, submaximal exercise and recovery) and specifically focused on significant between-group differences in glycerol $R_{a}$ during any of these phases. Levene's test showed homogeneity of variance of repeated measures of glycerol $R_{a}$ 's. In order to assess the variation explained by between-group differences and the variation explained by unsystematic factors, F-ratios were calculated. Mauchly's test of sphericity was performed to assess equality of variances of the differences between groups. Since the condition of sphericity was not 
met, Greenhouse-Geisser correction was applied in the production of F-ratios.

\section{Results}

General characteristics of all subjects are shown in Table 8.1.

Table 8.1 Baseline characteristics of the study groups (mean \pm SEM).

\begin{tabular}{|c|c|c|c|}
\hline & $\begin{array}{l}\text { Controls } \\
(n=7)\end{array}$ & $\begin{array}{c}\text { Sarcopenic COPD } \\
\qquad(n=7)\end{array}$ & $\begin{array}{l}\text { Underweight COPD } \\
\qquad(n=6)\end{array}$ \\
\hline Age, yr & $64 \pm 2$ & $64 \pm 4$ & $70 \pm 4$ \\
\hline \multicolumn{4}{|l|}{ Body composition } \\
\hline Height, cm & $173.7 \pm 2.2$ & $172.9 \pm 1.9$ & $168.1 \pm 1.5^{\mathrm{a}}$ \\
\hline Weight, kg & $85.5 \pm 5.6$ & $82.5 \pm 3.5$ & $58.2 \pm 2.1^{\mathrm{c}, \mathrm{e}}$ \\
\hline $\mathrm{BMI}, \mathrm{kg} \cdot \mathrm{m}^{-2}$ & $28.2 \pm 1.2$ & $27.5 \pm 0.9$ & $20.6 \pm 0.7^{c, f}$ \\
\hline FFM, kg & $62.6 \pm 2.7$ & $56.1 \pm 2.4^{\mathrm{g}}$ & $45.3 \pm 1.5^{c, e}$ \\
\hline FFMI, $\mathrm{kg} \cdot \mathrm{m}^{-2}$ & $20.7 \pm 0.5$ & $18.8 \pm 0.8^{a}$ & $16.0 \pm 0.4^{c, d}$ \\
\hline $\mathrm{FM}, \mathrm{kg}$ & $22.9 \pm 3.3$ & $26.4 \pm 2.9$ & $12.9 \pm 0.8^{\mathrm{a}, \mathrm{e}}$ \\
\hline $\mathrm{FMI}, \mathrm{kg} \cdot \mathrm{m}^{-2}$ & $7.5 \pm 0.9$ & $8.8 \pm 0.9$ & $4.6 \pm 0.3^{a, e}$ \\
\hline \multicolumn{4}{|l|}{ Pulmonary function } \\
\hline $\mathrm{FEV}_{1}, \%$ predicted & $105 \pm 4$ & $53 \pm 5^{c}$ & $51 \pm 5^{c}$ \\
\hline $\mathrm{FEV}_{1} / \mathrm{FVC}^{2} \%$ & $73.0 \pm 1.8$ & $43.0 \pm 1.9^{c}$ & $34.4 \pm 4.6^{c}$ \\
\hline $\mathrm{DL}_{\mathrm{co}}, \%$ predicted & $117 \pm 5$ & $62 \pm 7^{c}$ & $62 \pm 4^{c}$ \\
\hline RV/TLC\% & $36.3 \pm 1.6$ & $43.2 \pm 3.5$ & $51.0 \pm 10.0$ \\
\hline $\mathrm{PaO}_{2}, \mathrm{kPa}$ & - & $8.5 \pm 7.4$ & $8.5 \pm 7.8$ \\
\hline $\mathrm{PaCO}_{2}, \mathrm{kPa}$ & - & $5.1 \pm 0.2$ & $5.1 \pm 0.1$ \\
\hline \multicolumn{4}{|l|}{ Exercise capacity } \\
\hline Peak work rate, \%predicted & $129 \pm 9$ & $48 \pm 5^{c}$ & $44 \pm 4^{c}$ \\
\hline$\dot{\mathrm{V}} \mathrm{O}_{2 \max }, \%$ predicted & $110 \pm 6$ & $62 \pm 5^{c}$ & $57 \pm 3^{c}$ \\
\hline
\end{tabular}

BMI: body mass index; FFM: fat-free mass, assessed by bioelectrical impedance analysis; FFMI: fat-free mass index; FM: fat mass; FMI: fat mass index; $F V_{1}$ : forced expiratory volume in one second; $\mathrm{DL}_{\mathrm{CO}}$ : diffusing capacity for carbon monoxide; $\mathrm{RV}$ : residual volume; $\mathrm{P}_{a} \mathrm{O}_{2}$ : arterial oxygen tension; $\mathrm{P}_{\mathrm{a}} \mathrm{CO}_{2}$ : arterial carbon dioxide tension; $\mathrm{VO}_{2 \max }$ : maximal oxygen consumption. Significance of differences between COPD patients and controls is indicated as: ${ }^{a}: p<0.05,{ }^{b}: p<0.01,{ }^{c}: p<0.001$. Significant differences between sarcopenic and underweight COPD patients are shown as: ${ }^{d}$ : $\mathrm{p}<0.05,{ }^{e} \mathrm{p}<0.01,{ }^{f} \mathrm{p}<0.001 .{ }^{\mathrm{g}} \mathrm{p}=0.06$ versus controls.

As expected, the normal-weight COPD patients could be typified as sarcopenic based on a comparable FM but reduced fat-free mass index in comparison to controls. In the underweight COPD patients, fat mass (index) and fat-free mass (index) were significantly decreased in comparison to the other COPD group and controls (Figure 8.1). Lung function and arterial blood gases were equally impaired in both COPD groups. Functional capacity was impaired in 
COPD and was more reduced in underweight patients compared to sarcopenic patients. This was probably the result of the difference in fat-free mass, since $\dot{\mathrm{VO}}_{2 \max }$ was related to FFMI $(r=0.679, p<0.05)$.

Figure 8.1 Body composition of the study groups, displayed in stacked bars. The contribution of fat mass index (FMI, white area) and fat-free mass index (FFMI, grey area) to the body mass index (BMI) is shown. BMI of sarcopenic COPD patients was comparable to controls, although FFMI was significantly reduced. Underweight COPD patients were characterized by reduced BMI, FFMI and FMI. Standard errors of the mean and $p$ values are displayed in Table 8.1.

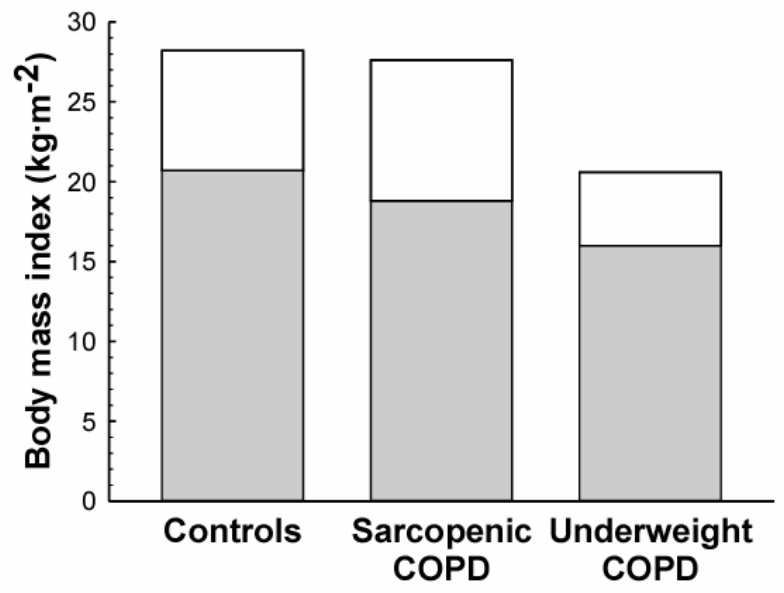

Resting postabsorptive rate of appearance of glycerol was comparable in sarcopenic COPD patients $\left(4.1 \pm 0.6 \mu \mathrm{mol} \cdot \mathrm{kgFFM}^{-1} \cdot \mathrm{min}^{-}\right.$ ${ }^{1}$ ) and controls (3.3 $\left.\pm 0.2 \mu \mathrm{mol} \cdot \mathrm{kgFFM}^{-1} \cdot \mathrm{min}^{-1}, \mathrm{p}=0.25\right)$ (Figure 8.2). Glycerol $R_{a}$ in underweight COPD patients $\left(4.3 \pm 0.5 \mu \mathrm{mol}^{\circ} \mathrm{kgFFM}^{-}\right.$ $\left.{ }^{1} \cdot \mathrm{min}^{-1}, \mathrm{NS}\right)$ was comparable to the other groups. Mixed design ANOVA for repeated measures revealed a non-significant effect of study group on whole-body glycerol $\mathrm{R}_{\mathrm{a}}$ at rest $(F(1,2)=308.47$, NS). Fasting plasma levels of FFA and glycerol were comparable in the three groups (Table 8.2). In underweight COPD patients, catecholamine concentrations were significantly increased compared to sarcopenic patients and controls. Also, insulin levels were significantly increased in sarcopenic patients, while insulin concentrations in underweight COPD patients were decreased. 
Table 8.2 Resting and end-of-exercise plasma free fatty acid (FFA), glycerol and hormone concentrations (mean \pm SEM).

\begin{tabular}{|c|c|c|c|}
\hline & $\begin{array}{l}\text { Controls } \\
(n=7)\end{array}$ & $\begin{array}{l}\text { Sarcopenic COPD } \\
\qquad(n=7)\end{array}$ & $\begin{array}{c}\text { Underweight COPD } \\
\qquad(n=6)\end{array}$ \\
\hline \multicolumn{4}{|l|}{ Resting state } \\
\hline $\mathrm{FFA}, \mathrm{mmol} \cdot \mathrm{I}^{-1}$ & $1.04 \pm 0.14$ & $1.08 \pm 0.13$ & $0.99 \pm 0.11$ \\
\hline Glycerol, $\left.\mathrm{mmol} \cdot\right|^{-1}$ & $79.9 \pm 6.4$ & $85.0 \pm 9.5$ & $97.1 \pm 11.1$ \\
\hline Insulin, $\mathrm{pmol}^{-1} \mathrm{I}^{-1}$ & $47 \pm 9$ & $76 \pm 12^{\mathrm{a}}$ & $22 \pm 6^{c}$ \\
\hline Epinephrine, $\mathrm{nmol} \cdot \mathrm{I}^{-1}$ & $0.45 \pm 0.07$ & $0.52 \pm 0.12$ & $1.01 \pm 0.24^{\mathrm{a}, \mathrm{b}}$ \\
\hline Norepinephrine, $\mathrm{nmol} \cdot \mathrm{I}^{-1}$ & $0.35 \pm 0.09$ & $0.85 \pm 0.21$ & $1.22 \pm 0.46^{\mathrm{a}}$ \\
\hline \multicolumn{4}{|l|}{ End-of-exercise ${ }^{1}$} \\
\hline $\mathrm{FFA}, \mathrm{mmol} \cdot \mathrm{l}^{-1}$ & $1.79 \pm 0.28$ & $1.45 \pm 0.15$ & $1.42 \pm 0.25$ \\
\hline Glycerol, $\left.\mathrm{mmol} \cdot\right|^{-1}$ & $230.6 \pm 41.2$ & $207.7 \pm 40.5$ & $229.1 \pm 49.7$ \\
\hline Insulin, $\mathrm{pmol} \cdot \mathrm{I}^{-1}$ & $51 \pm 8$ & $66 \pm 13$ & $19 \pm 3^{a, c}$ \\
\hline Epinephrine, $\mathrm{nmol} \cdot \mathrm{l}^{-1}$ & $0.85 \pm 0.18$ & $3.68 \pm 2.40$ & $2.88 \pm 1.00$ \\
\hline Norepinephrine, $\mathrm{nmol} \cdot \mathrm{I}^{-1}$ & $1.34 \pm 0.21$ & $2.41 \pm 0.51$ & $2.18 \pm 0.86$ \\
\hline
\end{tabular}

${ }^{1}$ : for controls, values after exercise at identical absolute workload are shown. Significance of differences between patients and controls is indicated as: ${ }^{a}: p<0.05$. Significant differences between COPD subgroups are shown as: ${ }^{b}: p<0.05$ and c: $p<0.01$.

Submaximal bicycle exercise resulted in significant increases in glycerol $R_{a}$ in all three groups (Figure 8.2 ). The proportional increase in glycerol $R_{a}$ during submaximal exercise was slightly less in sarcopenic COPD patients $(59 \pm 18 \%)$ in comparison to underweight patients $(82 \pm 22 \%, N S)$. In controls, the relative increment in glycerol $R_{a}$ was even greater during submaximal exercise at both identical absolute workload $(107 \pm 22 \%, N S)$ as well as identical proportional load $(177 \pm 39 \%, \mathrm{p}<0.05$ for both COPD groups). As a consequence, the end-of-exercise values for glycerol $R_{a}$ were lower in sarcopenic patients $\left(6.8 \pm 1.2 \mu \mathrm{mol} \cdot \mathrm{kgFFM}^{-1} \cdot \mathrm{min}^{-1}\right)$, than in underweight patients $\left(7.6 \pm 1.0 \mu \mathrm{mol} \cdot \mathrm{kgFFM}^{-1} \cdot \mathrm{min}^{-1}\right)$ and controls (30 Watt: $\quad 7.7 \pm 1.3 \mu \mathrm{mol} \cdot \mathrm{kgFFM}{ }^{-1} \cdot \mathrm{min}^{-1} ; \quad 50 \% \quad$ Wmax: $\quad 7.9 \pm 1.1$ $\mu \mathrm{mol} \cdot \mathrm{kgFFM}^{-1} \cdot \mathrm{min}^{-1}$ ), but differences were not significant (Figure 8.2). After exercise, glycerol $R_{a}$ recovered to baseline in all groups and values were comparable (Figure 8.2). No significant effects of study group on whole-body glycerol $R_{a}$ was observed during submaximal exercise at identical absolute work load $(F(1$, $2)=201.96$, NS) and identical relative work load $(F(1,2)=213.76$, NS) and during recovery periods $(F(1,2)=189.71$, NS and $F(1,2)=212.86$, NS, respectively). Plasma concentrations of FFA, glycerol and catecholamines increased significantly after submaximal exercise in all groups, and end-of-exercise values were also identical (Table 8.2). 
Figure 8.2 Whole-body lipolysis measured by rate of appearance $\left(R_{a}\right)$ of glycerol at rest, during submaximal cycle exercise and during recovery from exercise. Healthy controls $(n=7)$, closed triangles; sarcopenic COPD patients $(n=7)$, closed circles; underweight COPD patients $(n=6)$, open circles. No significant differences were observed between groups at any part of the study. For clearity, standard errors of the mean are not shown.

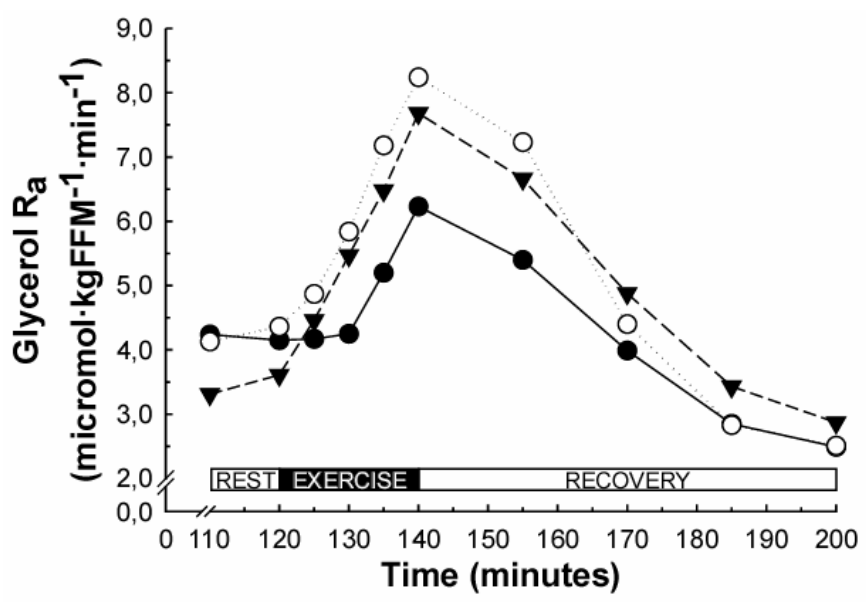

In bivariate correlation analysis in the total study population, resting glycerol $R_{a}$ was related to plasma epinephrine concentration $(r=0.520, p<0.05)$ and basal glycerol level $(r=0.760, p<0.001)$, while correlations with body mass index, fat-free mass (index) and fat mass (index) were absent. End-of-exercise glycerol $R_{a}$ was significantly related to post-exercise glycerol $(r=0.762, p<0.01)$ and FFA $(r=0.631, p<0.05)$ plasma levels and to resting norepinephrine concentration $(r=0.618, p<0.05)$ in COPD patients.

\section{Discussion}

This is the first study that investigated lipid kinetics using glycerol stable isotope tracer methodology in patients with COPD. Also, the contribution of derangements in whole-body lipolysis to body composition was not previously studied in COPD. No differences in resting and exercise-induced lipolysis were observed between sarcopenic patients with COPD and age-matched controls. Thus, in normal-weight and clinically stable COPD patients, (relative) 
maintenance of fat mass with evidence of muscle wasting is not related to altered adipocyte lipolysis.

Total body fat mass is determined by the balance between lipid synthesis and degradation. Lipids are stored in the adipocytes as triglycerides and constitute the main fuel reserve of the body. Following hormonal stimulation, the stored triglycerides are hydrolyzed to their components fatty acids and glycerol and this process is called lipolysis. The released fatty acids are either used for mitochondrial beta-oxidation to produce ATP or reesterified to triacylglycerol and restored. FFA are the major source of energy for resting muscle. It has been consistently shown that muscle fat oxidative capacity is reduced in COPD patients ${ }^{8}$, partly as an adaptation to a more sedentary lifestyle due to disease related symptoms. Although the effects of physical inactivity on adipose tissue lipolysis in COPD have not been studied, available evidence suggests that whole-body lipolytic rate is not related to training status $^{19}$. No difference in exercise-induced lipolysis was observed between untrained and endurance-trained healthy subjects, although fat oxidation was enhanced in the latter group ${ }^{20}$.

Previously, Schiffelers et al. ${ }^{9}$ reported a reduced increase in plasma fatty acid levels and a blunted thermogenic response during $\beta$ adrenergic stimulation in normal-weight COPD patients with high fat mass compared to controls. The authors suggested that disturbed lipolytic responsiveness contributes to the development or maintenance of increased fat mass in the subgroup of sarcopenic COPD patients. In contrast to the present study, no patients with a reduced fat mass were studied and whole-body lipolysis was not assessed. However, the results of the present study are in line with these previous observations. Although whole-body lipolytic rate was comparable between groups, homeostatic control of lipolysis was altered in sarcopenic COPD patients, as indicated by hyperinsulinaemia. Thus, the inhibitory effect of insulin on lipolytic rate seemed impaired in sarcopenic COPD patients. Also, the lipolytic response to exercise tended to be decreased in this subgroup.

In contrast to the present results, Jakobsson et al. ${ }^{21}$ reported increased turnover rate and plasma levels of free fatty acids in normal-weight COPD patients (BMI: $23.6 \mathrm{~kg} \cdot \mathrm{m}^{-2}$ ), suggestive for increased state of lipolysis. The fact that included patients were chronically hypoxaemic may account for the distinct results compared to the normoxaemic patients in the present study. In healthy subjects, elevated levels of FFA were observed during 
chronic hypobaric hypoxia, probably related to enhanced epinephrine-induced lipolysis ${ }^{22}$.

Lipolytic rate was not enhanced in underweight COPD patients in comparison to normal-weight patients or controls, despite significantly elevated catecholamine levels. Since catecholamines are the primary stimulators of lipolysis via $\beta$-adrenoceptors, alterations in sympathetic tone may result in changes in fat mass and body weight in COPD patients. Indeed, Hofford et al. ${ }^{23}$ reported nearly doubled plasma norepinephrine levels in underweight patients with severe COPD in comparison to healthy normal-weight control subjects. However, results of the present study suggests a reduced sensitivity to circulating catecholamines and confirm the observations by Schiffelers et al. ${ }^{9}$. Due to chronic overstimulation of the sympathic nervous system in COPD $^{24}$ and the long-term usage of $\beta_{2}$-agonists for bronchodilatation, $\beta$-adrenoceptors may become desensitized and subsequently the lipolytic response following hormonal stimulation might be reduced ${ }^{25}$.

Since the contribution of impaired lipolysis to the sarcopenic phenotype of COPD patients is unlikely, selective wasting of fat-free mass rather than preservation of fat mass seems to be the predominant pathophysiological mechanism. Indeed, increased whole-body myofibrillar protein breakdown, assessed by a methylhistidine stable isotope tracer protocol, has been reported in underweight COPD patients with reduced fat-free mass and fat mass, in comparison to normal-weight patients and controls with preserved fat-free mass ${ }^{5}$. In addition, increased cellular ${ }^{6}$ and muscular protein catabolism ${ }^{7}$ was observed in COPD patients with evidence for muscle atrophy. This suggests that increased muscle protein breakdown is the trigger in the body compositional shift in COPD, towards reduced fat-free mass.

This study assessed potential differences in lipolytic rate in clinically stable sarcopenic COPD patients without recent weight loss. However, the present body composition of these COPD patients may result from foregoing episodes of shifts in body fat and fat-free tissues. During acute exacerbations of the disease a combination of enhanced hypoxemia, increased sympathetic tone, more frequent use $\beta_{2}$-agonists as reliever therapy, administration of systemic corticosteroids and a reduced dietary intake may induce short-term bursts of increased lipolysis resulting in degradation of body fat mass and weight loss. Thus, it might be interesting to study potential periods with deranged lipid metabolism during acute exacerbation in 
relation to longitudinal changes in body composition in COPD in the future.

In summary, resting and exercise-induced whole-body lipolytic rate was comparable in sarcopenic COPD patients, underweight patients and matched control subjects, despite significant alterations in endocrinological control of lipolysis. Disturbances in lipolytic rate do not contribute to alterations in body composition in COPD. 


\section{References}

1. Schols AM, Broekhuizen R, Weling-Scheepers CA, Wouters EF. Body composition and mortality in chronic obstructive pulmonary disease. Am J Clin Nutr 2005;82:53-59.

2. Vermeeren MA, Creutzberg EC, Schols AM, Postma DS, Pieters WR, Roldaan AC, Wouters EF. Prevalence of nutritional depletion in a large out-patient population of patients with COPD. Respir Med 2006;100:1349-1355.

3. Schols AM, Soeters PB, Dingemans AM, Mostert R, Frantzen PJ, Wouters EF. Prevalence and characteristics of nutritional depletion in patients with stable COPD eligible for pulmonary rehabilitation. Am Rev Respir Dis 1993;147:11511156.

4. Vestbo J, Prescott E, Almdal T, Dahl M, Nordestgaard BG, Andersen T, Sorensen TI, Lange P. Body mass, fat-free body mass, and prognosis in patients with chronic obstructive pulmonary disease from a random population sample: Findings from the Copenhagen City Heart Study. Am J Respir Crit Care Med 2006; 173:79-83.

5. Rutten EP, Franssen FM, Engelen MP, Wouters EF, Deutz NE, Schols AM. Greater whole-body myofibrillar protein breakdown in cachectic patients with chronic obstructive pulmonary disease. Am J Clin Nutr 2006;83:829-834.

6. Bolton CE, Broekhuizen R, Ionescu AA, Nixon LS, Wouters EF, Shale DJ, Schols AM. Cellular protein breakdown and systemic inflammation are unaffected by pulmonary rehabilitation in COPD. Thorax 2007;62:109-114.

7. Doucet M, Russell AP, Leger B, Debigare R, Joanisse DR, Caron MA, Leblanc P, Maltais $\mathrm{F}$. Muscle atrophy and hypertrophy signalling in patients with chronic obstructive pulmonary disease. Am J Respir Crit Care Med 2007.

8. Maltais F, LeBlanc P, Whittom F, Simard C, Marquis K, Belanger M, Breton MJ, Jobin J. Oxidative enzyme activities of the vastus lateralis muscle and the functional status in patients with COPD. Thorax 2000;55:848-853.

9. Schiffelers SL, Blaak EE, Baarends EM, Van Baak MA, Saris WH, Wouters EF, Schols AM. Beta-adrenoceptor-mediated thermogenesis and lipolysis in patients with chronic obstructive pulmonary disease. Am J Physiol Endocrinol Metab 2001;280:E357-E364.

10. Legaspi A, Jeevanandam M, Starnes HF, Jr., Brennan MF. Whole-body lipid and energy metabolism in the cancer patient. Metabolism 1987;36:958-963.

11. American Thoracic Society Statement. Standards for the diagnosis and care of patients with chronic obstructive pulmonary disease. Am J Respir Crit Care Med 1995;152:S77-121.

12. Lukaski HC, Johnson PE, Bolonchuk WW, Lykken GI. Assessment of fat-free mass using bioelectrical impedance measurements of the human body. Am J Clin Nutr $1985 ; 41: 810-817$.

13. Steiner MC, Barton RL, Singh SJ, Morgan MD. Bedside methods versus dual energy x-ray absorptiometry for body composition measurement in COPD. Eur Respir J 2002;19:626-631.

14. Kyle UG, Bosaeus I, De Lorenzo AD, Deurenberg P, Elia M, Gomez JM, Heitmann $\mathrm{BL}$, Kent-Smith L, Melchior JC, Pirlich M, et al. Bioelectrical impedance analysis part I: Review of principles and methods. Clin Nutr 2004;23:1226-1243.

15. Franssen FM, Broekhuizen R, Janssen PP, Wouters EF, Schols AM. Effects of whole-body exercise training on body composition and functional capacity in normal-weight patients with COPD. Chest 2004;125:2021-2028.

16. Ackermans MT, Ruiter AF, Endert E. Determination of glycerol concentrations and glycerol isotopic enrichments in human plasma by gas chromatography/mass spectrometry. Anal Biochem 1998;258:80-86. 
17. Wolfe RR. Radioactive and stable isotope tracers in biomedicine: Principles and practice of kinetic analysis. New York: Wiley-Liss; 1992.

18. Romijn JA, Coyle EF, Sidossis LS, Gastaldelli A, Horowitz JF, Endert E, Wolfe RR. Regulation of endogenous fat and carbohydrate metabolism in relation to exercise intensity and duration. Am J Physiol 1993;265:E380-391.

19. Horowitz JF, Klein S. Lipid metabolism during endurance exercise. Am J Clin Nutr $2000 ; 72: 558 S-563 S$.

20. Klein S, Coyle EF, Wolfe RR. Fat metabolism during low-intensity exercise in endurance-trained and untrained men. Am J Physiol 1994;267:E934-940.

21. Jakobsson $P$, Jorfeldt $L$, von Schenck $H$. Fat metabolism and its response to infusion of insulin and glucose in patients with advanced chronic obstructive pulmonary disease. Clin Physiol 1995;15:319-329.

22. Roberts AC, Butterfield GE, Cymerman A, Reeves JT, Wolfel EE, Brooks GA. Acclimatization to 4,300-m altitude decreases reliance on fat as a substrate. $J$ Appl Physiol 1996;81:1762-1771.

23. Hofford JM, Milakofsky L, Vogel WH, Sacher RS, Savage GJ, Pell S. The nutritional status in advanced emphysema associated with chronic bronchitis. A study of amino acid and catecholamine levels. Am Rev Respir Dis 1990;141:902-908.

24. Andreas S, Anker SD, Scanlon PD, Somers VK. Neurohumoral activation as a link to systemic manifestations of chronic lung disease. Chest 2005;128:3618-3624.

25. Holgate ST, Stubbs WA, Wood PJ, McCaughey ES, Alberti KG, Tattersfield AE. Airway and metabolic resistance to intravenous salbutamol: A study in normal man. Clin Sci (Lond) 1980;59:155-161. 


\section{Chapter 9}

\section{Greater whole-body myofibrillar protein breakdown in cachectic patients with chronic obstructive pulmonary disease}
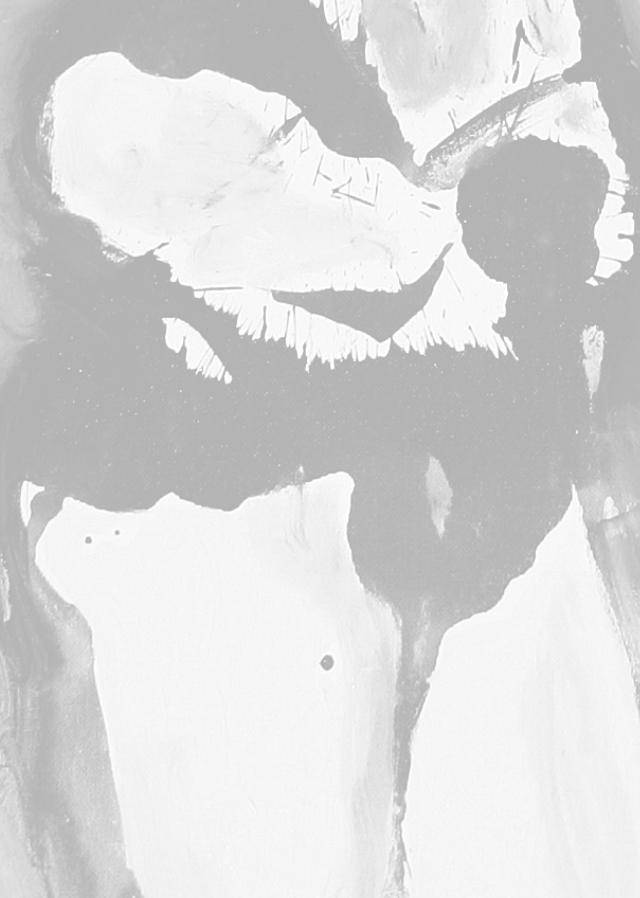

Erica P.A. Rutten, Frits M.E. Franssen, Marielle P.K.J. Engelen, Emiel F.M. Wouters, Nicolaas E.P. Deutz, Annemie M.W.J. Schols American Journal Of Clinical Nutrition 2006; 83: 829-834 


\section{Abstract}

\section{Introduction}

Experimental studies indicate that greater skeletal muscle protein breakdown is a trigger for the cachexia that often is prevalent in chronic obstructive pulmonary disease (COPD).

\section{Methods}

We compared myofibrillar protein breakdown (MPB) with to whole-body (WB) protein breakdown $(\mathrm{PB})$ in nine cachectic COPD patients $\left(\mathrm{FEV}_{1}: 48 \pm 4 \%\right.$ of predicted), seven noncachectic COPD patients $\left(\mathrm{FEV}_{1}: 53 \pm 5 \%\right.$ of predicted), and seven age-matched healthy control subjects, who were matched by body mass index with the noncachectic patients.

After the subjects fasted overnight (10 hours) and discontinued the maintenance medication, a primed constant and continuous infusion protocol was used to infuse L[ring- $\left.{ }^{2} \mathrm{H}_{5}\right]$-phenylalanine and $\mathrm{L}-\left[\right.$ ring $\left.-{ }^{2} \mathrm{H}_{2}\right]$-tyrosine to measure WB protein turnover and $L-\left[{ }^{2} \mathrm{H}_{3}\right]-3$-methylhistidine to measure WB MPB. Three arterialized venous blood samples were taken between 80 and 90 minutes of infusion to measure amino acid concentrations and tracer enrichments.

\section{Results}

Body composition, WB protein turnover and WB MPB did not differ significantly between the noncachectic COPD and control subjects. Cachectic COPD had lower fat mass and fat-free mass values (both: $p<0.01$ ) than did the noncachectic COPD patients. WB MPB was significantly $(p<0.05)$ higher in the cachectic COPD group $(18 \pm 3$ $\left.\mathrm{nmol} \cdot \mathrm{kg}^{-1} \cdot \mathrm{min}^{-1}\right)$ than in the combined control and noncachectic COPD groups $(10 \pm 1$ $\mathrm{nmol} \cdot \mathrm{kg}^{-1} \cdot \mathrm{min}^{-1}$ ), but WB protein turnover did not differ significantly between the groups. Correlations with fat-free mass were significant $(p<0.05)$ for plasma glutamate and branched-chain amino acids, and that for WB MPB trended toward significance $(p=0.07)$.

\section{Conclusions}

Cachexia in clinically stable patients with moderate COPD is characterized by increased WB MPB, which indicates that myofibrillar protein wasting is an important target for nutritional and pharmacological modulation. 


\section{Introduction}

Weight loss and muscle wasting are prevalent in patients with moderate-to-severe chronic obstructive pulmonary disease $(\mathrm{COPD})^{1,2}$, a combination that is commonly referred to as pulmonary cachexia. Low fat-free mass (FFM), reflecting the amount of skeletal muscle mass, is associated with exercise intolerance ${ }^{3}$ related to reduced skeletal muscle strength ${ }^{4,5}$, impaired health status ${ }^{6}$ and shorter survival ${ }^{7}$. Experimental studies in acute disease models indicate that increased skeletal muscle protein breakdown (PB) is a typical feature of cachexia, and activation of the ubiquitineproteasome pathway has been identified as an important trigger of proteolysis $^{8}$. Surprising little information is available about protein metabolism in relation to cachexia in clinically stable chronic disease states. In comparing underweight patients with emphysema with healthy control subjects, Morrison et al. $^{9}$ found no difference in skeletal muscle PB but lower whole-body protein synthesis in the emphysema patients. This study was, however, limited by the facts that the control group was significantly younger than the COPD group (mean age: 45 and $62 \mathrm{yr}$, respectively) and that no noncachectic COPD patients were included. Recently, elevated concentrations of urinary pseudouridine, used as an indirect biomarker for cellular PB, were found in cachectic COPD patients than in noncachectic patients and healthy controls ${ }^{10}$. In addition, the noncachectic patients had higher urinary pseudouridine concentrations than did the controls. The plasma amino acid profile in cachectic COPD patients is more extensively investigated than is protein metabolism, and it consistently shows a low concentration of the branched-chain amino acids (BCAAs) leucine, isoleucine, and valine ${ }^{9,11,12}$.

Measurements of whole-body (WB) protein metabolism do not necessarily reflect skeletal muscle metabolism. Vissers et al. ${ }^{13}$ described a technique to measure the rate of myofibrillar PB (MPB) by using the primed constant and continuous infusion protocol with deuterated 3-methylhistidine. Although myofibrillar protein is also present in other tissue such as intestine and skin, it is mainly found in muscle. Therefore, WB MPB gives an indication for skeletal muscle PB. The current study is the first to measure the rate of WB MPB in humans. The main purpose of the current study was to investigate whether WB MPB is greater in cachectic COPD patients than in noncachectic COPD patients or healthy controls. The secondary purpose was to study whether WB MPB is reflected in WB PB. 


\section{Methods}

\section{Study population}

In total, 16 clinically stable males with moderate-to-severe COPD ${ }^{14}$ and seven age- and sex-matched healthy control subjects were studied. Each member of the healthy control group was matched for BMI with a member of the noncachectic COPD group $(n=7$; BMI: $\left.28 \pm 1 \mathrm{~kg} \cdot \mathrm{m}^{-2}\right)$. The remaining COPD patients $(n=9)$ were defined as the cachectic COPD group (BMI: $20 \pm 1 \mathrm{~kg} \cdot \mathrm{m}^{-2}$ ). Exclusion criteria for all subjects were malignancy, cardiac failure, distal arteriopathy, recent surgery, and severe endocrine, hepatic, or renal disorder. In addition, patients who were using systemic corticosteroids $\leq 3$ months before the study were excluded, because it has been shown that systemic corticosteroids may affect muscle protein metabolism ${ }^{15}$. The following pulmonary maintenance medications were being used by various proportions of the patients: inhaled short- and long-acting $\beta_{2}$-adrenoceptor agonists, 56\%; anticholinergics by inhalation, $54 \%$; combined inhalers of short-acting $\beta_{2}$-adrenoceptor agonists and short-acting anticholinergics, $8 \%$; inhalation corticosteroids, $19 \%$; combined inhalers of sympathycomimetics and corticosteroids, $46 \%$; xanthines, $31 \%$; and oral $\mathrm{N}$ acetylcysteine, $23 \%$. On the evening before the test day and the morning of the test day, the maintenance medication was suspended to avoid potential acute effects of these medications on substrate metabolism ${ }^{16}$, because glucose and glycerol metabolism were also measured in the study (data presented in chapter 7 and 8).

Written informed consent was obtained from all subjects. The study was approved by the medical ethics committee of the University Hospital Maastricht.

\section{Pulmonary function tests}

Before the test day, all subjects underwent spirometry for measurement of forced expiratory volume in one second $\left(\mathrm{FEV}_{1}\right)$ and forced vital capacity; the highest value from three technically acceptable maneuvers was then used. Total lung capacity, intrathoracic gas volume, and residual volume were assessed by using WB plethysmography (Masterlab; Jaeger, Wurzburg, Germany). Diffusion capacity for carbon monoxide was measured by using the single-breath method (Masterlab; Jaeger). All values obtained were related to a reference value and expressed as percentages of the predicted value ${ }^{17}$. On the morning of the lung 
function measurements, the pulmonary maintenance medications were suspended.

\section{Experimental protocol}

\section{Study design}

Subjects were in a supine position for $1.5 \mathrm{~h}$. A catheter was placed in an antecubital vein of the arm for tracer infusion (at a rate of $85 \mathrm{ml} \cdot \mathrm{h}^{-1}$ ) according to a primed constant and continuous infusion protocol. The stable isotopes $\mathrm{L}-\left[\mathrm{ring}^{2} \mathrm{H}_{5}\right]$-phenylalanine (PHE), L-[ring- $\left.{ }^{2} \mathrm{H}_{2}\right]$-tyrosine (TYR) were used to measure WB total protein turnover. $\mathrm{L}-\left[{ }^{2} \mathrm{H}_{3}\right]-3$-methylhistidine $(3 \mathrm{MH})$ was infused to measure WB MPB. The following priming doses (PDs) and infusion rates (IRs) were used: $\quad L-\left[\right.$ ring $\left._{-}{ }^{2} \mathrm{H}_{5}\right]-\mathrm{PHE}: \quad \mathrm{PD}=2.19 \mu \mathrm{mol} \cdot \mathrm{kg}^{-1}, \quad \mathrm{IR}=3.20$ $\mu \mathrm{mol} \cdot \mathrm{kgFFM}^{-1} \cdot \mathrm{h}^{-1}, \mathrm{~L}-\left[\mathrm{ring}_{-}{ }^{2} \mathrm{H}_{2}\right]-\mathrm{TYR}: \mathrm{PD}=0.95 \mu \mathrm{mol} \cdot \mathrm{kgFFM}^{-1}, \mathrm{IR}=0.77$ $\mu \mathrm{mol} \cdot \mathrm{kgFFM}^{-1} \cdot \mathrm{h}^{-1}, \quad \mathrm{~L}-\left[{ }^{2} \mathrm{H}_{3}\right]-3 \mathrm{MH}: \quad \mathrm{PD}=0.09 \mu \mathrm{mol} \cdot \mathrm{kgFFM}^{-1}, \quad \mathrm{IR}=0.03$ $\mu \mathrm{mol} \cdot \mathrm{kgFFM}{ }^{-1} \cdot \mathrm{h}^{-1}$. Moreover, a bolus dose of $\mathrm{L}-\left[\right.$ ring $\left.^{2}{ }^{2} \mathrm{H}_{4}\right]-\mathrm{TYR}$ was also given to prime the phenylalanine-derived plasma tyrosine pool $\left(P D=0.31 \mu \mathrm{mol} \cdot \mathrm{kgFFM}^{-1}\right)$. The tracers were obtained from Cambridge Isotopic Laboratories (Woburn, MA, USA). After a baseline venous blood sample was collected, the PD was administrated intravenously. Subsequently, constant continuous tracer infusion was started until the end of the test day. A second catheter for arterialized venous blood sampling was placed in a superficial dorsal vein of the hand of the contralateral arm, which was placed in a thermostatically controlled hot box (internal temperature: $60^{\circ} \mathrm{C}$ ), at least 20 minutes before the first blood sampling. The use of the hot box is a technique to mimic direct arterial sampling ${ }^{18}$. Three arterialized venous blood samples were taken between 80 and 90 minutes after the start of the infusion to measure enrichments [the ratio of tracer to tracee (TTR)] of the stable isotopes at plasma steady state level.

\section{Biochemical analyses}

Venous and arterialized venous blood samples were collected in a heparinized tube that was immediately put on ice and centrifuged $\left(3120 \times \mathrm{g}, 4^{\circ} \mathrm{C}\right.$ for 10 minutes) to obtain plasma. Subsequently, $250 \mu \mathrm{l}$ plasma was deproteinized with $20 \mathrm{mg}$ sulfosalicylic acid to analyze plasma amino acid concentrations and enrichments. All samples were frozen in liquid nitrogen and stored at $-80^{\circ} \mathrm{C}$ until analysis. Amino acid concentrations were analyzed from venous blood by high-performance liquid chromatography (HPLC) system ${ }^{19}$. 
PHE, TYR, and 3MH enrichments were analyzed by using a liquid chromatography mass spectrometry system (LC-MS, Thermoquest, Veenendaal, The Netherlands) ${ }^{20}$.

\section{Calculations}

All metabolic data were determined under steady state conditions. Therefore, WB rate of appearance $\left(R_{a}\right)$ of PHE represents WB PB. Because $3 M H$ is released only from MPB, the WB $R_{a}$ of $3 M H$ gives an indication of WB MPB. The following calculation was used:

WB $R_{a}=I / T T R$,

where $I$ represents the tracer infusion rate in plasma.

Moreover, WB protein synthesis was calculated by subtracting the hydroxylation of PHE to TYR [WB $\mathrm{R}_{a}$ TYR $\times$ (TTR TYR4/TTR PHE5)] from $W B P^{21}$. WB net balance was calculated by subtracting $W B$ protein synthesis from WB PB.

WB FFM was measured in each subject by using bioelectrical impedance analysis to express metabolic data per kg FFM. The FFM of the COPD patients was calculated by using each patient's specific regression equation ${ }^{22}$, while the FFM of the healthy control subjects was calculated by using a specific regression equation described by Dey et al. ${ }^{23}$. Body weight and height were measured to the nearest $0.1 \mathrm{~kg}$ and $0.1 \mathrm{~cm}$, respectively, while the subjects were standing and wearing light indoor clothing but no shoes.

\section{Statistical analyses}

Results are expressed as mean \pm standard error of the mean (SEM). The mean values of the data obtained from the three arterialized venous blood samples were used as WB protein turnover and MPB in the postabsorptive state. All data were tested for normality with a normal probability plot. The one-way analysis of variance with the post hoc Scheffé test was used to test whether there were significant differences between the groups in general characteristics, lung function, amino acid concentration, and protein turnover. To increase the size of the noncachectic group, which will increase the statistical power for comparison, the control group and the noncachectic COPD patients were taken together (control + noncachectic COPD groups, $\mathrm{n}=14$ ) to ascertain the effect of a change in body composition on protein metabolism by using the Scheffé test. The bivariate Pearson correlation coefficient was measured to test data for correlations. All 
$p$ values $<0.05$ were considered significant. SPSS for Windows software (version 11.0; SPSS Inc, Chicago, IL, USA) was used for data analysis.

\section{Results}

\section{General characteristics}

General characteristics of the subjects are shown in Table 9.1. There were no significant differences in FFM, FFM index (FFMI: FFM.height ${ }^{-2}$ ), fat mass (FM), or FM index (FMI: FM.height ${ }^{-2}$ ) between the noncachectic COPD group and the BMI-matched healthy control group. Cachectic COPD patients had lower values for FFM, FFMI, and FM (all: $p<0.01)$ and FMI $(p<0.05)$ than did the noncachectic COPD group.

Table 9.1 General characteristics of the study participants (mean \pm SEM).

\begin{tabular}{|c|c|c|c|}
\hline & $\begin{array}{l}\text { Control group } \\
\qquad(n=7)\end{array}$ & $\begin{array}{c}\text { Noncachectic COPD group } \\
\qquad(n=7)\end{array}$ & $\begin{array}{l}\text { Cachectic COPD group } \\
\qquad(n=9)\end{array}$ \\
\hline Age, yr & $65 \pm 2$ & $64 \pm 4$ & $70 \pm 3$ \\
\hline Weight, kg & $86 \pm 6$ & $82 \pm 3$ & $59 \pm 3^{1,2}$ \\
\hline $\mathrm{BMI}, \mathrm{kg} \cdot \mathrm{m}^{-2}$ & $28 \pm 1$ & $28 \pm 1$ & $20 \pm 1^{1,2}$ \\
\hline FFM, kg & $63 \pm 3$ & $56 \pm 2$ & $45 \pm 1^{1,3}$ \\
\hline FFMI, $\mathrm{kg} \cdot \mathrm{m}^{-2}$ & $21 \pm 1$ & $19 \pm 1$ & $16 \pm 0^{1,3}$ \\
\hline $\mathrm{FM}, \mathrm{kg}$ & $25 \pm 3$ & $26 \pm 3$ & $14 \pm 2^{1,3}$ \\
\hline $\mathrm{FMI}, \mathrm{kg} \cdot \mathrm{m}^{-2}$ & $8 \pm 1$ & $9 \pm 1$ & $5 \pm 1^{3,4}$ \\
\hline \multicolumn{4}{|l|}{ Lung function } \\
\hline $\mathrm{FEV}_{1}, \%$ predicted & $102 \pm 4$ & $53 \pm 5$ & $48 \pm 4^{3}$ \\
\hline FVC, \% predicted & $109 \pm 4$ & $101 \pm 6$ & $109 \pm 6$ \\
\hline ITGV, \% predicted & $104 \pm 9$ & $131 \pm 10$ & $167 \pm 7^{1,3}$ \\
\hline RV, \% predicted & $111 \pm 8$ & $124 \pm 10$ & $170 \pm 9^{1,2}$ \\
\hline $\mathrm{DL}_{\mathrm{CO}}, \%$ predicted & $113 \pm 6$ & $62 \pm 7$ & $59 \pm 4^{1}$ \\
\hline TLC, \% predicted & $104 \pm 5$ & $105 \pm 6$ & $123 \pm 5^{3,4}$ \\
\hline
\end{tabular}

BMI: body mass index, FFM: fat free mass, FFMI: fat-free mass index, FM: fat mass, FMI: fat mass index, $\mathrm{FEV}_{1}$ : forced expiratory volume in one second; FVC: forced vital capacity, ITGV: intrathoracic gas volume, RV: residual volume, DLco: diffusing capacity for carbon monoxide, TLC: total lung capacity. ${ }^{1,4}$ Significantly different from control group (one-way ANOVA and post hoc Scheffé test): ${ }^{1} p<0.01,{ }^{4} p<0.05 .{ }^{2,3}$ Significantly different from noncachectic group (one-way ANOVA and post hoc Scheffé test): ${ }^{2} p<0.01,{ }^{3} p<0.05$.

All COPD patients were characterized by lower values for $\mathrm{FEV}_{1}$ and diffusion capacity for carbon monoxide $(p<0.01)$. The cachectic COPD group had higher values for residual volume $(p<0.05)$ than did the control group. Moreover, the cachectic COPD group had 
significantly higher intrathoracic gas volume and residual volume (both: $p<0.01)$ and total lung capacity $(p<0.05)$ than did the noncachectic COPD group, which indicated mild hyperinflation at rest.

\section{Whole-body protein turnover and myofibrillar protein breakdown}

Data on WB PB, synthesis, and net balance, shown in Table 9.2, did not differ significantly between the three groups. MPB (Figure 9.1) was significantly higher in the cachectic COPD group than in the control group $(p<0.05)$. There was one outlier for MPB in the noncachectic COPD group (BMI: $32 \mathrm{~kg} \cdot \mathrm{m}^{-2}$; WB MPB: 24 $\left.\mathrm{nmol} \cdot \mathrm{kgFFM}^{-1} \cdot \mathrm{min}^{-1}\right)$. When the combined control and noncachectic COPD groups $(n=14)$ were compared with the cachectic COPD group, WB MPB was significantly higher in the latter $(p<0.05)$. Moreover, WB MPB tended to significantly correlate with FFM $(r=-0.38, p=0.07$; Figure 9.2).

Table 9.2 Whole-body total protein turnover in the control and COPD groups (mean \pm SEM).

\begin{tabular}{lccc}
\hline & $\begin{array}{c}\text { Control group } \\
(\mathrm{n}=7)\end{array}$ & $\begin{array}{c}\text { Noncachectic COPD group } \\
(\mathrm{n}=7)\end{array}$ & $\begin{array}{c}\text { Cachectic COPD group } \\
(\mathrm{n}=9)\end{array}$ \\
$\mathrm{nmol} \cdot \mathrm{kgFFM})^{-1} \cdot \mathrm{min}^{-1}$ & $\mathrm{nmol} \cdot \mathrm{kgFFM}{ }^{-1} \cdot \mathrm{min}^{-1}$ & $769 \pm 47$ & $\mathrm{nmol} \cdot \mathrm{kgFFM}^{-1} \cdot \mathrm{min}^{-1}$ \\
\hline WB PB & $839 \pm 45$ & $697 \pm 46$ & $774 \pm 28$ \\
WB PS & $772 \pm 54$ & $-59 \pm 12$ & $-62 \pm 5$ \\
WB NB & $-63 \pm 7$ & 26 & $708 \pm 26$ \\
\hline
\end{tabular}

WB PB: whole-body protein breakdown, WB PS: whole-body protein synthesis, WB NB: whole-body net balance. There were no significant differences in protein turnover between the groups (one-way ANOVA with post hoc Scheffé test).

\section{Plasma amino acid concentrations}

Plasma concentrations of glutamate were significantly $(p<0.05)$ lower in the cachectic COPD group than in the control group or the noncachectic COPD group (Table 9.3). Plasma tyrosine, isoleucine, and BCAA concentrations were significantly lower in the cachectic group than in the noncachectic COPD group $(p<0.05)$. When the cachectic COPD group was compared with the combined control and noncachectic COPD groups, we found that plasma tyrosine and glutamate (both: $p<0.01$ ), leucine, isoleucine, valine, and the sum of BCAAs $(p<0.05)$ were significantly lower in the former group. Plasma glutamate concentrations were significantly correlated with BMI, FFM, and FFMI [BMI: $r=0.67, p<0.01 ; F F M: r=0.70, p<0.01$ (Figure 
9.3); FFMI: $r=0.59, p<0.01$ ] but not with FMI. Plasma BCAA concentrations were significantly correlated with FFM and FFMI [FFM: $r=0.55, p<0.01$ (Figure 9.3); FFMI: $r=0.52$, $p<0.01$ ].

Figure 9.1 Box-whisker plot of myofibrillar protein breakdown (WB MPB) in the healthy control, noncachectic COPD, and cachectic COPD groups. Values indicate minimum, $25^{\text {th }}$ percentile, mean, $75^{\text {th }}$ percentile, maximum, and outlier. MPB differed significantly between the control group and the cachectic COPD group and between the combined control and noncachectic COPD groups and the cachectic COPD group, $\mathrm{p}<0.05$ for both (one-way ANOVA and post hoc Scheffé test). FFM: fat-free mass.

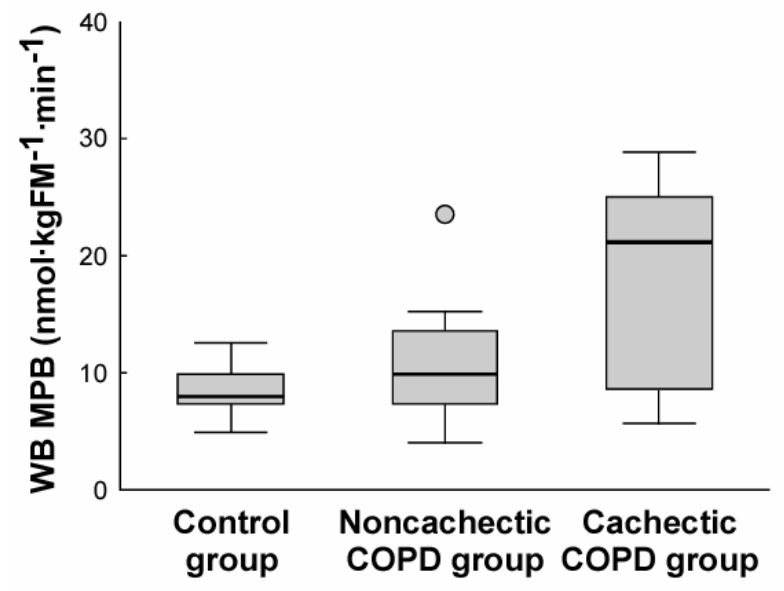

Figure 9.2 Scatter plot of whole-body myofibrillar protein breakdown (WB MPB) and fat-free mass (FFM) in the healthy control (closed triangles; $n=7$ ), noncachectic COPD (closed circles; $n=7$ with one outlier: grey circle), and cachectic COPD groups (open circles; $n=9$ ). Bivariate Pearson's correlation coefficient was measured: $r=-0.38, p=0.07$.

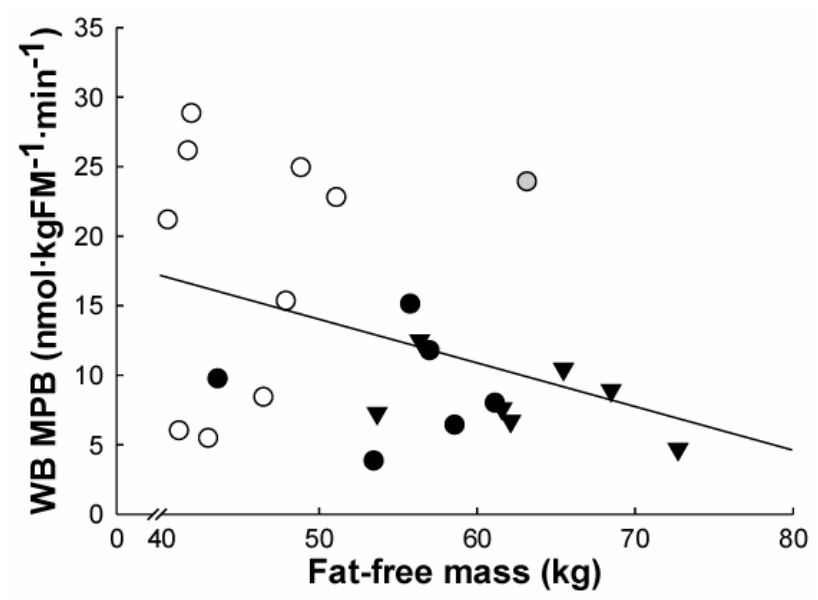


Table 9.3 Plasma amino acid concentrations in the control group, the noncachectic COPD group and the cachectic COPD group (mean \pm SEM).

\begin{tabular}{lccc}
\hline & Control group & $\begin{array}{c}\text { Noncachectic COPD } \\
\text { Group } \\
(n=7)\end{array}$ & $\begin{array}{c}\text { Cachectic COPD } \\
\text { group } \\
(\mathrm{n}=9)\end{array}$ \\
\hline Phenylalanine, $\mu \mathrm{mol} \cdot \mathrm{I}^{-1}$ & $62 \pm 1$ & $64 \pm 2$ & $60 \pm 2$ \\
Tyrosine, $\mu \mathrm{mol} \cdot \mathrm{I}^{-1}$ & $68 \pm 3$ & $71 \pm 4$ & $58 \pm 2^{1,2}$ \\
Glutamate, $\mu \mathrm{mol} \cdot \mathrm{I}^{-1}$ & $84 \pm 10$ & $84 \pm 4$ & $52 \pm 6^{1-3}$ \\
Leucine, $\mu \mathrm{mol} \cdot \mathrm{I}^{-1}$ & $130 \pm 7$ & $82 \pm 5$ & $65 \pm 1^{4}$ \\
Isoleucine, $\mu \mathrm{mol} \cdot \mathrm{I}^{-1}$ & $78 \pm 4$ & $82 \pm 5$ & $65 \pm 1^{1,4}$ \\
Valine, $\mu \mathrm{mol} \cdot \mathrm{I}^{-1}$ & $229 \pm 13$ & $228 \pm 11$ & $201 \pm 3^{4}$ \\
BCAAs, $\left.\mu \mathrm{mol} \cdot\right|^{-1}$ & $435 \pm 24$ & $439 \pm 19$ & $380 \pm 4^{1,4}$ \\
\hline
\end{tabular}

BCAAs, branched-chain amino acids (the sum of leucine, isoleucine, and valine).

${ }^{1}$ Significantly different from the noncachectic COPD group, $\mathrm{p}<0.05$ (one-way ANOVA and post hoc Scheffé test). ${ }^{2,4}$ Significantly different from both noncachectic groups (one-way ANOVA and post hoc Scheffé test): ${ }^{2} p<0.01,{ }^{4} p<0.05$.

${ }^{3}$ Significantly different from the control group, $p<0.05$ (one-way ANOVA and post hoc Scheffé test).

Figure 9.3 Scatter plots of plasma glutamate and branched-chain amino acid (BCAA) concentrations and fat-free mass (FFM) in the healthy control (closed triangles; $n=7$ ), noncachectic COPD (closed circles; $n=7$ with one outlier: grey circle), and cachectic COPD groups (open circles; $n=9$ ). Pearson's correlation coefficient was 0.70 for plasma glutamate and 0.55 for BCAA's (both: $p<0.01$ )
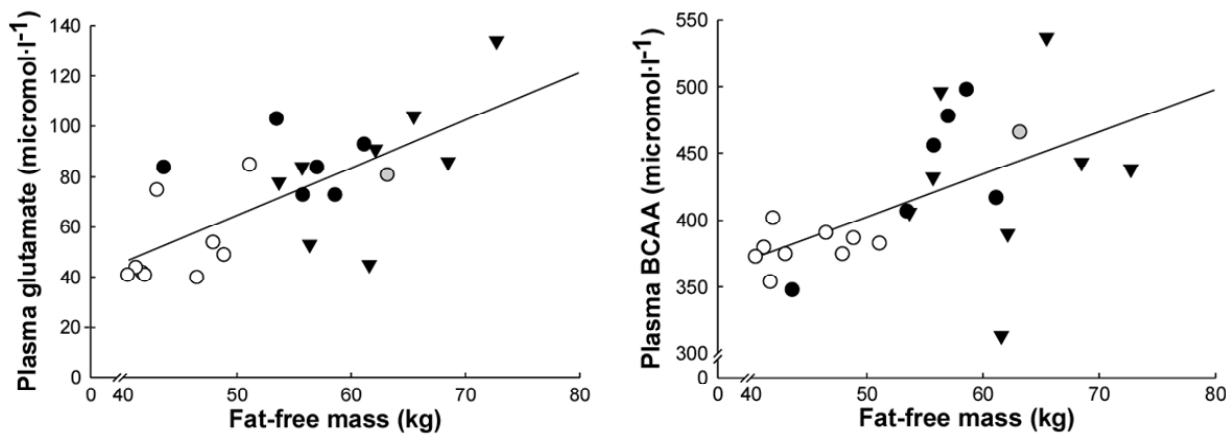

\section{Discussion}

The current study shows that WB MPB is higher in clinically stable cachectic patients with moderate COPD than in noncachectic patients and control subjects. However, no difference in WB total protein turnover was found between the two groups. 


\section{Whole-body myofibrillar protein breakdown}

The greatest storage of protein in the body occurs in skeletal muscle. However, WB measurements of protein metabolism do not always reflect skeletal muscle protein metabolism ${ }^{24} .3 \mathrm{MH}$ is present solely in myofibrillar protein, and the proteolysis of myofibrils releases $3 \mathrm{MH}$ that cannot be reused. Therefore, measurement of the TTR of $3 \mathrm{MH}$ in plasma can be used as a valid method of measuring MPB. Because $\approx$ $90 \%$ of the total body pool of $3 \mathrm{MH}$ is present in skeletal muscle ${ }^{25}$, MPB gives an indication of skeletal muscle PB.

The finding in the current study that WB MPB did not differ significantly between noncachectic COPD patients and healthy control subjects is consistent with data from a previous study, in which the measurement of urinary concentrations of $3 \mathrm{MH}$ was used as a noninvasive method of measuring $\mathrm{MPB}^{26}$. However, when both methods of measuring MPB are compared, several practical disadvantages to the collection of urinary $3 \mathrm{MH}$ concentrations should be described. First, the amount of $3 \mathrm{MH}$ in the urine is dependent on the amount of meat intake of the subjects. Thus, it is necessary for subjects to follow a meat-restricted diet for 3 days before the measurement. Second, because the urine has to be collected for 24 hours, the effect of acute stressors on MPB, such as feeding or exercise, cannot be measured. Both items are covered by measuring MPB by using the tracer technique.

The most striking observation of the current study was that cachexia, characterized by low BMI, FFM, and FM, was associated with increased WB MPB in COPD patients. MPB in the cachectic COPD patients was significantly higher than that in the combined control and noncachectic COPD groups and tended to be higher than that in the noncachectic COPD patients if the outlier was excluded $(p=0.062)$. This outlier had a BMI of $32 \mathrm{~kg} \cdot \mathrm{m}^{-2}$, which indicated an obese person. Whether the high MPB was related to the high BMI requires further investigation. The lack of significance between the noncachectic and cachectic COPD groups could also be due to the small study population. The degree of airflow limitation did not differ significantly between the noncachectic and the cachectic COPD patients. Until now, no available study has compared MPB in cachectic and noncachectic patients.

The increased MPB was accompanied with low concentrations of glutamate and BCAA in plasma, and both plasma glutamate and BCAA concentrations were highly correlated with FFM and FFMI. In addition, lower plasma glutamate concentrations were found in FFMdepleted COPD patients than in control subjects ${ }^{11,27}$. Moreover, lower 
BCAA concentrations were shown in underweight COPD patients than in normal-weight COPD patients and control subjects ${ }^{28}$. In that study, the lower BCAA concentrations were associated with enhanced resting energy expenditure. BCAA and glutamate are amino acids whose transamination products can be further oxidized in the skeletal muscle or the liver. The results of the current study and of the study by Yoneda et al. ${ }^{28}$ suggest that the transamination of glutamate and BCAA from plasma and from MPB increases in skeletal muscle during wasting.

The higher MPB in cachectic COPD patients is in line with the hypothesis of increased skeletal muscle PB in the muscle wasting syndrome. The underlying mechanism of muscle proteolysis is thus an important target for therapeutic intervention to prevent or reverse this process. The ubiquitine-proteasome pathway is assumed to provide most of the proteolytic activity required for the degradation of myofibrillar protein ${ }^{29}$. Recently, activation of nuclear factor-kappa $\mathrm{B}(\mathrm{NF}-\mathrm{KB})$ in skeletal muscle was shown to result in muscle atrophy through increased muscle protein degradation by the ubiquitineproteasome pathway ${ }^{30}$. Recently, Agusti et al. ${ }^{31}$ showed increased NF-KB activation in underweight COPD patients. Tumour necrosis factor-a (TNF-a) activates NF- $K B$ transcription ${ }^{32}$. Increased systemic levels of TNF-a or the soluble TNF-receptors have been consistently shown in COPD patients ${ }^{10}$ and were associated with systemic hypoxia33.

This is the first study to measure WB MPB in humans. WB myofibrillar protein synthesis, however, was not measured. Consequently, no conclusions can yet be drawn about net myofibrillar protein balance in cachexia or about potential additional disturbances in skeletal muscle anabolism.

\section{Whole-body total protein turnover}

WB total protein turnover did not differ significantly between the control and COPD groups. This is in contrast with the findings of Engelen et al. $^{21}$ who showed a higher WB PB and synthesis in normal-weight COPD patients than in healthy control subjects. Two factors may explain this discrepancy between the studies: first, in the study by Engelen et al., patients had more severe disease than did the subjects in the current study $\left(\mathrm{FEV}_{1}: 37 \pm 12 \%\right.$ and $50 \pm 3 \%$ of predicted, respectively). Second, patients in the current study did not take their maintenance medication on the evening before and on the morning of the test day, whereas the patients in the study by Engelen et al. continued their medication. In the past, an effect of 
the use of inhalation medication on glucose metabolism was shown ${ }^{16}$, and therefore, the current study, the intake of the medication was stopped. No information is yet available on the acute effect of the withdrawal of medication on substrate metabolism. Theoretically, an acute effect on protein metabolism cannot be excluded.

As mentioned earlier, Broekhuizen et al. ${ }^{10}$, in a recent large epidemiologic study, found significantly higher urinary pseudouridine concentrations in COPD patients than in healthy control subjects. That study also found significantly higher urinary pseudouridine concentrations in cachectic COPD patients than in noncachectic COPD patients or healthy control subjects. Urinary pseudouridine is a stable metabolite of RNA and consequently is used as a marker for cellular $\mathrm{PB}$. As did those in the study by Engelen et al. ${ }^{21}$, patients in the study by Broekhuizen et al. continued taking their habitual medication; the same differences in WB PB were detected between COPD patients and control subjects in both studies. Caution in the comparison of these studies is necessary, however, because the measurement of urinary pseudouridine as a marker for PB has not yet been compared with isotopic protein turnover measurements.

In the current study, WB MPB was not reflected by WB total PB. It is likely that a significant proportion of nonmyofibrillar protein degradation, possibly protein in the intestine or the liver, overwhelms the myofibrillar protein degradation. Assuming that muscle contributes to $25 \%$ of the WB protein turnover in humans ${ }^{24}$, an increase in MPB of $50 \%$ results in an increase in WB PB of $12 \%$, a difference that may be too low to detect.

In summary, cachectic COPD patients with moderate disease severity are characterized by higher WB MPB and lower plasma concentrations of glutamate and BCAAs than are those in the combined control and noncachectic COPD groups. Future studies are needed to relate MPB to proteolytic and regulatory markers in skeletal muscle biopsies so as to further unravel the pathogenesis of MPB in COPD and to identify relevant targets for nutritional and pharmacologic modulation. 


\section{References}

1. Schols AM, Soeters PB, Dingemans AM, Mostert R, Frantzen PJ, Wouters EF. Prevalence and characteristics of nutritional depletion in patients with stable COPD eligible for pulmonary rehabilitation. Am Rev Respir Dis 1993;147: 1151-1156.

2. Engelen MP, Schols AM, Lamers RJ, Wouters EF. Different patterns of chronic tissue wasting among patients with chronic obstructive pulmonary disease. Clin Nutr 1999;18:275-280.

3. Baarends EM, Schols AM, Mostert R, Wouters EF. Peak exercise response in relation to tissue depletion in patients with chronic obstructive pulmonary disease. Eur Respir J 1997;10:2807-2813.

4. Gosker HR, Lencer NH, Franssen FM, van der Vusse GJ, Wouters EF, Schols AM. Striking similarities in systemic factors contributing to decreased exercise capacity in patients with severe chronic heart failure or COPD. Chest 2003; 123:1416-1424.

5. Engelen MP, Schols AM, Does JD, Wouters EF. Skeletal muscle weakness is associated with wasting of extremity fat-free mass but not with airflow obstruction in patients with chronic obstructive pulmonary disease. Am J Clin Nutr 2000;71:733-738.

6. Mostert R, Goris A, Weling-Scheepers C, Wouters EF, Schols AM. Tissue depletion and health related quality of life in patients with chronic obstructive pulmonary disease. Respir Med 2000;94:859-867.

7. Schols AM, Broekhuizen R, Weling-Scheepers CA, Wouters EF. Body composition and mortality in chronic obstructive pulmonary disease. Am J Clin Nutr 2005;82: 53-59.

8. Tracey KJ. Lethal weight loss: The focus shifts to signal transduction. SCi STKE 2002;2002:PE21.

9. Morrison WL, Gibson JN, Scrimgeour C, Rennie MJ. Muscle wasting in emphysema. Clin Sci (Lond) 1988;75:415-420.

10. Broekhuizen R, Grimble RF, Howell WM, Shale DJ, Creutzberg EC, Wouters EF, Schols AM. Pulmonary cachexia, systemic inflammatory profile, and the interleukin 1 beta-511 single nucleotide polymorphism. Am J Clin Nutr 2005;82: 1059-1064.

11. Hofford JM, Milakofsky L, Vogel WH, Sacher RS, Savage GJ, Pell S. The nutritional status in advanced emphysema associated with chronic bronchitis. A study of amino acid and catecholamine levels. Am Rev Respir Dis 1990;141:902-908.

12. Schols AM, Deutz NE, Mostert R, Wouters EF. Plasma amino acid levels in patients with chronic obstructive pulmonary disease. Monaldi Arch Chest Dis 1993;48: 546-548.

13. Vissers $\mathrm{YL}$, von Meyenfeldt MF, Braulio VB, Luiking YC, Deutz NE. Measuring whole-body actin/myosin protein breakdown in mice using a primed constant stable isotope-infusion protocol. Clin Sci (Lond) 2003;104:585-590.

14. Rabe KF, Hurd S, Anzueto A, Barnes PJ, Buist SA, Calverley P, Fukuchi $Y$, Jenkins $C$, Rodriguez-Roisin $R$, van Weel $C$, et al. Global strategy for the diagnosis, management, and prevention of chronic obstructive pulmonary disease: GOLD executive summary. Am J Respir Crit Care Med 2007; 176:532-555.

15. Picado C, Deulofeu R, Lleonart R, Agusti M, Casals E, Quinto L, Mullol J. Lipid and protein metabolism in asthma. Effects of diet and corticosteroid therapy. Allergy 1999;54:569-575.

16. Guhan AR, Cooper S, Oborne J, Lewis S, Bennett J, Tattersfield AE. Systemic effects of formoterol and salmeterol: A dose-response comparison in healthy subjects. Thorax 2000;55:650-656. 
17. Clausen $\mathrm{JL}$, Coates $\mathrm{AL}$, Quanjer $\mathrm{PH}$. Measurement of lung volumes in humans: Review and recommendations from an ATS/ERS workshop. Eur Respir J 1997;10: 1205-1206.

18. Abumrad NN, Rabin D, Diamond MP, Lacy WW. Use of a heated superficial hand vein as an alternative site for the measurement of amino acid concentrations and for the study of glucose and alanine kinetics in man. Metabolism 1981;30: 936-940.

19. van Eijk HM, Rooyakkers DR, Deutz NE. Rapid routine determination of amino acids in plasma by high-performance liquid chromatography with a 2-3 microns spherisorb ods II column. J Chromatogr 1993;620:143-148.

20. van Eijk HM, Rooyakkers DR, Soeters PB, Deutz NE. Determination of amino acid isotope enrichment using liquid chromatography-mass spectrometry. Anal Biochem 1999;271:8-17.

21. Engelen MP, Deutz NE, Wouters EF, Schols AM. Enhanced levels of whole-body protein turnover in patients with chronic obstructive pulmonary disease. Am J Respir Crit Care Med 2000;162:1488-1492.

22. Steiner MC, Barton RL, Singh SJ, Morgan MD. Bedside methods versus dual energy x-ray absorptiometry for body composition measurement in COPD. Eur Respir J 2002;19:626-631.

23. Kyle UG, Bosaeus I, De Lorenzo AD, Deurenberg P, Elia M, Gomez JM, Heitmann $\mathrm{BL}$, Kent-Smith L, Melchior JC, Pirlich M, et al. Bioelectrical impedance analysis-part i: Review of principles and methods. Clin Nutr 2004;23:1226-1243.

24. Deutz NE, Wagenmakers AJ, Soeters PB. Discrepancy between muscle and wholebody protein turnover. Curr Opin Clin Nutr Metab Care 1999;2:29-32.

25. Ballard FJ, Tomas FM. 3-methylhistidine as a measure of skeletal muscle protein breakdown in human subjects: The case for its continued use. Clin Sci (Lond) 1983;65:209-215.

26. Wei IW, McFadden ER, Jr., Hoppel CL. Effect of theophylline on urinary excretion of 3-methylhistidine in patients with lung disease. Metabolism 1991;40:702-706.

27. Pouw EM, Schols AM, Deutz NE, Wouters EF. Plasma and muscle amino acid levels in relation to resting energy expenditure and inflammation in stable chronic obstructive pulmonary disease. Am J Respir Crit Care Med 1998;158:797-801.

28. Yoneda T, Yoshikawa M, Fu A, Tsukaguchi K, Okamoto Y, Takenaka H. Plasma levels of amino acids and hypermetabolism in patients with chronic obstructive pulmonary disease. Nutrition 2001;17:95-99.

29. Hasselgren PO, Fischer JE. Muscle cachexia: Current concepts of intracellular mechanisms and molecular regulation. Ann Surg 2001;233:9-17.

30. Glass DJ. Skeletal muscle hypertrophy and atrophy signaling pathways. Int J Biochem Cell Biol 2005;37:1974-1984.

31. Agusti A, Morla M, Sauleda J, Saus C, Busquets X. NF-kappa B activation and INOS upregulation in skeletal muscle of patients with COPD and low body weight. Thorax 2004;59:483-487.

32. Langen RC, Schols AM, Kelders MC, Wouters EF, Janssen-Heininger YM. Inflammatory cytokines inhibit myogenic differentiation through activation of nuclear factor-kappa B. FASEB J 2001;15:1169-1180.

33. Takabatake $N$, Nakamura $H$, Abe $S$, Inoue $S$, Hino $T$, Saito $H$, Yuki $H$, Kato $S$, Tomoike $\mathrm{H}$. The relationship between chronic hypoxemia and activation of the tumor necrosis factor-alpha system in patients with chronic obstructive pulmonary disease. Am J Respir Crit Care Med 2000;161:1179-1184. 



\section{Chapter 10}

Perspective: chronic obstructive pulmonary disease and obesity: more than adipose tissue mass matters

Frits M.E. Franssen, Denis E. O'Donnell, Gijs H. Goossens, Ellen E. Blaak, Annemie M.W.J. Schols Thorax 2008; 63: 1110-1117 


\section{Abstract}

Chronic obstructive pulmonary disease (COPD) and obesity are common and disabling chronic health conditions with increasing prevalence worldwide. A relationship between COPD and obesity is increasingly recognized, although the nature of this association remains unknown. This review focuses on the epidemiology of obesity in COPD and the impact of excessive fat mass on lung function, exercise capacity and prognosis. We also review the evidence for altered adipose tissue functions in obesity, including reduced lipid storage capacity, altered expression and secretion of inflammatory factors, adipose tissue hypoxia and macrophage infiltration in adipose tissue. We consider how these factors might be interrelated and contribute to the development of insulin resistance in obesity. We propose that in patients with COPD, reduced oxidative capacity and systemic hypoxia may amplify these disturbances, not only in obese patients but also in subjects with hidden loss of fat-free mass. The potential interaction between abnormal adipose tissue function, systemic inflammation and COPD may provide more insight in the pathogenesis and reversibility of systemic pathology in this disease. 


\section{Introduction}

Chronic obstructive pulmonary disease (COPD) and obesity are major causes of morbidity and mortality worldwide and according to current estimates the global burden of these conditions will increase even further. While spirometry is used for diagnosis and gradation of COPD severity according to the Global initiative for chronic Obstructive Lung Disease (GOLD) guidelines ${ }^{1}$, classification of overweight and obesity is based on body mass index (BMI) as defined by the World Health Organization ${ }^{2}$.

According to the Burden of Obstructive Lung Disease (BOLD) Initiative ${ }^{3}$, the estimated international prevalence of stage II or higher COPD is currently $10.1 \%$ in individuals aged 40 years and older. COPD was the fifth leading cause of mortality around the world in 2001 and will be the third most frequent cause of death by the year $2020^{4}$. The prevalence of obesity, defined as a body mass index (BMI) $\geq 30 \mathrm{~kg} \cdot \mathrm{m}^{-2} 2$ has multiplied during the last decades and varies from 10 to $20 \%$ in most European countries to more than $32 \%$ in the population of the United States of America ${ }^{2}$. According to the most recent global WHO projections 400 million adults were obese in 2005 and it is estimated that this number will exceed 700 million by the year $2015^{5}$. Obesity plays a major role in the development of the metabolic syndrome and has been identified as an important risk factor for chronic diseases such as type 2 diabetes mellitus and cardiovascular disease. Obesity is linked to respiratory diseases such as obstructive sleep apnoea syndrome and obesity hypoventilation syndrome $^{6}$ and accumulating evidence suggests an association between obesity and asthma ${ }^{7}$. A potential link between obesity and COPD is also increasingly recognized ${ }^{8}$ although very little is known about the mechanisms underlying this association. At least, the risk for development of obesity is increased in COPD as a result of a reduced level of physical activities in daily life in these patients compared to healthy age-matched controls ${ }^{9}$.

\section{Prevalence of obesity in COPD}

Steuten et al. ${ }^{10}$ studied the prevalence of obesity in a large primary care population of COPD patients in the Netherlands. The overall prevalence of obesity in this population was $18 \%$ with the highest prevalence in GOLD 1 and 2 (16-24\%) and the lowest in GOLD 4 $(6 \%)$. For comparison, the current prevalence of obesity in the 
general population in the Netherlands is $10 \%$ in adult men and $12 \%$ in adult females ${ }^{11}$. A much higher prevalence of obesity was reported by Eisner et al. ${ }^{12}$ in an adult multi-ethnic cohort of early stage COPD patients in Northern California, USA. Fifty-four percent of COPD patients had a $B M I \geq 30 \mathrm{~kg} \cdot \mathrm{m}^{-2}$, which is considerably more than the $20-24 \%$ of obese in the same US state reported by the Centres for Disease Control and Prevention using annual data from the Behavioural Risk Factor Surveillance System (www.cdc.gov/BRFSS/). Thus, available data suggest that obesity is more prevalent in COPD patients than in the general population, depending on the severity of chronic airflow limitation. Indeed, a study in moderately severe patients participating in cardiopulmonary rehabilitation showed that abdominal obesity measured by waist circumference was almost twice as common in COPD patients as in age and gender matched controls $^{13}$. In addition, the occurrence of obesity might differ between various clinical phenotypes of COPD. The classical distinction of "pink puffers" and "blue bloaters" was based on anthropometric characteristics of patients with emphysema and chronic bronchitis respectively. By definition, "pink puffers" were thin in appearance with a frequent history of weight loss, while "blue bloaters" showed no marked weight loss and tended to be overweight ${ }^{14}$. In fact, a significantly increased prevalence of (pre)obesity (BMI $\geq 28 \mathrm{~kg} \cdot \mathrm{m}^{-2}$ ) was reported in patients with chronic bronchitis (25\%) compared to controls (16\%) in the Tucson prospective cohort study ${ }^{15}$, while underweight was more prevalent in emphysema patients.

There are no published studies on the prevalence of COPD in obesity. However, data from the 4th examination of The Copenhagen City Heart Study suggest that the prevalence of COPD among obese individuals is significantly lower than among the rest of the population ( $11.2 \%$ vs. $18.6 \%)$, due to a lower occurrence of mild and moderate disease (personal communication with Jørgen Vestbo, Department of Cardiology and Respiratory Medicine, Hvidovre Hospital, Copenhagen, Denmark).

In addition to obesity characterized by an absolute abundance of fat mass in patients with COPD, it is well-recognized that alterations in body composition commonly occur in normal-weight COPD patients as well. Selective wasting of fat-free mass (FFM; i.e. muscle mass) occurs in $10-15 \%$ of normal-weight COPD patients ${ }^{16,17}$, resulting in a relative or absolute increase in fat mass ${ }^{18}$. This situation shows resemblance to the involuntary loss of muscle mass with advanced age, defined as sarcopenia ${ }^{19}$. 


\section{Effect of obesity on respiratory function and exercise performance}

In any given individual, the effects of obesity on respiratory function depend on the mass and anatomical distribution of the excessive adipose tissue on the thorax and abdomen ${ }^{20,21}$. The nature of the physiological impairment induced by obesity will vary with its extent and will ultimately reflect integrated abnormalities of ventilatory mechanics/muscle function, pulmonary gas exchange, ventilatory control and cardiac performance ${ }^{20-37}$. These respiratory derangements are consistently accentuated upon adopting the supine posture. Common physiological abnormalities associated with eucapnic obesity (excluding obesity hypoventilation syndrome) are listed in Table 10.1. Restrictive mechanics are manifest by reduced expiratory reserve volume and functional residual capacity. Residual volume and total lung capacity are preserved except in extreme obesity. The forced expiratory volume in one second $\left(\mathrm{FEV}_{1}\right) /$ forced vital capacity (FVC) ratio is preserved but tests of small airway function may be abnormal ${ }^{20-37}$. Diffusing capacity of the lung for carbon monoxide ( $\mathrm{DL}_{\mathrm{co}}$ ) is in the normal range or increased; gas exchange is compromised in severe obesity particularly in the supine posture. Normative predictive equations for spirometric measurements, plethysmographic lung volumes and $\mathrm{DL}_{\mathrm{co}}$ are generally not corrected for weight. This has implications for the clinical interpretation of pulmonary function tests in the overweight and obese who comprise an increasing proportion of those tested.

Table 10.1 Respiratory function in eucapnic obesity.

\section{Decreased chest wall and lung compliance}

Small airway dysfunction and expiratory flow limitation

Preservation of $\mathrm{FEV}_{1} / \mathrm{FVC}$ ratio

Variable reduction of (or preserved) ventilatory muscle strength and endurance

Increased work and oxygen cost of breathing

Normal or increased diffusion capacity for carbon monoxide ( $\left.D L_{c o}\right)$

Abnormal ventilation/perfusion relations and arterial oxygen desaturation

Normal or increased central respiratory drive

\section{Exercise performance}

Peak oxygen uptake $\left(\dot{\mathrm{VO}}_{2}\right)$, corrected for weight, is surprisingly preserved in obesity, at least during weight-supported cycle 
exercise ${ }^{26,38-40}$. When comparing oxygen uptake measurements during exercise in obese individuals with predictive normal values, underestimation in the former can be avoided by expressing $\mathrm{VO}_{2}$ as a percentage of ideal body weight. Obese individuals have a higher metabolic demand at any given power output as a result of the high oxygen cost of lifting heavy limbs ${ }^{26,38-40}$. Pulmonary gas exchange is rarely critically compromised in obesity and arterial oxygen saturation may even improve during exercise, reflecting an improvement in $\mathrm{V} / \mathrm{Q}$ relationships ${ }^{26,38-40}$. Patients with obesity may have expiratory flow limitation at rest which, when compounded by high ventilatory requirements, leads to significant air trapping and dynamic increase in EELV during exercise ${ }^{26,39,40}$ (Figure 10.1). Given the increase in ventilatory demand (secondary to increased metabolic loading) and the excessive intrinsic mechanical loading of the inspiratory muscles in obesity, the muscular effort required to support a given ventilation is elevated at any given power output compared to normal-weight individuals ${ }^{40-42}$. Not surprisingly, the work and oxygen cost of breathing is also increased at rest and during exercise $38,41,43,44$. Exertional dyspnea intensity is uniformly increased for any given power output and rises sharply as ventilation (and therefore contractile muscle effort) approach maximal capacity $^{26}$. In some patients, exercise performance is further compromised by attendant skeletal muscle deconditioning, peripheral muscle dysfunction and cardiac impairment (e.g., eccentric left ventricular hypertrophy of obesity $)^{45,46}$.

\section{Combined deleterious effects of obesity and COPD}

The physiological derangements that occur at rest and during exercise in obesity and in COPD, when each is considered in isolation, are well understood. However, no mechanistic studies have explored the pathophysiological interactions that occur when both conditions coexist in the same individual, as is increasingly the case. Given the vast pathophysiological heterogeneity of COPD, the concomitant effects of aging and gender on physical performance, and the existence in many of serious comorbidities in conjunction with obesity, the mechanisms of exercise intolerance in obese COPD are necessarily complex. Clinical experience indicates that the combined restrictive/obstructive deficits evident in obese patients with COPD culminate in worsening symptomatology and activity limitation ${ }^{8,47,48}$. 
Figure 10.1 Maximal and tidal flow-volume loops are shown for a series of agematched women: a lean woman with normal lung function, an obese woman with normal lung function, a lean woman with $\mathrm{COPD}\left(\mathrm{FEV}_{1}=46 \%\right.$ predicted), and an obese woman with COPD ( $\mathrm{FEV}_{1}=45 \%$ predicted). Inner tidal loops are shown at rest (solid inner loops) and at ventilations of $\sim 32 \mathrm{I} \cdot \mathrm{min}^{-1}$ (dotted loops); the latter corresponding to the symptomlimited peak of exercise for both women with COPD. While the healthy lean woman decreased her end-expiratory lung volume during exercise, the other women experienced dynamic pulmonary hyperinflation (leftward arrows). Additional flow and volume constraints on tidal volume expansion in the women with COPD limited the peak ventilation that could be attained during exercise. In women with COPD, a critically reduced inspiratory reserve volume (IRV) limited any further increase in tidal volume during exercise and resulted in severe exertional dyspnoea. Ratings of dyspnea intensity using the modified 10-point Borg scale are shown at comparable ventilations during exercise. BMI: body mass index.

$\begin{array}{lll}\text { Lean woman } & \begin{array}{l}\text { Obese woman } \\ \text { age }=56 \text { years }\end{array} & \begin{array}{l}\text { with COPD } \\ \text { age }=60 \text { years }\end{array} \\ \mathrm{BMI}=24 \mathrm{~kg} / \mathrm{m}^{2} & \mathrm{BMI}=44 \mathrm{~kg} / \mathrm{m}^{2} & \mathrm{BMI}=24 \mathrm{~kg} / \mathrm{m}^{2}\end{array}$

Obese woman with COPD

age $=59$ years $\mathrm{BMI}=40 \mathrm{~kg} / \mathrm{m}^{2}$

dyspnea $=$ Borg 6
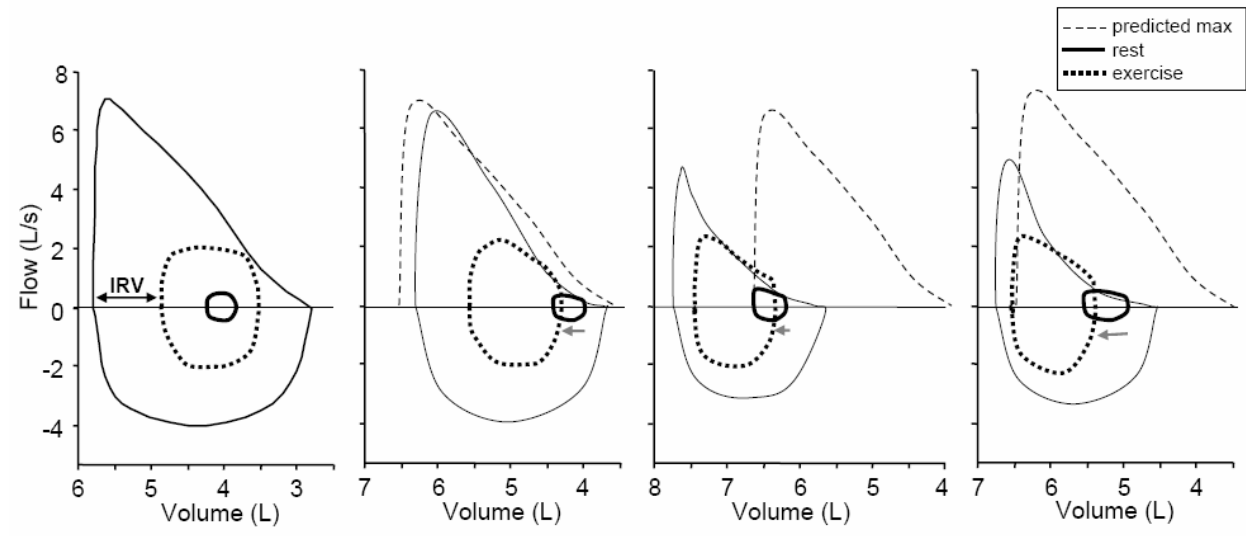

Obesity would be expected to amplify the abnormalities of dynamic ventilatory mechanics and ventilatory demand that characterize COPD. Thus, ventilatory requirements are predictably higher in obese COPD patients compared with normal-weight COPD patients as a result of the increase in chemostimulation that arises from the combination of increased metabolic loading, high fixed physiological deadspace and possibly earlier metabolic acidosis due to impairment in oxygen uptake from deconditioning or cardiac dysfunction. The increased recoil of the chest wall and lung in patients with central obesity may increase expiratory flow rates at a given operating lung volume compared with non-obese COPD patients. However, the 
relatively reduced absolute EELV in obese COPD patients may worsen expiratory flow limitation and air trapping during exercise (Figure 10.1), particularly in the setting of the relatively increased ventilatory requirement ${ }^{49,50}$. The net effect of these abnormalities is an earlier mechanical limitation of ventilation with greater dyspnoea and exercise curtailment in the obese COPD patient. The accompanying rapid shallow breathing pattern (at a relatively low power output and ventilation) may compromise dynamic inspiratory muscle function and deleteriously effect alveolar ventilation ${ }^{49-51}$. In obese COPD patients compared with their non-obese counterparts, the increased contractile muscle effort required to sustain ventilation during exercise in the face of serious mechanical constraints on tidal volume expansion would be expected to cause significant neuromechanical uncoupling of the respiratory system and lead to incapacitating dyspnoea earlier in exercise.

\section{Effects of body composition on exercise performance in obese COPD}

In addition to ventilatory limitations, alterations in body composition contribute to exercise intolerance in patients with COPD. It is wellrecognized that loss of FFM contributes to muscle weakness ${ }^{52}$ and reduced exercise capacity ${ }^{53}$ in patients with moderate-to-severe COPD. Available data in these patients suggest that the contribution of alterations in fat mass to exercise intolerance is limited in comparison to the impact of muscle wasting. The degree of physical impairment, assessed by 12 minute walking test, was greater in normal-weight patients with depleted FFM and relatively enhanced fat mass compared to underweight patients with preserved $\mathrm{FFM}^{16}$. Less is known about effects of obesity or relatively increased fat mass on physical performance in less severe COPD patients. In patients with early stage COPD, obesity, decreased lean-to-fat mass ratio and increased sagittal abdominal diameter were associated with functional limitation on the six minute walk test ${ }^{12}$. Particularly the accumulation of fat mass and not the loss of lean mass had a negative impact on performance. This observation is not unique for early stage COPD patients. In a cohort of elderly from the general population, high body fatness was associated with increased risk of self-reported mobility-related disability, while low FFM was not predictive of disability ${ }^{54}$. In another community-based cohort study of older persons, higher fat mass was related to increased risk of functional limitation assessed by walking speed ${ }^{55}$. Although absolute 
lean mass was not related to physical performance, a higher ratio of lean mass-to-fat mass was predictive for walking speed. Thus, it seems that both absolute and relative accumulation of fat mass contribute to functional limitation in the elderly and early in the course of COPD, while the influence of muscle wasting on physical performance becomes apparent in more severe patients when FFM drops to very low levels ${ }^{16,56}$.

\section{The obesity paradox in COPD}

The prognostic value of nutritional status is well established in patients with COPD. Low BMI is associated with increased all-cause and COPD-related mortality, unrelated to disease severity ${ }^{57}$. Recent studies indicate that FFM-index is an even more important determinant of prognosis in moderate-to-severe COPD than $\mathrm{BMI}^{17,56}$. Fat mass index was not predictive for prognosis in moderate-tosevere COPD $^{56}$. Remarkably the relative risk for mortality seems decreased in overweight and obese COPD patients in GOLD stage 34 , while it is increased in GOLD 1-2 patients with (pre)obesity ${ }^{57}$. A possibly protective role for obesity in COPD was also observed in early studies on the association between body weight and mortality ${ }^{58}$, in the epidemiologic Copenhagen City Heart Study ${ }^{17}$ and in a population of severe COPD patients treated by long-term oxygen therapy ${ }^{59}$. This possible association between (pre)obesity and improved outcome in COPD contrasts with epidemiological data from the general population, where obesity is associated with a largely decreased life expectancy, independent of smoking status ${ }^{60}$. This phenomenon is referred to as a "reverse epidemiology of obesity" or the "obesity paradox" and was identified in several other chronic disease states such as end-stage chronic kidney disease, chronic heart failure and rheumatoid arthritis ${ }^{61}$. The pathophysiological mechanisms of the obesity paradox are yet to be unravelled. In obese men with COPD, the annual decline in $\mathrm{FEV}_{1}$ was significantly lower compared to men of normal BMI range while this effect was not seen in women ${ }^{62}$. This suggests a gender specific protective role for obesity in the progression of chronic airflow limitation. Furthermore, it is not yet clear whether excessive fat mass or muscle mass contributes to the survival advantage in chronic wasting diseases ${ }^{61}$.

In apparent contradiction to the possible existence of a obesity paradox in COPD, it is well recognized that the risk of cardiovascular 
mortality is increased in patients with chronic airflow limitation, independent of $\mathrm{BMI}^{63}$. Epidemiological studies indicated that low forced expiratory volume in one second $\left(F V_{1}\right)$ is a risk factor for coronary heart disease in subjects without pulmonary disease ${ }^{64}$. Besides the presence of chronic airflow obstruction, low-grade systemic inflammation is one of the mechanisms that may be responsible for the increased rate of cardiovascular complications in $\mathrm{COPD}^{65}$. The role for smoking-related systemic inflammation is evident in COPD pathogenesis and led to the proposition of the term "chronic systemic inflammatory syndrome" complementary to the diagnosis of COPD ${ }^{66}$. Insulin resistance may also contribute to the increased cardiovascular mortality in COPD patients. It plays an important role in the pathogenesis of type II diabetes mellitus and it clusters with a variety of risk factors for cardiovascular disease, such as abdominal obesity, dyslipidemia and hypertension in the metabolic syndrome ${ }^{67}$. In a recent meta-analysis of longitudinal studies, the presence of the metabolic syndrome was strongly associated with cardiovascular morbidity and mortality ${ }^{68}$. Indeed, some studies suggest the presence of insulin resistance in COPD $^{69}$, especially in normal-weight to obese ${ }^{70,71}$ and hypoxemic patients ${ }^{71}$.

Based on the evidence outlined above, it can be hypothesized that obesity exerts divergent effects in subgroups of COPD with different severity of disease. Obesity may protect against mortality in advanced COPD patients, in which loss of FFM is a particularly important short-term risk factor for death. By contrast, in earlier stage COPD, the harmful long-term effects of obesity-related conditions such as low-grade systemic inflammation and insulin resistance may result in increased cardiovascular and all-cause mortality.

In recent years, new insights in the functioning of adipose tissue in obesity have evolved that are reviewed in the next section and may be of importance to further unravel the clinical significance and pathophysiology of obesity in COPD. 


\section{Adipose tissue dysfunction in obesity and the influence of hypoxia}

The association between abdominal obesity, insulin resistance and cardiovascular disease is well-recognized ${ }^{72}$, but the underlying mechanisms are not yet fully understood. Adiposity is associated with insulin resistance even over relatively normal ranges of body fatness. There is strong evidence that altered adipose tissue function plays a crucial role in the pathogenesis of obesity-related insulin resistance and type 2 diabetes, as has recently been reviewed ${ }^{73}$.

\section{Lipid storage capacity of adipose tissue in obesity}

Adipose tissue is the main lipid storage depot in our body, and is of crucial importance in buffering the daily influx of dietary fat entering the circulation. One characteristic of adipose tissue in obesity is the enlargement of adipocytes, which may represent an impaired adipocyte differentiation. The hyperthrophic adipocytes of obese subjects are overloaded with stored triacylglycerol (TAG) and it is likely that the buffering capacity for further lipid storage in these adipocytes is decreased, especially in the postprandial state ${ }^{74}$. Nonadipose tissues are therefore exposed to an excessive influx of lipids, which could lead to ectopic fat deposition when the oxidative capacity is insufficient. It is well-established that accumulation of lipids in skeletal muscle $e^{75-77}$, pancreatic islets ${ }^{78}$ and the liver ${ }^{79,80}$ play an important role in the development of insulin resistance and/or impaired insulin secretion in obese individuals. Another explanation for the observation that adipocyte hypertrophy is associated with insulin resistance and the development of type 2 diabetes relates to the endocrine function of adipose tissue.

\section{Adipose tissue as a source of inflammation in obesity}

Adipocytes express and secrete a variety of adipokines, including cytokines, growth factors, adiponectin, resistin, adipsin, leptin, acylation stimulating protein (ASP), plasminogen activator inhibitor-1 (PAI-1), lipoprotein lipase (LPL), and components of the reninangiotensin system ${ }^{81-83}$, which may exert local and systemic effects. Chronic low-grade inflammation is a hallmark of obesity, insulin resistance and type 2 diabetes ${ }^{84-87}$. Importantly, inflammatory pathways play a prominent role in the mechanisms underlying insulin resistance and type 2 diabetes in cultured cells and animal 
models ${ }^{88-92}$, and this may also be the case in humans.

The inflammatory response that is often present in obesity appears to be triggered and to reside predominantly in the enlarged adipose tissue $^{93-97}$. The expression and/or secretion of inflammatory molecules, including tumour necrosis factor- $\alpha$ (TNF- $\alpha)^{95,98-100 \text {, }}$ interleukin (IL)-6 ${ }^{99-102}$, PAI-1 ${ }^{103,104}$ and leptin ${ }^{100,105-107}$ are increased in adipose tissue of obese insulin resistant individuals. In contrast, the expression of the insulin-sensitizing factor adiponectin is reduced in obese and insulin resistant subjects ${ }^{108-110}$. Interestingly, enlarged adipocytes seem to express pro-inflammatory and anti-inflammatory factors with a shift toward dominance of pro-inflammatory adipokines compared to smaller adipocytes ${ }^{111}$.

Recent data indicate that adipose tissue of obese individuals is infiltrated by macrophages, which may be a major source of locallyproduced pro-inflammatory adipokines ${ }^{108,112,113}$. There seems to be cross-talk between adipocytes and macrophages within adipose tissue. For example, macrophage-secreted factors exert effects on adipocytes that may increase systemic inflammation and insulin resistance associated with obesity ${ }^{114,115}$. The mechanisms underlying the impaired adipokine secretion and macrophage infiltration in adipose tissue in obesity remain to be elucidated but there is evidence to support a major role for adipose tissue hypoxia in these events.

\section{Adipose tissue hypoxia in obesity}

Recently, evidence has emerged that adipose tissue hypoxia is present in obese mice ${ }^{116}$. Accordingly, it has been shown that weight-loss decreased adipose tissue expression of hypoxiaresponsive genes ${ }^{117}$. An alteration in oxygen pressure and/or oxygen content of the blood was not apparent in the obese animals ${ }^{116}$. Based on the above, it can be speculated that hypoxia in adipose tissue may contribute to obesity-related insulin resistance.

Since adipose tissue blood flow (ATBF) per unit tissue mass is reduced in obese humans ${ }^{118-122}$ and rodents ${ }^{116,123}$, decreased blood supply to adipose tissue may explain adipose tissue hypoxia in obesity. Indeed, it has been suggested that the expansion of adipose tissue mass during the progressive development of obesity may lead to hypoxia in certain parts of adipose tissue, because angiogenesis is insufficient to maintain normoxia in the entire adipose tissue $\operatorname{depot}^{124}$. As a consequence, adipose tissue hypoxia may induce an increased secretion of inflammatory factors, acute phase proteins 
and angiogenic factors by adipose tissue in order to increase blood flow and vascularization. The transcription factor hypoxia inducible factor-1 (HIF-1) is a key regulator in the response to alterations in oxygen tension and modulates the expression of genes that are involved in angiogenesis, erythropoiesis, inflammation and glucose metabolism ${ }^{124-130}$.

Recent studies have demonstrated that adiponectin and PPAR $\gamma$ mRNA expression were decreased, whereas PAI-1 and visfatin mRNA expression were elevated in hypoxic 3T3-L1 adipocytes compared with normoxic control cells 116,131,132. Likewise, hypoxia altered the expression and secretion of inflammation-related adipokines in human adipocytes ${ }^{133}$. Furthermore, weight-loss led to improved oxygenation and reduced inflammation in dietary obese mice ${ }^{134}$. Secondly, severe hypoxia may induce adipocyte death. A hypoxic environment devoid of nutrients prevents the cell undergoing energy dependent apoptosis and cells become necrotic ${ }^{135}$. Subsequently, macrophages fuse and form syncytia that sequester and scavenge adipocyte debris ${ }^{136}$. Hypoxia-induced adipocyte death may thus evoke macrophage infiltration in adipose tissue of obese individuals. These data suggest that adipose tissue hypoxia modulates, either directly or indirectly via recruitment of macrophages, adipokine expression and secretion and may therefore provide an important link between obesity and insulin resistance ${ }^{73}$. Thirdly, hypoxia inhibits adipocyte differentiation ${ }^{137,138}$, which appears to be a precipitating factor in the development of type 2 diabetes as mentioned earlier ${ }^{139,140}$. Finally, unfolded protein response (UPR), a HIF-1-independent signalling pathway, contributes to cellular adaptation to hypoxia ${ }^{141}$. Many disturbances, including hypoxia, cause accumulation of unfolded proteins in the endoplasmatic reticulum $(E R)^{141,142}$, leading to $E R$ stress ${ }^{137,143}$. It has been demonstrated that ER stress is elevated in adipose tissue and liver of obese mice, which activates the inflammatory response, thereby contributing to insulin resistance ${ }^{144,145}$. In conclusion, adipose tissue hypoxia, possibly due to an impaired ATBF as a consequence of adipose tissue expansion, may be an important factor in the development of obesity-related insulin resistance via effects on adipokine expression and/or adipocyte differentiation ${ }^{73}$.

In summary, evidence suggests that enlargement of adipocytes, impaired adipose tissue blood flow, adipose tissue hypoxia, local inflammation and macrophage infiltration in adipose tissue are interrelated in obesity and may lead to disturbances in adipokine secretion and excessive fat storage in non-adipose tissues, which 
together may result in insulin resistance and ultimately type 2 diabetes mellitus ${ }^{73}$. The following section will focus on the possible impact of altered adipose tissue function on skeletal muscle oxidative capacity, systemic inflammation and insulin sensitivity in COPD.

\section{Potential impact of adipose tissue dysfunction on the pathophysiology of COPD}

\section{Adipose tissue and fat oxidative capacity in COPD}

There is a lack of studies on adipose tissue morphology in patients with COPD. While available evidence suggests an increased prevalence of abdominal obesity at the macroscopic level ${ }^{13}$, no microscopic data are available in COPD. As a consequence, possible alterations in size, differentiation and lipid buffering capacity of adipocytes remain unknown.

If fatty acid delivery to skeletal muscle exceeds fat oxidation, lipids and lipid intermediates accumulate in skeletal muscle cells. Intramyocellular fat accumulation is closely related to the development of insulin resistance ${ }^{76}$. Reduced peripheral skeletal muscle fat oxidative capacity is consistently reported in patients with COPD $^{146}$. It is reflected by a muscle fibre type shift from type I to II (or slow-twitch to fast-twitch) and reduced activities of enzymes involved in oxidative energy metabolism ${ }^{147}$. In the case of high nonesterified fatty acid (FFA) release into the circulation in COPD, the reduced fat oxidative capacity would be a potential risk factor for development of metabolic syndrome. Since obesity is associated with increased exposure of skeletal muscle to TAG and FFA, obese COPD patients would be at particular risk. Indeed, increased fasting lipolytic rate and enhanced levels of circulatory FFA have been reported in hypoxemic COPD patients in comparison to controls ${ }^{148}$, although another study did not confirm this ${ }^{149}$. Also reduced intramyocellular triglyceride content (IMTG) was reported in a small group of normal-weight COPD patients. However, levels of oxidative enzymes were not reported in that study and no obese COPD patients were included.

\section{Adipose tissue as a source of inflammation in COPD}

In addition to pulmonary inflammation, persistent low-grade systemic inflammation is frequently demonstrated in patients with 
COPD. Increased levels of pro-inflammatory cells and mediators have been reported in the circulation of COPD patients. Enhanced plasma concentrations of fibrinogen, C-reactive protein (CRP), TNF- $a$ and circulating leukocytes have been consistently observed in stable COPD patients in comparison to healthy controls ${ }^{150}$, while raised levels of IL- $6{ }^{70,151}, \mathrm{IL}-8{ }^{152}$, IL-10 ${ }^{70}$, IL-18 ${ }^{153}$ have also been shown. The presence of low-grade systemic inflammation was associated with several systemic consequences in patients with COPD, including reduced exercise capacity and worse health-related quality of life ${ }^{154}$. Also, increased circulatory levels of TNF-a, IL- 6 and their soluble receptors were observed in FFM-depleted COPD patients in comparison to patients with preserved FFM, both in patients with low body weight as well as in COPD patients with normal $\mathrm{BMI}^{155}$. This suggests a role for systemic inflammation in COPD-related muscle wasting, even in patients without apparent weight loss such as subgroups of sarcopenic or obese patients. In addition, a link between systemic inflammation and markedly increased cardiovascular mortality in COPD was suggested ${ }^{65}$.

Despite the growing awareness that systemic inflammation is a hallmark in the pathogenesis of COPD, remarkably little is known about the underlying mechanisms. Although it is often hypothesized that inflammation in the systemic compartment is the result of spill over of the inflammatory process in the airways, lung parenchyma and pulmonary vasculature, evidence from cross-sectional studies indicates no correlation between pulmonary and circulatory inflammatory markers in stable COPD ${ }^{152,156}$.

Adipose tissue is another possible source of systemic inflammation. As discussed before, adipose tissue expresses several proinflammatory mediators with potential systemic metabolic effects. The importance of these adipokines released from fat tissue in the pathogenesis of systemic inflammation in obesity is recognized. By measurements of arterio-venous concentration differences of cytokines, in combination with measurement of adipose tissue blood flow, release of IL-6 from abdominal subcutaneous adipose tissue into the systemic circulation has been demonstrated in healthy human subjects ${ }^{102}$. Furthermore, the rate of IL- 6 release per unit abdominal subcutaneous adipose tissue has been shown to be equal or greater in obese subjects, depending on the degree of obesity ${ }^{157}$. Taken into consideration the absolute increased fat mass in the obese, these findings indicate that IL- 6 release from abdominal subcutaneous adipose tissue is elevated at the whole-body level in these individuals. In another study in obese subjects, IL-6 
concentrations in the portal vein, which drains the visceral fat, were significantly increased compared to IL- 6 levels in peripheral arterial blood, demonstrating that visceral fat is an important source of IL- 6 in obesity ${ }^{158}$. Furthermore, portal vein IL- 6 levels were related to arterial CRP concentrations, suggesting a mechanistic link between visceral fat mass and systemic inflammation in vivo.

The role of adipose tissue in the pathogenesis of systemic inflammation in patients with COPD has not been studied. Also, the possible cross-talk between fat mass-derived inflammatory factors and loss of FFM in COPD is speculative. However, based on the foregoing it can be hypothesized that in early-stage COPD patients with obesity or relatively abundant fat mass, adipose tissue may act as additional source of inflammation (Figure 10.2). Since systemic inflammation is associated with loss of skeletal muscle in COPD ${ }^{155}$, this may contribute to loss of FFM and amplify alterations in body composition towards loss of lean body mass and preservation of fat mass. Additionally, excretion of adipokines by adipose tissue in COPD might be reinforced by the presence of chronic or intermittent hypoxia.

Figure 10.2 Proposed mechanistic links between COPD, body composition, adipose tissue dysfunction, systemic inflammation and insulin resistance.

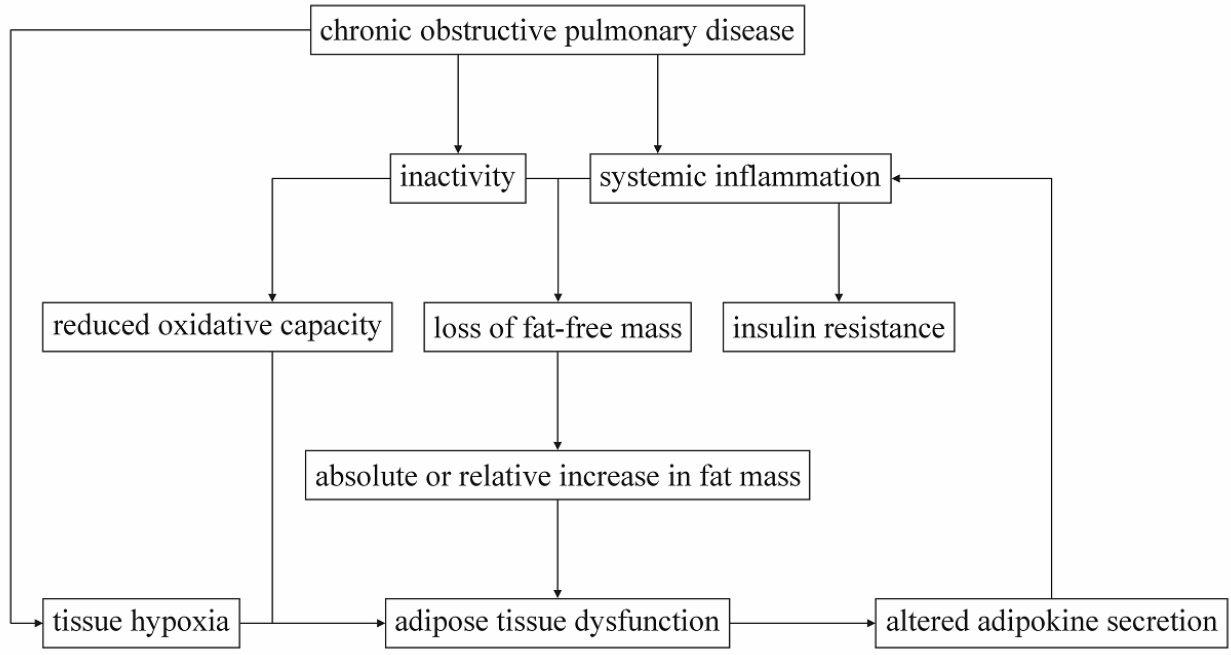




\section{Adipose tissue hypoxia and insulin resistance in COPD}

As mentioned earlier, there is evidence for adipose tissue hypoxia in obesity $^{116}$. It has recently been demonstrated that hypoxia induces expression and secretion of several pro-inflammatory mediators including IL-6, leptin, PAI-1 and monocyte migration inhibitory factor (MIF) in human adipocytes ${ }^{133}$. As stated before, adipose tissue hypoxia might thus provide an important link between obesity and insulin resistance through secretion of inflammatory adipokines.

In COPD patients with obesity or relatively abundant fat mass the link between adipose tissue hypoxia and systemic metabolic effects might be further enhanced by the presence of systemic hypoxemia in more advanced stages of disease, which does not occur in healthy obese. Although there are no studies that directly focussed on this issue, there is growing evidence for insulin resistance in COPD, especially in normal-to-overweight and hypoxic patients. Glucose intolerance was first reported in normal-weight chronic hypoxemic COPD patients on long-term oxygen therapy, although results might have been confounded by the use of systemic glucocorticosteroids ${ }^{159}$. More recently, the presence of insulin resistance was reported in normal-weight COPD patients with normal systemic oxygen saturation $^{69}$. Interestingly, both BMI as well as systemic IL-6 concentration were independent determinants of insulin resistance. In line with this observation, there is evidence for decreased insulin sensitivity in a large group of normal-weight COPD patients in comparison to underweight patients and normal-weight controls ${ }^{70}$. However, insulin sensitivity was not related to BMI in that study. Finally, supplemental oxygen resulted in increased glucose tolerance and insulin sensitivity in hypoxemic COPD patients, and this effect tended to be greater in obese than in lean subjects ${ }^{71}$.

Potential mechanistic links between adipose tissue mass, local and systemic hypoxia, systemic inflammation and insulin resistance in patients with COPD offer challenging research opportunities not only in the field of the extrapulmonary manifestations of the disease, but also in the area of pathogenesis of obesity-related metabolic disturbances. 


\section{References}

1. Rabe KF, Hurd S, Anzueto A, Barnes PJ, Buist SA, Calverley P, Fukuchi Y, Jenkins $C$, Rodriguez-Roisin R, van Weel C, Zielinski J; Global Initiative for Chronic Obstructive Lung Disease. Global strategy for the diagnosis, management, and prevention of chronic obstructive pulmonary disease: GOLD executive summary. Am J Respir Crit Care Med 2007;176:532-555.

2. WHO. Overweight and obesity - a new nutrition emergency? Monitoring the rapidly emerging public health problem of overweight and obesity: The WHO global database on body mass index. SCN News 2004:5-12.

3. Buist AS, McBurnie MA, Vollmer WM, Gillespie S, Burney P, Mannino DM, Menezes AM, Sullivan SD, Lee TA, Weiss KB, Jensen RL, Marks GB, Gulsvik A, Nizankowska-Mogilnicka E; BOLD Collaborative Research Group. International variation in the prevalence of COPD (the BOLD study): A population-based prevalence study. Lancet 2007;370:741-750.

4. Murray CJ, Lopez AD. Alternative projections of mortality and disability by cause 1990-2020: Global burden of disease study. Lancet 1997;349:1498-1504.

5. WHO. Obesity: Preventing and managing the global epidemic. Report of a WHO consultation. WHO Technical Report Series 8942000.

6. Jubber AS. Respiratory complications of obesity. Int J Clin Pract 2004;58: 573-580.

7. Shore SA, Fredberg JJ. Obesity, smooth muscle, and airway hyperresponsiveness. J Allergy Clin Immunol 2005;115:925-927.

8. Poulain M, Doucet M, Major GC, Drapeau V, Series F, Boulet LP, Tremblay A, Maltais $F$. The effect of obesity on chronic respiratory diseases: Pathophysiology and therapeutic strategies. Cmaj 2006;174:1293-1299.

9. Pitta F, Troosters T, Spruit MA, Probst VS, Decramer M, Gosselink R. Characteristics of physical activities in daily life in chronic obstructive pulmonary disease. Am J Respir Crit Care Med 2005;171:972-977.

10. Steuten LM, Creutzberg EC, Vrijhoef HJ, Wouters EF. COPD as a multicomponent disease: Inventory of dyspnoea, underweight, obesity and fat free mass depletion in primary care. Prim Care Respir J 2006;15:84-91.

11. Schokker DF, Visscher TL, Nooyens AC, van Baak MA, Seidell JC. Prevalence of overweight and obesity in the Netherlands. Obes Rev 2007;8:101-108.

12. Eisner MD, Blanc PD, Sidney S, Yelin EH, Lathon PV, Katz PP, Tolstykh I, Ackerson L, Iribarren C. Body composition and functional limitation in COPD. Respir Res 2007;8:7.

13. Marquis K, Maltais F, Duguay V, Bezeau AM, LeBlanc P, Jobin J, Poirier P. The metabolic syndrome in patients with chronic obstructive pulmonary disease. $J$ Cardiopulm Rehabil 2005;25:226-232; discussion 233-224.

14. Filley GF, Beckwitt HJ, Reeves JT, Mitchell RS. Chronic obstructive bronchopulmonary disease. Ii. Oxygen transport in two clinical types. Am J Med $1968 ; 44: 26-38$.

15. Guerra S, Sherrill DL, Bobadilla A, Martinez FD, Barbee RA. The relation of body mass index to asthma, chronic bronchitis, and emphysema. Chest 2002;122:1256-1263.

16. Schols AM, Soeters PB, Dingemans AM, Mostert R, Frantzen PJ, Wouters EF. Prevalence and characteristics of nutritional depletion in patients with stable COPD eligible for pulmonary rehabilitation. Am Rev Respir Dis 1993;147: 1151-1156. 
17. Vestbo J, Prescott E, Almdal T, Dahl M, Nordestgaard BG, Andersen T, Sorensen TI, Lange P. Body mass, fat-free body mass, and prognosis in patients with chronic obstructive pulmonary disease from a random population sample: Findings from the Copenhagen City Heart Study. Am J Respir Crit Care Med 2006;173:79-83.

18. Engelen MP, Schols AM, Lamers RJ, Wouters EF. Different patterns of chronic tissue wasting among patients with chronic obstructive pulmonary disease. Clin Nutr 1999;18:275-280.

19. Roubenoff R. The pathophysiology of wasting in the elderly. J Nutr 1999;129: 256S-259S.

20. Collins LC, Hoberty PD, Walker JF, Fletcher EC, Peiris AN. The effect of body fat distribution on pulmonary function tests. Chest 1995;107:1298-1302.

21. Lazarus R, Sparrow D, Weiss ST. Effects of obesity and fat distribution on ventilatory function: The normative aging study. Chest 1997;111:891-898.

22. Naimark A, Cherniack RM. Compliance of the respiratory system and its components in health and obesity. J Appl Physiol 1960;15:377-382.

23. Sharp JT, Henry JP, Sweany SK, Meadows WR, Pietras RJ. The total work of breathing in normal and obese men. J Clin Invest 1964;43:728-739.

24. Suratt PM, Wilhoit SC, Hsiao HS, Atkinson RL, Rochester DF. Compliance of chest wall in obese subjects. J Appl Physiol 1984;57:403-407.

25. Ray CS, Sue DY, Bray G, Hansen JE, Wasserman K. Effects of obesity on respiratory function. Am Rev Respir Dis 1983;128:501-506.

26. Ofir D, Laveneziana $P$, Webb KA, O'Donnell DE. Ventilatory and perceptual responses to cycle exercise in obese women. J Appl Physiol 2007;102:2217-2226.

27. Ferretti A, Giampiccolo P, Cavalli A, Milic-Emili J, Tantucci C. Expiratory flow limitation and orthopnea in massively obese subjects. Chest 2001;119: 1401-1408.

28. Rubinstein I, Zamel N, DuBarry L, Hoffstein V. Airflow limitation in morbidly obese, nonsmoking men. Ann Intern Med 1990;112:828-832.

29. Zerah F, Harf A, Perlemuter L, Lorino H, Lorino AM, Atlan G. Effects of obesity on respiratory resistance. Chest 1993;103:1470-1476.

30. Thomas PS, Cowen ER, Hulands G, Milledge JS. Respiratory function in the morbidly obese before and after weight loss. Thorax 1989;44:382-386.

31. Barrera F, Hillyer P, Ascanio G, Bechtel J. The distribution of ventilation, diffusion, and blood flow in obese patients with normal and abnormal blood gases. Am Rev Respir Dis 1973;108:819-830.

32. Holley HS, Milic-Emili J, Becklake MR, Bates DV. Regional distribution of pulmonary ventilation and perfusion in obesity. J Clin Invest 1967;46:475-481.

33. Sampson MG, Grassino K. Neuromechanical properties in obese patients during carbon dioxide rebreathing. Am J Med 1983;75:81-90.

34. Gilbert R, Sipple JH, Auchincloss JH, Jr. Respiratory control and work of breathing in obese subjects. J Appl Physiol 1961;16:21-26.

35. Kelly TM, Jensen RL, Elliott CG, Crapo RO. Maximum respiratory pressures in morbidly obese subjects. Respiration 1988;54:73-77.

36. Weiner $P$, Waizman J, Weiner $M$, Rabner $M$, Magadle $R$, Zamir D. Influence of excessive weight loss after gastroplasty for morbid obesity on respiratory muscle performance. Thorax 1998;53:39-42.

37. Refsum HE, Holter PH, Lovig T, Haffner JF, Stadaas JO. Pulmonary function and energy expenditure after marked weight loss in obese women: Observations before and one year after gastric banding. Int J Obes 1990;14:175-183.

38. Dempsey JA, Reddan W, Balke B, Rankin J. Work capacity determinants and physiologic cost of weight-supported work in obesity. J Appl Physiol 1966;21: 1815-1820.

39. Whipp BJ, Davis JA. The ventilatory stress of exercise in obesity. Am Rev Respir Dis 1984;129:S90-92. 
40. Babb TG, Buskirk ER, Hodgson JL. Exercise end-expiratory lung volumes in lean and moderately obese women. Int J Obes 1989;13:11-19.

41. Babb TG, Korzick D, Meador M, Hodgson JL, Buskirk ER. Ventilatory response of moderately obese women to submaximal exercise. Int J Obes 1991;15:59-65.

42. Chlif M, Keochkerian D, Feki Y, Vaidie A, Choquet D, Ahmaidi S. Inspiratory muscle activity during incremental exercise in obese men. Int $J$ Obes (Lond) 2007;31:1456-1463.

43. Li J, Li S, Feuers RJ, Buffington CK, Cowan GS. Influence of body fat distribution on oxygen uptake and pulmonary performance in morbidly obese females during exercise. Respirology 2001;6:9-13.

44. Kress JP, Pohlman AS, Alverdy J, Hall JB. The impact of morbid obesity on oxygen cost of breathing at rest. Am J Respir Crit Care Med 1999;160:883-886.

45. Lennmarken C, Sandstedt S, von Schenck H, Larsson J. Skeletal muscle function and metabolism in obese women. JPEN J Parenter Enteral Nutr 1986;10:583-587.

46. Alpert MA, Lambert CR, Terry BE, Cohen MV, Mukerji V, Massey CV, Hashimi MW, Panayiotou $\mathrm{H}$. Interrelationship of left ventricular mass, systolic function and diastolic filling in normotensive morbidly obese patients. Int J Obes Relat Metab Disord 1995; 19:550-557.

47. Swinburn CR, Cooper BG, Mould H, Corris PA, Gibson GJ. Adverse effect of additional weight on exercise against gravity in patients with chronic obstructive airways disease. Thorax 1989;44:716-720.

48. Gibson GJ. Obesity, respiratory function and breathlessness. Thorax 2000;55 Suppl 1:S41-44.

49. O'Donnell DE, Ofir D, Laveneziana P. Patterns of cardiopulmonary response to exercise in lung diseases. Eur Respir Mon 2006;40:69-92.

50. O'Donnell DE, Voduc N. Mechanisms of dyspnea in restrictive lung disorders. Boca Raton, FL: Taylor \& Francis Group; 2005.

51. O'Donnell DE, Hamilton AL, Webb KA. Sensory-mechanical relationships during high-intensity, constant-work-rate exercise in COPD. J Appl Physiol 2006;101:1025-1035.

52. Engelen MP, Schols AM, Does JD, Wouters EF. Skeletal muscle weakness is associated with wasting of extremity fat- free mass but not with airflow obstruction in patients with chronic obstructive pulmonary disease. Am J Clin Nutr 2000;71:733-738.

53. Baarends EM, Schols AM, Mostert R, Wouters EF. Peak exercise response in relation to tissue depletion in patients with chronic obstructive pulmonary disease. Eur Respir J 1997;10:2807-2813.

54. Visser M, Langlois J, Guralnik JM, Cauley JA, Kronmal RA, Robbins J, Williamson JD, Harris TB. High body fatness, but not low fat-free mass, predicts disability in older men and women: The cardiovascular health study. Am J Clin Nutr 1998; 68:584-590.

55. Sternfeld B, Ngo L, Satariano WA, Tager IB. Associations of body composition with physical performance and self-reported functional limitation in elderly men and women. Am J Epidemiol 2002;156:110-121.

56. Schols AM, Broekhuizen R, Weling-Scheepers CA, Wouters EF. Body composition and mortality in chronic obstructive pulmonary disease. Am J Clin Nutr 2005; 82:53-59.

57. Landbo C, Prescott E, Lange P, Vestbo J, Almdal TP. Prognostic value of nutritional status in chronic obstructive pulmonary disease. Am J Respir Crit Care Med 1999;160:1856-1861.

58. Wilson DO, Rogers RM, Wright EC, Anthonisen NR. Body weight in chronic obstructive pulmonary disease. The national institutes of health intermittent positive-pressure breathing trial. Am Rev Respir Dis 1989;139:1435-1438. 
59. Chailleux E, Laaban JP, Veale D. Prognostic value of nutritional depletion in patients with COPD treated by long-term oxygen therapy: Data from the ANTADIR observatory. Chest 2003;123:1460-1466.

60. Peeters A, Barendregt JJ, Willekens F, Mackenbach JP, Al Mamun A, Bonneux L. Obesity in adulthood and its consequences for life expectancy: A life-table analysis. Ann Intern Med 2003;138:24-32.

61. Kalantar-Zadeh K, Horwich TB, Oreopoulos A, Kovesdy CP, Younessi H, Anker SD, Morley JE. Risk factor paradox in wasting diseases. Curr Opin Clin Nutr Metab Care 2007; 10:433-442.

62. Watson L, Vonk JM, Lofdahl CG, Pride NB, Pauwels RA, Laitinen LA, Schouten JP, Postma DS. Predictors of lung function and its decline in mild to moderate COPD in association with gender: Results from the EUROSCOP study. Respir Med 2006;100:746-753.

63. Schunemann HJ, Dorn J, Grant BJ, Winkelstein W, Jr., Trevisan M. Pulmonary function is a long-term predictor of mortality in the general population: 29-year follow-up of the Buffalo health study. Chest 2000;118:656-664.

64. Hole DJ, Watt GC, Davey-Smith G, Hart CL, Gillis CR, Hawthorne VM. Impaired lung function and mortality risk in men and women: Findings from the Renfrew and Paisley prospective population study. Bmj 1996;313:711-715; discussion 715-716.

65. Sin DD, Man SF. Why are patients with chronic obstructive pulmonary disease at increased risk of cardiovascular diseases? The potential role of systemic inflammation in chronic obstructive pulmonary disease. Circulation 2003;107:1514-1519.

66. Fabbri LM, Rabe KF. From COPD to chronic systemic inflammatory syndrome? Lancet 2007;370:797-799.

67. Eckel RH, Grundy SM, Zimmet PZ. The metabolic syndrome. Lancet 2005;365:1415-1428.

68. Gami AS, Witt BJ, Howard DE, Erwin PJ, Gami LA, Somers VK, Montori VM. Metabolic syndrome and risk of incident cardiovascular events and death: $A$ systematic review and meta-analysis of longitudinal studies. J Am Coll Cardiol 2007;49:403-414.

69. Bolton CE, Evans M, Ionescu AA, Edwards SM, Morris RH, Dunseath G, Luzio SD, Owens DR, Shale DJ. Insulin resistance and inflammation - a further systemic complication of COPD. COPD 2007;4:121-126.

70. Koehler F, Doehner W, Hoernig S, Witt C, Anker SD, John M. Anorexia in chronic obstructive pulmonary disease - association to cachexia and hormonal derangement. Int J Cardiol 2007;119:83-89.

71. Jakobsson P, Jorfeldt L. Oxygen supplementation increases glucose tolerance during euglycaemic hyperinsulinaemic glucose clamp procedure in patients with severe COPD and chronic hypoxaemia. Clin Physiol Funct Imaging 2006;26: 271-274.

72. Grundy SM, Brewer HB, Jr., Cleeman JI, Smith SC, Jr., Lenfant C. Definition of metabolic syndrome: Report of the National heart, lung, and blood institute/American Heart Association conference on scientific issues related to definition. Circulation 2004;109:433-438.

73. Goossens GH. The role of adipose tissue dysfunction in the pathogenesis of obesity-related insulin resistance. Physiol Behav 2007.

74. Frayn KN. Adipose tissue and the insulin resistance syndrome. Proc Nutr Soc 2001;60:375-380.

75. Forouhi NG, Jenkinson G, Thomas EL, Mullick S, Mierisova S, Bhonsle U, McKeigue PM, Bell JD. Relation of triglyceride stores in skeletal muscle cells to central obesity and insulin sensitivity in European and South Asian men. Diabetologia 1999;42:932-935. 
76. Jacob S, Machann J, Rett K, Brechtel K, Volk A, Renn W, Maerker E, Matthaei S, Schick F, Claussen CD, Häring HU. Association of increased intramyocellular lipid content with insulin resistance in lean nondiabetic offspring of type 2 diabetic subjects. Diabetes 1999;48:1113-1119.

77. Pan DA, Lillioja S, Kriketos AD, Milner MR, Baur LA, Bogardus $C$, Jenkins $A B$, Storlien LH. Skeletal muscle triglyceride levels are inversely related to insulin action. Diabetes 1997;46:983-988.

78. Koyama K, Chen G, Lee $\mathrm{Y}$, Unger RH. Tissue triglycerides, insulin resistance, and insulin production: Implications for hyperinsulinemia of obesity. Am J Physiol 1997;273:E708-713.

79. Banerji MA, Buckley MC, Chaiken RL, Gordon D, Lebovitz HE, Kral JG. Liver fat, serum triglycerides and visceral adipose tissue in insulin-sensitive and insulinresistant black men with NIDDM. Int J Obes Relat Metab Disord 1995;19:846850.

80. Bjorntorp P. Liver triglycerides and metabolism. Int J Obes Relat Metab Disord 1995; 19:839-840.

81. Frayn KN, Karpe F, Fielding BA, Macdonald IA, Coppack SW. Integrative physiology of human adipose tissue. Int J Obes Relat Metab Disord 2003;27: 875-888.

82. Fruhbeck G, Gomez-Ambrosi J, Muruzabal FJ, Burrell MA. The adipocyte: A model for integration of endocrine and metabolic signaling in energy metabolism regulation. Am J Physiol Endocrinol Metab 2001;280:E827-847.

83. Kershaw EE, Flier JS. Adipose tissue as an endocrine organ. J Clin Endocrinol Metab 2004;89:2548-2556.

84. Bastard JP, Maachi M, Lagathu C, Kim MJ, Caron M, Vidal H, Capeau J, Feve B. Recent advances in the relationship between obesity, inflammation, and insulin resistance. Eur Cytokine Netw 2006;17:4-12.

85. Engstrom G, Hedblad $B$, Stavenow $L$, Lind $P$, Janzon $L$, Lindgarde $F$. Inflammation-sensitive plasma proteins are associated with future weight gain. Diabetes 2003;52:2097-2101.

86. Festa A, D'Agostino R, Jr., Howard G, Mykkanen L, Tracy RP, Haffner SM. Chronic subclinical inflammation as part of the insulin resistance syndrome: The insulin resistance atherosclerosis study (IRAS). Circulation 2000;102:42-47.

87. Yudkin JS. Adipose tissue, insulin action and vascular disease: Inflammatory signals. Int J Obes Relat Metab Disord 2003;27 Suppl 3:S25-28.

88. Cai D, Yuan M, Frantz DF, Melendez PA, Hansen L, Lee J, Shoelson SE. Local and systemic insulin resistance resulting from hepatic activation of IKK-beta and NFkappaB. Nat Med 2005;11:183-190.

89. Hirosumi J, Tuncman G, Chang L, Gorgun CZ, Uysal KT, Maeda K, Karin M, Hotamisligil GS. A central role for JNK in obesity and insulin resistance. Nature 2002;420:333-336.

90. Perreault M, Marette A. Targeted disruption of inducible nitric oxide synthase protects against obesity-linked insulin resistance in muscle. Nat Med 2001;7:1138-1143.

91. Uysal KT, Wiesbrock SM, Marino MW, Hotamisligil GS. Protection from obesityinduced insulin resistance in mice lacking TNF-alpha function. Nature 1997;389:610-614.

92. Yuan M, Konstantopoulos N, Lee J, Hansen L, Li ZW, Karin M, Shoelson SE. Reversal of obesity- and diet-induced insulin resistance with salicylates or targeted disruption of IKK-beta. Science 2001;293:1673-1677.

93. Bastard JP, Jardel C, Bruckert E, Blondy P, Capeau J, Laville M, Vidal H, Hainque B. Elevated levels of interleukin 6 are reduced in serum and subcutaneous adipose tissue of obese women after weight loss. J Clin Endocrinol Metab 2000;85:3338-3342. 
94. Bruun JM, Lihn AS, Verdich C, Pedersen SB, Toubro S, Astrup A, Richelsen B. Regulation of adiponectin by adipose tissue-derived cytokines: In vivo and in vitro investigations in humans. Am J Physiol Endocrinol Metab 2003;285: E527-533.

95. Hotamisligil GS, Arner P, Caro JF, Atkinson RL, Spiegelman BM. Increased adipose tissue expression of tumor necrosis factor-alpha in human obesity and insulin resistance. J Clin Invest 1995;95:2409-2415.

96. Ouchi N, Kihara S, Funahashi T, Nakamura T, Nishida M, Kumada M, Okamoto Y, Ohashi K, Nagaretani H, Kishida K, Nishizawa H, Maeda N, Kobayashi H, Hiraoka $\mathrm{H}$, Matsuzawa $\mathrm{Y}$. Reciprocal association of c-reactive protein with adiponectin in blood stream and adipose tissue. Circulation 2003;107:671-674.

97. Rotter V, Nagaev I, Smith U. Interleukin-6 (IL-6) induces insulin resistance in 3T3-L1 adipocytes and is, like IL-8 and tumor necrosis factor-alpha, overexpressed in human fat cells from insulin-resistant subjects. $\mathrm{J}$ Biol Chem 2003;278:45777-45784.

98. Hotamisligil GS, Spiegelman BM. Tumor necrosis factor alpha: A key component of the obesity-diabetes link. Diabetes 1994;43:1271-1278.

99. Kern PA, Ranganathan S, Li C, Wood L, Ranganathan G. Adipose tissue tumor necrosis factor and interleukin-6 expression in human obesity and insulin resistance. Am J Physiol Endocrinol Metab 2001;280:E745-751.

100. Maachi M, Pieroni L, Bruckert E, Jardel C, Fellahi S, Hainque B, Capeau J, Bastard JP. Systemic low-grade inflammation is related to both circulating and adipose tissue TNFalpha, leptin and IL-6 levels in obese women. Int J Obes Relat Metab Disord 2004;28:993-997.

101. Fried SK, Bunkin DA, Greenberg AS. Omental and subcutaneous adipose tissues of obese subjects release interleukin-6: Depot difference and regulation by glucocorticoid. J Clin Endocrinol Metab 1998;83:847-850.

102. Mohamed-Ali V, Goodrick S, Rawesh A, Katz DR, Miles JM, Yudkin JS, Klein S, Coppack SW. Subcutaneous adipose tissue releases interleukin-6, but not tumor necrosis factor-alpha, in vivo. J Clin Endocrinol Metab 1997;82:4196-4200.

103. Alessi MC, Bastelica D, Morange P, Berthet B, Leduc I, Verdier M, Geel O, JuhanVague I. Plasminogen activator inhibitor 1 , transforming growth factor-beta ${ }_{1}$, and BMI are closely associated in human adipose tissue during morbid obesity. Diabetes 2000;49:1374-1380.

104. Alessi MC, Poggi M, Juhan-Vague I. Plasminogen activator inhibitor-1, adipose tissue and insulin resistance. Curr Opin Lipidol 2007;18:240-245.

105. Considine RV, Sinha MK, Heiman ML, Kriauciunas A, Stephens TW, Nyce MR, Ohannesian JP, Marco CC, McKee LJ, Bauer TL, et al. Serum immunoreactiveleptin concentrations in normal-weight and obese humans. $N$ Engl J Med 1996;334:292-295.

106. Klein S, Coppack SW, Mohamed-Ali V, Landt M. Adipose tissue leptin production and plasma leptin kinetics in humans. Diabetes 1996;45:984-987.

107. Ostlund RE, Jr., Yang JW, Klein S, Gingerich R. Relation between plasma leptin concentration and body fat, gender, diet, age, and metabolic covariates. J Clin Endocrinol Metab 1996;81:3909-3913.

108. Fain JN. Release of interleukins and other inflammatory cytokines by human adipose tissue is enhanced in obesity and primarily due to the nonfat cells. Vitam Horm 2006;74:443-477.

109. Hotta K, Funahashi T, Arita Y, Takahashi M, Matsuda M, Okamoto Y, Iwahashi H, Kuriyama $\mathrm{H}$, Ouchi N, Maeda K, et al. Plasma concentrations of a novel, adiposespecific protein, adiponectin, in type 2 diabetic patients. Arterioscler Thromb Vasc Biol 2000;20:1595-1599. 
110. Weyer C, Funahashi T, Tanaka S, Hotta K, Matsuzawa Y, Pratley RE, Tataranni PA. Hypoadiponectinemia in obesity and type 2 diabetes: Close association with insulin resistance and hyperinsulinemia. J Clin Endocrinol Metab 2001;86: 1930-1935.

111. Skurk T, Alberti-Huber C, Herder C, Hauner H. Relationship between adipocyte size and adipokine expression and secretion. J Clin Endocrinol Metab 2007;92:1023-1033.

112. Weisberg SP, McCann D, Desai M, Rosenbaum M, Leibel RL, Ferrante AW, Jr. Obesity is associated with macrophage accumulation in adipose tissue. J Clin Invest 2003;112:1796-1808.

113. Xu H, Barnes GT, Yang Q, Tan G, Yang D, Chou CJ, Sole J, Nichols A, Ross JS, Tartaglia LA, et al. Chronic inflammation in fat plays a crucial role in the development of obesity-related insulin resistance. J Clin Invest 2003;112: 1821-1830.

114. Lacasa D, Taleb S, Keophiphath M, Miranville A, Clement K. Macrophage-secreted factors impair human adipogenesis: Involvement of proinflammatory state in preadipocytes. Endocrinology 2007;148:868-877.

115. Permana PA, Menge C, Reaven PD. Macrophage-secreted factors induce adipocyte inflammation and insulin resistance. Biochem Biophys Res Commun 2006;341:507-514.

116. Hosogai N, Fukuhara A, Oshima K, Miyata Y, Tanaka S, Segawa K, Furukawa S, Tochino $\mathrm{Y}$, Komuro R, Matsuda $\mathrm{M}$, et al. Adipose tissue hypoxia in obesity and its impact on adipocytokine dysregulation. Diabetes 2007;56:901-911.

117. Cancello R, Henegar C, Viguerie N, Taleb S, Poitou C, Rouault C, Coupaye M, Pelloux V, Hugol D, Bouillot JL, et al. Reduction of macrophage infiltration and chemoattractant gene expression changes in white adipose tissue of morbidly obese subjects after surgery-induced weight loss. Diabetes 2005;54:2277-2286.

118. Blaak EE, van Baak MA, Kemerink GJ, Pakbiers MT, Heidendal GA, Saris WH. Beta-adrenergic stimulation and abdominal subcutaneous fat blood flow in lean, obese, and reduced-obese subjects. Metabolism 1995;44:183-187.

119. Goossens GH, Jocken JW, Blaak EE, Schiffers PM, Saris WH, van Baak MA. Endocrine role of the renin-angiotensin system in human adipose tissue and muscle: Effect of beta-adrenergic stimulation. Hypertension 2007;49:542-547.

120. Jansson PA, Larsson A, Lonnroth PN. Relationship between blood pressure, metabolic variables and blood flow in obese subjects with or without non-insulindependent diabetes mellitus. Eur J Clin Invest 1998;28:813-818.

121. Summers LK, Samra JS, Humphreys SM, Morris RJ, Frayn KN. Subcutaneous abdominal adipose tissue blood flow: Variation within and between subjects and relationship to obesity. Clin Sci (Lond) 1996;91:679-683.

122. Virtanen KA, Lonnroth $P$, Parkkola $R$, Peltoniemi $P$, Asola M, Viljanen $T$, Tolvanen $T$, Knuuti J, Ronnemaa T, Huupponen R, et al. Glucose uptake and perfusion in subcutaneous and visceral adipose tissue during insulin stimulation in nonobese and obese humans. J Clin Endocrinol Metab 2002;87:3902-3910.

123. West DB, Prinz WA, Francendese AA, Greenwood MR. Adipocyte blood flow is decreased in obese Zucker rats. Am J Physiol 1987;253:R228-233.

124. Trayhurn $P$, Wood IS. Adipokines: Inflammation and the pleiotropic role of white adipose tissue. Br J Nutr 2004;92:347-355.

125. Hopfl G, Ogunshola O, Gassmann M. HIFs and tumors - causes and consequences. Am J Physiol Regul Integr Comp Physiol 2004;286:R608-623.

126. Lolmede K, Durand de Saint Front V, Galitzky J, Lafontan M, Bouloumie A. Effects of hypoxia on the expression of proangiogenic factors in differentiated 3T3-F442a adipocytes. Int J Obes Relat Metab Disord 2003;27:1187-1195.

127. Semenza GL. Surviving ischemia: Adaptive responses mediated by hypoxiainducible factor 1. J Clin Invest 2000;106:809-812. 
128. Trayhurn P. Endocrine and signalling role of adipose tissue: New perspectives on fat. Acta Physiol Scand 2005;184:285-293.

129. Trayhurn P, Wood IS. Signalling role of adipose tissue: Adipokines and inflammation in obesity. Biochem Soc Trans 2005;33:1078-1081.

130. Wenger RH. Cellular adaptation to hypoxia: $\mathrm{O}_{2}$-sensing protein hydroxylases, hypoxia-inducible transcription factors, and $\mathrm{O}_{2}$-regulated gene expression. Faseb J 2002;16:1151-1162.

131. Chen B, Lam KS, Wang Y, Wu D, Lam MC, Shen J, Wong L, Hoo RL, Zhang J, Xu A. Hypoxia dysregulates the production of adiponectin and plasminogen activator inhibitor-1 independent of reactive oxygen species in adipocytes. Biochem Biophys Res Commun 2006;341:549-556.

132. Segawa K, Fukuhara A, Hosogai N, Morita K, Okuno Y, Tanaka M, Nakagawa Y, Kihara S, Funahashi T, Komuro R, et al. Visfatin in adipocytes is upregulated by hypoxia through HIF-1alpha-dependent mechanism. Biochem Biophys Res Commun 2006;349:875-882.

133. Wang B, Wood IS, Trayhurn P. Dysregulation of the expression and secretion of inflammation-related adipokines by hypoxia in human adipocytes. Pflugers Arch 2007;455:479-492.

134. Ye J, Gao Z, Yin J, He Q. Hypoxia is a potential risk factor for chronic inflammation and adiponectin reduction in adipose tissue of ob/ob and dietary obese mice. Am J Physiol Endocrinol Metab 2007;293:E1118-1128.

135. Greijer $A E$, van der Wall $E$. The role of hypoxia inducible factor 1 (HIF-1) in hypoxia induced apoptosis. J Clin Pathol 2004;57:1009-1014.

136. Cinti S, Mitchell G, Barbatelli G, Murano I, Ceresi E, Faloia E, Wang S, Fortier M, Greenberg AS, Obin MS. Adipocyte death defines macrophage localization and function in adipose tissue of obese mice and humans. J Lipid Res 2005;46: 2347-2355.

137. Carriere A, Carmona MC, Fernandez Y, Rigoulet M, Wenger RH, Penicaud L, Casteilla L. Mitochondrial reactive oxygen species control the transcription factor chop-10/gadd153 and adipocyte differentiation: A mechanism for hypoxiadependent effect. J Biol Chem 2004;279:40462-40469.

138. Yun Z, Maecker HL, Johnson RS, Giaccia AJ. Inhibition of ppar gamma 2 gene expression by the HIF-1-regulated gene DEC1/stra13: A mechanism for regulation of adipogenesis by hypoxia. Dev Cell 2002;2:331-341.

139. Paolisso G, Tataranni PA, Foley JE, Bogardus C, Howard BV, Ravussin E. A high concentration of fasting plasma non-esterified fatty acids is a risk factor for the development of niddm. Diabetologia 1995;38:1213-1217.

140. Weyer C, Foley JE, Bogardus C, Tataranni PA, Pratley RE. Enlarged subcutaneous abdominal adipocyte size, but not obesity itself, predicts type II diabetes independent of insulin resistance. Diabetologia 2000;43:1498-1506.

141. Bi M, Naczki C, Koritzinsky M, Fels D, Blais J, Hu N, Harding H, Novoa I, Varia M, Raleigh J, et al. ER stress-regulated translation increases tolerance to extreme hypoxia and promotes tumor growth. Embo J 2005;24:3470-3481.

142. Feldman DE, Chauhan V, Koong AC. The unfolded protein response: A novel component of the hypoxic stress response in tumors. Mol Cancer Res 2005;3: 597-605.

143. Koumenis C, Naczki C, Koritzinsky M, Rastani S, Diehl A, Sonenberg N, Koromilas A, Wouters BG. Regulation of protein synthesis by hypoxia via activation of the endoplasmic reticulum kinase perk and phosphorylation of the translation initiation factor EIF2alpha. Mol Cell Biol 2002;22:7405-7416.

144. Nakatani Y, Kaneto H, Kawamori D, Yoshiuchi K, Hatazaki M, Matsuoka TA, Ozawa K, Ogawa S, Hori M, Yamasaki Y, et al. Involvement of endoplasmic reticulum stress in insulin resistance and diabetes. J Biol Chem 2005;280: 847-851. 
145. Ozcan U, Cao Q, Yilmaz E, Lee AH, Iwakoshi NN, Ozdelen E, Tuncman G, Gorgun C, Glimcher LH, Hotamisligil GS. Endoplasmic reticulum stress links obesity, insulin action, and type 2 diabetes. Science 2004;306:457-461.

146. Gosker H, Zeegers M, Wouters E, Schols AM. Muscle fibre type shifting in the vastus lateralis of patients with COPD is associated with disease severity: A systematic review and meta-analysis. Thorax 2007.

147. American Thoracic Society/European Respiratory Society Statement. Skeletal muscle dysfunction in chronic obstructive pulmonary disease. Am J Respir Crit Care Med 1999;159:S1-40.

148. Jakobsson $\mathrm{P}$, Jorfeldt $\mathrm{L}$, von Schenck $\mathrm{H}$. Fat metabolism and its response to infusion of insulin and glucose in patients with advanced chronic obstructive pulmonary disease. Clin Physiol 1995;15:319-329.

149. Schiffelers SL, Blaak EE, Baarends EM, Van Baak MA, Saris WH, Wouters EF, Schols AM. Beta-adrenoceptor-mediated thermogenesis and lipolysis in patients with chronic obstructive pulmonary disease. Am J Physiol Endocrinol Metab 2001;280:E357-E364.

150. Gan WQ, Man SF, Senthilselvan A, Sin DD. Association between chronic obstructive pulmonary disease and systemic inflammation: A systematic review and a meta-analysis. Thorax 2004;59:574-580.

151. Yasuda N, Gotoh K, Minatoguchi S, Asano K, Nishigaki K, Nomura M, Ohno A, Watanabe $\mathrm{M}$, Sano $\mathrm{H}$, Kumada $\mathrm{H}$, et al. An increase of soluble fas, an inhibitor of apoptosis, associated with progression of COPD. Respir Med 1998;92:993-999.

152. Vernooy JH, Kucukaycan M, Jacobs JA, Chavannes NH, Buurman WA, Dentener MA, Wouters EF. Local and systemic inflammation in patients with chronic obstructive pulmonary disease: Soluble tumor necrosis factor receptors are increased in sputum. Am J Respir Crit Care Med 2002;166:1218-1224.

153. Petersen AM, Penkowa M, Iversen $M$, Frydelund-Larsen $L$, Andersen JL, Mortensen J, Lange P, Pedersen BK. Elevated levels of IL-18 in plasma and skeletal muscle in chronic obstructive pulmonary disease. Lung 2007;185:161-171.

154. Broekhuizen R, Wouters EF, Creutzberg EC, Schols AM. Raised CRP levels mark metabolic and functional impairment in advanced COPD. Thorax 2006;61:17-22.

155. Eid AA, Ionescu AA, Nixon LS, Lewis-Jenkins V, Matthews SB, Griffiths TL, Shale DJ. Inflammatory response and body composition in chronic obstructive pulmonary disease. Am J Respir Crit Care Med 2001;164:1414-1418.

156. Donaldson GC, Seemungal TA, Patel IS, Bhowmik A, Wilkinson TM, Hurst JR, Maccallum PK, Wedzicha JA. Airway and systemic inflammation and decline in lung function in patients with COPD. Chest 2005;128:1995-2004.

157. Goossens GH, Jocken JWE, van Baak MA, Jansen EHJM, Saris WHM, Blaak EE. Short-term beta-adrenergic regulation of leptin, adiponectin and IL-6 secretion in vivo in lean and obese subjects. Diabetes Obes Metab 2008.

158. Fontana L, Eagon JC, Trujillo ME, Scherer PE, Klein S. Visceral fat adipokine secretion is associated with systemic inflammation in obese humans. Diabetes 2007; 56:1010-1013.

159. Hjalmarsen A, Aasebo U, Birkeland K, Sager G, Jorde R. Impaired glucose tolerance in patients with chronic hypoxic pulmonary disease. Diabetes Metab 1996;22:37-42. 


\section{Samenvatting}

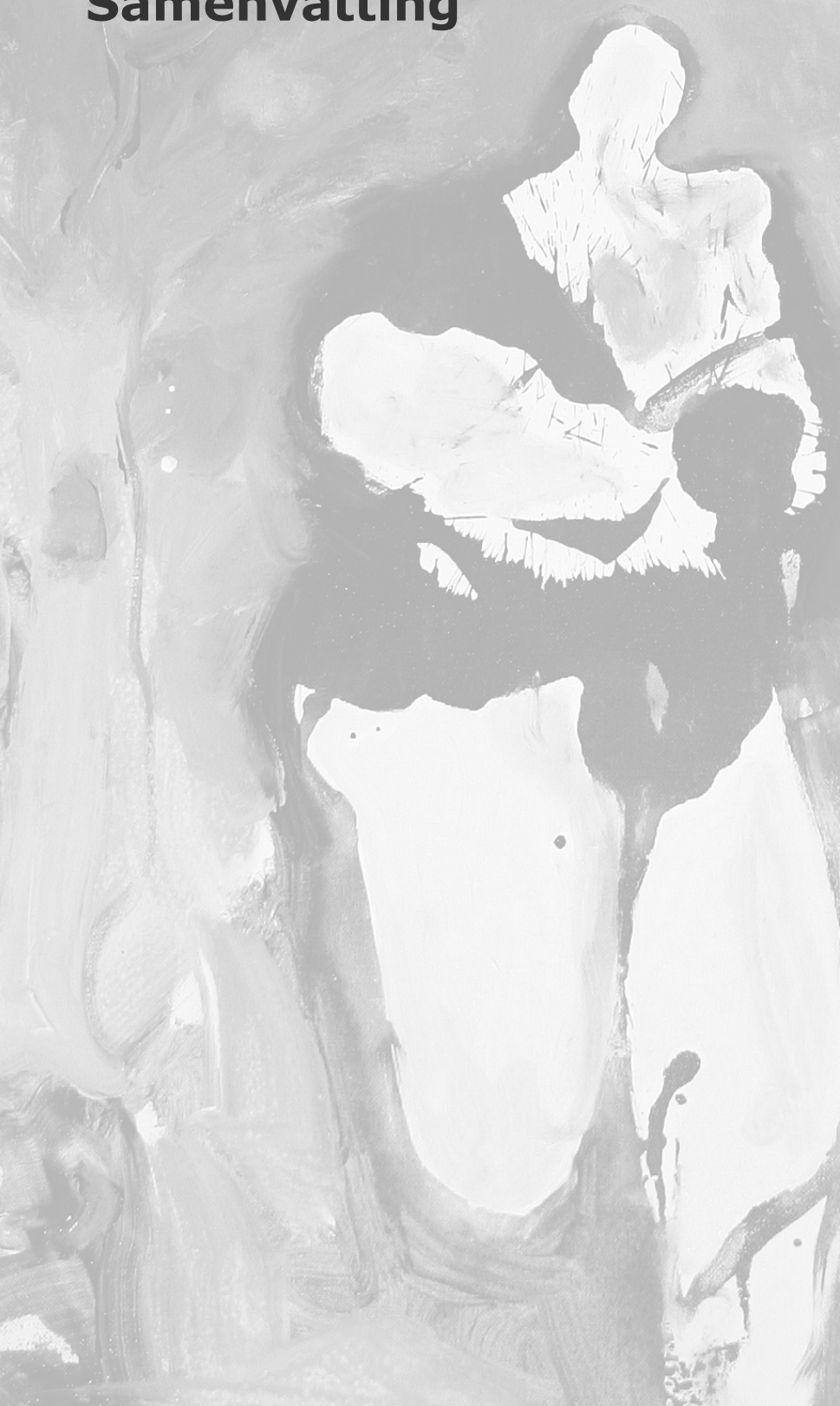





\section{Inleiding}

\section{COPD}

COPD is de afkorting van het Engelstalige "Chronic Obstructive Pulmonary Disease", hetgeen staat voor chronisch obstructieve longziekten. Deze aandoening wordt gekenmerkt door een progressieve en niet volledig omkeerbare vernauwing van de luchtwegen. COPD omvat de ziektebeelden chronische bronchitis en longemfyseem. Kortademigheid, hoesten en vermindering van het inspanningsvermogen zijn de voornaamste klachten van patiënten met COPD en leiden tot ernstige beperkingen in het dagelijks functioneren. Roken is de belangrijkste risicofactor voor het ontwikkelen van COPD, hoewel minder dan een kwart van alle rokers deze aandoening krijgt. Volgens de huidige schattingen heeft 10 procent van de volwassen wereldbevolking een matige tot zeer ernstige vorm van COPD; de verwachting is dat COPD in 2020 de derde meest voorkomende doodsoorzaak wereldwijd zal zijn.

In de klassieke benadering werd COPD puur gezien als een longziekte, gebaseerd op de aanwezigheid van chronische luchtwegvernauwing. In de laatste decennia zijn er echter belangrijke manifestaties buiten de longen beschreven bij patiënten met COPD. Deze manifestaties worden ook wel aangeduid als de systemische effecten van COPD en omvatten onder andere veranderingen in de voedingstoestand en abnormaal functioneren van de skeletspieren.

\section{Voedingstoestand}

Verstoringen in de voedingstoestand komen regelmatig voor bij patiënten met COPD. Het totale lichaamsgewicht is opgebouwd uit vetmassa en vetvrije massa. Om een indruk te krijgen van de voedingstoestand van patiënten met COPD wordt naast gewicht en lengte, tegenwoordig ook in toenemende mate de vetvrije massa gemeten. De vetvrije massa van het lichaam bestaat uit celmassa (de eiwitten en mineralen van spieren, organen en botten) en water. De vetvrije massa wordt gebruikt als maat voor de hoeveelheid spiermassa. In de afgelopen decennia is duidelijk geworden dat veranderingen in de voedingstoestand belangrijke gevolgen hebben voor COPD patiënten. Hoewel uit eerder onderzoek al bekend was dat gewichtsverlies een negatieve invloed heeft op de overleving van deze patiënten, is nog niet zo lang geleden aangetoond dat vooral verlies van vetvrije massa de prognose van COPD patiënten nadelig 
beïnvloedt. Daarnaast is verlies van vetvrije massa bij COPD patiënten, onafhankelijk van het lichaamsgewicht, een belangrijke oorzaak van spierzwakte, verminderd inspanningsvermogen en verlaagde kwaliteit van leven.

\section{Sarcopenie}

Het woord 'sarcopenia' is een samenvoegsel van het Griekse 'sarco' (vlees) en 'penia' (gebrek) en betekent in de letterlijke vertaling 'gebrek aan vlees'. De medische term 'sarcopenie' wordt gebruikt om het verlies aan spiermassa en spierfunctie op hoge leeftijd te beschrijven. Hoewel de afname van spiermassa deel uitmaakt van het natuurlijke verouderingsproces, is sarcopenie een belangrijke oorzaak van spierzwakte, verminderde mobiliteit en toenemende afhankelijkheid bij gezonde ouderen. Belangrijke factoren die bijdragen aan het ontstaan van sarcopenie zijn inactiviteit, afname van functioneren van het zenuwstelsel op hogere leeftijd en veranderingen in de eiwitstofwisseling.

De verstoringen in de voedingstoestand die optreden bij een deel van de patiënten met COPD vertonen gelijkenis met sarcopenie. Er wordt gesproken over COPD patiënten met 'sarcopene kenmerken' indien er sprake is van een verminderde vetvrije massa (als maat voor de spiermassa) in combinatie met een normaal of zelfs toegenomen lichaamsgewicht. In de afgelopen jaren is duidelijk geworden dat vooral het verlies aan vetvrije massa nadelige gevolgen heeft voor het functioneren en de overlevingskans van patiënten met COPD.

\section{Skeletspieren}

Abnormaal functioneren van de skeletspieren is een tweede systemisch effect van COPD en leidt tot spierzwakte en verminderd inspanningsvermogen bij patiënten met deze aandoening. In de afgelopen decennia is er veel onderzoek gedaan naar de aard en oorzaak van het disfunctioneren van de skeletspieren van met name de onderste ledematen. Naast afname van de hoeveelheid spiermassa, zijn er bij COPD patiënten veranderingen in de samenstelling van de skeletspiervezels. $\mathrm{Er}$ is sprake van een verschuiving van zuurstofafhankelijke vezels met een groot uithoudingsvermogen (type I vezels) naar zuurstofonafhankelijke vezels (type II vezels). Deze laatste worden gekenmerkt door een snellere en grotere kracht, maar ook door een toegenomen vermoeibaarheid. Naast deze verschuiving in spiervezelsamenstelling is de energiestofwisseling van de skeletspieren van COPD patiënten 
verstoord. De activiteit van enzymen die voedingsstoffen verbranden met behulp van zuurstof (oxidatieve enzymen) is verlaagd, waardoor de skeletspieren voor hun energievoorziening afhankelijker zijn van de afbraak van suikers in afwezigheid van zuurstof (glycolyse). De beschreven veranderingen leiden tot een verminderde kracht, uithoudingsvermogen en efficiëntie van de aangetaste skeletspieren.

\section{Overige systemische effecten}

Naast de verslechterde voedingstoestand en abnormaal functioneren van skeletspieren zijn er diverse andere systemische effecten beschreven bij patiënten met COPD. Hormonale verstoringen, veranderingen in de eiwitstofwisseling, botontkalking en angst en depressie komen frequent voor bij deze aandoening. Hoewel de lijst met systemische effecten steeds langer wordt, zijn de mechanismen die eraan ten grondslag liggen grotendeels onbekend. De afgelopen jaren is duidelijk geworden dat chronische ontstekingsreacties een belangrijke rol spelen bij het ontwikkelen van COPD. Naast een permanente ontsteking van de luchtwegen als gevolg van de inhalatie van sigarettenrook, is er sprake van chronische ontstekingsreacties in de bloedbaan. Hoewel de origine van deze systemische ontstekingsreacties nog grotendeels opgehelderd dient te worden, is de aanwezigheid van dergelijke chronische ontstekingsreacties bij patiënten met COPD geassocieerd met verlies aan spiermassa, verslechterde inspanningscapaciteit en verminderde kwaliteit van leven. Ook spelen deze chronische ontstekingsreacties mogelijk een rol bij het verhoogde risico op hart- en vaatziekten en bij de ontwikkeling van verminderde insuline gevoeligheid bij patiënten met COPD. Naast chronische ontstekingsreacties op lichaamsniveau spelen andere mechanismen een rol bij het ontstaan van de manifestaties van COPD buiten de longen. Gasuitwisselingsstoornissen, inactiviteit, verminderde voedselinname en medicatiegebruik dragen in meer of mindere mate bij aan veranderingen in voedingstoestand, energiestofwisseling en functionaliteit.

\section{Behandeling}

Het groeiend besef dat COPD een longziekte is met manifestaties buiten het primair aangedane orgaan, heeft belangrijke gevolgen voor de medische praktijk. In aanvulling op de traditionele medicamenteuze behandeling van de chronische luchtwegvernauwing vraagt de hedendaagse behandeling van COPD om een holistische 
benadering. Hierbij dient rekening te worden gehouden met de diverse aspecten van de aandoening. Aansluitend op de constatering dat verstoringen in de voedingstoestand en functioneren van skeletspieren belangrijke consequenties hebben voor deze patiënten, zijn er strategieën ontwikkeld om de nadelige veranderingen in lichaamssamenstelling en skeletspieren om te keren. Doel van deze nieuwe behandelingsmodaliteiten is het verlichten van symptomen en het verbeteren van overleving van COPD patiënten. Longrevalidatie, waarbij door middel van bijvoeding, inspanningstraining en gebruik van weefselopbouwende medicatie (zoals anabole steroïden) voedingstoestand en spierfunctie worden verbeterd, is uitgegroeid tot een essentiële component in de behandeling van patiënten met matig tot ernstig COPD.

\section{Doel van het onderzoek}

Het bestuderen van de verdeling van skeletspierdisfunctie tussen onderste en bovenste ledematen bij patiënten met COPD was het eerste doel van dit onderzoek. Met de verkregen resultaten wordt beoogd het inzicht in de oorzaak van abnormaal functioneren van de skeletspieren bij COPD patiënten te vergroten en de ontwikkeling van specifieke interventies gericht op het verbeteren van spierfunctie te bevorderen. De huidige kennis van skeletspieren van patiënten met COPD is grotendeels gebaseerd op resultaten van onderzoeken naar de onderste ledematen omdat er maar vrij weinig onderzoek gericht op de bovenste ledematen was. De resultaten van deze onderzoeken waren bovendien niet eenduidig. Verlaagde vetvrije massa en verstoringen in de energiestofwisseling dragen bij aan skeletspierdisfunctie. Heterogeniteit in de verdeling van deze factoren tussen verschillende spiergroepen kunnen leiden tot klinisch belangrijke verschillen in spierfunctie tussen onderste en bovenste extremiteiten. Derhalve worden in dit onderzoek diverse aspecten van skeletspierfunctie van onderste en bovenste ledematen gemeten en bestudeerd in relatie tot veranderingen in vetvrije massa. Naast kracht en uithoudingsvermogen van de skeletspieren wordt de mechanische efficiëntie bepaald. Dit is een maat voor energiegebruik van de spier per eenheid van geleverde arbeid.

De invloed van verstoringen in het energiemetabolisme en de functie van de skeletspieren bij patiënten met COPD op de cellulaire (intermediaire) stofwisseling, waarbij voedingsstoffen worden omgezet in energie en bouwstoffen, is vooralsnog onbekend. 
Bovendien dragen veranderingen in glucose (suiker) metabolisme, vetafbraak (lipolyse) en skeletspier-eiwitombouw mogelijk bij aan verstoringen in de voedingstoestand en in het bijzonder aan het verlies van vetvrije massa bij deze patiënten. Het tweede doel van dit onderzoek is dan ook het bestuderen van de substraatstofwisseling (glucose, vet en eiwit) in relatie tot veranderingen in de lichaamssamenstelling bij patiënten met COPD.

\section{Functionele gevolgen van sarcopenie in COPD}

In het eerste deel van dit proefschrift wordt de relatie tussen lichaamssamenstelling, spierfunctie en inspanningsvermogen bestudeerd. Hoofdstuk $\mathbf{2}$ bevat een systematische literatuurstudie naar de overeenkomsten in de veranderingen die optreden in de skeletspieren bij patiënten met chronisch orgaanfalen. Spierzwakte, verschuivingen in spiervezelsamenstelling en afname van de zuurstofafhankelijke energiestofwisseling zijn niet alleen kenmerken van patiënten met COPD, maar ook van patiënten met chronisch hartfalen of chronisch nierfalen. Hoofdstuk 2 onderzoekt tevens de potentiële invloed van enkele vaak voorkomende externe factoren op de relatie tussen het primair orgaanfalen en de veranderingen in de skeletspieren. Verminderde energie-inname komt vaak voor bij patiënten met COPD, mogelijk met gevolgen voor de skeletspieren. Anorexia nervosa is een ziektebeeld gekenmerkt door extreme en langdurige beperking van de energie-inname en deze aandoening leent zich daarom bij uitstek om de gevolgen van ondervoeding op de skeletspieren te bestuderen. Zoals beschreven in hoofdstuk 2 worden patiënten met anorexia nervosa gekenmerkt door spierzwakte in combinatie met gemiddeld kleinere type II spiervezels en een afname van zuurstofafhankelijke en zuurstofonafhankelijke skeletspier-stofwisselingscapaciteit.

Kortademigheid tijdens geringe inspanning leidt tot een vermindering van het niveau van dagelijkse activiteit bij veel patiënten met COPD. Afname van lichamelijke activiteit heeft grote invloed op het functioneren van skeletspieren en leidt tot een vermindering van het spiervezeloppervlakte en het percentage type I spiervezels en een verlies aan oxidatieve capaciteit.

COPD is een aandoening die vooral bij ouderen voorkomt. Zoals eerder in dit hoofdstuk beschreven, treden er met het stijgen van de leeftijd veranderingen op in de skeletspieren. Deze veranderingen worden in detail bestudeerd in hoofdstuk 2; ze omvatten naast 
verlies aan spiermassa en -functie onder andere vermindering van spiervezeloppervlakte van type II vezels, een verschuiving van type I naar type II skeletspiervezels en een verminderde oxidatieve capaciteit.

De resultaten van de literatuurstudie in hoofdstuk 2 laten zien dat een vermindering van energie-inname en inactiviteit zeer waarschijnlijk bijdragen aan de geobserveerde veranderingen in de skeletspieren van patiënten met COPD. Hoewel er overeenkomsten bestaan tussen de veranderingen die optreden in de skeletspieren met het natuurlijk verouderingsproces en in de skeletspieren van COPD patiënten, is op dit moment onvoldoende onderzocht of leeftijdsgerelateerde veranderingen in versterkte mate of op jongere leeftijd optreden bij patiënten met COPD.

De hoofdstukken $\mathbf{3}$ en $\mathbf{4}$ van dit proefschrift behandelen potentiële verschillen in spierfunctie en inspanningsvermogen tussen bovenste en onderste ledematen bij patiënten met COPD.

Een verhoogd energiegebruik tijdens lichamelijke inspanning werd eerder gerapporteerd bij COPD patiënten; dit kan leiden tot een verstoorde energiebalans en gewichtsverlies. In overeenstemming met deze observatie werd eerder aangetoond dat het energiegebruik per eenheid verrichte inspanning van de beenspieren verhoogd is bij patiënten met COPD. Dit duidt op een verlaging van de mechanische efficiëntie van de onderste extremiteiten bij deze patiënten. In hoofdstuk 3 zijn de mechanische efficiëntie en de inspanningscapaciteit van de bovenste ledematen vergeleken met die van de onderste ledematen bij COPD patiënten en bij gezonde vrijwilligers. In tegenstelling tot de verminderde mechanische efficiëntie gedurende beeninspanning, is de mechanische efficiëntie van de bovenste extremiteiten van de COPD patiënten vergelijkbaar met die van gezonde vrijwilligers. Daarnaast is het inspanningsvermogen van de bovenste ledematen, in tegenstelling tot het inspanningsvermogen van de onderste extremiteiten, relatief behouden bij COPD patiënten.

In hoofdstuk 4 van dit proefschrift worden de invloed van vetvrije massa en de effecten van inspanningstraining op spierfunctie van de bovenste en onderste extremiteiten bij patiënten met COPD onderzocht. Eerdere onderzoeken hadden vooral zwakte van de onderste ledematen aangetoond, terwijl spierfunctie van de bovenste extremiteiten onvoldoende was onderzocht. Ook de relatie tussen vetvrije massa enerzijds en kracht en uithoudingsvermogen van de skeletspier anderzijds was grotendeels onbekend. In deze studie worden beide facetten van spierfunctie gemeten op 
gestandaardiseerde wijze en in een vergelijkbaar protocol voor spieren van de onderste (quadriceps spier) en de bovenste (biceps spier) ledematen. Binnen de COPD patiënten wordt er onderscheid gemaakt tussen een groep met een normale vetvrije massa en een groep met een verlaagde vetvrije massa. Spierkracht van de quadriceps en de biceps blijkt in dezelfde mate te zijn aangedaan bij de COPD patiënten, terwijl het verlies van uithoudingsvermogen van de spieren beperkt blijft tot de onderste ledematen. Het verlies van quadriceps-kracht is groter bij patiënten met een verminderde vetvrije massa dan bij patiënten met een normale vetvrije massa, terwijl biceps-kracht en het uithoudingsvermogen van onderste en bovenste extremiteiten vergelijkbaar zijn bij beide groepen. $\mathrm{Na}$ inspanningstraining als onderdeel van een longrevalidatieprogramma wordt er een toename in kracht en uithoudingsvermogen van de quadriceps-spier waargenomen, terwijl de spierfunctie van de bicepsspier niet verandert.

In de afgelopen jaren is duidelijk geworden dat een verlaging van vetvrije massa niet alleen nadelige gevolgen heeft voor de spierfunctie en overlevingskans van COPD patiënten met ondergewicht, maar ook van COPD patiënten met een normaal lichaamsgewicht. Toename van vetvrije massa bij patiënten met een sarcopene voedingstoestand heeft derhalve in theorie positieve effecten. In hoofdstuk $\mathbf{5}$ wordt het effect van een trainingprogramma met intensieve inspanning op de lichaamssamenstelling van patiënten met een normaal gewicht maar een verlaagde vetvrije massa onderzocht. Daarnaast wordt de relatie tussen veranderingen in voedingstoestand en veranderingen in spierfunctie en inspanningsvermogen bestudeerd. In de studie wordt een significante toename in lichaamsgewicht geobserveerd, welke wordt veroorzaakt door een toename van vetvrije massa. Hoewel de vetvrije massa een belangrijke determinant is van inspanningsvermogen en spierkracht in deze sarcopene patiëntengroep, blijkt de associatie tussen de veranderingen in voedingstoestand en functionele capaciteit gering. Daarnaast blijkt de leeftijd van patiënten mede voorspellend voor spierkracht en inspanningsvermogen, onafhankelijk van de vetvrije massa. 


\section{Substraatstofwisseling in relatie tot sarcopenie in COPD}

Het tweede deel van dit proefschrift bevat de studies naar potentiële verstoringen in de intermediaire stofwisseling bij patiënten met COPD in relatie tot veranderingen in voedingstoestand. De intermediaire stofwisseling wordt in deze onderzoeken gemeten door gebruik te maken van stabiele isotopen. Dit zijn natuurlijk voorkomende maar zeldzame varianten van atomen met een andere massa. Het verschil in gewicht is het gevolg van een verschillend aantal neutronen. Door dit massaverschil kunnen deze isotopen onderscheiden worden van de natuurlijk veel voorkomende atomen. Door moleculen met ingebouwde stabiele isotopen via de bloedbaan toe te dienen aan COPD patiënten, is het mogelijk om de stofwisseling van deze moleculen in detail te bestuderen. Dit gebeurt aan de hand van de verschijningssnelheid van deze moleculen tijdens infusie, aangezien de verhouding tussen deze verzwaarde moleculen en de natuurlijk in het lichaam voorkomende moleculen een maat is voor de stofwisselingssnelheid.

In hoofdstuk $\mathbf{7}$ wordt de suikerstofwisseling bestudeerd. Door middel van een stabiel isotoop van glucose (suiker) worden potentiële verschillen in glucoseproductie van het lichaam gemeten tussen COPD patiënten en gezonde vrijwilligers. Op grond van de verminderde zuurstofafhankelijke skeletspierstofwisseling, chronisch zuurstofgebrek en veranderingen in de voedingstoestand werden er aanpassingen in glucosemetabolisme verwacht bij COPD-patiënten. De studie laat zien dat de basale glucoseproductie verhoogd is bij patiënten met COPD, in vergelijking met gezonde vrijwilligers. Deze verhoging is aanwezig in rusttoestand, maar wordt versterkt door lichamelijke inspanning. De veranderingen in glucoseproductie zijn het meest uitgesproken bij patiënten met ondergewicht, maar treden tijdens inspanning ook op bij patiënten met een normaal lichaamsgewicht. Daarnaast zijn er indirecte aanwijzingen voor verminderde insulinegevoeligheid bij de COPD patiënten met een normaal lichaamsgewicht.

In de hoofdstukken 8 en $\mathbf{9}$ van dit proefschrift wordt de rol van potentiële verstoringen in vet- en spiereiwitafbraak onderzocht binnen de veranderingen in voedingstoestand die optreden bij sarcopene COPD patiënten.

Op grond van eerder onderzoek waren er indirecte aanwijzingen dat een verminderde vetafbraak bijdraagt aan het ontstaan of 
handhaven van een relatief grote vetmassa bij COPD patiënten met een sarcopene voedingstoestand. In hoofdstuk 8 wordt de vetafbraak van sarcopene COPD patiënten vergeleken met die van gezonde vrijwilligers met een vergelijkbare Quetelet-index (gewicht gedeeld door lengte in het kwadraat). Daarnaast worden mogelijke verschillen in vetafbraak gemeten tussen sarcopene patiënten en COPD patiënten met ondergewicht en een verlaagde vetmassa. Studies bij kankerpatiënten hebben immers aangetoond dat een verhoogde vetafbraak een oorzaak kan zijn van verlies aan vetmassa en gewichtsverlies. In de huidige studie wordt de vetafbraak gemeten met behulp van een stabiele isotoop van glycerol. Vetafbraak en concentraties van hormonen betrokken bij de vetafbraak (catecholamines, insuline) worden gemeten in rust en tijdens stimulatie door middel van een submaximale fietsinspanning. Uit het onderzoek blijkt dat de basale en inspanningsgeïnduceerde vetafbraak van sarcopene COPD patiënten vergelijkbaar is met de vetafbraak van gezonde vrijwilligers. Daarnaast is de vetafbraak van COPD patiënten met ondergewicht niet verschillend van de andere twee groepen. Desondanks blijken er significante verschillen te bestaan in concentraties van hormonen betrokken bij de vetafbraak. De resultaten van dit onderzoek suggereren dat verstoringen in de vetafbraak niet bijdragen aan verstoringen in de voedingstoestand bij patiënten met COPD. Waarschijnlijk is niet het behoud van vetmassa maar het selectieve verlies aan vetvrije massa een belangrijk mechanisme in het ontstaan van een sarcopene voedingstoestand bij patiënten met COPD. Deze hypothese wordt onderzocht in hoofdstuk 9, waarin eiwitafbraak en eiwitstofwisseling van de skeletspier op het hele lichaamsniveau worden gemeten bij COPD patiënten met ondergewicht en een verlaagde vetvrije massa. Deze worden vergeleken met de eiwitafbraak en -stofwisseling van COPD patiënten en gezonde vrijwilligers met een normaal gewicht en vetvrije massa. In de studie wordt een stabiele isotoop van het aminozuur 3-methylhistidine gebruikt om de afbraaksnelheid van spiereiwit te bepalen. Er wordt geen verschil gevonden in eiwitstofwisseling op heel lichaamsniveau tussen de verschillende groepen. De skeletspier-eiwitafbraak van patiënten met ondergewicht en een verlaagde vetvrije massa blijkt echter duidelijk verhoogd ten opzichte van patiënten en gezonde vrijwilligers met een normaal gewicht en vetvrije massa. De resultaten van dit onderzoek suggereren dat selectief verlies van skeletspiermassa een belangrijke rol speelt bij de afname van vetvrije massa en bijdraagt 
aan het ontstaan van een sarcopene lichaamssamenstelling bij een subgroep van COPD-patiënten.

Naast de groep van sarcopene COPD patiënten (gekenmerkt door een verlaagde vetvrije massa in combinatie met een behouden vetmassa en lichaamsgewicht) komt er ook vetzucht (obesitas) voor bij patiënten met COPD. Mensen met obesitas hebben een sterk verhoogd lichaamsgewicht, hetgeen vooral het gevolg is van toegenomen vetmassa. Er zijn steeds meer aanwijzingen voor een verband tussen COPD en vetzucht, hoewel de aard hiervan vooralsnog onbekend is. Hoofdstuk 10 van dit proefschrift biedt een perspectief op deze associatie en richt zich vooral op de potentiële bijdrage van vetzucht aan de systemische ontstekingsreacties en het ontstaan van insuline resistentie binnen COPD. Net als patiënten met COPD worden personen met obesitas gekenmerkt door chronische ontstekingsreacties op lichaamsniveau; deze dragen bij aan de ontwikkeling van verminderde gevoeligheid voor insuline en uiteindelijk zelfs aan diabetes mellitus type 2 (ouderdomssuiker). Het wordt steeds duidelijker dat chronische ontstekingsreacties bij mensen met vetzucht het gevolg zijn van abnormaal functioneren van de vetcellen. Deze zijn vergroot en bevatten grote aantallen ontstekingscellen, vooral macrofagen. Daarnaast is de afgelopen jaren bekend geworden dat vetcellen ontstekingsstoffen (adipokines) produceren en uitscheiden. Lokaal zuurstoftekort ten gevolge van verminderde doorbloeding van de vergrote vetcellen draagt waarschijnlijk bij hieraan.

COPD patiënten met een relatief of absoluut toegenomen vetmassa hebben in theorie een verhoogde kans op abnormale vetcelfunctie. De verminderde capaciteit van de skeletspieren om vetten te verbranden in combinatie met het verhoogde aanbod van vetten vanuit het overtollige vetweefsel leidt tot een verhoogde kans op vetstapeling in de skeletspieren. Deze vetstapeling is gerelateerd aan het ontstaan van verminderde insuline gevoeligheid. Daarnaast treedt er bij patiënten met ernstig COPD regelmatig zuurstoftekort op lichaamsniveau op, hetgeen niet het geval is bij gezonde personen met vetzucht. Dit systemische zuurstoftekort kan in theorie het gebrek aan zuurstof in de vergrote vetcellen van COPD patiënten met overmatige vetmassa versterken. Daarmee kan het vrijkomen van ontstekingsstoffen uit de vetcellen in de bloedbaan worden gestimuleerd en kunnen de chronische ontstekingsreacties in stand worden gehouden. Zoals reeds beschreven worden deze chronische ontstekingsreacties gezien als een belangrijke factor in het verlies van vetvrije massa bij patiënten met COPD en in het ontstaan van 
een verminderde gevoeligheid voor insuline. Onderzoek naar het functioneren van vetcellen in relatie tot zuurstofgebrek en chronische ontstekingsreacties op lichaamsniveau bij patiënten met COPD is een uitdaging voor de nabije toekomst; mogelijk geeft dit meer inzicht in de ontwikkeling van systemische effecten van de aandoening, zoals verlies aan vetvrije massa. 



\section{List of publications}
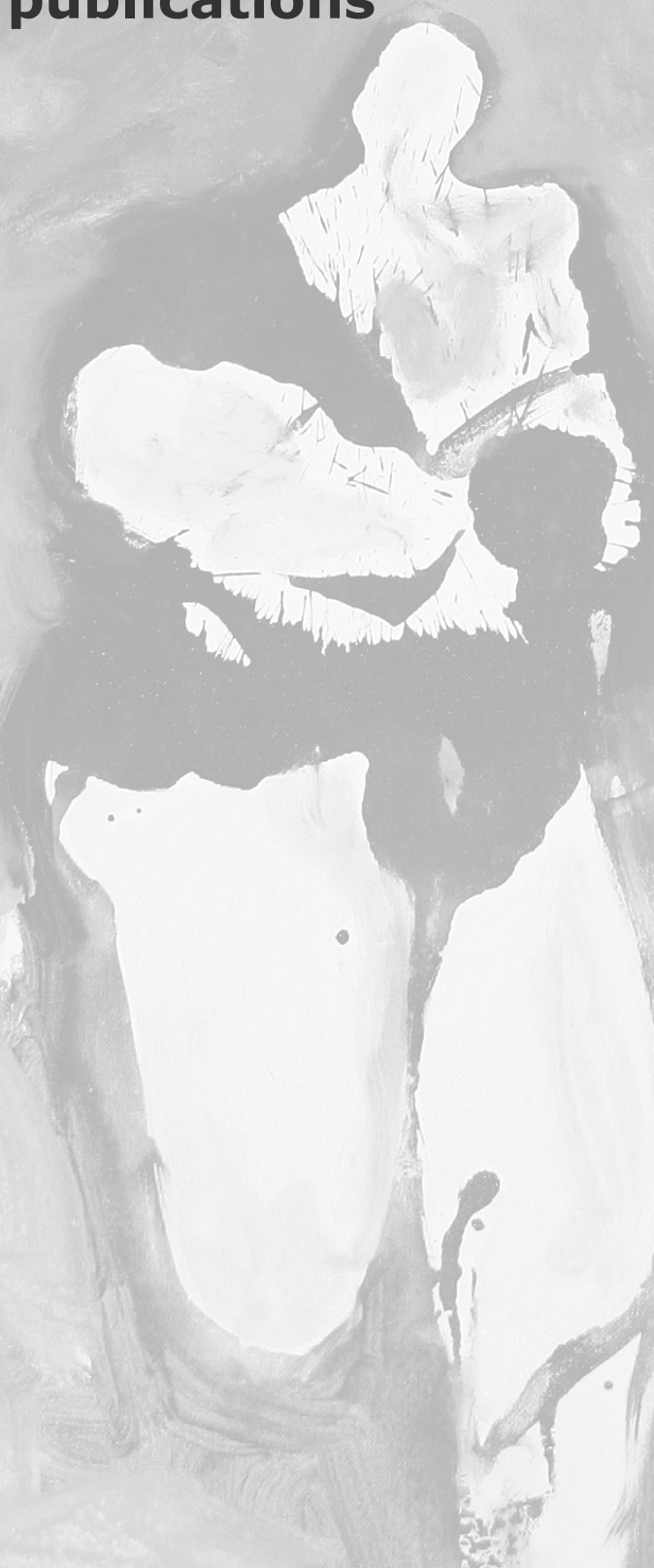



\section{List of publications}

Franssen FM, Wouters EF, Schols AM. The contribution of starvation, deconditioning and aging to the observed alterations in peripheral skeletal muscle in chronic organ diseases. Clin Nutr. 2002; 21: 1-14. Review.

Franssen FM, Wouters EF, Baarends EM, Akkermans MA, Schols AM. Arm mechanical efficiency and arm exercise capacity are relatively preserved in chronic obstructive pulmonary disease. Med Sci Sports Exerc. 2002; 34: 1570-1576.

Gosker HR, Lencer NH, Franssen FM, van der Vusse GJ, Wouters EF, Schols AM. Striking similarities in systemic factors contributing to decreased exercise capacity in patients with severe chronic heart failure or COPD. Chest. 2003; 123: 1416-1424.

Franssen FM, Broekhuizen R, Janssen PP, Wouters EF, Schols AM. Effects of whole-body exercise training on body composition and functional capacity in normal-weight patients with COPD. Chest. 2004; 125: 2021-2028.

Franssen FM, Broekhuizen R, Janssen PP, Wouters EF, Schols AM. Limb muscle dysfunction in COPD: effects of muscle wasting and exercise training. Med Sci Sports Exerc. 2005; 37: 2-9.

van den Ham EC, Kooman JP, Schols AM, Nieman FH, Does JD, Franssen FM, Akkermans MA, Janssen PP, van Hooff JP. Similarities in skeletal muscle strength and exercise capacity between renal transplant and hemodialysis patients. Am J Transplant. 2005; 5: 1957-1965.

Gosker HR, Schrauwen P, Broekhuizen R, Hesselink MK, MoonenKornips E, Ward KA, Franssen FM, Wouters EF, Schols AM. Exercise training restores uncoupling protein-3 content in limb muscles of patients with chronic obstructive pulmonary disease. Am J Physiol Endocrinol Metab. 2006; 290: E976-981.

Rutten EP, Franssen FM, Engelen MP, Wouters EF, Deutz NE, Schols AM. Greater whole-body myofibrillar protein breakdown in cachectic patients with chronic obstructive pulmonary disease. Am J Clin Nutr. 2006; 83: 829-834. 
Franssen FM, Sauerwein HP, Rutten EP, Wouters EF, Schols AM. Whole-body resting and exercise-induced lipolysis in sarcopaenic patients with COPD. Eur Respir J. 2008; 32: 1466-1471

Franssen FM, O'Donnell DE, Goossens GH, Blaak EE, Schols AM. Obesity and the lung: 5. Obesity and COPD. Thorax 2008; 63: 11101117

Franssen FM, Sauerwein HP, Ackermans MT, Rutten EP, Wouters EF, Schols AM. Increased postabsorptive and exercise-induced wholebody glucose production in patients with COPD. 2008. Submitted. 


\section{Dankwoord}
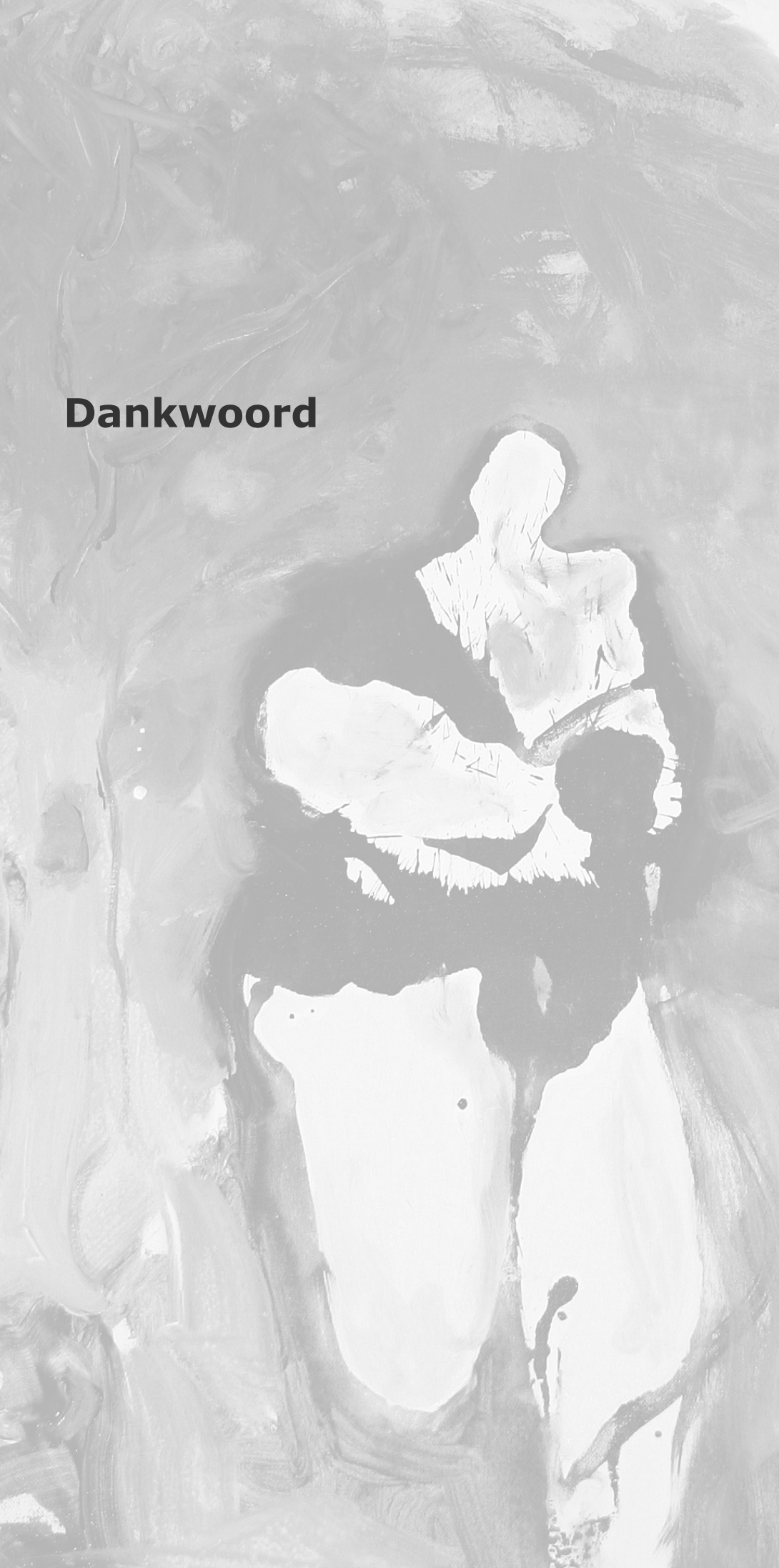



\section{Dankwoord}

Nadat u de inhoud van de voorgaande tien hoofdstukken en de samenvatting aandachtig heeft doorgenomen, is het nu tijd voor een luchtiger hoofdstuk. Hierin wil ik de personen bedanken die mij gedurende het lange promotietraject hebben geholpen. Hoewel mijn naam de kaft van dit proefschrift siert, was de voltooiing hiervan onmogelijk geweest zonder de bijdrage en steun van deze personen.

Allereerst uiteraard dank aan mijn promotoren, prof. dr. ir. Annemie Schols en prof. dr. Emiel Wouters. Beste Annemie, bedankt dat je mij betrokken hebt bij de prachtige onderzoekslijn die jij samen met prof. dr. Wouters in de afgelopen decennia vorm hebt gegeven en die inmiddels zoveel waardevolle resultaten heeft opgeleverd. Als geen ander weet $\mathrm{jij}$ onderzoekers met diverse achtergronden en aandachtsgebieden met elkaar aan tafel en vervolgens aan het werk te krijgen. Daarbij houd je niet alleen de individuele belangen van de betrokkenen op korte termijn in het oog, maar heb je ook altijd een duidelijke visie op wetenschappelijke ontwikkelingen en samenwerkingsverbanden op de langere termijn. Je enthousiasme en creativiteit binnen het onderzoek, ervaring en onvoorwaardelijke steun die ik altijd van jou heb gevoeld, waardeer ik enorm. Hoewel mijn promotietraject veel langer heeft geduurd dan gepland, toonde je altijd begrip voor de opgelopen vertraging ten gevolge van mijn opleiding of privé aangelegenheden. Naast je promotorschap, heb ik ook genoten van je fanatisme op de squash- en tennisbaan. De boog kan immers niet altijd gespannen staan...

Prof. dr. Wouters, ik wil u hartelijk danken voor de kansen die u mij in de afgelopen jaren heeft geboden. Zonder $u$ als promotor, opleider en voorbeeld, was ik niet waar ik nu ben. Als wetenschapper voert u al jaren de frontlinie van het internationale COPD onderzoek aan, waarbij uw lezingen, publicaties en visie immer toonaangevend en richtinggevend zijn voor collega's. Uw kritische en altijd waardevolle begeleiding van mijn onderzoek heb ik bijzonder gewaardeerd. Ook bent $u$ ondanks uw ontelbare bezigheden nauw betrokken geweest bij de dagelijkse praktijk van mijn opleiding in het azM. Tenslotte wil ik $u$ bedanken voor de geboden gelegenheid om mij op internationaal niveau te presenteren en ontwikkelen.

De leden van de beoordelingscommissie bedank ik voor de kritische beoordeling en goedkeuring van het manuscript. Naast voorzitter prof. dr. ir. R.P. Mensink bestond de commissie uit prof. dr. S.D. Anker (Campus Virchow-Klinikum, Berlijn, Duitsland), prof. dr. M.P. 
Van Dieijen-Visser, prof. dr. M.I. Polkey (Royal Brompton Hospital, London, Verenigd Koninkrijk) en prof. dr. C.D.A. Stehouwer.

Klinisch onderzoek is mensenwerk. Graag wil ik dan ook de COPD patiënten en gezonde vrijwilligers bedanken die hebben deelgenomen aan de studies die beschreven zijn in dit proefschift.

Graag wil ik ook mijn collega onderzoekers van de afdeling Longziekten bedanken. Toen ik in 2000 begon aan mijn promotieonderzoek, was ik als jonge dokter een vreemde eend in de bijt in de onderzoekerskamer aan het Peter Debyeplein, waar onderzoekers met diverse achtergronden verschillende systemische aspecten van COPD probeerden te ontrafelen. Door de uiteenlopende expertise en vaardigheden van de diverse onderzoekers had ik al snel het gevoel deel uit te maken van een team, waarbinnen iedereen zich optimaal kon ontplooien zonder steeds opnieuw het wetenschappelijke wiel te hoeven uitvinden. Naast Eva Creutzberg, Mieke Dentener, Mariëlle Engelen, Ramon Langen, Jos van Der Velden, Marja Vermeeren en Juanita Vernooij wil ik in het bijzonder Erica Baarends en Roelinka Broekhuizen bedanken. Met behulp van data verkregen door hun inspanningen, kreeg mijn onderzoek een snelle start. Speciale dank ook voor Erica Rutten, die mij hielp bij de opzet en uitvoering van de metabole studies.

Prof. dr. Hans Sauerwein (Academisch Medisch Centrum, Amsterdam) dank ik voor zijn bijdrage aan de metabole studies en introductie in het onderzoek met stabiele isotopen. Mariette Ackermans wil ik bedanken voor de analyse van de bloedmonsters.

Mijn collega arts-assistenten van de afdeling Longziekten (Jaclyn, Karin, Khaled, Lowie, Mariana, Michiel, Robert, Ruud, Selene, Tamara, Vivian, Xiang) bedank ik voor de mogelijkheid om zo nu en dan een stapje terug te doen uit de hectiek van de dagelijkse zorg om tijd te besteden aan mijn promotieonderzoek. En bedankt voor de dagelijkse gezelligheid natuurlijk. De stafleden, verpleging en longfunktie laboranten van de afdeling Longziekten wil ik bedanken voor de prettige sfeer waarin mijn opleiding heeft plaatsgevonden en voor de plezierige samenwerking in de afgelopen jaren. Daarnaast bedank ik de dames van het secretariaat voor hun ondersteuning.

De medewerkers van CIRO Horn, in het bijzonder de afdelingen fysiotherapie/bewegingsagogiek en diëtetiek, wil ik bedanken voor hun hulp bij het verzamelen van de gegevens over spierfunktie, 
uithoudingsvermogen en lichaamssamenstelling in het kader van mijn onderzoek.

Een speciaal woord van dank gaat uit naar mijn paranimfen, Jeroen Jansen en Harry Gosker. Ik heb lang zitten denken over mogelijke overeenkomsten tussen jullie, omdat het me leuk leek daar iets over te schrijven. Ik moet echter tot de conclusie komen dat jullie significant verschillend zijn. Waar Jeroen bekendheid verwierf als onderwerp van een artikel in een lokale krant getiteld 'Inbreker blijkt uitbreker', heeft Harry vele wetenschappelijke artikelen gepubliceerd. Terwijl Harry jaren geleden op de squashbaan bijna gereanimeerd diende te worden, wint Jeroen al jaren elke denkbare sportactiviteit met ogenschijnlijk minimale inspanning. Jeroen, de vraag of jij mijn paranimf wilde zijn, heb je al jaren geleden (na een paar pilsjes?) beantwoord. Ik ben blij dat je deze rol wilt vervullen. Pas je op dat ik niet struikel tijdens mijn verdediging of ander gestuntel uithaal? Harry, als kamergenoot aan het begin van mijn promotieonderzoek heb ik veel van je kunnen afkijken en hebben we veel lol gehad. Naast overeenkomsten in het COPD onderzoek, bleken we allebei van dezelfde slechte films en sportieve activiteiten te houden. Help je me ook weer als mijn computer crashed tijdens het lekenpraatje?

Groot is mijn dank richting mijn ouders. Pa en ma, jullie hebben mij altijd de ruimte hebben gegeven om mijn keuzes op gebied van prive en opleidingen tot een succes te maken. Op alle mogelijke manieren staan jullie altijd onvoorwaardelijk voor mij klaar. Zonder mij ooit in een bepaalde richting te hebben gedwongen, weet ik dat jullie trots zijn op de afronding van mijn proefschrift en specialisatie. Zonder jullie hulp en liefde was het onmogelijke geweest de graad van Doctor te behalen.

Tenslotte wil ik mijn liefje bedanken. Lieve Mara, door de combinatie van een hectische opleiding met onregelmatige werktijden en een promotie-onderzoek was er heel weinig tijd voor jou. Vaak stond je er alleen voor. Bij herhaling heb je ondervonden dat een artikel weliswaar 'klaar' was, maar dat dat niet betekende dat het ook 'gereed', 'af' of 'voltooid' was. Er leek nooit een einde te komen aan mijn promotie-onderzoek en vaak ging mijn wetenschappelijk ambitie ten koste van jou. Je zult het bijna niet geloven, maar nu ben ik ECHT klaar! Bedankt voor je liefde, steun en trouw. Ik ben gelukkig met jou en Marijn (en Luna en Jet). Laten we iets leuks gaan doen! 



\section{Curriculum vitae}
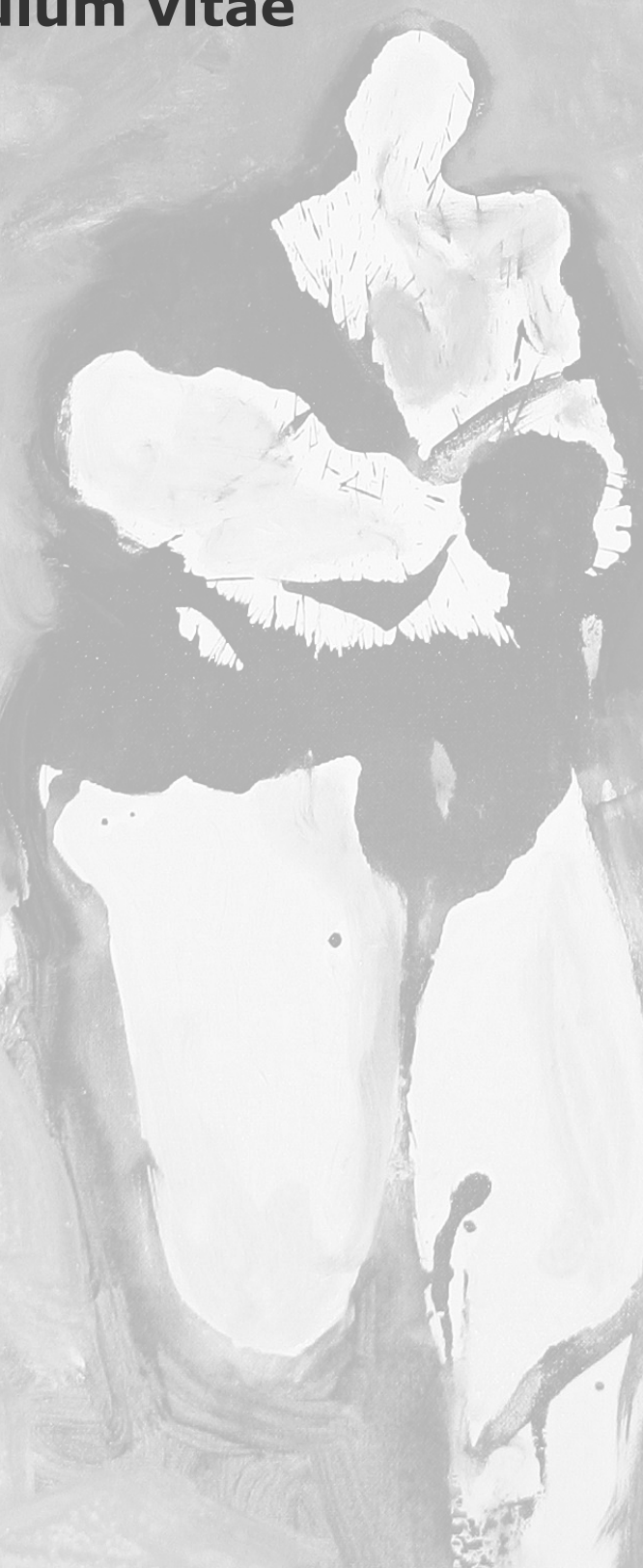



\section{Curriculum vitae}

Frits Franssen werd geboren op 19 november 1973 in Heerlen. In 1992 behaalde hij zijn Gymnasium- $B$ diploma aan het Bernardinus College in Heerlen. In hetzelfde jaar begon hij aan de studie Gezondheidswetenschappen aan de Universiteit Maastricht. Na het behalen van de propedeuse, koos hij in 1993 voor de afstudeerrichting Milieugezondheidkunde. In 1994 werd hij toegelaten tot de Geneeskunde opleiding aan de Universiteit Maastricht. Tijdens zijn studie was hij actief lid van O.M.S.G. Plutarchus en vervulde hij verscheidene bestuursfunkties. Een onderzoeksstage op de afdeling Longziekten resulteerde in een abstract voor het congres van de European Respiratory Society in $\mathbf{2 0 0 0}$ met als titel 'Isokinetic muscle performance and 12 minute walking distance predict daily activity pattern in patients with COPD'. Na het behalen van zijn artsdiploma, startte Frits in september 2000 met zijn promotieonderzoek onder begeleiding van prof. dr. ir. A.M.W.J. Schols en prof. dr. E.F.M. Wouters. In februari 2002 begon hij aan de opleiding tot longarts in het academisch ziekenhuis Maastricht. Daarnaast neemt hij sinds 2005 deel aan een Europees netwerk van jonge onderzoekers op het gebied van COPD en asthma. Ook was hij enkele jaren actief binnen het bestuur van de arts-assistentenvereniging van het academisch ziekenhuis Maastricht, waarvan de laatste tijd als voorzitter. Tevens is hij lid van Junior Chamber International regio Maastricht. In 2007 trouwde Frits met Mara Crombach en zij hebben 1 zoon, Marijn (2008). Hobbies van Frits zijn muziek luisteren, hardlopen, squashen en backpacken. 


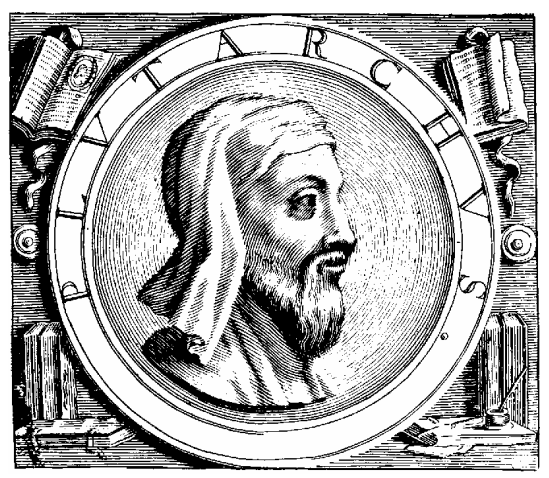

